Mariana Mungioli

Estudos morfológicos e moleculares de algas pardas filamentosas (Phaeophyceae) no litoral sudeste do Brasil

Morphological and molecular studies of filamentous brown algae (Phaeophyceae) in the brazilian southeast coast

São Paulo, SP 
Mariana Mungioli

\title{
Estudos morfológicos e moleculares de algas pardas filamentosas (Phaeophyceae) no litoral sudeste do Brasil
}

\section{Morphological and molecular studies of filamentous brown algae (Phaeophyceae) in the brazilian southeast coast}

\author{
Dissertação apresentada ao Instituto de \\ Biociências da Universidade de São Paulo, \\ como parte dos requisitos necessários à \\ obtenção do Título de Mestre em Ciências, \\ na Área de Botânica.
}

Orientadora: Prof. ${ }^{a}$ Dra. Valéria Cassano.

São Paulo, SP 
Mungioli, Mariana

Estudos morfológicos e moleculares de algas pardas filamentosas Phaeophyceae) no litoral sudeste do Brasil. Mariana Mungioli São Paulo: M.M., 2017154 p.

Dissertação (Mestrado) - Instituto de Biociências da Universidade de São Paulo. Departamento de Botânica, 2017.

1. Phaeophyceae, 2. DNA barcode, 3. Filogenia, 4. COI-5P, 5. rbcL. Universidade de São Paulo. Instituto de Biociências. Departamento de Botânica. II. Títtulo

Comissão Julgadora:

Prof(a). Dr(a).

$\operatorname{Prof}(\mathrm{a}) . \operatorname{Dr}(\mathrm{a})$.

Profa. Dra.Valéria Cassano

Orientadora 


\section{AGRADECIMENTOS}

À Profa. Dra. Valéria Cassano, pela orientação, dedicação e permanente atenção em todas as etapas no desenvolvimento deste estudo. Sem sua presença, este trabalho não teria sido concluído;

Ao CNPq (Conselho Nacional de Desenvolvimento Científico e Tecnológico) pela bolsa de mestrado, tornando possível a execução desta pesquisa.

Ao Instituto de Biociências, em especial ao Departamento de Botânica da Universidade de São Paulo.

Ao Prof. Dr. Joel Campos de Paula, pelo inestimável auxílio nas primeiras coletas realizadas.

Ao Prof. Dr. Wilson Freshwater, que gentilmente cedeu amostras de especial importância para a compilação dos resultados alcançados.

Às ProfessorasDra. Mariana Cabral de Oliveira, Dra. Fanly Fungyi Chow Ho, Dra. Mutue Fujii e Dra. Silvia Guimarãespelascontribuiçõeserecursos disponibilizadosemcoletas.

Aos colegas, técnicos e professores do Laboratório de Algas Marinhas "Edson José De Paula", da Universidade de São Paulo, pelo incessante e rotineiro apoio prestado ao longo de toda a pesquisa.

Um agradecimento especial às minhas amigas Carolina Azevedo, Silvia Pope e Talita Vieira pela troca de experiências, inúmeras coletas e apoio emocional diário.

Aos meus pais, pelo apoio incondicional, à minha avó materna (In memorian), à minha tia Regina Célia, aos meus padrinhos Rubens e Luisa e à Valéria Henriques, pelo incentivo ao longo destes anos, o meu muito obrigada!

E ao meu amor, Guilherme, pelo companheirismo e por principalmente, participar com tanto afinco de uma,das primeiras etapas das nossas vidas. 
Resumo. 10

Abstract 12

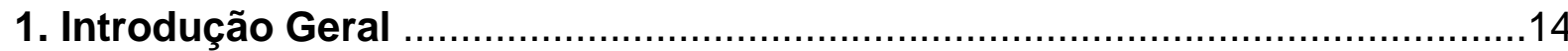

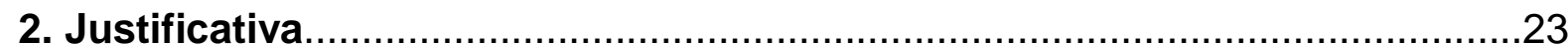

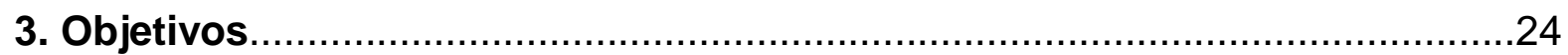

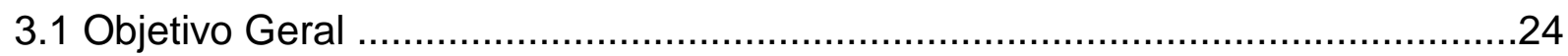

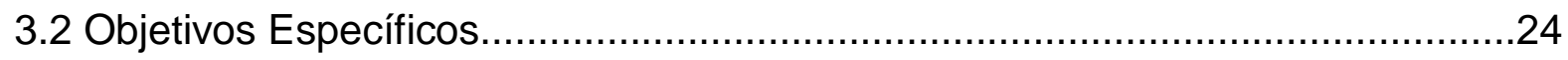

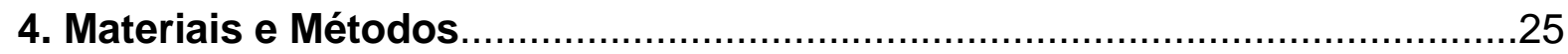

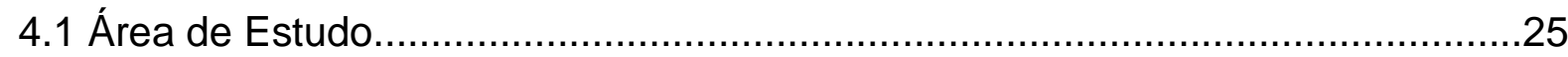

4.2 Coleta e Processamento das Amostras ................................................26

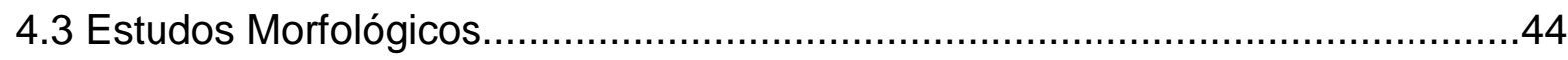

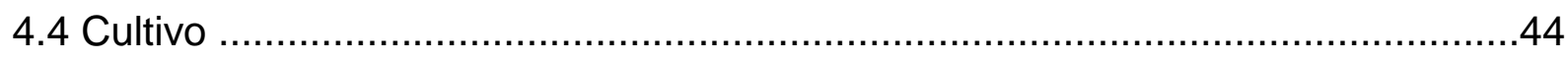

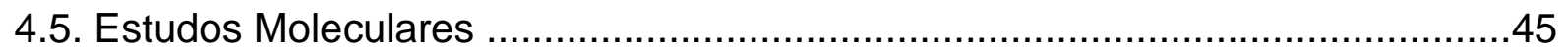

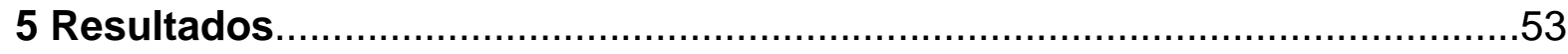

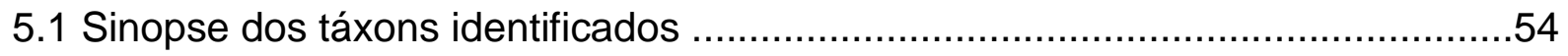

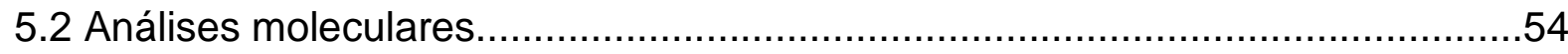

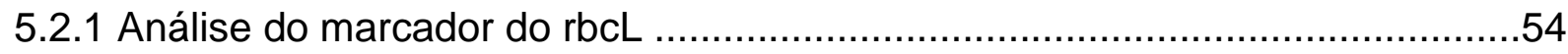

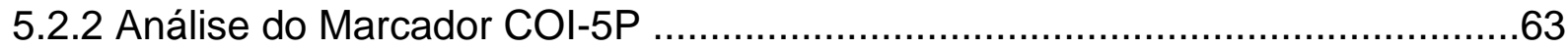

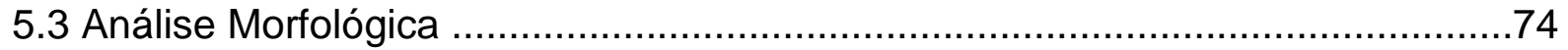

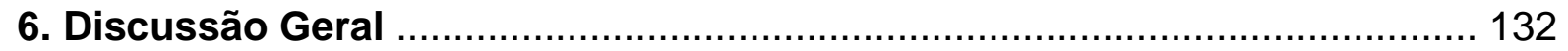

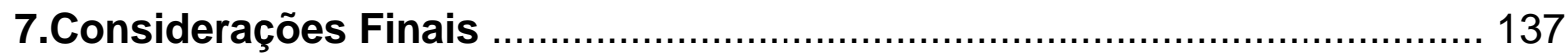

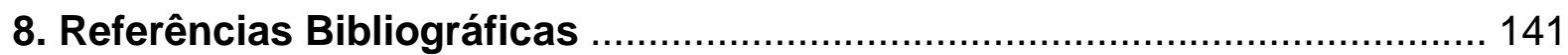


Tabela 1. Lista das espécies de algas pardas filamentosas citadas para o Brasil e sua distribuição geográfica.

Tabela 2. Listagem das amostras coletadas ao longo do litoral sudeste do Brasil utilizadas para análises morfológicas e moleculares com os marcadores COI-5P e rbcL

Tabela 3. Desenvolvimento em vitro de espécies cultivadas no laboratório de algas marinhas Édison José de Paula. .45

Tabela 4. Oligonucleotídeos dos marcadores mitocondrial (COI-5P) e plastidial $(r b c L)$ utilizados na amplificação e no sequenciamento deste estudo. .46

Tabela 5. Oligonucleotídeos testados para a amplificação e para o sequenciamento de cada marcador molecular .47

Tabela 6. Sequências obtidas do banco de dados GenBank com seus respectivos códigos de acesso utilizadas nas análises moleculares de COI$5 P$. .49

Tabela 7. Sequências obtidas do banco de dados GenBank com seus respectivos códigos de acesso utilizadas nas análises filogenéticas de $r b c \mathbf{L}$ .51

Tabela 08. Amplitude de divergência genética entre os gêneros estudados para o gene rbcL .60

Tabela 09. Amplitude de divergência genética entre os gêneros estudados para o gene COI-5P.

Tabela 10. Comparação da amplitude de variação da divergência genética entre os marcadores estudados. .70 
Figura 1. Mapa político do Brasil com destaque ao litoral Sudeste e número total de amostras coletadas porestado 25

Figura2.Ilhote de Ubu, Anchieta, Espírito Santo. Aspecto do ambiente recifal. .26

Figura 3. Ilhote de Ubu, Anchieta, Espírito Santo. Detalhe de Bachelotia antillarum sobre Udotea sp .26

Figuras 4 e 5. Pontal do Atalaia, Arraial do Cabo, Rio de Janeiro.Costão rochoso.27

Figura 6.Praia Desertinha, Reserva Juréia-Itatins, Peruíbe, São Paulo.Aspecto do ambiente apresentando poça-de-maré 27

Figura 7.Praia Desertinha, Reserva Juréia-Itatins, Peruíbe, São Paulo.Detalhe de pardas filamentosas sobre costão batido. .28

Figura 8.Árvore consenso gerada a partir da análise de Neighbor-Joining (NJ) para sequências do rbcL. Valores de bootstrap indicados nos ramos são referentes a NJ (2000 réplicas), Máxima Verossimilhança (ML) (100 réplicas) e probabilidade a posteriori (PP), respectivamente. Valores de bootstrapinferiores a 50 não apresentados. Amostras geradas neste estudo estão destacadas em negrito; indica falta de suporte; * indica suporte total do ramo (valor de bootstrap $=100 \%$ e PP (probabilidade a posteriori = $1.00)$ 62

Figura 9.Árvore de Neighbor-Joining (NJ) para sequências do COI-5P. Valores de bootstrap estão indicados nos ramos (2000 réplicas). Valores de bootstrapinferiores a 50 não apresentados. Amostras geradas neste estudo estão destacadas em negrito

Figura 10 a 16.Acinetospora filamentosa. Anatomia vegetativa e reprodutiva.........70

Figura 17 a 23. "Feldmannia" irregularis. Anatomia vegetativa e reprodutiva..........87

Figura 24 a 33. "Feldmannia irregularis" 1. Anatomia vegetativa e reprodutiva........91

Figura 34 a 41: "Feldmannia irregularis" 2. Anatomia vegetativa e reprodutiva........95 
Figura 42 a 50. "Feldmannia" mitchelliae. Anatomia vegetativa e reprodutiva..........102

Figura 51 a 59. "Hincksia" conifera. Anatomia vegetativa e reprodutiva...................108

Figura 60 a 69 . Hincksia sandriana. Anatomia vegetativa e reprodutiva..................113

Figura 70 a 77 . Ectocarpus fasciculatus. Anatomia vegetativa e reprodutiva...........119

Figura78 a 84. "Asteronema" breviarticulatum. Anatomia vegetativa e

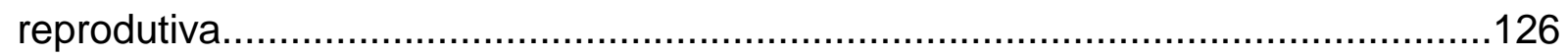

Figura 85 a 91. Bachelotia antillarum. Anatomia vegetativa e reprodutiva...............131 


\section{LISTA DE ABREVIATURAS}

atp9: Subunidade9 da ATP sintase mitocondrial;

atpB: Subunidade B daATP sintase plastidial;

BOLD: Barcode of Life Database Systems;

COI-5P: região 5' do gene que codifica para a enzima citocromo c oxidase subunidade 1;

cox1:Subunidade I do Citocromo c Oxidase;

cox3:Subunidade 3 do Cytochromo c Oxidase;

DNA: Ácido Desoxirribonucleico;

dNTP: Desoxirribonucleotídeos fosfatados;

EDTA:Ácido etilenodiamino tetra-acético;

GenBank:International NucleotideSequence Database Collaboration;

ITS: Espaçador transcrito interno;

Kb: Kilo-Base (1kb equivale à 1000 nucleotídeos);

LSU:Subunidade Grande do Ribossomo;

ML: Máxima Verossimilhança;

nad1:Gene da subunidade 1 da NADH-desidrogenase;

nad4:Gene da subunidade 4 da NADH desidrogenase;

NJ: Neighbor-joining;

pb: Pares de Base nucleotídicas;

PCR: Reação em cadeia da polimerase;

psaA:Proteína do fotosistema l; 
psbA:Proteína do fotosistema II;

rbcL: Gene codificante da subunidade grande da Rubisco (ribulose-1, 5-bifosfato carboxilaseoxigenase);

SPF: Herbário da Universidade de São Paulo;

UPA: "Universal Plastid Amplicom" domínio V do gene plastidial que codifica o RNA da subunidade ribossomal grande. 
As algas pardas filamentosas (Phaeophyceae) constituem um grupo essencialmente marinho com morfologia extremamente simples. A identificação taxonômica dessas algas é bastante difícil quando empregados apenas caracteres morfológicos devido à grande plasticidade fenotípica que apresentam. No Brasil, nenhum estudo sistemático foi feito com seus representantes empregando-se dados moleculares. Neste contexto, a diversidade de algas pardas filamentosas dos gêneros Acinetospora, Asteronema, Bachelotia, Ectocarpus, Hincksia e Feldmannia foi investigada pela primeira vez no Brasil sob uma abordagem molecular, complementada com dados morfológicos. As coletas abrangeram a região sudeste do Brasil, incluindo a área de ressurgência dos litorais do Rio de Janeiro e Espírito Santo, que abriga quase que a totalidade de táxons de algas pardas filamentosas citadas para o país. Foi utilizado o marcador mitocondrial do tipo DNA Barcode, COI-5P e o marcador plastidial para inferências filogenéticas, o $r b c L$. Os estudos moleculares e morfológicos permitiram identificar no mínimo 10 táxons para o litoral sudeste brasileiro: oito da ordem Ectocarpales: Acinetospora filamentosa, "Feldmannia" irregularis, "Feldmannia irregularis" 1, "Feldmannia irregularis" 2, "Feldmannia" mitchelliae, "Hincksia" conifera e Hincksiasandriana (família Acinetosporaceae) e Ectocarpusfasciculatus (família Ectocarpaceae) e dois da ordem Scytothamnales: "Asteronema" breviarticulatum (família Asteronemataceae) e Bachelotia antillarum (família Bachelotiaceae). A família Acinetosporaceae se dividiu em dois agrupamentos, Acinetosporaceae 1, que incluiu a maioria dos representantes brasileiros e a espécie tipo da família, Acinetospora crinita; e Acinetosporaceae 2, que incluiu os autênticos gêneros Feldmannia, Hincksia e Pylaiella com suas respectivas espécies-tipo, Feldmannia lebelli, Hincksia hincksiae e Pylaiella litorallis . Hincksia sandriana foi a única espécie estudada que se agrupou no clado do autêntico gênero Hincksia e é citada pela primeira vez para o Brasil, constituindo um caso de introdução recente. Para os demais representantes agrupados em Acinetosporaceae 1, excluindo Acinetospora, um novo gênero para a ciência deverá ser proposto. Os táxons " $H$." conifera, "F." irregularis, "F. irregularis" 1, "F. irregularis" 2 e "F." mitchelliae não pertencem aos autênticos gêneros Feldmannia e Hincksia, já que não se agruparam com as respectivas espécies-tipo dos gêneros,e, portanto, devem ser transferidos para um novo gênero. As análises com os dois marcadores moleculares demonstraram que " $F$." irregularis, "F. irregularis" 1 e "F. irregularis" 2, previamente citados sob uma única espécie ( $F$. irregularis), representam três entidades taxonômicas independentes. Sequências do COI-5P de F. irregularis da Itália, considerada próxima à localidade tipo (Mar Adriático), confirmaram que parte do material analisado deve ser mantido sob o epíteto irregularis, enquanto duas 
novas espécies devem ser propostas para a ciência para acomodar " $F$. irregularis" 1 e " $F$. irregularis" 2. As análises moleculares com o COI-5P dividiu "F." mitchelliae em três agrupamentos com alta divergência genética e variabilidade morfológica indicando que " $F$." mitchelliae forma um complexo. Uma sequência de "F." mitchelliae procedente dos EUA (Carolina do Norte), próxima à localidade tipo (Massachusetts), gerada no presente estudo, confirmou que o material brasileiro deve ser descrito sob o epíteto mitchelliae. Nossos resultados moleculares demonstraram claramente que o gênero Acinetospora não é monofilético. Acinetospora filamentosa é citada pela primeira vez para o Oceano Atlântico e foi revelada por meio de dados moleculares, tanto pelo COI-5P quanto pelo rbcL. A espécie Acinetospora crinita,referida previamente para o litoral sudeste do Brasil, não foi recoletada neste estudo. Diferenças morfológicas nas estruturas pluriloculares entre as duas espécies e ausência de monosporângios em $A$. filamentosa,descritos como típico apenas para $A$. crinita, confirmaram a ocorrência de $A$. filamentosa para o Atlântico. Nossos resultados com o rbcL revelaram que a família Asteronemataceae não é monofilética. O táxon "Asteronema" breviarticulatum se agrupou com Asterocladon lobatum, espécie tipo do gênero, e deve ser alocado na família Asterocladaceae, assim como transferido para o gênero Asterocladon,propondo-se uma combinação nova para resolver o posicionamento taxonômico dessa espécie. A alta divergência genética verificada para os marcadores COI-5P e rbcL demonstraram que Bachelotia antillarum é uma espécie críptica. A utilização da ferramenta molecular no estudo de algas pardas filamentosas na região sudeste do Brasil foi fundamental para desvendar a sua diversidade, que comprovadamente estava subestimada, assim como melhor delimitar seus gêneros e espécies e revelar espécies crípticas. Os dados aqui apresentados são pioneiros e constituem uma fonte relevante de informação sobre a taxonomia e sistemática deste grupo de algas pardas. Mais investigações por meio de uma ampla revisão, especialmente da família Acinetosporaceae, uma maior amostragem no litoral brasileiro e inclusão de mais gêneros de algas pardas filamentosas nas análises podem ainda mudar o panorama da classificação desse grupo. 


\section{ABSTRACT}

Filamentous brown algae (Phaeophyceae) constitute an essentially marine group that display an extremely simple morphology. The taxonomic identification of these algae is very difficult when based only on morphological characters, due to the high incidence of phenotypic plasticity. In Brazil, no systematic study using molecular data has investigated their representatives. In this context, this study aims to investigate the diversity of filamentous brown algae of the genera Acinetospora, Asteronema, Bachelotia, Ectocarpus, Hincksia and Feldmannia for the first time in Brazil, applying the molecular approach coupled with morphological data. The sampling sites covered the southeastern region of Brazil, including the upwelling area of the Rio de Janeiro and Espírito Santo coasts, which include almost all the filaments of brown algae mentioned for the country. The DNA barcode mitochondrial marker, COI-5P, and the plastid marker for phylogenetic inferences, $r b c \mathrm{~L}$, were sequenced. The molecular and morphological studies allowed at least the recognition of 10 taxa on the Brazilian southeastern coast, out of which eight taxa correspond to the order Ectocarpales, and two to the order Scytothamnales. Ectocarpales is represented by the families Acinetosporaceae (Acinetospora filamentosa, "Feldmannia" irregularis, "Feldmannia irregularis" 1 , "Feldmannia irregularis" 2, "Feldmannia" mitchelliae, "Hincksia" conifera and Hincksia sandriana), and Ectocarpaceae (Ectocarpus fasciculatus). The order Scytothamnales, in turn, includes the families Asteronemataceae ("Asteronema" breviarticulatum) and Bachelotiaceae (Bachelotia antillarum) The Acinetosporaceae family was divided into two clusters: Acinetosporaceae 1 that included the type species of the family (Acinetospora crinita) and most of the Brazilian representatives; and Acinetosporaceae 2 that included the genera Feldmannia, Hincksia and Pylaiella represented by their respective type species, Feldmannia lebelli, Hincksia hincksiae and Pylaiella litorallis. Hincksia sandriana was the only species studied that grouped in the clade of the authentic genus Hincksia. Besides, this is the first record of $H$. sandrianafor Brazil, which constitutes a case of recent introduction. For the other representatives of Acinetosporaceae 1, except Acinetospora, a new genus for science should be proposed. The taxa "H." conifera, "F." irregularis, "F. irregularis" 1, "F. irregularis" 2 and "F." mitchelliae do not belong to the authentic genera Feldmannia and Hincksia, since they did not group with the respective generitypes. Therefore, should be transferred to the new genus. Analyzes applying both molecular markers showed that "F." irregularis, "F. irregularis" 1 and " $F$. irregularis" 2, previously cited as a single species ( $F$. irregularis), constitute three independent taxonomic entities. COI-5P sequences of $F$. irregularis from Italy, close to the type locality (Adriatic Sea), demonstrate that part of the analyzed material should be maintained under the epithet irregularis, whereas two new scientific species should be proposed to accommodate " $F$. irregularis "1 and " F. irregularis "2. COI-5P molecular analyzes divided "F." mitchelliae into three clusters with high genetic divergence and morphological variability indicating that "F." mitchelliae corresponds to a species complex. A sequence of "F." mitchelliae from the United States (North Carolina), near the type locality (Massachusetts), obtained and included in the present study, confirmed that the Brazilian 
material should be described under the epithet mitchelliae. Our molecular results have clearly demonstrated that the genus Acinetospora is non-monophyletic. Acinetospora filamentosa is for the first time mentioned for the Atlantic Ocean and was revealed by molecular data, both by COI-5P and $r b c \mathrm{~L}$. The species Acinetospora crinita recorded on the southeastern coast of Brazil was not collected in this study. Morphological differences in plurilocular structures between two species and absence of monosporangia in $A$. filamentosa, described as typical only for $A$. crinita, confirmed the occurrence of $A$. filamentosa for the Atlantic. Our results with the $r b c L$ revealed that the family Asteronemataceae is non-monophyletic. "Asteronema" breviarticulatum was grouped with Asterocladon lobatum, the type species of the genus, and should be transferred to the genus Asterocladon and to the family Asterocladaceae. Consequently, a new combination should be proposed to solve taxonomic placement of this species. The high genetic divergence observed for the COI-5P and rbcL markers demonstrated that Bachelotia antillarum is a cryptic species. The use of the molecular tool in the study of filamentous brown algae in the southeastern region of Brazil was fundamental to uncover their diversity, previously underestimated, as well as to allow a better delimitation of their genera and species. The innovative data presented here constitute a relevant source of information to the taxonomy and systematics of filamentous brown algae. More investigations through a broad review, especially of the Acinetosporaceae family, a wider sampling in the Brazilian coast and the inclusion of more genera of filamentous brown algae in the analyses can still change the classification scenario of this group. 


\section{INTRODUÇÃO}

A classe Phaeophyceae está inserida no Sub-Reino Heterokonta (CavalierSmith 1986 = Stramenopila Patterson 1989), caracterizado por apresentar células flageladas heterocotes. Os organismos fototróficos heterocontes (algas marromdouradas) estão reunidos no filo Ochrophyta (Cavalier-Smith \& Chao 1996) ou Heterokontophyta (Hoek et al. 1995), cujas algas são definidas por seus cloroplastos de origem endossimbiótica secundária com algas vermelhas (Reviers et al. 2007). A classe Phaeophyceae constitui uma das principais linhagens do filo, abrigando 2.014 espécies (Guiry \& Guiry 2017), todas multicelulares, distribuídas em 285 gêneros (Reviers et al. 2007).

As algas pardas filamentosas constituem um grupo essencialmente marinho com morfologia extremamente simples, incluídas em diferentes famílias das ordens Asterocladales, Discosporangiales, Ectocarpales, Onslowiales e Scytothamnales da classe Phaeophyceae.

A classe Phaeophyceae está inserida no Sub-Reino Heterokonta (CavalierSmith 1986 = Stramenopila Patterson 1989), caracterizado por apresentar células flageladas heterocotes. Os organismos fototróficos heterocontes (algas marromdouradas) estão reunidos no filo Ochrophyta (Cavalier-Smith \& Chao 1996) ou Heterokontophyta (Hoek et al. 1995), cujas algas são definidas por seus cloroplastos de origem endossimbiótica secundária com algas vermelhas (Reviers et al. 2007). A classe Phaeophyceae constitui uma das principais linhagens do filo, abrigando 2.014 espécies (Guiry \& Guiry 2017), todas multicelulares, distribuídas em 285 gêneros (Reviers et al. 2007).

Das ordens citadas acima, três ocorrem no Brasil: Asterocladales, Ectocarpales e Scytothamnales (Wynne 2011). A ordem Ectocarpales é a mais representativa abrigando 761 espécies (Guiry \& Guiry 2017). A ordem foi estabelecida por Bessey (1907) e sua circunscrição foi controversa por várias décadas. Um dos principais embates com relação à classificação das algas pardas diz respeito justamente em reconhecer a circunscrição das Ectocarpales de forma ampla (sensu lato) ou de forma restrita (sensu stricto) (Reviers et al. 2007). Quando 
estabelecida, a ordem Ectocarpales foi descrita sob uma ampla circunscrição, incluindo gêneros filamentosos, pseudoparenquimatosos e parenquimatosos. Esse sistema foi seguido por Fristch $(1943,1945)$ e Fletcher (1987), com algumas modificações. Contudo, a circunscrição da ordem teve seu conceito mais restrito quando Setchell \& Gardner (1925) removeram a família Chordariaceae(pseudoparenquimatosa) para a nova ordem Chordariales e estabeleceram a ordem Dictyosiphonales para acomodar um único gênero parenquimatoso, Dictyosiphon Greville. Kylin (1933) seguiu essencialmente essa circunscrição e restringiu às Ectocarpales apenas espécies filamentosas, removendo todas as espécies de talo pseudoparenquimatoso para as Chordariales e as de talos parenquimatosos para as Dictyosiphonales, a parte Punctaria Greville para o qual Kylin propôs uma nova ordem, Punctariales. Wynne $(1982,1998)$ reconheceu as Ectocarpales como um grupo essencialmente filamentoso, adotando, portanto, o status de ordem para o grupo das Chordariales, Dictyosiphonales e Scytosiphonales. Esse sistema foi seguido em vários levantamentos florísticos e em estudos de algas pardas da costa brasileira realizados nas décadas de 1980 e 1990 (Figueiredo 1989, Széchy \& Cordeiro-Marino 1991, Reis-Santos 1990, Amado Filho 1991, Cassano 1997, Ouriques 1997, Nunes 1999, Gestinari et al. 1998). Na década seguinte, estudos moleculares utilizando marcadores nucleares e plastidiais (sequências parciais do LSU e SSU rDNA, rbcL e o espaçador rbcL-S) solucionaram essa questão, demonstrando que as Ectocarpales formam um único clado composto por representantes filamentosos, pseudoparenquimatosos e parenquimatosos (Peters \& Ramírez 2001, Adl et al. 2005). Cinco famílias foram propostas para a ordem Ectocarpales de acordo com os clados resolvidos nos estudos moleculares da época (Peters \& Ramírez 2001), ao invés das 23 listadas por Reviers \& Rousseau (1999). Esse sistema foi adotado por Wynne $(2005,2011)$ em seu checklist de macroalgas marinhas do Atlântico ocidental.

O estudo tradicional de taxonomia de algas pardas tem levado em consideração quatro características principais para a separação de ordens: o tipo de histórico de vida (isomórfico ou heteromórfico), o tipo de fertilização (iso-, aniso- ou oogâmica), o tipo de crescimento (apical, intercalar ou difuso) e a arquitetura do talo: i) haplóstica, fundamentamente composta de filamentos cujas células se dividem apenas transversalmente, ii) polística, fundamentamente composta de 
filamentoscujas células se dividem também longitudinalmente, muitas vezes sendo também qualificada de parenquimatosa de acordo com Reviers (2006), iii) parenquimatosa, produzida por uma célula ou grupo inicial de células que sofrem clivagens em todos os planos(Silberfeld et al. 2010). As Ectocarpales s.s. que mostram uma combinação de caracteres considerados plesiomórficos, como um histórico de vida isomórfico, fertilização isogâmica e construção haplóstica do taloforam consideradas a priori como uma linhagem antiga, mais divergente de algas pardas (Fristch 1943, Cardinal 1964, Clayton 1974, Russell \& Garbary 1978, Reviers \& Rousseau 1999), enquanto todas as outras ordens, exceto Fucales, foram consideradas derivadas de um ancestral do tipo "Ectocarpus" que desenvolveu um histórico de vida diplo-haplôntico (Silberfeld et al. 2011). Devido ao seu ciclo de vida peculiar, sem alternância de gerações, as Fucales foram consideradas como uma linhagem antiga, divergente que evoluiu de forma independente (Wynne \& Loiseaux 1976).Um dos gêneros mais antigos de algas pardas filamentosas é Ectocarpus Lyngbye (1819), gênerotipo da ordem, que foi proposto como um organismo modelo para as algas pardas (Peters et al. 2004). O gênero, assim como toda a ordem Ectocarpales, está relacionado com os kelps e teve o genoma da sua espécie tipo sequenciado, E. siliculosus (Dillwyn) Lyngbye, por Cock et al. (2010).

Estudos pioneiros de filogenia molecular de algas pardas mostraram que 0 status "primitivo" das Ectocarpales estava errado (Tan \& Druehl 1994, 1996). Estudos posteriores reavaliaram as relações evolutivas dentro da classe Phaeophyceae com um aumento considerável da amostragem de táxons de diferentes ordens e de genes (Reviers \& Rousseau 1999, Rousseau \& Reviers 1999, Draisma et al. 2001, Draisma \& Prud'homme van Reine 2001, Peters \& Ramírez 2001, Rousseau et al. 2001, Yoon et al. 2001, Cho et al. 2004, Cho \& Boo 2006, Kawai \& Sasaki 2004, Lane et al. 2006, 2007, Kawai et al. 2007, Bittner et al. 2008, Phillips et al. 2008). Dentre os estudos citados acima, Rousseau \& Reviers (1999) e Peters \& Ramírez (2001) concentraram-se em melhor circunscrever os limites das Ectocarpales.

Estudos mais recentes têm avaliado as relações evolutivas das Phaoephyceae por meio de análises multigênicas (Silberfeld et al. 2010, 2011) na tentativa de solucionar as ordens agrupadas em uma grande politomia,gerada pela falta de sinal filogenético dos marcadores utilizados,e que se tornou conhecida como 
"brown algal crown radiation (BACR)". Silberfeld et al. (2010) analisaram 72 táxons empregando 10 genes: cinco mitocondriais ( $\operatorname{cox} 1, \operatorname{cox} 3$, nad1, nad4 e atp9), quarto plastidiais ( $r b c \mathrm{~L}, p s a \mathrm{~A}, p s b \mathrm{~A}$ e atpB), e um nuclear (LSU - 28S rDNA) em um alinhamento com mais de 10.000 nucleotídeos. Os autores demonstraram que um aumento substancial no tamanho do alinhamento promoveu a resolução de várias relações dentro do BACR, embora ainda vários ramos não tivessem suporte satisfatório. Do ponto de vista da classificação das algas pardas algumas espécies Insertae sedis reveladas por Silberfeld et al. (2010) foram resolvidas em uma publicação posterior na qual foi feita também uma análise multigênica com sete marcadores, e novas ordens e famílias foram estabelecidas ou emendadas (Silberfeld et al. 2011).

Estudos de DNA Barcoding utilizando a região 5' do gene mitocondrial cox1 (COI-5P) foram feitos por Peters et al. (2015) com o intuito de identificar estádios crípticos de algas pardas cultivadas. Uma alta diversidade específica foi revelada para as famílias Acinetosporaceae e Ectocarpaceae.Acinetosporaceae foi dividida em dois grupos ricos em espécies contendo Pylaiella Bory e Hincksia J.E. Gray em um grupo e Acinetospora em outro, com espécies de Feldmannia Hamel presentes em ambos os agrupamentos. Enquanto que em Ectocarpaceae, 16 linhagens de Ectocarpus foram reconhecidas com o critério do código de barras.

A classificação mais recente das algas pardas é fornecida por Silberfeld et al. (2014).Atualmente, as Ectocarpales Bessey (1907) emend. Rousseau \&Reviers (1999) estão distribuídas em seis famílias: Acinetosporaceae G. Hamel ex J. Feldmann (1937), Adenocystaceae Rousseau et al. (2000) emend. Silberfeld et al. (2011), Chordariaceae Greville (1830) emend. Peters \&Ramírez (2001), Ectocarpaceae C. Agardh (1828) emend. Silberfeld et al. (2011), Petrospongiaceae Racault et al. (2009) e Scytosiphonaceae Ardissone \&Straforello (1877). Das seis famílias, três ocorrem no Brasil e incluem representantes filamentosos: Acinetosporaceae, Chordariaceae e Ectocarpaceae (Tabela 1).

A ordem Ectocarpales como circunscrita atualmente é caracterizada por talos filamentosos com construção haplóstica ou polística, e talos parenquimatosos, crescimento intercalar, difuso ou tricotálico, células com um ou numerosos cloroplastos providos de um ou mais pirenoides salientes e pedunculados, ou ainda 
pirenoides ausentes, reprodução iso- ou anisogâmica, nunca oogâmica, histórico de vida diplo-haplôntico iso-, subisomórfico ou heteromórfico (Rousseau \& Reviers 1999, Reviers \& Rousseau 1999, Cormaci et al. 2010).

Taxons antes alocados em Ectocarpaceae e considerados Insertaesedis por Silberfeld et al. 2010, foram posicionados em ordens e famílias por Silberfeld et al. 2011: a família,Asterocladaceae Silberfeld et al. (2011) para acomodar Asterocladon rhodochortonoides (Børgesen) Uwai, Nagasato, Motomura \& Kogame. Assim como as novas famílias, Bachelotiaceae Silberfeld et al. (2011) para acomodar Bachelotia antillarum (Bornet) Kuckuck ex Hamel e AsteronemataceaeSilberfeld et al. (2011) para acomodar Asteronema breviarticulatum (J. Agardh) Ouriques \& Bouzon. As famílias e Bachelotiaceae e Asteronemataceaeestão alocadas na ordem ScytothamnalesPeters \& Claytonemend. Silberfeld et al. (2011) (Tabela 1).

A ordem Asterocladales é caracterizada pela construção haplóstica do talo, crescimento apical, pêlos laterais, vários cloroplastos alongados e, exceto em Levringia (Chordariaceae), cada um com um pirenoide lateral, associados em um arranjo estrelado e voltados para o pólo de seus pirenoides, que são agrupados no centro da célula,reprodução anisogâmica, histórico de vida diplo-haplôntico isomórfico (Uwai et al. 2005, Silberfeld et al. 2011).

A ordem ScytothamnalesA.F.Peters \& M.N.Clayton, é caracterizada pela construção há plóstica do talo ou parenquimatosa, crescimento apical por célula ou meristema, pelos agrupados crecendo a partir de criptóstomas ou conceptáculos, células com vários cloroplastos alongados em uma configuração estrelada, cada um com um perinoide terminal, cloroplastos reunidos pelos pólos de seus pirenoides, ou células com cloroplasto único, lobado e em forma de estrela com um grande pirenoide central, reprodução iso- ou anisogâmica, histórico de vida diplo-haplôntico heteromórfico (Peters \& Clayton 1998, Silberfeld et al. 2011).

As algas pardas filamentosas, especialmente as das famílias Acinetosporaceae e Ectocarpaceae, apresentam grande variabilidade morfológica e a dificuldade em delimitar gêneros, assim como suas categorias infragenéricas e infraespecíficas é amplamente reconhecida na literatura (Knoepffler-Pèguy 1970, Ravanko 1970, Clayton 1974, Russell \& Fletcher 1975, Russell \& Garbary 1978, Yoneshigue 1985, Kim \& Lee 1994). Morfologicamente, gêneros e espécies são 
delimitados por particularidades dos filamentos e pelas características das estruturas de reprodução, tais como: dominância relativa do filamento ereto ou do filamento prostrado, localização da zona meristemática, presença ou ausência de pêlos verdadeiros ou pseudopêlos, forma dos cloroplastos, localização, forma e dimensões das estruturas pluriloculares, presença de mais de um tipo de estrutura plurilocular, presença ou ausência de estruturas uniloculares e monosporângios. Muitas dessas características se sobrepõem em muitas espécies tornando a taxonomia clássica extremamente difícil (Cassano 1997).

Nesse contexto, a ferramenta molecular tem promovido um melhor conhecimento das relações evolutivas entre as algas pardas como um todo e, como consequência de seu uso, uma hipótese filogenética completamente nova tem sido revelada, o que implica em um novo conceito de sua evolução (Reviers et al. 2007).

Algas pardas filamentosas se distribuem amplamente em todo o mundo em águas tropicais, subtropicais e temperadas dos hemisférios norte e sul. No litoral brasileiro, ocupam grande extensão da costa, desde o estado do Ceará (Oliveira Filho 1977) até o Rio Grande do Sul (Coutinho 1982). Há registro de 26 espécies de algas pardas filamentosas no Brasil, distribuídas em 14 gêneros (Tabela 1). Os estudos de algas pardas filamentosas no país estão inseridos em levantamentos florísticos (Joly 1957, 1965, Yoneshigue 1985, Yoneshigue\& Figueiredo 1987, Figueiredo 1989, Reis-Santos 1990, Amado Filho 1991, Gestinari et al. 1998) ou em levantamentos de Phaeophyceae como os realizados por Széchy \& Cordeiro-Marino (1991), Ouriques (1997), Nunes (1999), Crispino (2000), Nunes \& Paula (2004), Guimarães et al. (2016), sendo que o único estudo sistemático, exclusivo de pardas filamentosas no Brasil, incluindo culturas, foi feito por Cassano (1997).

A região sudeste abriga quase que a totalidade das citações de algas pardas filamentosas no Brasil (Tabela 1). Pelo menos, cinco táxons ocorrem em águas frias da região de ressurgência: Acinetospora crinita(Carmichael ex Harvey) Kornmann,Ectocarpus fasciculatus Harvey, Kuckukia spinosa (Kützing) Kuckuck, Elachista minutissima W.R. Taylor e Elachistiella leptonematoides Cassano, Yoneshigue-Valentin \& Wynne (Yoneshigue 1985, Cassano et al. 2004, Brasileiro et al. 2009). Essa ocorrência está relacionada ao fenômeno da ressurgência que ocorre no estado do Rio de Janeiro e do Espírito Santo (Yoneshigue 1985, Amado 
Filho \& Yoneshigue-Valentin 1992, Cassano et al. 2004). Eventos de ressurgência são comuns entre Cabo Frio e Cabo de São Tomé (norte do Rio de Janeiro) (Castro \& Miranda 1998). Essa região é uma área biogeograficamente disjunta na costa brasileira, com locais regularmente expostos a esse fenômeno, exibindo táxons característicos de águas frias (Oliveira Filho 1977, Yoneshigue 1985). O estado do Espírito Santo é considerado uma zona de transição entre duas regiões principais, explicadas pelas diferenças de temperatura: tropical (norte do Brasil) e temperada quente (sul do Brasil, incluindo a região de Cabo Frio) (Horta et al. 2001). A zona de transição do Espírito Santo é caracterizada pela presença de alguns locais de afloramento de águas frias, causado pela ressurgência o que torna possível a ocorrência de espécies típicas de regiões temperadas quentes (Cassano et al. 2004).

Tabela 1. Lista das espécies de algas pardas filamentosas citadas para o Brasil e sua distribuição geográfica.

\begin{tabular}{|c|c|c|c|}
\hline Táxons & Localidade tipo & $\begin{array}{l}\text { Distribuição na } \\
\text { costa brasileira }\end{array}$ & Referências \\
\hline \multicolumn{4}{|l|}{ Ordem Asterocladales } \\
\hline \multicolumn{4}{|l|}{ Asterocladaceae } \\
\hline $\begin{array}{l}\text { Asterocladum rhodochortonoides } \\
\text { (Børgesen) Uwai et al. }\end{array}$ & & SC, RJ, ES, BA, CE & $\begin{array}{l}\text { Asterocladum rhodochortonoides } \\
\text { (Børgesen) Uwai et al. }\end{array}$ \\
\hline \multicolumn{4}{|l|}{$\begin{array}{l}\text { Ordem Scytothamnales } \\
\text { Asteronemataceae }\end{array}$} \\
\hline $\begin{array}{l}\text { Asteronema breviarticulatum (J. } \\
\text { Agardh) Ouriques \& Bouzon }\end{array}$ & $\begin{array}{l}\text { St. Agustín, Oaxaca, } \\
\text { México }\end{array}$ & $\begin{array}{l}\mathrm{SC}, \mathrm{RJ}, \mathrm{ES}, \mathrm{SP}, \mathrm{BA}, \\
\mathrm{CE}\end{array}$ & $\begin{array}{l}\text { Cassano (1997), Ouriques \& } \\
\text { Cordeiro-Marino (2004), Nunes \& } \\
\text { Paula (2004), Széchy \& De Paula } \\
\text { (2015), Guimarães et al. (2016) }\end{array}$ \\
\hline \multicolumn{4}{|l|}{ Bachelotiaceae } \\
\hline $\begin{array}{l}\text { Bachelotia antillarum } \\
\text { (Grunow)Gerloff }\end{array}$ & Guadalupe & $\begin{array}{l}P R, S C, R S, R J, E S \\
S P, B A, P E, C E\end{array}$ & $\begin{array}{l}\text { Yoneshigue (1985), Figueiredo } \\
\text { (1989), Nunes \& Paula (2004), } \\
\text { Széchy \& De Paula (2015), } \\
\text { Guimarães et al. (2016) }\end{array}$ \\
\hline
\end{tabular}

*Ordem Ectocarpales[ = Chordariales, Dictyosiphonales, Mesogloiales, Scytosiphonales]

Acinetosporaceae

\begin{tabular}{|c|c|c|c|}
\hline $\begin{array}{l}\text { AcinetosporacrinitaCarmich. ex } \\
\text { Harv.) Kornmann }\end{array}$ & Appin, Escócia & RJ, SP & $\begin{array}{l}\text { Figueiredo \& Yoneshigue (1983), } \\
\text { Yoneshigue (1985), Széchy \& } \\
\text { Cordeiro-Marino (1991), Széchy\& } \\
\text { Paula (2000) }\end{array}$ \\
\hline
\end{tabular}


Feldmannia indica (Sonder) Guadalupe $\quad$ RJ, ES, SP, RN
Womers. \& Bailey

F. irregularis (Kütizing) Hamel
Mar Adriático
PR, SC, RS, RJ, SP, $E S, B A, A L$
Oliveira Filho e Ugadim (1974), Cassano (1997), Széchy \& De Paula (2015), Guimarães et al. (2016)

Cassano (1997), Nunes \& Paula (2004), Széchy \& De Paula (2015), Guimarães et al. (2016)

\section{Cont. Tabela 1}

\begin{tabular}{|c|c|c|c|}
\hline Táxons & Localidade tipo & $\begin{array}{l}\text { Distribuição na } \\
\text { costa brasileira }\end{array}$ & Referências \\
\hline $\begin{array}{l}\text { F.lebelii(Areschoug ex P.L. } \\
\text { Crouan \& H.M. Crouan) Hamel 且 }\end{array}$ & $\begin{array}{l}\text { Brest, Finistère, } \\
\text { França }\end{array}$ & RN & $\begin{array}{l}\text { Oliveira Filho e Ugadim (1974, } \\
\text { como Feldmannia caespitula (J. } \\
\text { Agardh) Knoepffler-Pèguy) }\end{array}$ \\
\hline $\begin{array}{l}\text { F. mitchelliae (Harvey) H.-S. Kim } \\
\text { (como Hincksia mitchelliae (Harvey) } \\
\text { P.C. Silva) }\end{array}$ & $\begin{array}{l}\text { Nantucket, } \\
\text { Massachusetts, } \\
\text { EUA }\end{array}$ & $\begin{array}{l}P R, S C, R S, R J, S P \\
E S, B A, C E, A L\end{array}$ & $\begin{array}{l}\text { Cassano (1997), Széchy \& Cordeiro- } \\
\text { Marino (1991), Nunes \& Paula } \\
\text { (2004), Széchy \& De Paula (2015), } \\
\text { Guimarães et al. (2016) }\end{array}$ \\
\hline $\begin{array}{l}\text { F. simplex (P.L. Crouan \& H.M. } \\
\text { Crouan) Hamel }\end{array}$ & $\begin{array}{l}\text { Rade de Brest, } \\
\text { Brittany, França }\end{array}$ & RJ & $\begin{array}{l}\text { Széchy \& Cordeiro-Marino } \\
\text { (1991)OBS. Considerada nome mal } \\
\text { aplicado de F. irregularis por } \\
\text { Cassano (1997) }\end{array}$ \\
\hline $\begin{array}{l}\text { Herponema tortugense (W.R. } \\
\text { Taylor) W.R. Taylor }\end{array}$ & $\begin{array}{l}\text { Dry Tortugas, } \\
\text { Florida, EUA }\end{array}$ & $P E, A L, R N$ & $\begin{array}{l}\text { Cordeiro-Marino \& Guimarães } \\
\text { (1981) }\end{array}$ \\
\hline $\begin{array}{l}\text { Hincksia conifera(Børgesen) I.A. } \\
\text { Abbott }\end{array}$ & $\begin{array}{l}\text { St. John, Ilhas } \\
\text { Virgens }\end{array}$ & RJ, SP & $\begin{array}{l}\text { Cassano (1997), Guimarães et al. } \\
\text { (2016) }\end{array}$ \\
\hline $\begin{array}{l}\text { Hincksia onslowensis (Amsler \& } \\
\text { Kapraun) P.C. Silva }\end{array}$ & $\begin{array}{l}\text { Baía de Onslow, } \\
\text { Carolina do Norte, } \\
\text { EUA }\end{array}$ & RJ, ES, SP, BA & $\begin{array}{l}\text { Cassano \& Yoneshigue-Valentin } \\
\text { (2001), Nassar et al. (2001), Pereira } \\
\text { (2007), Széchy \& De Paula (2015) }\end{array}$ \\
\hline $\begin{array}{l}\text { Kuetzingiellabattersii (Bornet) } \\
\text { Kornmann }\end{array}$ & $\begin{array}{l}\text { Sidmouth, Devon, } \\
\text { Inglaterra }\end{array}$ & PE & $\begin{array}{l}\text { Cordeiro-Marino \& Guimarães } \\
\text { (1981) }\end{array}$ \\
\hline $\begin{array}{l}\text { Kuetzingiella } \\
\text { elachistaeformis(Heydr.) M.S } \\
\text {.Balakr. \& Kinkar }\end{array}$ & $\begin{array}{l}\text { Hatzfeldthaven, } \\
\text { Papua Nova Guiné }\end{array}$ & RJ, SP, ES, RN & $\begin{array}{l}\text { Oliveira Filho \& Ugadim (1974), } \\
\text { Crispino (2000), Guimarães et al. } \\
\text { (2016) }\end{array}$ \\
\hline
\end{tabular}

*Chordariaceae [ = Dictyosiphonaceae, Elachistaceae, Leathesiaceae, Myrionemataceae, Myriotrichiaceae, Punctariaceae, Spermatochnaceae, Stilophoraceae, Striariaceae]

\begin{tabular}{|c|c|c|c|}
\hline AscocyclushypneaeBørgesen & Ilhas Virgens & SP & Ugadim (1973) \\
\hline $\begin{array}{l}\text { Hecatonemafloridanum(W.R.Taylor) } \\
\text { W.R.Taylor }\end{array}$ & $\begin{array}{l}\text { Dry Tortugas, } \\
\text { Florida, EUA }\end{array}$ & $R J, S P, B A$ & $\begin{array}{l}\text { Amado Filho \& Yoneshigue- } \\
\text { Valentin (1992), Guimarães et al. } \\
\text { (2016) }\end{array}$ \\
\hline H. terminale(Kützing) Kylin & $\begin{array}{l}\text { Helgoland, } \\
\text { Alemanha }\end{array}$ & RJ, SP, ES & Ugadim (1973), Yoneshigue (1985) \\
\hline $\begin{array}{l}\text { Myriactula minor(Farlow) W.R. } \\
\text { Taylor }\end{array}$ & $\begin{array}{l}\text { Woods Hole, } \\
\text { Massachusetts, } \\
\text { EUA }\end{array}$ & ES & Crispino (2000) \\
\hline Myrionema strangulans Greville & $\begin{array}{l}\text { Appin, Argyll, } \\
\text { Escócia }\end{array}$ & RJ, ES & Crispino (2000) \\
\hline $\begin{array}{l}\text { Protectocarpus speciosus(Bornet) } \\
\text { Kuckuck }\end{array}$ & $\begin{array}{l}\text { Vaags Ejde, Syder } \varnothing \text {, } \\
\text { Faeroes }\end{array}$ & $P R, R J, E S, S P$ & $\begin{array}{l}\text { Crispino (2000), Guimarães et } \\
\text { al. (2016) }\end{array}$ \\
\hline Streblonema parasiticum & Le Croisic (Loire- & CE,SP & Joly et al. (1967, como Entonema \\
\hline
\end{tabular}




\section{Ectocarpaceae}

\section{Cont. Tabela 1}

\begin{tabular}{|c|c|c|c|}
\hline Táxons & Localidade tipo & $\begin{array}{l}\text { Distribuição na } \\
\text { costa brasileira }\end{array}$ & Referências \\
\hline Ectocarpus fasciculatus Harvey & $\begin{array}{l}\text { Irlanda (Mangan's } \\
\text { Bay, Co. } \\
\text { Waterford), } \\
\text { Irlanda do Norte } \\
\text { (Strangford Lough), } \\
\text { Reino Unido }\end{array}$ & RJ, ES, SP & $\begin{array}{l}\text { Yoneshigue (1985), Crispino } \\
(2000) \text {, Pereira (2007) }\end{array}$ \\
\hline E. siliculosus (Dillwyn) Lyngbye & $\begin{array}{l}\text { Cromer em Norfolk } \\
\text { e Hastings em East } \\
\text { Sussex, Inglaterra }\end{array}$ & $\mathrm{RS}, \mathrm{RJ}$ & Coutinho (1982) \\
\hline $\begin{array}{l}\text { E.siliculosus var. pygmaeus } \\
\text { (Areschoug) Gallardo }\end{array}$ & Split, Croácia & RJ & $\begin{array}{l}\text { Yoneshigue (1985, } \\
\text { comoE.fasciculatusvar. pygmaeus } \\
\text { (Areschoug) Batters }\end{array}$ \\
\hline E. variabilis Vickers & $\begin{array}{l}\text { Bathsheba, } \\
\text { Barbados }\end{array}$ & CE & Joly et al. (1967) \\
\hline E. rallsiae Vickers & Barbados & RJ, BA & Yoneshigue (1985), Nunes (1999) \\
\hline Kuckukia spinosa(Kützing) Kuckuck & Bretanha, França & RJ & $\begin{array}{l}\text { Yoneshigue \& Figueiredo (1983), } \\
\text { Yoneshigue (1985) }\end{array}$ \\
\hline
\end{tabular}

*Wynne (2011) 


\section{JUSTIFICATIVA}

A maioria das algas pardas filamentosas integrantes das ordens Asterocladales, Scytothamnales e Ectocarpales são organismos de ampla distribuição no litoral brasileiro. Entretanto, muitos representantes são diminutos, epífitos ou parcialmente endófitos, alguns encontrados em águas profundas, portanto de difícil coleta e triagem. A região sudeste do Brasil abriga quase que a totalidade de táxons de algas pardas filamentosas citadas para o país, sendo que algumas delas são de ocorrência exclusiva da zona de ressurgência dos litorais do Rio de Janeiro e Espírito Santo. Assim, esse projeto pretende concentrar o estudo nos representantes comuns do litoral sudeste do país como os dos gêneros Acinetospora, Asteronema, Bachelotia, Ectocarpus, Hincksia e Feldmannia. O grupo apresenta um histórico taxonômico extremamente problemático, ampliado pela grande plasticidade fenotípica que o grupo apresenta.

No Brasil, há uma carência de estudos do ponto de vista sistemático que incluam dados moleculares desses representantes, o que faz com que a diversidade do grupo possa estar subestimada. Apesar do avanço no conhecimento das relações evolutivas do grupo, do reconhecimento de novos gêneros e espécies, assim como de categorias taxonômicas superiores e da correção de inúmeras identificações taxonômicas equivocadas, nenhum estudo molecular foi feito com as espécies de algas pardas filamentosas brasileiras.Considerando isso, abordagens taxonômicas e moleculares sobre esses organismos são indispensáveis ao conhecimento e à conservação da biodiversidade marinha brasileira. Esse estudo é pioneiro no Brasil e visa suprir uma enorme lacuna no conhecimento das algas pardas filamentosas da nossa costa. 


\subsection{Objetivo Geral}

Investigar a diversidade das algas pardas filamentosas, especialmente os gêneros Acinetospora, Asteronema, Bachelotia, Ectocarpus, Hincksia e Feldmannia no litoral sudeste do Brasil, de forma a contribuir para o conhecimento da nossa flora marinha.

\subsection{Objetivos Específicos}

- Utilizar as ferramentas moleculares e morfológicas no estudo da taxonomia das espécies de algas pardas filamentosas existentes no litoral sudeste; 


\section{1. Área de Estudo}

A área de estudo compreende o litoral dos Estados do Espírito Santo, Rio de Janeiro e São Paulo, entre as coordenadas geográficas 18¹9'53.84"S, $39^{\circ} 40^{\prime} 04.67^{\prime \prime} \mathrm{O}$ e $25^{\circ} 18^{\prime} 37.79^{\prime \prime} \mathrm{S}, 48^{\circ} 05^{\prime} 39.81^{\prime \prime} \mathrm{O}$. O litoral sudeste do Brasil apresenta $1.650 \mathrm{~km}$ de extensão tendo por limites, ao norte, o Estado da Bahia, ao Sul, o Estado do Paraná, e a oeste, o Oceano Atlântico (Figura 1).Ao longo da região sudeste, 57 praias foram visitadas (Tabela 2), sendo que em 37 delas foram encontrados exemplares examinados neste estudo.

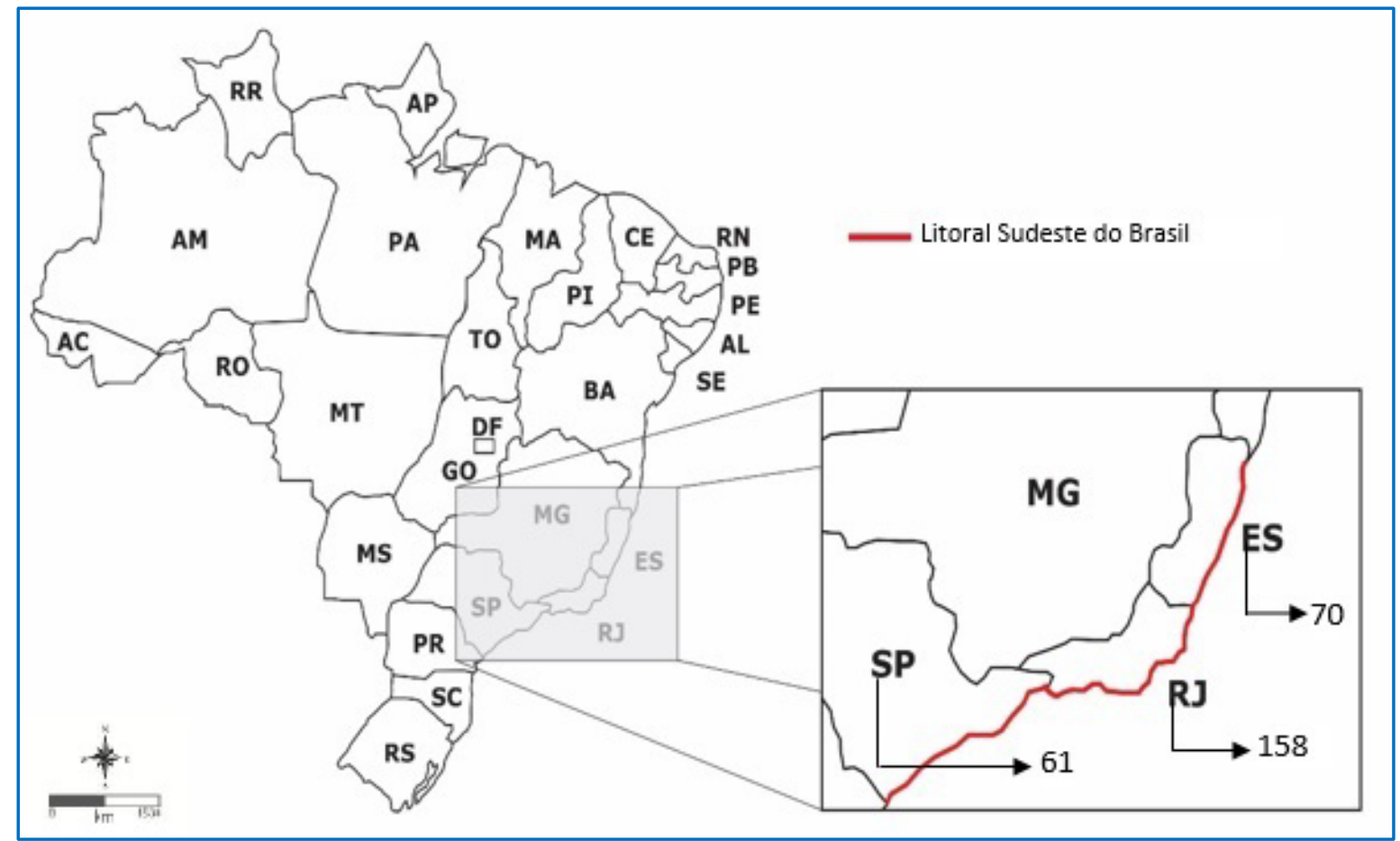

Figura 1. Mapa político do Brasil com destaque ao litoral Sudeste e número total de amostras coletadas por estado.

\subsection{Coleta e Processamento das Amostras}


Os espécimes foram coletados em diversos pontos georeferenciados do litoral sudeste do Brasilem 2014-2015 (Tabela 2). Amostras cedidas por outros pesquisadores também foram incluídas nas análises. As amostras foram obtidas através de coleta manual ou com auxílio de espátula metálica, da região entremarés até a franja do infralitoral, preferencialmente em maré baixa, conforme dados obtidos da Diretoria de Hidrografia e Navegação (DNH), referentes aos Portos de São Sebastião e de Santos para o Estado de São Paulo, ao Porto do Forno para o Estado do Rio de Janeiro e ao Terminal da Ponta do Ubu, para o Estado do Espírito Santo (http://www.mar.mil.br/dhn/chm/box-previsao-mare/tabuas/).
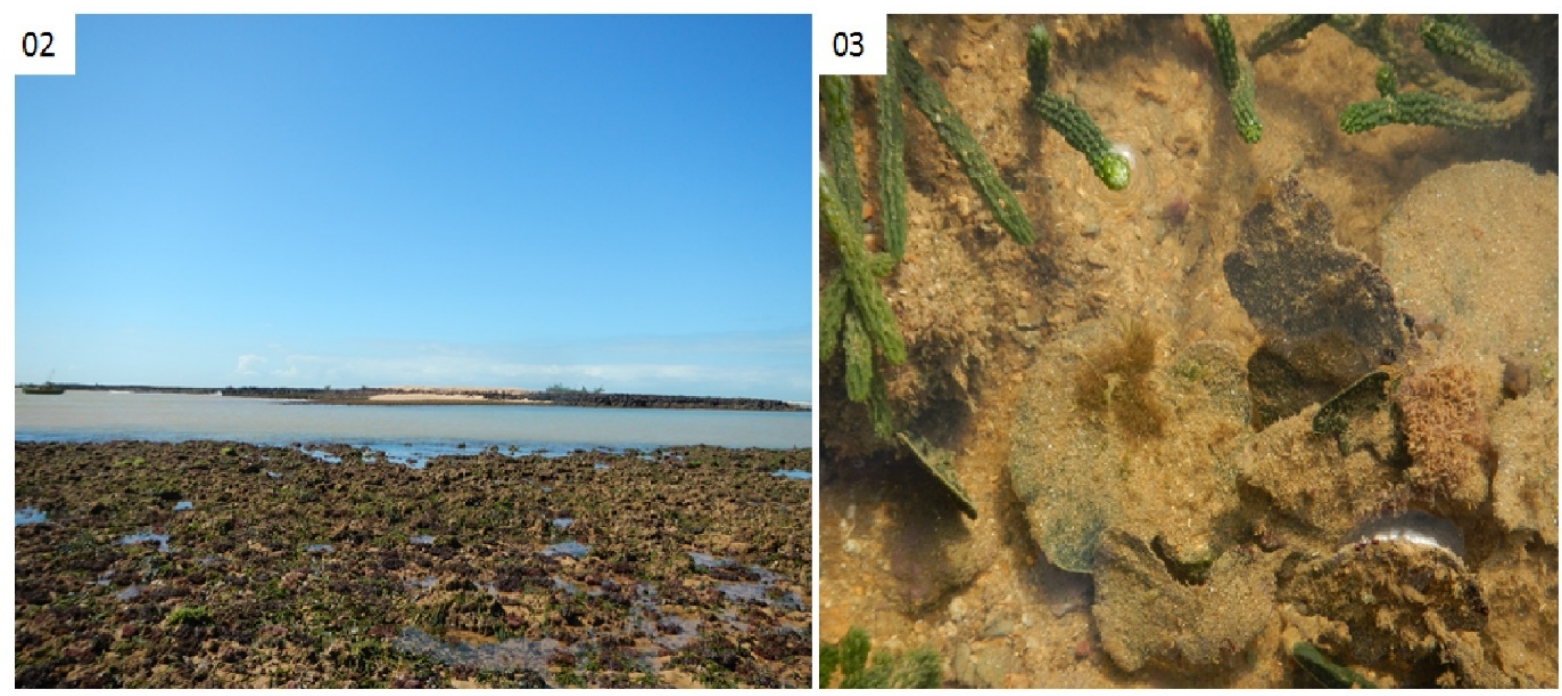

Figuras 2 e 3: Ilhote de Ubu, Anchieta, Espírito Santo. Figura 2: Aspecto do ambiente recifal. Figura 3: Detalhe de Bachelotia antillarum sobreUdotea sp. 


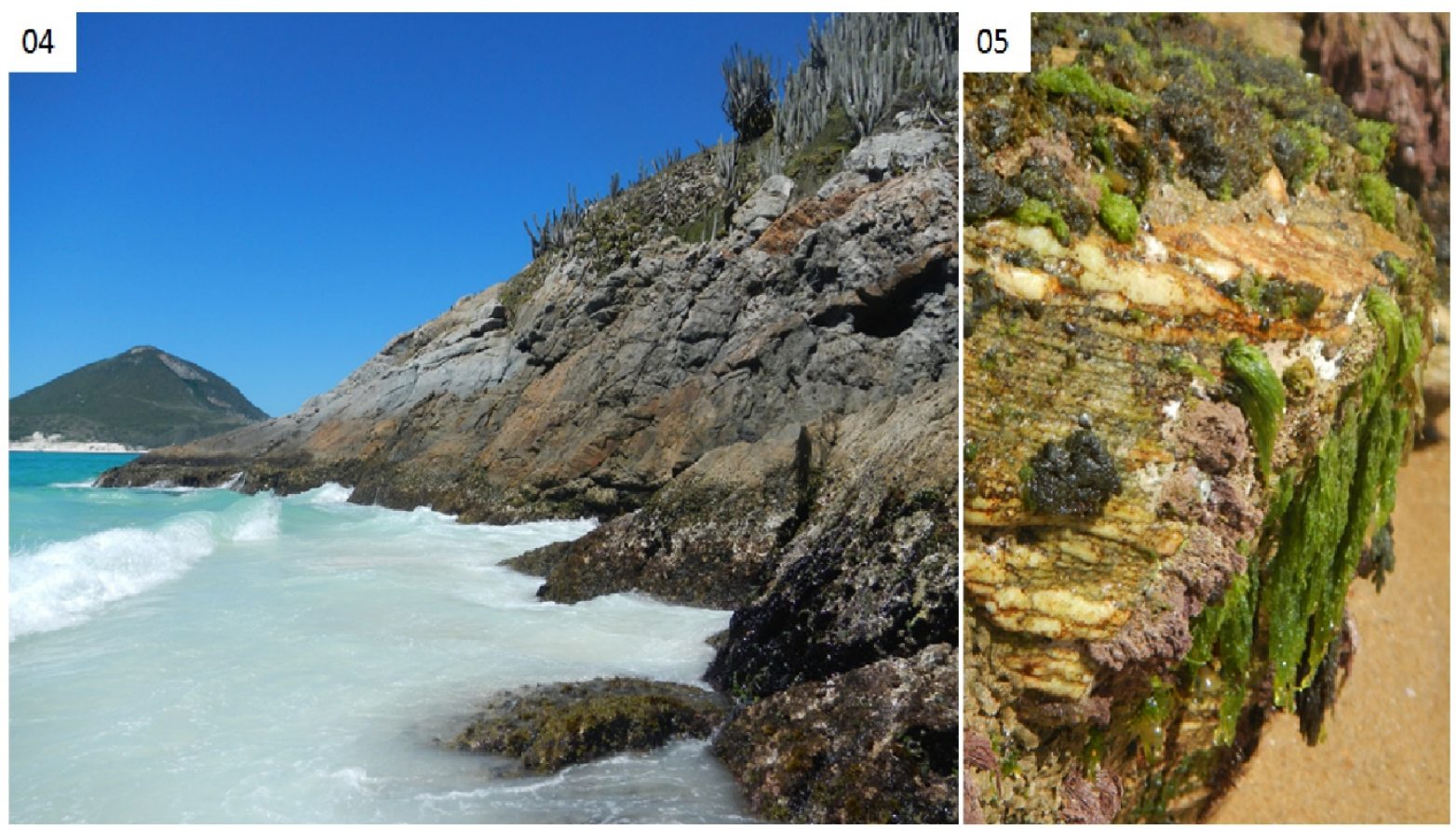

Figuras 4 e 5: Pontal do Atalaia, Arraial do Cabo,Rio de Janeiro. Figura 4: Costão rochoso. Figura 5: Detalhe docostão.

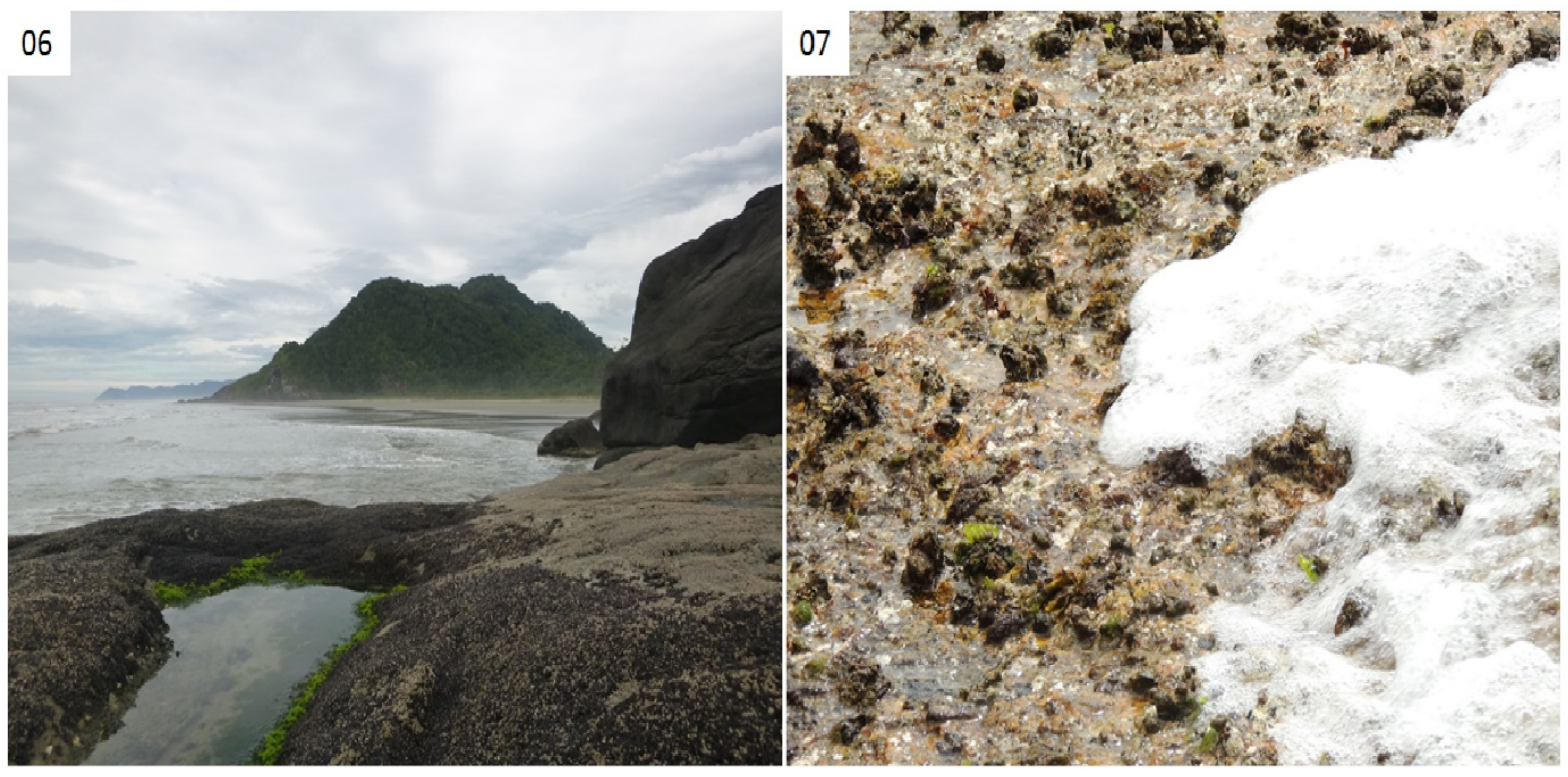

Figuras 6 e 7: Praia Desertinha, Reserva Juréia-Itatins, Peruíbe, São Paulo. Figura 6: Aspecto do ambiente apresentando poça-de-maré. Figura 7: Detalhe de pardas filamentosas sobre costão batido. 
Tabela 2. Listagem das amostras coletadas ao longo do litoral sudeste do Brasil utilizadas para análises morfológicas e moleculares com os marcadores COI-5P e rbcL (X= com êxito, - sem êxitoe $\mathrm{CH}^{2} \mathrm{O}=$ apenas em formol).

\begin{tabular}{|c|c|c|c|c|c|c|c|c|}
\hline $\begin{array}{l}\text { Código } \\
\text { de } \\
\text { Coleta }\end{array}$ & Amostra & $\begin{array}{l}\text { Local de } \\
\text { Coleta }\end{array}$ & Cidade & Data & Coletor (s) & $\begin{array}{l}\text { Latitude / } \\
\text { Longitude }\end{array}$ & $\begin{array}{l}\text { COI- } \\
5 P\end{array}$ & $r b c \mathrm{~L}$ \\
\hline $\begin{array}{c}\mathrm{MM} \\
001\end{array}$ & $\begin{array}{l}\text { Bachelotia } \\
\text { antillarum }\end{array}$ & $\begin{array}{c}\text { Praia da Foca } \\
\text { - Pta da } \\
\text { Lagoinha }\end{array}$ & $\begin{array}{c}\text { Armação } \\
\text { dos Búzios, } \\
\text { RJ }\end{array}$ & $15 / 04 / 2014$ & $\begin{array}{c}\text { M. Mungioli; V. } \\
\text { Cassano; J.C. De- } \\
\text { Paula }\end{array}$ & $\begin{array}{l}22^{\circ} 45^{\prime} 53^{\prime \prime} \mathrm{S} \\
41^{\circ} 52^{\prime} 41^{\prime \prime} \mathrm{W}\end{array}$ & $\mathrm{X}$ & $\mathrm{X}$ \\
\hline $\begin{array}{c}\text { MM } \\
002\end{array}$ & $\begin{array}{l}\text { “Feldmannia” } \\
\text { irregularis" }\end{array}$ & $\begin{array}{c}\text { Praia da Foca } \\
\text { - Pta da } \\
\text { Lagoinha }\end{array}$ & $\begin{array}{c}\text { Armação } \\
\text { dos Búzios, } \\
\text { RJ }\end{array}$ & $15 / 04 / 2014$ & $\begin{array}{l}\text { M. Mungioli; V. } \\
\text { Cassano; J.C. De- } \\
\text { Paula }\end{array}$ & $\begin{array}{l}22^{\circ} 45^{\prime} 53^{\prime \prime S} ; \\
41^{\circ} 52^{\prime} 41^{\prime \prime} \mathrm{W}\end{array}$ & $\mathrm{X}$ & $\mathrm{X}$ \\
\hline $\begin{array}{c}\text { MM } \\
003\end{array}$ & $\begin{array}{c}\text { "Feldmannia" } \\
\text { mitchelliae }\end{array}$ & $\begin{array}{c}\text { Praia da Foca } \\
\text { - Pta da } \\
\text { Lagoinha }\end{array}$ & $\begin{array}{c}\text { Armação } \\
\text { dos Búzios, } \\
\text { RJ }\end{array}$ & $15 / 04 / 2014$ & $\begin{array}{c}\text { M. Mungioli; V. } \\
\text { Cassano; J.C. De- } \\
\text { Paula }\end{array}$ & $\begin{array}{l}22^{\circ} 45^{\prime} 53^{\prime \prime} \mathrm{S} \\
41^{\circ} 52^{\prime} 41^{\prime \prime} \mathrm{W}\end{array}$ & $\mathrm{X}$ & $\mathrm{X}$ \\
\hline $\begin{array}{c}\text { MM } \\
004\end{array}$ & $\begin{array}{c}\text { “Feldmannia" } \\
\text { mitchelliae }\end{array}$ & $\begin{array}{c}\text { Praia da Foca } \\
\text { - Pta da } \\
\text { Lagoinha }\end{array}$ & $\begin{array}{c}\text { Armação } \\
\text { dos Búzios, } \\
\text { RJ }\end{array}$ & $15 / 04 / 2014$ & $\begin{array}{l}\text { M. Mungioli; V. } \\
\text { Cassano; J.C. De- } \\
\text { Paula }\end{array}$ & $\begin{array}{l}22^{\circ} 45^{\prime} 53^{\prime \prime S} \text {; } \\
41^{\circ} 52^{\prime} 41^{\prime \prime} \mathrm{W}\end{array}$ & $\mathrm{X}$ & $\mathrm{X}$ \\
\hline $\begin{array}{c}\text { MM } \\
005\end{array}$ & $\begin{array}{l}\text { "Feldmannia" } \\
\text { mitchelliae }\end{array}$ & $\begin{array}{c}\text { Praia da Foca } \\
\text { - Pta da } \\
\text { Lagoinha }\end{array}$ & $\begin{array}{c}\text { Armação } \\
\text { dos Búzios, } \\
\text { RJ }\end{array}$ & $15 / 04 / 2014$ & $\begin{array}{l}\text { M. Mungioli; V. } \\
\text { Cassano; J.C. De- } \\
\text { Paula }\end{array}$ & $\begin{array}{l}22^{\circ} 45^{\prime} 53^{\prime \prime} \mathrm{S} \\
41^{\circ} 52^{\prime} 41^{\prime \prime} \mathrm{W}\end{array}$ & $\mathrm{X}$ & $\mathrm{X}$ \\
\hline $\begin{array}{c}\text { MM } \\
006\end{array}$ & $\begin{array}{l}\text { "Feldmannia } \\
\text { irregularis" }\end{array}$ & $\begin{array}{c}\text { Praia da Foca } \\
\text { - Pta da } \\
\text { Lagoinha }\end{array}$ & $\begin{array}{c}\text { Armação } \\
\text { dos Búzios, } \\
\text { RJ }\end{array}$ & $15 / 04 / 2014$ & $\begin{array}{l}\text { M. Mungioli; V. } \\
\text { Cassano; J.C. De- } \\
\text { Paula }\end{array}$ & $\begin{array}{l}22^{\circ} 45^{\prime} 53^{\prime \prime S} ; \\
41^{\circ} 52^{\prime} 41^{\prime \prime} \mathrm{W}\end{array}$ & $\mathrm{X}$ & $\mathrm{X}$ \\
\hline $\begin{array}{c}\text { MM } \\
007\end{array}$ & $\begin{array}{c}\text { "Feldmannia" } \\
\text { mitchelliae }\end{array}$ & $\begin{array}{c}\text { Praia da Foca } \\
\text { - Pta da } \\
\text { Lagoinha }\end{array}$ & $\begin{array}{c}\text { Armação } \\
\text { dos Búzios, } \\
\text { RJ }\end{array}$ & $15 / 04 / 2014$ & $\begin{array}{c}\text { M. Mungioli; V. } \\
\text { Cassano; J.C. De- } \\
\text { Paula }\end{array}$ & $\begin{array}{l}22^{\circ} 45^{\prime} 53^{\prime \prime} \mathrm{S} \\
41^{\circ} 52^{\prime} 41^{\prime \prime} \mathrm{W}\end{array}$ & $\mathrm{X}$ & $\mathrm{X}$ \\
\hline $\begin{array}{c}\mathrm{MM} \\
008\end{array}$ & $\begin{array}{l}\text { “Feldmannia } \\
\text { irregularis” }\end{array}$ & $\begin{array}{c}\text { Praia da Foca } \\
\text { - Pta da } \\
\text { Lagoinha }\end{array}$ & $\begin{array}{c}\text { Armação } \\
\text { dos Búzios, } \\
\text { RJ }\end{array}$ & $15 / 04 / 2014$ & $\begin{array}{l}\text { M. Mungioli; V. } \\
\text { Cassano; J.C. De- } \\
\text { Paula }\end{array}$ & $\begin{array}{l}22^{\circ} 45^{\prime} 53^{\prime \prime} \mathrm{S} \\
41^{\circ} 52^{\prime} 41^{\prime \prime} \mathrm{W}\end{array}$ & $\mathrm{X}$ & $\mathrm{X}$ \\
\hline $\begin{array}{c}\text { MM } \\
009\end{array}$ & $\begin{array}{l}\text { "Feldmannia } \\
\text { irregularis" }\end{array}$ & $\begin{array}{c}\text { Praia da Foca } \\
\text { - Pta da } \\
\text { Lagoinha }\end{array}$ & $\begin{array}{c}\text { Armação } \\
\text { dos Búzios, } \\
\text { RJ }\end{array}$ & $15 / 04 / 2014$ & $\begin{array}{l}\text { M. Mungioli; V. } \\
\text { Cassano; J.C. De- } \\
\text { Paula }\end{array}$ & $\begin{array}{l}22^{\circ} 45^{\prime} 53^{\prime \prime} \mathrm{S} \\
41^{\circ} 52^{\prime} 41^{\prime \prime} \mathrm{W}\end{array}$ & $\mathrm{X}$ & $\mathrm{X}$ \\
\hline $\begin{array}{c}\text { MM } \\
010\end{array}$ & $\begin{array}{c}\text { "Feldmannia" } \\
\text { irregularis - } \\
\text { COI-5P }\end{array}$ & $\begin{array}{c}\text { Praia da Foca } \\
\text { - Pta da } \\
\text { Lagoinha }\end{array}$ & $\begin{array}{c}\text { Armação } \\
\text { dos Búzios, } \\
\text { RJ }\end{array}$ & $15 / 04 / 2014$ & $\begin{array}{l}\text { M. Mungioli; V. } \\
\text { Cassano; J.C. De- } \\
\text { Paula }\end{array}$ & $\begin{array}{l}22^{\circ} 45^{\prime} 53^{\prime \prime S} \\
41^{\circ} 52^{\prime} 41^{\prime \prime} \mathrm{W}\end{array}$ & $\mathrm{X}$ & $\mathrm{X}$ \\
\hline $\begin{array}{c}\text { MM } \\
011\end{array}$ & $\begin{array}{c}\text { "Feldmannia" } \\
\text { mitchelliae }\end{array}$ & $\begin{array}{c}\text { Praia da Foca } \\
\text { - Pta da } \\
\text { Lagoinha }\end{array}$ & $\begin{array}{c}\text { Armação } \\
\text { dos Búzios, } \\
\text { RJ }\end{array}$ & $15 / 04 / 2014$ & $\begin{array}{c}\text { M. Mungioli; V. } \\
\text { Cassano; J.C. De- } \\
\text { Paula }\end{array}$ & $\begin{array}{l}22^{\circ} 45^{\prime} 53^{\prime \prime} \mathrm{S} \\
41^{\circ} 52^{\prime} 41^{\prime \prime} \mathrm{W}\end{array}$ & $\mathrm{X}$ & $\mathrm{X}$ \\
\hline $\begin{array}{c}\text { MM } \\
012\end{array}$ & $\begin{array}{l}\text { “Feldmannia } \\
\text { irregularis" }\end{array}$ & $\begin{array}{c}\text { Praia da Foca } \\
\text { - Pta da } \\
\text { Lagoinha }\end{array}$ & $\begin{array}{c}\text { Armação } \\
\text { dos Búzios, } \\
\text { RJ }\end{array}$ & $15 / 04 / 2014$ & $\begin{array}{c}\text { M. Mungioli; V. } \\
\text { Cassano; J.C. De- } \\
\text { Paula }\end{array}$ & $\begin{array}{l}22^{\circ} 45^{\prime} 53^{\prime \prime S} \\
41^{\circ} 52^{\prime} 41^{\prime \prime} \mathrm{W}\end{array}$ & $\mathrm{X}$ & $\mathrm{X}$ \\
\hline $\begin{array}{c}\text { MM } \\
013\end{array}$ & $\begin{array}{c}\text { “Feldmannia” } \\
\text { irregularis }\end{array}$ & $\begin{array}{c}\text { Praia da Foca } \\
\text { - Pta da } \\
\text { Lagoinha }\end{array}$ & $\begin{array}{c}\text { Armação } \\
\text { dos Búzios, } \\
\text { RJ }\end{array}$ & $15 / 04 / 2014$ & $\begin{array}{c}\text { M. Mungioli; V. } \\
\text { Cassano; J.C. De- } \\
\text { Paula }\end{array}$ & $\begin{array}{l}22^{\circ} 45^{\prime} 53^{\prime \prime} \mathrm{S} \\
41^{\circ} 52^{\prime} 41^{\prime \prime} \mathrm{W}\end{array}$ & $\mathrm{X}$ & - \\
\hline $\begin{array}{c}\text { MM } \\
014\end{array}$ & Sphacelaria & $\begin{array}{c}\text { Praia da Foca } \\
\text { - Pta da } \\
\text { Lagoinha }\end{array}$ & $\begin{array}{c}\text { Armação } \\
\text { dos Búzios, } \\
\text { RJ }\end{array}$ & $15 / 04 / 2014$ & $\begin{array}{c}\text { M. Mungioli; V. } \\
\text { Cassano; J.C. De- } \\
\text { Paula }\end{array}$ & $\begin{array}{l}22^{\circ} 45^{\prime} 53^{\prime \prime} \mathrm{S} \\
41^{\circ} 52^{\prime} 41^{\prime \prime} \mathrm{W}\end{array}$ & - & - \\
\hline $\begin{array}{c}\text { MM } \\
015\end{array}$ & $\begin{array}{c}\text { “Feldmannia" } \\
\text { mitchelliae }\end{array}$ & $\begin{array}{c}\text { Praia da Foca } \\
\text { - Pta da } \\
\text { Lagoinha }\end{array}$ & $\begin{array}{c}\text { Armação } \\
\text { dos Búzios, } \\
\text { RJ }\end{array}$ & $15 / 04 / 2014$ & $\begin{array}{c}\text { M. Mungioli; V. } \\
\text { Cassano; J.C. De- } \\
\text { Paula }\end{array}$ & $\begin{array}{l}22^{\circ} 45^{\prime} 53^{\prime \prime} \mathrm{S} \\
41^{\circ} 52^{\prime} 41^{\prime \prime} \mathrm{W}\end{array}$ & - & - \\
\hline $\begin{array}{c}\text { MM } \\
016\end{array}$ & $\begin{array}{c}\text { “Feldmannia” } \\
\text { irregularis }\end{array}$ & $\begin{array}{l}\text { Praia do } \\
\text { Forno }\end{array}$ & $\begin{array}{c}\text { Armação } \\
\text { dos Búzios, } \\
\text { RJ }\end{array}$ & $15 / 04 / 2014$ & $\begin{array}{l}\text { M. Mungioli; V. } \\
\text { Cassano; J.C. De- } \\
\text { Paula }\end{array}$ & $\begin{array}{l}22^{\circ} 96^{\prime} 813^{\prime S} ; \\
42^{\circ} 01^{\prime} 596^{\prime \prime} \mathrm{W}\end{array}$ & $\mathrm{X}$ & - \\
\hline $\begin{array}{c}\text { MM } \\
017\end{array}$ & $\begin{array}{c}\text { “Híncksia” } \\
\text { conifera }\end{array}$ & $\begin{array}{l}\text { Praia do } \\
\text { Forno }\end{array}$ & $\begin{array}{c}\text { Armação } \\
\text { dos Búzios, } \\
\text { RJ }\end{array}$ & $15 / 04 / 2014$ & $\begin{array}{c}\text { M. Mungioli; V. } \\
\text { Cassano; J.C. De- } \\
\text { Paula }\end{array}$ & $\begin{array}{l}22^{0} 96^{\prime} 813^{\prime} \mathrm{S} \\
42^{0} 01^{\prime} 596^{\prime \prime} \mathrm{W}\end{array}$ & $\mathrm{X}$ & $\mathrm{X}$ \\
\hline $\begin{array}{c}\text { MM } \\
018\end{array}$ & $\begin{array}{c}\text { “Híncksia” } \\
\text { conifera }\end{array}$ & $\begin{array}{l}\text { Praia do } \\
\text { Forno }\end{array}$ & $\begin{array}{c}\text { Armação } \\
\text { dos Búzios, } \\
\text { RJ }\end{array}$ & $15 / 04 / 2014$ & $\begin{array}{l}\text { M. Mungioli; V. } \\
\text { Cassano; J.C. De- } \\
\text { Paula }\end{array}$ & $\begin{array}{l}22^{0} 96^{\prime} 813^{\prime S} \text {; } \\
42^{0} 01^{\prime} 596^{\prime \prime} \mathrm{W}\end{array}$ & $\mathrm{X}$ & $\mathrm{X}$ \\
\hline
\end{tabular}


Tabela 2. Continuação

\begin{tabular}{|c|c|c|c|c|c|c|c|c|}
\hline $\begin{array}{c}\text { Código } \\
\text { de } \\
\text { Coleta }\end{array}$ & Amostra & $\begin{array}{l}\text { Local de } \\
\text { Coleta }\end{array}$ & Cidade & Data & Coletor (s) & $\begin{array}{l}\text { Latitude / } \\
\text { Longitude }\end{array}$ & $\begin{array}{l}\text { COI- } \\
5 P\end{array}$ & $r b c L$ \\
\hline $\begin{array}{c}\mathrm{MM} \\
019\end{array}$ & $\begin{array}{c}\text { "Feldmannia" } \\
\text { mitchelliae }\end{array}$ & $\begin{array}{l}\text { Praia do } \\
\text { Forno }\end{array}$ & $\begin{array}{c}\text { Armação } \\
\text { dos Búzios, } \\
\text { RJ }\end{array}$ & $15 / 04 / 2014$ & $\begin{array}{l}\text { M. Mungioli; V. } \\
\text { Cassano; J.C. De- } \\
\text { Paula }\end{array}$ & $\begin{array}{l}22^{0} 96^{\prime} 813^{\prime} \mathrm{S} ; \\
42^{0} 01^{\prime} 596^{\prime \prime} \mathrm{W}\end{array}$ & $\mathrm{X}$ & $\mathrm{X}$ \\
\hline $\begin{array}{l}\mathrm{MM} \\
020\end{array}$ & $\begin{array}{c}\text { "Feldmannia" } \\
\text { mitchelliae }\end{array}$ & $\begin{array}{l}\text { Praia do } \\
\text { Forno }\end{array}$ & $\begin{array}{c}\text { Armação } \\
\text { dos Búzios, } \\
\text { RJ }\end{array}$ & $15 / 04 / 2014$ & $\begin{array}{l}\text { M. Mungioli; V. } \\
\text { Cassano; J.C. De- } \\
\text { Paula }\end{array}$ & $\begin{array}{l}22^{0} 96^{\prime} 813^{\prime S} ; \\
42^{0} 01^{\prime} 596^{\prime \prime} \mathrm{W}\end{array}$ & $\mathrm{X}$ & - \\
\hline $\begin{array}{c}\text { MM } \\
021\end{array}$ & $\begin{array}{l}\text { Hincksia } \\
\text { sandriana }\end{array}$ & $\begin{array}{c}\text { Ponta da } \\
\text { Cabeça, Praia } \\
\text { Grande }\end{array}$ & $\begin{array}{l}\text { Arraial do } \\
\text { Cabo, RJ }\end{array}$ & $16 / 04 / 2014$ & $\begin{array}{l}\text { M. Mungioli; V. } \\
\text { Cassano; J.C. De- } \\
\text { Paula }\end{array}$ & $\begin{array}{l}22^{\circ} 58 ' 35.7 " \mathrm{~S} \\
42^{\circ} 02^{\prime} 05.6^{\prime \prime} \mathrm{W}\end{array}$ & - & $\mathrm{X}$ \\
\hline $\begin{array}{l}\mathrm{MM} \\
022\end{array}$ & $\begin{array}{l}\text { Hincksia } \\
\text { sandriana }\end{array}$ & $\begin{array}{c}\text { Ponta da } \\
\text { Cabeça, Praia } \\
\text { Grande }\end{array}$ & $\begin{array}{l}\text { Arraial do } \\
\text { Cabo, RJ }\end{array}$ & $16 / 04 / 2014$ & $\begin{array}{l}\text { M. Mungioli; V. } \\
\text { Cassano; J.C. De- } \\
\text { Paula }\end{array}$ & $\begin{array}{l}22^{\circ} 58 ' 35.7^{\prime \prime S} \\
42^{\circ} 02^{\prime} 05.6^{\prime \prime} \mathrm{W}\end{array}$ & $\mathrm{X}$ & - \\
\hline $\begin{array}{c}\mathrm{MM} \\
023\end{array}$ & $\begin{array}{l}\text { Ectocarpus } \\
\text { fasciculatus }\end{array}$ & $\begin{array}{c}\text { Ponta da } \\
\text { Cabeça, Praia } \\
\text { Grande }\end{array}$ & $\begin{array}{l}\text { Arraial do } \\
\text { Cabo, RJ }\end{array}$ & $16 / 04 / 2014$ & $\begin{array}{l}\text { M. Mungioli; V. } \\
\text { Cassano; J.C. De- } \\
\text { Paula }\end{array}$ & $\begin{array}{c}22^{\circ} 58 ' 35.7 " \mathrm{~S} \\
42^{\circ} 02^{\prime} 05.6^{\prime \prime} \mathrm{W}\end{array}$ & $\mathrm{X}$ & - \\
\hline $\begin{array}{c}\text { MM } \\
024\end{array}$ & Ectocarpales & $\begin{array}{c}\text { Ponta da } \\
\text { Cabeça, Praia } \\
\text { Grande }\end{array}$ & $\begin{array}{c}\text { Arraial do } \\
\text { Cabo, RJ }\end{array}$ & $16 / 04 / 2014$ & $\begin{array}{l}\text { M. Mungioli; V. } \\
\text { Cassano; J.C. De- } \\
\text { Paula }\end{array}$ & $\begin{array}{l}22^{\circ} 58 ' 35.7 " \mathrm{~S} \\
42^{\circ} 02^{\prime} 05.6^{\prime \prime} \mathrm{W}\end{array}$ & - & - \\
\hline $\begin{array}{l}\text { MM } \\
025\end{array}$ & $\begin{array}{l}\text { Hincksia } \\
\text { sandriana }\end{array}$ & $\begin{array}{c}\text { Ponta da } \\
\text { Cabeça, Praia } \\
\text { Grande }\end{array}$ & $\begin{array}{l}\text { Arraial do } \\
\text { Cabo, RJ }\end{array}$ & $16 / 04 / 2014$ & $\begin{array}{l}\text { M. Mungioli; V. } \\
\text { Cassano; J.C. De- } \\
\text { Paula }\end{array}$ & $\begin{array}{l}22^{\circ} 58 ' 35.7 " \mathrm{~S} \\
42^{\circ} 02^{\prime} 05.6^{\prime \prime} \mathrm{W}\end{array}$ & $\mathrm{X}$ & - \\
\hline $\begin{array}{l}\text { MM } \\
026\end{array}$ & $\begin{array}{c}\text { "Asteronema" } \\
\text { breviarticulatu } \\
m\end{array}$ & $\begin{array}{l}\text { Prainhas - } \\
\text { Pontal do } \\
\text { Atalaia }\end{array}$ & $\begin{array}{l}\text { Arraial do } \\
\text { Cabo, RJ }\end{array}$ & $16 / 04 / 2014$ & $\begin{array}{l}\text { M. Mungioli; V. } \\
\text { Cassano; J.C. De- } \\
\text { Paula }\end{array}$ & $\begin{array}{l}22^{\circ} 59 ' 27.2^{\prime \prime S} \\
42^{\circ} 00^{\prime} 45.9^{\prime \prime} \mathrm{W}\end{array}$ & $\mathrm{X}$ & $\mathrm{X}$ \\
\hline $\begin{array}{c}\mathrm{MM} \\
027\end{array}$ & $\begin{array}{c}\text { Elachistiella } \\
\text { leptonematoide } \\
s\end{array}$ & $\begin{array}{l}\text { Prainhas - } \\
\text { Pontal do } \\
\text { Atalaia }\end{array}$ & $\begin{array}{l}\text { Arraial do } \\
\text { Cabo, RJ }\end{array}$ & $16 / 04 / 2014$ & $\begin{array}{l}\text { M. Mungioli; V. } \\
\text { Cassano; J.C. De- } \\
\text { Paula }\end{array}$ & $\begin{array}{l}22^{\circ} 59 ' 27.2^{\prime \prime S} \\
42^{\circ} 00^{\prime} 45.9^{\prime \prime} \mathrm{W}\end{array}$ & $\mathrm{X}$ & - \\
\hline $\begin{array}{c}\mathrm{MM} \\
028\end{array}$ & Ectocarpales & $\begin{array}{l}\text { Prainhas - } \\
\text { Pontal do } \\
\text { Atalaia }\end{array}$ & $\begin{array}{l}\text { Arraial do } \\
\text { Cabo, RJ }\end{array}$ & $16 / 04 / 2014$ & $\begin{array}{l}\text { M. Mungioli; V. } \\
\text { Cassano; J.C. De- } \\
\text { Paula }\end{array}$ & $\begin{array}{l}22^{\circ} 59 ' 27.2^{\prime \prime S} \\
42^{\circ} 00^{\prime} 45.9^{\prime \prime} \mathrm{W}\end{array}$ & - & - \\
\hline $\begin{array}{l}\text { MM } \\
029\end{array}$ & Ectocarpales & $\begin{array}{l}\text { Prainhas - } \\
\text { Pontal do } \\
\text { Atalaia }\end{array}$ & $\begin{array}{l}\text { Arraial do } \\
\text { Cabo, RJ }\end{array}$ & $16 / 04 / 2014$ & $\begin{array}{c}\text { M. Mungioli; V. } \\
\text { Cassano, J.C. De- } \\
\text { Paula e } \\
\text { C.A.A.Azevedo. }\end{array}$ & $\begin{array}{l}22^{\circ} 59 ' 27.2^{\prime \prime S} \\
42^{\circ} 00^{\prime} 45.9^{\prime \prime} \mathrm{W}\end{array}$ & - & - \\
\hline $\begin{array}{c}\mathrm{MM} \\
030\end{array}$ & $\begin{array}{l}\text { “Híncksia” } \\
\text { conifera }\end{array}$ & Praia Rasa & $\begin{array}{c}\text { Armação } \\
\text { dos Búzios, } \\
\text { RJ }\end{array}$ & $17 / 04 / 2015$ & $\begin{array}{l}\text { M. Mungioli; V. } \\
\text { Cassano e } \\
\text { C.A.A.Azevedo. }\end{array}$ & $\begin{array}{l}22^{\circ} 43^{\prime} 59.5^{\prime \prime S} ; \\
41^{\circ} 57^{\prime} 26.1^{\prime \prime} \mathrm{W}\end{array}$ & $\mathrm{X}$ & $\mathrm{X}$ \\
\hline $\begin{array}{c}\mathrm{MM} \\
031\end{array}$ & $\begin{array}{c}\text { "Feldmannia" } \\
\text { mitchelliae }\end{array}$ & Praia Rasa & $\begin{array}{c}\text { Armação } \\
\text { dos Búzios, } \\
\text { RJ }\end{array}$ & $17 / 04 / 2015$ & $\begin{array}{l}\text { M. Mungioli; V. } \\
\text { Cassano e } \\
\text { C.A.A.Azevedo. }\end{array}$ & $\begin{array}{l}22^{\circ} 43^{\prime} 59.5^{\prime \prime} \mathrm{S} \\
41^{\circ} 57^{\prime} 26.1^{\prime \prime} \mathrm{W}\end{array}$ & - & - \\
\hline $\begin{array}{c}\text { MM } \\
032\end{array}$ & $\begin{array}{c}\text { Feldmannia } \\
\text { mitchelliae }\end{array}$ & Praia Rasa & $\begin{array}{c}\text { Armação } \\
\text { dos Búzios, } \\
\text { RJ }\end{array}$ & $17 / 04 / 2015$ & $\begin{array}{l}\text { M. Mungioli; V. } \\
\text { Cassano e } \\
\text { C.A.A.Azevedo. }\end{array}$ & $\begin{array}{l}22^{\circ} 43^{\prime} 59.5^{\prime \prime} \mathrm{S} \\
41^{\circ} 57^{\prime} 26.1^{\prime \prime} \mathrm{W}\end{array}$ & - & - \\
\hline $\begin{array}{c}\text { MM } \\
033\end{array}$ & $\begin{array}{l}\text { Bachelotia } \\
\text { antillarum }\end{array}$ & Praia Rasa & $\begin{array}{c}\text { Armação } \\
\text { dos Búzios, } \\
\text { RJ }\end{array}$ & $17 / 04 / 2015$ & $\begin{array}{l}\text { M. Mungioli; V. } \\
\text { Cassano e } \\
\text { C.A.A.Azevedo. }\end{array}$ & $\begin{array}{l}22^{\circ} 43^{\prime} 59.5^{\prime \prime} \mathrm{S} \\
41^{\circ} 57^{\prime} 26.1^{\prime \prime} \mathrm{W}\end{array}$ & - & - \\
\hline $\begin{array}{c}\mathrm{MM} \\
034\end{array}$ & $\begin{array}{c}\text { Elachistiella } \\
\text { leptonematoide } \\
s\end{array}$ & $\begin{array}{l}\text { Prainhas - } \\
\text { Pontal do } \\
\text { Atalaia }\end{array}$ & $\begin{array}{c}\text { Arraial do } \\
\text { Cabo, RJ }\end{array}$ & $16 / 04 / 2014$ & $\begin{array}{l}\text { M. Mungioli; V. } \\
\text { Cassano e } \\
\text { C.A.A.Azevedo. }\end{array}$ & $\begin{array}{c}22^{\circ} 59^{\prime} 27.2^{\prime \prime S} \\
42^{\circ} 00^{\prime} 45.9^{\prime \prime} \mathrm{W}\end{array}$ & $\mathrm{X}$ & - \\
\hline $\begin{array}{c}\text { MM } \\
035\end{array}$ & $\begin{array}{c}\text { Feldmannia } \\
\text { irregularis }\end{array}$ & $\begin{array}{l}\text { Prainhas - } \\
\text { Pontal do } \\
\text { Atalaia }\end{array}$ & $\begin{array}{l}\text { Arraial do } \\
\text { Cabo, RJ }\end{array}$ & $16 / 04 / 2014$ & $\begin{array}{l}\text { M. Mungioli; V. } \\
\text { Cassano e } \\
\text { C.A.A.Azevedo. }\end{array}$ & $\begin{array}{l}22^{\circ} 59 ' 27.2^{\prime \prime S} \\
42^{\circ} 00^{\prime} 45.9^{\prime \prime} \mathrm{W}\end{array}$ & $\mathrm{X}$ & - \\
\hline $\begin{array}{c}\text { MM } \\
036\end{array}$ & $\begin{array}{c}\text { Feldmannia } \\
\text { irregularis }\end{array}$ & $\begin{array}{l}\text { Prainhas - } \\
\text { Pontal do } \\
\text { Atalaia }\end{array}$ & $\begin{array}{c}\text { Arraial do } \\
\text { Cabo, RJ }\end{array}$ & $16 / 04 / 2014$ & $\begin{array}{l}\text { M. Mungioli; V. } \\
\text { Cassano e } \\
\text { C.A.A.Azevedo. }\end{array}$ & $\begin{array}{c}22^{\circ} 59^{\prime} 27.2^{\prime \prime S} \\
42^{\circ} 00^{\prime} 45.9^{\prime \prime} \mathrm{W}\end{array}$ & $\mathrm{X}$ & - \\
\hline
\end{tabular}


Tabela 2. Continuação

\begin{tabular}{|c|c|c|c|c|c|c|c|c|}
\hline $\begin{array}{l}\text { Código } \\
\text { de } \\
\text { Coleta }\end{array}$ & Amostra & $\begin{array}{l}\text { Local de } \\
\text { Coleta }\end{array}$ & Cidade & Data & $\begin{array}{c}\text { Coletor } \\
\text { (s) }\end{array}$ & $\begin{array}{l}\text { Latitude / } \\
\text { Longitude }\end{array}$ & $\begin{array}{l}\text { COI- } \\
5 P\end{array}$ & $r b c \mathbf{L}$ \\
\hline $\begin{array}{c}\mathrm{MM} \\
037\end{array}$ & $\begin{array}{l}\text { “Feldmannia } \\
\text { irregularis" }\end{array}$ & $\begin{array}{l}\text { Prainhas - } \\
\text { Pontal do } \\
\text { Atalaia }\end{array}$ & $\begin{array}{l}\text { Arraial do } \\
\text { Cabo, RJ }\end{array}$ & $16 / 04 / 2014$ & $\begin{array}{l}\text { M. Mungioli; V. } \\
\text { Cassano e } \\
\text { C.A.A.Azevedo. }\end{array}$ & $\begin{array}{l}22^{\circ} 59 ' 27.2^{\prime \prime S} \\
42^{\circ} 00^{\prime} 45.9^{\prime \prime} \mathrm{W}\end{array}$ & $\mathrm{X}$ & - \\
\hline $\begin{array}{c}\mathrm{MM} \\
038\end{array}$ & $\begin{array}{l}\text { "Feldmannia } \\
\text { irregularis" }\end{array}$ & $\begin{array}{l}\text { Prainhas - } \\
\text { Pontal do } \\
\text { Atalaia }\end{array}$ & $\begin{array}{l}\text { Arraial do } \\
\text { Cabo, RJ }\end{array}$ & $16 / 04 / 2014$ & $\begin{array}{l}\text { M. Mungioli; V. } \\
\text { Cassano e } \\
\text { C.A.A.Azevedo. }\end{array}$ & $\begin{array}{l}22^{\circ} 59 ' 27.2^{\prime \prime S} \\
42^{\circ} 00^{\prime} 45.9^{\prime \prime} \mathrm{W}\end{array}$ & $\mathrm{X}$ & - \\
\hline $\begin{array}{c}\text { MM } \\
039\end{array}$ & $\begin{array}{c}\text { "Feldmannia" } \\
\text { mitchelliae }\end{array}$ & $\begin{array}{l}\text { Ponta da } \\
\text { Cabeça, Praia } \\
\text { Grande }\end{array}$ & $\begin{array}{l}\text { Arraial do } \\
\text { Cabo, RJ }\end{array}$ & $16 / 04 / 2014$ & $\begin{array}{l}\text { M. Mungioli; V. } \\
\text { Cassano e } \\
\text { C.A.A.Azevedo. }\end{array}$ & $\begin{array}{l}22^{\circ} 58 ' 35.7^{\prime \prime S} \\
42^{\circ} 02^{\prime} 05.6^{\prime \prime} \mathrm{W}\end{array}$ & T & - \\
\hline $\begin{array}{c}\text { MM } \\
040\end{array}$ & $\begin{array}{c}\text { “Feldmannia" } \\
\text { irregularis }\end{array}$ & $\begin{array}{l}\text { Praia do } \\
\text { Cibratel II }\end{array}$ & $\begin{array}{l}\text { Itanhaém, } \\
\text { SP }\end{array}$ & 05/11/2014 & $\begin{array}{l}\text { M. Mungioli; } \\
\text { C.A.A. Azevedo }\end{array}$ & $\begin{array}{l}24^{\circ} 12^{\prime} 06.5^{\prime \prime S} \\
46^{\circ} 48^{\prime} 40.1^{\prime \prime} \mathrm{W}\end{array}$ & $\mathrm{X}$ & - \\
\hline $\begin{array}{c}\text { MM } \\
041\end{array}$ & $\begin{array}{c}\text { Feldmannia } \\
\text { irregularis }\end{array}$ & $\begin{array}{l}\text { Praia do } \\
\text { Cibratel II }\end{array}$ & $\begin{array}{l}\text { Itanhaém, } \\
\text { SP }\end{array}$ & 05/11/2014 & $\begin{array}{l}\text { M. Mungioli; } \\
\text { C.A.A. Azevedo }\end{array}$ & $\begin{array}{l}24^{\circ} 12^{\prime} 06.5^{\prime \prime} \mathrm{S} \\
46^{\circ} 48^{\prime} 40.1^{\prime \prime} \mathrm{W}\end{array}$ & $\mathrm{X}$ & - \\
\hline $\begin{array}{c}\text { MM } \\
042\end{array}$ & $\begin{array}{c}\text { Feldmannia } \\
\text { irregularis }\end{array}$ & $\begin{array}{l}\text { Praia do } \\
\text { Cibratel II }\end{array}$ & $\begin{array}{l}\text { Itanhaém, } \\
\text { SP }\end{array}$ & 05/11/2014 & $\begin{array}{l}\text { M. Mungioli; } \\
\text { C.A.A. Azevedo }\end{array}$ & $\begin{array}{l}24^{\circ} 12^{\prime} 06.5^{\prime \prime S} \\
46^{\circ} 48^{\prime} 40.1^{\prime \prime} \mathrm{W}\end{array}$ & - & - \\
\hline $\begin{array}{c}\text { MM } \\
043\end{array}$ & $\begin{array}{l}\text { Bachelotia } \\
\text { antillarum }\end{array}$ & $\begin{array}{l}\text { Praia do } \\
\text { Cibratel II }\end{array}$ & $\begin{array}{l}\text { Itanhaém, } \\
\text { SP }\end{array}$ & 05/11/2014 & $\begin{array}{l}\text { M. Mungioli; } \\
\text { C.A.A. Azevedo }\end{array}$ & $\begin{array}{l}24^{\circ} 12^{\prime} 06.5^{\prime \prime S} \\
46^{\circ} 48^{\prime} 40.1^{\prime \prime} \mathrm{W}\end{array}$ & $X$ & - \\
\hline $\begin{array}{c}\mathrm{MM} \\
044\end{array}$ & $\begin{array}{l}\text { Bachelotia } \\
\text { antillarum }\end{array}$ & $\begin{array}{l}\text { Praia do } \\
\text { Cibratel II }\end{array}$ & $\begin{array}{l}\text { Itanhaém, } \\
\text { SP }\end{array}$ & 05/11/2014 & $\begin{array}{l}\text { M. Mungioli; } \\
\text { C.A.A. Azevedo }\end{array}$ & $\begin{array}{l}24^{\circ} 12^{\prime} 06.5^{\prime \prime} \mathrm{S} \\
46^{\circ} 48^{\prime} 40.1^{\prime \prime} \mathrm{W}\end{array}$ & 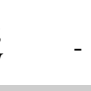 & - \\
\hline $\begin{array}{c}\text { MM } \\
045\end{array}$ & $\begin{array}{c}\text { Asteronema } \\
\text { breviarticulatu } \\
m\end{array}$ & $\begin{array}{l}\text { Praia do } \\
\text { Cibratel II }\end{array}$ & $\begin{array}{l}\text { Itanhaém, } \\
\text { SP }\end{array}$ & 05/11/2014 & $\begin{array}{l}\text { M. Mungioli; } \\
\text { C.A.A. Azevedo }\end{array}$ & $\begin{array}{l}24^{\circ} 12^{\prime} 06.5^{\prime \prime} \mathrm{S} \\
46^{\circ} 48^{\prime} 40.1^{\prime \prime} \mathrm{W}\end{array}$ & $\mathrm{X}$ & - \\
\hline $\begin{array}{c}\mathrm{MM} \\
046\end{array}$ & $\begin{array}{l}\text { "Feldmannia } \\
\text { irregularis" }\end{array}$ & $\begin{array}{l}\text { Praia do } \\
\text { Cibratel II }\end{array}$ & $\begin{array}{l}\text { Itanhaém, } \\
\text { SP }\end{array}$ & 05/11/2014 & $\begin{array}{l}\text { M. Mungioli; } \\
\text { C.A.A. Azevedo }\end{array}$ & $\begin{array}{l}24^{\circ} 12^{\prime} 06.5^{\prime \prime S} \\
46^{\circ} 48^{\prime} 40.1^{\prime \prime} \mathrm{W}\end{array}$ & $X$ & - \\
\hline $\begin{array}{c}\mathrm{MM} \\
047\end{array}$ & $\begin{array}{l}\text { Bachelotia } \\
\text { antillarum }\end{array}$ & $\begin{array}{l}\text { Praia do } \\
\text { Cibratel II }\end{array}$ & $\begin{array}{l}\text { Itanhaém, } \\
\text { SP }\end{array}$ & 05/11/2014 & $\begin{array}{l}\text { M. Mungioli; } \\
\text { C.A.A. Azevedo }\end{array}$ & $\begin{array}{l}24^{\circ} 12^{\prime} 06.5^{\prime \prime} \mathrm{S} \\
46^{\circ} 48^{\prime} 40.1^{\prime \prime} \mathrm{W}\end{array}$ & $\mathrm{X}$ & - \\
\hline $\begin{array}{c}\mathrm{MM} \\
048\end{array}$ & $\begin{array}{l}\text { Bachelotia } \\
\text { antillarum }\end{array}$ & $\begin{array}{l}\text { Praia do } \\
\text { Cibratel II }\end{array}$ & $\begin{array}{l}\text { Itanhaém, } \\
\text { SP }\end{array}$ & 05/11/2014 & $\begin{array}{l}\text { M. Mungioli; } \\
\text { C.A.A. Azevedo }\end{array}$ & $\begin{array}{l}24^{\circ} 12^{\prime} 06.5^{\prime \prime} \mathrm{S} \\
46^{\circ} 48^{\prime} 40.1^{\prime \prime} \mathrm{W}\end{array}$ & $\mathrm{X}$ & - \\
\hline $\begin{array}{c}\text { MM } \\
049\end{array}$ & $\begin{array}{c}\text { Levringia } \\
\text { brasiliensis }\end{array}$ & $\begin{array}{l}\text { Praia do } \\
\text { Cibratel II }\end{array}$ & $\begin{array}{l}\text { Itanhaém, } \\
\text { SP }\end{array}$ & 05/11/2014 & $\begin{array}{l}\text { M. Mungioli; } \\
\text { C.A.A. Azevedo }\end{array}$ & $\begin{array}{l}24^{\circ} 12^{\prime} 06.5^{\prime \prime} \mathrm{S} \\
46^{\circ} 48^{\prime} 40.1^{\prime \prime} \mathrm{W}\end{array}$ & - & - \\
\hline $\begin{array}{c}\mathrm{MM} \\
050\end{array}$ & $\begin{array}{l}\text { Feldmannia } \\
\text { mitchelliae }\end{array}$ & $\begin{array}{l}\text { Praia do } \\
\text { Cibratel II }\end{array}$ & $\begin{array}{l}\text { Itanhaém, } \\
\text { SP }\end{array}$ & 05/11/2014 & $\begin{array}{l}\text { M. Mungioli; } \\
\text { C.A.A. Azevedo }\end{array}$ & $\begin{array}{l}24^{\circ} 12^{\prime} 06.5^{\prime \prime} \text {; } \\
46^{\circ} 48^{\prime} 40.1^{\prime \prime W}\end{array}$ & 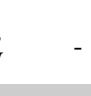 & - \\
\hline $\begin{array}{c}\mathrm{MM} \\
051\end{array}$ & $\begin{array}{l}\text { Bachelotia } \\
\text { antillarum }\end{array}$ & $\begin{array}{l}\text { Praia do } \\
\text { Cibratel II }\end{array}$ & $\begin{array}{l}\text { Itanhaém, } \\
\text { SP }\end{array}$ & 05/11/2014 & $\begin{array}{l}\text { M. Mungioli; } \\
\text { C.A.A. Azevedo }\end{array}$ & $\begin{array}{l}24^{\circ} 12^{\prime} 06.5^{\prime \prime S} \\
46^{\circ} 48^{\prime} 40.1^{\prime \prime} \mathrm{W}\end{array}$ & 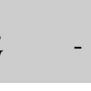 & - \\
\hline $\begin{array}{c}\text { MM } \\
052\end{array}$ & $\begin{array}{l}\text { Bachelotia } \\
\text { antillarum }\end{array}$ & $\begin{array}{l}\text { Praia de } \\
\text { Paúba }\end{array}$ & $\begin{array}{l}\text { São } \\
\text { Sebastião, } \\
\text { SP }\end{array}$ & $27 / 11 / 2014$ & $\begin{array}{l}\text { M.Mungioli; } \\
\text { V.Cassano. }\end{array}$ & $\begin{array}{l}23^{\circ} 48^{\prime} 18.8^{\prime \prime S} \\
45^{\circ} 33^{\prime} 07.6^{\prime \prime} \mathrm{W}\end{array}$ & 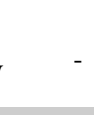 & - \\
\hline $\begin{array}{c}\text { MM } \\
053\end{array}$ & $\begin{array}{l}\text { Bachelotia } \\
\text { antillarum }\end{array}$ & $\begin{array}{l}\text { Praia de } \\
\text { Paúba }\end{array}$ & $\begin{array}{l}\text { São } \\
\text { Sebastião, } \\
\text { SP }\end{array}$ & $27 / 11 / 2014$ & $\begin{array}{l}\text { M.Mungioli; } \\
\text { V.Cassano. }\end{array}$ & $\begin{array}{l}23^{\circ} 48^{\prime} 18.8^{\prime \prime S} \\
45^{\circ} 33^{\prime} 07.6^{\prime \prime} \mathrm{W}\end{array}$ & - & - \\
\hline $\begin{array}{c}\text { MM } \\
054\end{array}$ & $\begin{array}{c}\text { "Feldmanniain } \\
\text { dica" }\end{array}$ & $\begin{array}{c}\text { Praia das } \\
\text { Cigarras }\end{array}$ & $\begin{array}{l}\text { São } \\
\text { Sebastião, } \\
\text { SP }\end{array}$ & 27/01/2015 & $\begin{array}{l}\text { M.Mungioli; } \\
\text { V.Cassano. }\end{array}$ & $\begin{array}{l}23^{\circ} 43^{\prime} 40.8^{\prime \prime S} \\
45^{\circ} 23^{\prime} 54.4^{\prime \prime} \mathrm{W}\end{array}$ & $X$ & - \\
\hline $\begin{array}{c}\text { MM } \\
055\end{array}$ & $\begin{array}{l}\text { Feldmannia } \\
\text { mitchelliae }\end{array}$ & $\begin{array}{c}\text { Praia de } \\
\text { Toque-Toque } \\
\text { Pequeno }\end{array}$ & $\begin{array}{l}\text { São } \\
\text { Sebastião, } \\
\text { SP }\end{array}$ & 29/01/2015 & $\begin{array}{l}\text { M.Mungioli; } \\
\text { V.Cassano. }\end{array}$ & $\begin{array}{l}23^{\circ} 49^{\prime} 25.1^{\prime \prime S} \\
45^{\circ} 32^{\prime} 00.8^{\prime \prime} \mathrm{W}\end{array}$ & - & - \\
\hline $\begin{array}{c}\mathrm{MM} \\
056\end{array}$ & $\begin{array}{l}\text { Feldmannia } \\
\text { mitchelliae }\end{array}$ & $\begin{array}{l}\text { Ponta da } \\
\text { Cabeça, Praia } \\
\text { Grande }\end{array}$ & $\begin{array}{l}\text { Arraial do } \\
\text { Cabo, RJ }\end{array}$ & 05/03/2015 & $\begin{array}{l}\text { M. Mungioli; V. } \\
\text { Cassano }\end{array}$ & $\begin{array}{l}22^{\circ} 58 ' 35.7 " \mathrm{~S} \\
42^{\circ} 02^{\prime} 05.6^{\prime \prime} \mathrm{W}\end{array}$ & $X$ & - \\
\hline $\begin{array}{c}\text { MM } \\
057\end{array}$ & $\begin{array}{l}\text { Feldmannia } \\
\text { mitchelliae }\end{array}$ & $\begin{array}{c}\text { Ponta da } \\
\text { Cabeça, Praia } \\
\text { Grande }\end{array}$ & $\begin{array}{l}\text { Arraial do } \\
\text { Cabo, RJ }\end{array}$ & 05/03/2015 & $\begin{array}{l}\text { M. Mungioli; V. } \\
\text { Cassano }\end{array}$ & $\begin{array}{l}22^{\circ} 58 ' 35.7 " \mathrm{~S} \\
42^{\circ} 02^{\prime} 05.6^{\prime \prime} \mathrm{W}\end{array}$ & - & - \\
\hline
\end{tabular}


Tabela 2. Continuação

\begin{tabular}{|c|c|c|c|c|c|c|c|c|}
\hline $\begin{array}{c}\text { Código } \\
\text { de } \\
\text { Coleta }\end{array}$ & Amostra & $\begin{array}{l}\text { Local de } \\
\text { Coleta }\end{array}$ & Cidade & Data & $\begin{array}{c}\text { Coletor } \\
\text { (s) }\end{array}$ & $\begin{array}{l}\text { Latitude / } \\
\text { Longitude }\end{array}$ & $\begin{array}{l}\text { COI- } \\
5 P\end{array}$ & $r b c L$ \\
\hline $\begin{array}{c}\text { MM } \\
058\end{array}$ & $\begin{array}{l}\text { "Feldmannia } \\
\text { irregularis" }\end{array}$ & $\begin{array}{l}\text { Ponta da } \\
\text { Cabeça, Praia } \\
\text { Grande }\end{array}$ & $\begin{array}{l}\text { Arraial do } \\
\text { Cabo, RJ }\end{array}$ & 05/03/2015 & $\begin{array}{l}\text { M. Mungioli; V. } \\
\text { Cassano }\end{array}$ & $\begin{array}{c}22^{\circ} 58^{\prime} 35.7^{\prime \prime} \mathrm{S} \\
42^{\circ} 02^{\prime} 05.6^{\prime \prime} \mathrm{W}\end{array}$ & $\mathrm{X}$ & - \\
\hline $\begin{array}{c}\text { MM } \\
059\end{array}$ & $\begin{array}{l}\text { "Feldmannia } \\
\text { irregularis" }\end{array}$ & $\begin{array}{l}\text { Ponta da } \\
\text { Cabeça, Praia } \\
\text { Grande }\end{array}$ & $\begin{array}{l}\text { Arraial do } \\
\text { Cabo, RJ }\end{array}$ & 05/03/2015 & $\begin{array}{l}\text { M. Mungioli; V. } \\
\text { Cassano }\end{array}$ & $\begin{array}{c}22^{\circ} 58^{\prime} 35.7 " \mathrm{~S} \\
42^{\circ} 02^{\prime} 05.6^{\prime \prime} \mathrm{W}\end{array}$ & $\mathrm{X}$ & - \\
\hline $\begin{array}{c}\text { MM } \\
060\end{array}$ & $\begin{array}{c}\text { "Feldmannia" } \\
\text { mitchelliae }\end{array}$ & $\begin{array}{l}\text { Ponta da } \\
\text { Cabeça, Praia } \\
\text { Grande }\end{array}$ & $\begin{array}{l}\text { Arraial do } \\
\text { Cabo, RJ }\end{array}$ & 05/03/2015 & $\begin{array}{l}\text { M. Mungioli; V. } \\
\text { Cassano }\end{array}$ & $\begin{array}{c}22^{\circ} 58^{\prime} 35.7^{\prime \prime S} \\
42^{\circ} 02^{\prime} 05.6^{\prime \prime} \mathrm{W}\end{array}$ & $\mathrm{X}$ & $\mathrm{X}$ \\
\hline $\begin{array}{c}\text { MM } \\
061\end{array}$ & $\begin{array}{c}\text { "Feldmannia" } \\
\text { mitchelliae }\end{array}$ & $\begin{array}{l}\text { Ponta da } \\
\text { Cabeça, Praia } \\
\text { Grande }\end{array}$ & $\begin{array}{l}\text { Arraial do } \\
\text { Cabo, RJ }\end{array}$ & 05/03/2015 & $\begin{array}{l}\text { M. Mungioli; V. } \\
\text { Cassano }\end{array}$ & $\begin{array}{c}22^{\circ} 58^{\prime} 35.7^{\prime \prime} \mathrm{S} \\
42^{\circ} 02^{\prime} 05.6^{\prime \prime} \mathrm{W}\end{array}$ & - & $\mathrm{X}$ \\
\hline $\begin{array}{c}\text { MM } \\
062\end{array}$ & $\begin{array}{c}\text { "Feldmannia" } \\
\text { mitchelliae }\end{array}$ & $\begin{array}{l}\text { Ponta da } \\
\text { Cabeça, Praia } \\
\text { Grande }\end{array}$ & $\begin{array}{l}\text { Arraial do } \\
\text { Cabo, RJ }\end{array}$ & 05/03/2015 & $\begin{array}{l}\text { M. Mungioli; V. } \\
\text { Cassano }\end{array}$ & $\begin{array}{c}22^{\circ} 58^{\prime} 35.7 " \mathrm{~S} \\
42^{\circ} 02^{\prime} 05.6^{\prime \prime} \mathrm{W}\end{array}$ & $\mathrm{X}$ & $\mathrm{X}$ \\
\hline $\begin{array}{c}\text { MM } \\
063\end{array}$ & $\begin{array}{l}\text { "Feldmannia } \\
\text { irregularis" }\end{array}$ & $\begin{array}{l}\text { Ponta da } \\
\text { Cabeça, Praia } \\
\text { Grande }\end{array}$ & $\begin{array}{l}\text { Arraial do } \\
\text { Cabo, RJ }\end{array}$ & 05/03/2015 & $\begin{array}{l}\text { M. Mungioli; V. } \\
\text { Cassano }\end{array}$ & $\begin{array}{l}22^{\circ} 58^{\prime} 35.7^{\prime \prime S} \\
42^{\circ} 02^{\prime} 05.6^{\prime \prime} \mathrm{W}\end{array}$ & $\mathrm{X}$ & $\mathrm{X}$ \\
\hline $\begin{array}{c}\text { MM } \\
064\end{array}$ & $\begin{array}{c}\text { "Feldmannia" } \\
\text { mitchelliae }\end{array}$ & $\begin{array}{l}\text { Ponta da } \\
\text { Cabeça, Praia } \\
\text { Grande }\end{array}$ & $\begin{array}{l}\text { Arraial do } \\
\text { Cabo, RJ }\end{array}$ & 05/03/2015 & $\begin{array}{l}\text { M. Mungioli; V. } \\
\text { Cassano }\end{array}$ & $\begin{array}{l}22^{\circ} 58 \cdot 35.7 " \mathrm{~S} \\
42^{\circ} 02^{\prime} 05.6^{\prime \prime} \mathrm{W}\end{array}$ & - & $\mathrm{X}$ \\
\hline $\begin{array}{c}\text { MM } \\
065\end{array}$ & $\begin{array}{l}\text { "Feldmannia } \\
\text { irregularis" }\end{array}$ & $\begin{array}{l}\text { Ponta da } \\
\text { Cabeça, Praia } \\
\text { Grande }\end{array}$ & $\begin{array}{l}\text { Arraial do } \\
\text { Cabo, RJ }\end{array}$ & 05/03/2015 & $\begin{array}{l}\text { M. Mungioli; V. } \\
\text { Cassano }\end{array}$ & $\begin{array}{c}22^{\circ} 58^{\prime} 35.7 " \mathrm{~S} \\
42^{\circ} 02^{\prime} 05.6^{\prime \prime} \mathrm{W}\end{array}$ & $\mathrm{X}$ & $\mathrm{X}$ \\
\hline $\begin{array}{c}\text { MM } \\
066\end{array}$ & $\begin{array}{l}\text { "Feldmannia } \\
\text { irregularis" }\end{array}$ & $\begin{array}{l}\text { Ponta da } \\
\text { Cabeça, Praia } \\
\text { Grande }\end{array}$ & $\begin{array}{l}\text { Arraial do } \\
\text { Cabo, RJ }\end{array}$ & 05/03/2015 & $\begin{array}{l}\text { M. Mungioli; V. } \\
\text { Cassano }\end{array}$ & $\begin{array}{l}22^{\circ} 58^{\prime} 35.7 " \mathrm{~S} \\
42^{\circ} 02^{\prime} 05.6^{\prime \prime} \mathrm{W}\end{array}$ & $\mathrm{X}$ & $\mathrm{X}$ \\
\hline $\begin{array}{c}\text { MM } \\
067\end{array}$ & $\begin{array}{l}\text { "Feldmannia" } \\
\text { mitchelliae }\end{array}$ & $\begin{array}{l}\text { Ponta da } \\
\text { Cabeça, Praia } \\
\text { Grande }\end{array}$ & $\begin{array}{l}\text { Arraial do } \\
\text { Cabo, RJ }\end{array}$ & 05/03/2015 & $\begin{array}{l}\text { M. Mungioli; V. } \\
\text { Cassano }\end{array}$ & $\begin{array}{l}22^{\circ} 58^{\prime} 35.7^{\prime \prime S} \\
42^{\circ} 02^{\prime} 05.6^{\prime \prime} \mathrm{W}\end{array}$ & $\mathrm{X}$ & $\mathrm{X}$ \\
\hline $\begin{array}{c}\text { MM } \\
068\end{array}$ & $\begin{array}{l}\text { "Feldmannia } \\
\text { irregularis" }\end{array}$ & $\begin{array}{l}\text { Ponta da } \\
\text { Cabeça, Praia } \\
\text { Grande }\end{array}$ & $\begin{array}{l}\text { Arraial do } \\
\text { Cabo, RJ }\end{array}$ & 05/03/2015 & $\begin{array}{l}\text { M. Mungioli; V. } \\
\text { Cassano }\end{array}$ & $\begin{array}{c}22^{\circ} 58^{\prime} 35.7 " \mathrm{~S} \\
42^{\circ} 02^{\prime} 05.6^{\prime \prime} \mathrm{W}\end{array}$ & $\mathrm{X}$ & $\mathrm{X}$ \\
\hline $\begin{array}{c}\text { MM } \\
069\end{array}$ & $\begin{array}{c}\text { Feldmannia } \\
\text { mitchelliae }\end{array}$ & $\begin{array}{l}\text { Ponta da } \\
\text { Cabeça, Praia } \\
\text { Grande }\end{array}$ & $\begin{array}{l}\text { Arraial do } \\
\text { Cabo, RJ }\end{array}$ & 05/03/2015 & $\begin{array}{l}\text { M. Mungioli; V. } \\
\text { Cassano }\end{array}$ & $\begin{array}{c}22^{\circ} 58^{\prime} 35.7 " \mathrm{~S} \\
42^{\circ} 02^{\prime} 05.6^{\prime \prime} \mathrm{W}\end{array}$ & $\mathrm{CH} 2 \mathrm{O}$ & CH2O \\
\hline $\begin{array}{c}\text { MM } \\
070\end{array}$ & $\begin{array}{c}\text { Feldmannia } \\
\text { irregularis }\end{array}$ & $\begin{array}{l}\text { Ponta da } \\
\text { Cabeça, Praia } \\
\text { Grande }\end{array}$ & $\begin{array}{l}\text { Arraial do } \\
\text { Cabo, RJ }\end{array}$ & 05/03/2015 & $\begin{array}{l}\text { M. Mungioli; V. } \\
\text { Cassano }\end{array}$ & $\begin{array}{l}22^{\circ} 58^{\prime} 35.7^{\prime \prime S} \\
42^{\circ} 02^{\prime} 05.6^{\prime \prime} \mathrm{W}\end{array}$ & $\mathrm{CH} 2 \mathrm{O}$ & CH2O \\
\hline $\begin{array}{c}\text { MM } \\
071\end{array}$ & $\begin{array}{c}\text { Feldmannia } \\
\text { irregularis }\end{array}$ & $\begin{array}{l}\text { Ponta da } \\
\text { Cabeça, Praia } \\
\text { Grande }\end{array}$ & $\begin{array}{l}\text { Arraial do } \\
\text { Cabo, RJ }\end{array}$ & 05/03/2015 & $\begin{array}{l}\text { M. Mungioli; V. } \\
\text { Cassano }\end{array}$ & $\begin{array}{l}22^{\circ} 58^{\prime} 35.7^{\prime \prime S} \\
42^{\circ} 02^{\prime} 05.6^{\prime \prime} \mathrm{W}\end{array}$ & $\mathrm{CH} 2 \mathrm{O}$ & CH2O \\
\hline $\begin{array}{c}\text { MM } \\
072\end{array}$ & $\begin{array}{c}\text { Feldmannia } \\
\text { mitchelliae }\end{array}$ & $\begin{array}{l}\text { Ponta da } \\
\text { Cabeça, Praia } \\
\text { Grande }\end{array}$ & $\begin{array}{l}\text { Arraial do } \\
\text { Cabo, RJ }\end{array}$ & 05/03/2015 & $\begin{array}{l}\text { M. Mungioli; V. } \\
\text { Cassano }\end{array}$ & $\begin{array}{l}22^{\circ} 58^{\prime} 35.7^{\prime \prime S} \\
42^{\circ} 02^{\prime} 05.6^{\prime \prime} \mathrm{W}\end{array}$ & $\mathrm{CH} 2 \mathrm{O}$ & CH2O \\
\hline $\begin{array}{c}\text { MM } \\
073\end{array}$ & $\begin{array}{c}\text { Feldmannia } \\
\text { mitchelliae }\end{array}$ & $\begin{array}{l}\text { Ponta da } \\
\text { Cabeça, Praia } \\
\text { Grande }\end{array}$ & $\begin{array}{l}\text { Arraial do } \\
\text { Cabo, RJ }\end{array}$ & 05/03/2015 & $\begin{array}{l}\text { M. Mungioli; V. } \\
\text { Cassano }\end{array}$ & $\begin{array}{l}22^{\circ} 58^{\prime} 35.7^{\prime \prime S} \\
42^{\circ} 02^{\prime} 05.6^{\prime \prime} \mathrm{W}\end{array}$ & $\mathrm{CH} 2 \mathrm{O}$ & $\mathrm{CH} 2 \mathrm{O}$ \\
\hline $\begin{array}{c}\text { MM } \\
074\end{array}$ & $\begin{array}{c}\text { "Feldmannia" } \\
\text { mitchelliae }\end{array}$ & $\begin{array}{l}\text { Ponta da } \\
\text { Cabeça, Praia } \\
\text { Grande }\end{array}$ & $\begin{array}{l}\text { Arraial do } \\
\text { Cabo, RJ }\end{array}$ & 05/03/2015 & $\begin{array}{l}\text { M. Mungioli; V. } \\
\text { Cassano }\end{array}$ & $\begin{array}{l}22^{\circ} 58^{\prime} 35.7^{\prime \prime S} \\
42^{\circ} 02^{\prime} 05.6^{\prime \prime} \mathrm{W}\end{array}$ & $\mathrm{X}$ & $\mathrm{X}$ \\
\hline $\begin{array}{c}\text { MM } \\
075\end{array}$ & $\begin{array}{c}\text { Feldmannia } \\
\text { irregularis }\end{array}$ & $\begin{array}{l}\text { Ponta da } \\
\text { Cabeça, Praia } \\
\text { Grande }\end{array}$ & $\begin{array}{l}\text { Arraial do } \\
\text { Cabo, RJ }\end{array}$ & 05/03/2015 & $\begin{array}{l}\text { M. Mungioli; V. } \\
\text { Cassano }\end{array}$ & $\begin{array}{l}22^{\circ} 58^{\prime} 35.7^{\prime \prime S} \\
42^{\circ} 02^{\prime} 05.6^{\prime \prime} \mathrm{W}\end{array}$ & $\mathrm{CH} 2 \mathrm{O}$ & $\mathrm{CH} 2 \mathrm{O}$ \\
\hline $\begin{array}{c}\text { MM } \\
076\end{array}$ & $\begin{array}{c}\text { Feldmannia } \\
\text { mitchelliae }\end{array}$ & $\begin{array}{l}\text { Ponta da } \\
\text { Cabeça, Praia } \\
\text { Grande }\end{array}$ & $\begin{array}{l}\text { Arraial do } \\
\text { Cabo, RJ }\end{array}$ & 05/03/2015 & $\begin{array}{l}\text { M. Mungioli; V. } \\
\text { Cassano }\end{array}$ & $\begin{array}{c}22^{\circ} 58^{\prime} 35.7^{\prime \prime} \mathrm{S} \\
42^{\circ} 02^{\prime} 05.6^{\prime \prime} \mathrm{W}\end{array}$ & $\mathrm{CH} 2 \mathrm{O}$ & $\mathrm{CH} 2 \mathrm{O}$ \\
\hline
\end{tabular}


Tabela 2. Continuação

\begin{tabular}{|c|c|c|c|c|c|c|c|c|}
\hline $\begin{array}{c}\text { Código } \\
\text { de } \\
\text { Coleta }\end{array}$ & Amostra & $\begin{array}{l}\text { Local de } \\
\text { Coleta }\end{array}$ & Cidade & Data & $\begin{array}{c}\text { Coletor } \\
\text { (s) }\end{array}$ & $\begin{array}{l}\text { Latitude / } \\
\text { Longitude }\end{array}$ & $\begin{array}{l}\text { COI- } \\
5 P\end{array}$ & $r b c L$ \\
\hline $\begin{array}{c}\text { MM } \\
077\end{array}$ & $\begin{array}{l}\text { "Feldmannia" } \\
\text { mitchelliae }\end{array}$ & $\begin{array}{l}\text { Prainhas - } \\
\text { Pontal do } \\
\text { Atalaia }\end{array}$ & $\begin{array}{l}\text { Arraial do } \\
\text { Cabo, RJ }\end{array}$ & 06/03/2015 & $\begin{array}{l}\text { M. Mungioli; V. } \\
\text { Cassano }\end{array}$ & $\begin{array}{l}22^{\circ} 59^{\prime} 27.2^{\prime \prime S} \\
42^{\circ} 00^{\prime} 45.9^{\prime \prime} \mathrm{W}\end{array}$ & $\mathrm{X}$ & $\mathrm{X}$ \\
\hline $\begin{array}{c}\text { MM } \\
078\end{array}$ & $\begin{array}{l}\text { Levringia } \\
\text { brasiliensis }\end{array}$ & $\begin{array}{l}\text { Prainhas - } \\
\text { Pontal do } \\
\text { Atalaia }\end{array}$ & $\begin{array}{l}\text { Arraial do } \\
\text { Cabo, RJ }\end{array}$ & 06/03/2015 & $\begin{array}{l}\text { M. Mungioli; V. } \\
\text { Cassano }\end{array}$ & $\begin{array}{l}22^{\circ} 599^{\prime} 27.2^{\prime \prime S} \\
42^{\circ} 00^{\prime} 45.9^{\prime \prime} \mathrm{W}\end{array}$ & - & - \\
\hline $\begin{array}{c}\text { MM } \\
079\end{array}$ & $\begin{array}{l}\text { Levringia } \\
\text { brasiliensis }\end{array}$ & $\begin{array}{l}\text { Prainhas - } \\
\text { Pontal do } \\
\text { Atalaia }\end{array}$ & $\begin{array}{l}\text { Arraial do } \\
\text { Cabo, RJ }\end{array}$ & 06/03/2015 & $\begin{array}{l}\text { M. Mungioli; V. } \\
\text { Cassano }\end{array}$ & $\begin{array}{l}22^{\circ} 59^{\prime} 27.2^{\prime \prime} \mathrm{S} \\
42^{\circ} 00^{\prime} 45.9^{\prime \prime} \mathrm{W}\end{array}$ & - & - \\
\hline $\begin{array}{c}\text { MM } \\
080\end{array}$ & $\begin{array}{c}\text { Feldmannia } \\
\text { mitchelliae }\end{array}$ & $\begin{array}{l}\text { Prainhas - } \\
\text { Pontal do } \\
\text { Atalaia }\end{array}$ & $\begin{array}{l}\text { Arraial do } \\
\text { Cabo, RJ }\end{array}$ & 06/03/2015 & $\begin{array}{l}\text { M. Mungioli; V. } \\
\text { Cassano }\end{array}$ & $\begin{array}{l}22^{\circ} 59^{\prime} 27.2^{\prime \prime S} \\
42^{\circ} 00^{\prime} 45.9^{\prime \prime} \mathrm{W}\end{array}$ & $\mathrm{CH} 2 \mathrm{O}$ & $\mathrm{CH} 2 \mathrm{O}$ \\
\hline $\begin{array}{c}\text { MM } \\
081\end{array}$ & $\begin{array}{c}\text { Feldmannia } \\
\text { mitchelliae }\end{array}$ & $\begin{array}{c}\text { Prainhas - } \\
\text { Pontal do } \\
\text { Atalaia }\end{array}$ & $\begin{array}{l}\text { Arraial do } \\
\text { Cabo, RJ }\end{array}$ & 06/03/2015 & $\begin{array}{l}\text { M. Mungioli; V. } \\
\text { Cassano }\end{array}$ & $\begin{array}{l}22^{\circ} 59^{\prime} 27.2^{\prime \prime S} \\
42^{\circ} 00^{\prime} 45.9^{\prime \prime} \mathrm{W}\end{array}$ & $\mathrm{CH} 2 \mathrm{O}$ & $\mathrm{CH} 2 \mathrm{O}$ \\
\hline $\begin{array}{c}\text { MM } \\
082\end{array}$ & $\begin{array}{c}\text { "Feldmannia" } \\
\text { mitchelliae }\end{array}$ & $\begin{array}{l}\text { Praia do } \\
\text { Forno }\end{array}$ & $\begin{array}{l}\text { Arraial do } \\
\text { Cabo, RJ }\end{array}$ & 06/03/2015 & $\begin{array}{l}\text { M. Mungioli; V. } \\
\text { Cassano }\end{array}$ & $\begin{array}{c}22^{\circ} 58^{\prime} 05.0^{\prime \prime} \mathrm{S} \\
42^{\circ} 00^{\prime} 58.0^{\prime \prime} \mathrm{W}\end{array}$ & $\mathrm{X}$ & $\mathrm{X}$ \\
\hline $\begin{array}{c}\text { MM } \\
083\end{array}$ & $\begin{array}{c}\text { Feldmannia } \\
\text { mitchelliae }\end{array}$ & $\begin{array}{l}\text { Praia do } \\
\text { Forno }\end{array}$ & $\begin{array}{l}\text { Arraial do } \\
\text { Cabo, RJ }\end{array}$ & 06/03/2015 & $\begin{array}{l}\text { M. Mungioli; V. } \\
\text { Cassano }\end{array}$ & $\begin{array}{l}22^{\circ} 58^{\prime} 05.0^{\prime \prime} \mathrm{S} \\
42^{\circ} 00^{\prime} 58.0^{\prime \prime} \mathrm{W}\end{array}$ & $\mathrm{X}$ & - \\
\hline $\begin{array}{c}\text { MM } \\
084\end{array}$ & $\begin{array}{l}\text { Bachelotia } \\
\text { antillarum }\end{array}$ & $\begin{array}{l}\text { Prainhas - } \\
\text { Pontal do } \\
\text { Atalaia }\end{array}$ & $\begin{array}{l}\text { Arraial do } \\
\text { Cabo, RJ }\end{array}$ & 06/03/2015 & $\begin{array}{l}\text { M. Mungioli; V. } \\
\text { Cassano }\end{array}$ & $\begin{array}{l}22^{\circ} 59^{\prime} 27.2^{\prime \prime S} \\
42^{\circ} 00^{\prime} 45.9^{\prime \prime} \mathrm{W}\end{array}$ & - & - \\
\hline $\begin{array}{c}\text { MM } \\
085\end{array}$ & $\begin{array}{l}\text { Bachelotia } \\
\text { antillarum }\end{array}$ & $\begin{array}{c}\text { Prainhas - } \\
\text { Pontal do } \\
\text { Atalaia }\end{array}$ & $\begin{array}{l}\text { Arraial do } \\
\text { Cabo, RJ }\end{array}$ & 06/03/2015 & $\begin{array}{l}\text { M. Mungioli; V. } \\
\text { Cassano }\end{array}$ & $\begin{array}{l}22^{\circ} 59^{\prime} 27.2^{\prime \prime S} \\
42^{\circ} 00^{\prime} 45.9^{\prime \prime} \mathrm{W}\end{array}$ & - & $\mathrm{X}$ \\
\hline $\begin{array}{c}\text { MM } \\
086\end{array}$ & $\begin{array}{l}\text { Bachelotia } \\
\text { antillarum }\end{array}$ & $\begin{array}{c}\text { Prainhas - } \\
\text { Pontal do } \\
\text { Atalaia }\end{array}$ & $\begin{array}{l}\text { Arraial do } \\
\text { Cabo, RJ }\end{array}$ & 06/03/2015 & $\begin{array}{l}\text { M. Mungioli; V. } \\
\text { Cassano }\end{array}$ & $\begin{array}{l}22^{\circ} 59^{\prime} 27.2^{\prime \prime S} \\
42^{\circ} 00^{\prime} 45.9^{\prime \prime} \mathrm{W}\end{array}$ & - & - \\
\hline $\begin{array}{c}\text { MM } \\
087\end{array}$ & $\begin{array}{l}\text { "Feldmannia" } \\
\text { mitchelliae }\end{array}$ & $\begin{array}{l}\text { Prainhas - } \\
\text { Pontal do } \\
\text { Atalaia }\end{array}$ & $\begin{array}{l}\text { Arraial do } \\
\text { Cabo, RJ }\end{array}$ & 06/03/2015 & $\begin{array}{l}\text { M. Mungioli; V. } \\
\text { Cassano }\end{array}$ & $\begin{array}{l}22^{\circ} 59^{\prime} 27.2^{\prime \prime} \mathrm{S} \\
42^{\circ} 00^{\prime} 45.9^{\prime \prime} \mathrm{W}\end{array}$ & $\mathrm{X}$ & $\mathrm{X}$ \\
\hline $\begin{array}{c}\text { MM } \\
088\end{array}$ & $\begin{array}{l}\text { "Feldmannia" } \\
\text { mitchelliae }\end{array}$ & $\begin{array}{l}\text { Prainhas - } \\
\text { Pontal do } \\
\text { Atalaia }\end{array}$ & $\begin{array}{l}\text { Arraial do } \\
\text { Cabo, RJ }\end{array}$ & 06/03/2015 & $\begin{array}{l}\text { M. Mungioli; V. } \\
\text { Cassano }\end{array}$ & $\begin{array}{l}22^{\circ} 59^{\prime} 27.2^{\prime \prime} \mathrm{S} \\
42^{\circ} 00^{\prime} 45.9^{\prime \prime} \mathrm{W}\end{array}$ & $\mathrm{X}$ & $\mathrm{X}$ \\
\hline $\begin{array}{c}\text { MM } \\
089\end{array}$ & $\begin{array}{l}\text { "Feldmannia } \\
\text { irregularis" }\end{array}$ & $\begin{array}{l}\text { Prainhas - } \\
\text { Pontal do } \\
\text { Atalaia }\end{array}$ & $\begin{array}{l}\text { Arraial do } \\
\text { Cabo, RJ }\end{array}$ & 06/03/2015 & $\begin{array}{l}\text { M. Mungioli; V. } \\
\text { Cassano }\end{array}$ & $\begin{array}{l}22^{\circ} 59^{\prime} 27.2^{\prime \prime S} \\
42^{\circ} 00^{\prime} 45.9^{\prime \prime} \mathrm{W}\end{array}$ & - & $\mathrm{X}$ \\
\hline $\begin{array}{c}\text { MM } \\
090\end{array}$ & $\begin{array}{c}\text { Feldmannia } \\
\text { mitchelliae }\end{array}$ & $\begin{array}{l}\text { Prainhas - } \\
\text { Pontal do } \\
\text { Atalaia }\end{array}$ & $\begin{array}{l}\text { Arraial do } \\
\text { Cabo, RJ }\end{array}$ & 06/03/2015 & $\begin{array}{l}\text { M. Mungioli; V. } \\
\text { Cassano }\end{array}$ & $\begin{array}{l}22^{\circ} 59^{\prime} 27.2^{\prime \prime S} \\
42^{\circ} 00^{\prime} 45.9^{\prime \prime} \mathrm{W}\end{array}$ & - & - \\
\hline $\begin{array}{c}\text { MM } \\
091\end{array}$ & $\begin{array}{c}\text { Feldmannia } \\
\text { mitchelliae }\end{array}$ & $\begin{array}{l}\text { Prainhas - } \\
\text { Pontal do } \\
\text { Atalaia }\end{array}$ & $\begin{array}{l}\text { Arraial do } \\
\text { Cabo, RJ }\end{array}$ & 06/03/2015 & $\begin{array}{l}\text { M. Mungioli; V. } \\
\text { Cassano }\end{array}$ & $\begin{array}{l}22^{\circ} 59^{\prime} 27.2^{\prime \prime S} \\
42^{\circ} 00^{\prime} 45.9^{\prime \prime} \mathrm{W}\end{array}$ & - & - \\
\hline $\begin{array}{c}\text { MM } \\
092\end{array}$ & $\begin{array}{l}\text { Bachelotia } \\
\text { antillarum }\end{array}$ & $\begin{array}{l}\text { Praia das } \\
\text { Conchas }\end{array}$ & $\begin{array}{l}\text { Cabo Frio, } \\
\text { RJ }\end{array}$ & 07/03/2015 & $\begin{array}{l}\text { M. Mungioli; V. } \\
\text { Cassano }\end{array}$ & $\begin{array}{l}22^{\circ} 52^{\prime} 16.8^{\prime \prime S} \\
41^{\circ} 58^{\prime} 52.1^{\prime \prime} \mathrm{W}\end{array}$ & - & - \\
\hline $\begin{array}{c}\text { MM } \\
093\end{array}$ & $\begin{array}{c}\text { "Feldmannia" } \\
\text { mitchelliae }\end{array}$ & $\begin{array}{l}\text { Praia das } \\
\text { Conchas }\end{array}$ & $\begin{array}{l}\text { Cabo Frio, } \\
\text { RJ }\end{array}$ & 07/03/2015 & $\begin{array}{l}\text { M. Mungioli; V. } \\
\text { Cassano }\end{array}$ & $\begin{array}{l}22^{\circ} 52^{\prime} 16.8^{\prime \prime S} \\
41^{\circ} 58 ' 52.1^{\prime \prime W}\end{array}$ & - & $\mathrm{X}$ \\
\hline $\begin{array}{c}\text { MM } \\
094\end{array}$ & $\begin{array}{l}\text { "Feldmannia } \\
\text { irregularis" }\end{array}$ & $\begin{array}{l}\text { Praia das } \\
\text { Conchas }\end{array}$ & $\begin{array}{l}\text { Cabo Frio, } \\
\text { RJ }\end{array}$ & 07/03/2015 & $\begin{array}{l}\text { M. Mungioli; V. } \\
\text { Cassano }\end{array}$ & $\begin{array}{l}22^{\circ} 52^{\prime} 16.8^{\prime \prime S} \\
41^{\circ} 58^{\prime} 52.1^{\prime \prime} \mathrm{W}\end{array}$ & - & $\mathrm{X}$ \\
\hline $\begin{array}{c}\text { MM } \\
095\end{array}$ & $\begin{array}{c}\text { "Feldmannia" } \\
\text { mitchelliae }\end{array}$ & $\begin{array}{l}\text { Praia das } \\
\text { Conchas }\end{array}$ & $\begin{array}{c}\text { Cabo Frio, } \\
\text { RJ }\end{array}$ & 07/03/2015 & $\begin{array}{l}\text { M. Mungioli; V. } \\
\text { Cassano }\end{array}$ & $\begin{array}{l}22^{\circ} 52^{\prime} 16.8^{\prime \prime S} \\
41^{\circ} 58^{\prime} 52.1^{\prime \prime} \mathrm{W}\end{array}$ & - & $\mathrm{X}$ \\
\hline $\begin{array}{c}\text { MM } \\
096\end{array}$ & $\begin{array}{l}\text { Bachelotia } \\
\text { antillarum }\end{array}$ & $\begin{array}{l}\text { Praia das } \\
\text { Conchas }\end{array}$ & $\begin{array}{c}\text { Cabo Frio, } \\
\text { RJ }\end{array}$ & 07/03/2015 & $\begin{array}{l}\text { M. Mungioli; V. } \\
\text { Cassano }\end{array}$ & $\begin{array}{l}22^{\circ} 52^{\prime} 16.8^{\prime \prime S} \\
41^{\circ} 58^{\prime} 52.1^{\prime \prime W}\end{array}$ & - & - \\
\hline
\end{tabular}


Tabela 2. Continuação

\begin{tabular}{|c|c|c|c|c|c|c|c|c|}
\hline $\begin{array}{c}\text { Código } \\
\text { de } \\
\text { Coleta }\end{array}$ & Amostra & $\begin{array}{l}\text { Local de } \\
\text { Coleta }\end{array}$ & Cidade & Data & $\begin{array}{c}\text { Coletor } \\
\text { (s) }\end{array}$ & $\begin{array}{l}\text { Latitude / } \\
\text { Longitude }\end{array}$ & $\begin{array}{l}\text { COI- } \\
5 P\end{array}$ & $r b c L$ \\
\hline $\begin{array}{l}\text { MM } \\
097\end{array}$ & $\begin{array}{l}\text { "Feldmannia" } \\
\text { mitchelliae }\end{array}$ & $\begin{array}{l}\text { Praia das } \\
\text { Conchas }\end{array}$ & $\begin{array}{c}\text { Cabo Frio, } \\
\text { RJ }\end{array}$ & 07/03/2015 & $\begin{array}{l}\text { M. Mungioli; V. } \\
\text { Cassano }\end{array}$ & $\begin{array}{l}22^{\circ} 52^{\prime} 16.8^{\prime \prime} \mathrm{S} \\
41^{\circ} 58^{\prime} 52.1^{\prime \prime} \mathrm{W}\end{array}$ & - & $\mathrm{X}$ \\
\hline $\begin{array}{c}\text { MM } \\
098\end{array}$ & $\begin{array}{c}\text { Feldmannia } \\
\text { mitchelliae }\end{array}$ & $\begin{array}{l}\text { Praia das } \\
\text { Conchas }\end{array}$ & $\begin{array}{c}\text { Cabo Frio, } \\
\text { RJ }\end{array}$ & 07/03/2015 & $\begin{array}{l}\text { M. Mungioli; V. } \\
\text { Cassano }\end{array}$ & $\begin{array}{l}22^{\circ} 52 ' 16.8 " \mathrm{~S} \\
41^{\circ} 58^{\prime} 52.1^{\prime \prime W}\end{array}$ & - & - \\
\hline $\begin{array}{c}\text { MM } \\
099\end{array}$ & $\begin{array}{c}\text { "Feldmannia" } \\
\text { mitchelliae }\end{array}$ & $\begin{array}{l}\text { Praia das } \\
\text { Conchas }\end{array}$ & $\begin{array}{c}\text { Cabo Frio, } \\
\text { RJ }\end{array}$ & 07/03/2015 & $\begin{array}{l}\text { M. Mungioli; V. } \\
\text { Cassano }\end{array}$ & $\begin{array}{l}22^{\circ} 52^{\prime} 16.8^{\prime \prime S} \\
41^{\circ} 58^{\prime} 52.1^{\prime \prime W}\end{array}$ & - & $\mathrm{X}$ \\
\hline $\begin{array}{c}\text { MM } \\
100\end{array}$ & $\begin{array}{c}\text { Feldmannia } \\
\text { mitchelliae }\end{array}$ & $\begin{array}{l}\text { Praia das } \\
\text { Conchas }\end{array}$ & $\begin{array}{l}\text { Cabo Frio, } \\
\text { RJ }\end{array}$ & 07/03/2015 & $\begin{array}{l}\text { M. Mungioli; V. } \\
\text { Cassano }\end{array}$ & $\begin{array}{l}22^{\circ} 52^{\prime} 16.8^{\prime \prime S} \\
41^{\circ} 58^{\prime} 52.1 " \mathrm{~W}\end{array}$ & $\mathrm{CH} 2 \mathrm{O}$ & $\mathrm{CH} 2 \mathrm{O}$ \\
\hline $\begin{array}{c}\text { MM } \\
101\end{array}$ & Ectocarpales & Praia Rasa & $\begin{array}{c}\text { Armação } \\
\text { dos Búzios, } \\
\text { RJ }\end{array}$ & 08/03/2015 & $\begin{array}{l}\text { M. Mungioli; V. } \\
\text { Cassano }\end{array}$ & $\begin{array}{l}22^{\circ} 43^{\prime} 59.5^{\prime \prime S} \\
41^{\circ} 57 ' 26.1^{\prime \prime} \mathrm{W}\end{array}$ & - & - \\
\hline $\begin{array}{c}\text { MM } \\
102\end{array}$ & $\begin{array}{l}\text { Bachelotia } \\
\text { antillarum }\end{array}$ & Praia Rasa & $\begin{array}{c}\text { Armação } \\
\text { dos Búzios, } \\
\text { RJ }\end{array}$ & 08/03/2015 & $\begin{array}{l}\text { M. Mungioli; V. } \\
\text { Cassano }\end{array}$ & $\begin{array}{l}22^{\circ} 43^{\prime} 59.5 " \mathrm{~S} ; \\
41^{\circ} 57^{\prime} 26.1^{\prime \prime} \mathrm{W}\end{array}$ & - & - \\
\hline $\begin{array}{c}\text { MM } \\
103\end{array}$ & $\begin{array}{l}\text { Bachelotia } \\
\text { antillarum }\end{array}$ & Praia Rasa & $\begin{array}{c}\text { Armação } \\
\text { dos Búzios, } \\
\text { RJ }\end{array}$ & 08/03/2015 & $\begin{array}{l}\text { M. Mungioli; V. } \\
\text { Cassano }\end{array}$ & $\begin{array}{l}22^{\circ} 43^{\prime} 59.5^{\prime \prime S} \\
41^{\circ} 57^{\prime} 26.1^{\prime \prime} \mathrm{W}\end{array}$ & - & - \\
\hline $\begin{array}{c}\text { MM } \\
104\end{array}$ & $\begin{array}{l}\text { Bachelotia } \\
\text { antillarum }\end{array}$ & Praia Rasa & $\begin{array}{c}\text { Armação } \\
\text { dos Búzios, } \\
\text { RJ }\end{array}$ & 08/03/2015 & $\begin{array}{l}\text { M. Mungioli; V. } \\
\text { Cassano }\end{array}$ & $\begin{array}{l}22^{\circ} 43^{\prime} 59.5 " \mathrm{~S} \\
41^{\circ} 57^{\prime} 26.1^{\prime \prime W}\end{array}$ & - & - \\
\hline $\begin{array}{c}\text { MM } \\
105\end{array}$ & $\begin{array}{l}\text { "Feldmannia } \\
\text { irregularis" }\end{array}$ & Praia Rasa & $\begin{array}{c}\text { Armação } \\
\text { dos Búzios, } \\
\text { RJ }\end{array}$ & 08/03/2015 & $\begin{array}{l}\text { M. Mungioli; V. } \\
\text { Cassano }\end{array}$ & $\begin{array}{l}22^{\circ} 43^{\prime} 59.5^{\prime \prime S} \\
41^{\circ} 57^{\prime} 26.1^{\prime \prime} \mathrm{W}\end{array}$ & - & $\mathrm{X}$ \\
\hline $\begin{array}{c}\text { MM } \\
106\end{array}$ & $\begin{array}{l}\text { "Feldmannia } \\
\text { irregularis" }\end{array}$ & Praia Rasa & $\begin{array}{c}\text { Armação } \\
\text { dos Búzios, } \\
\text { RJ }\end{array}$ & 08/03/2015 & $\begin{array}{l}\text { M. Mungioli; V. } \\
\text { Cassano }\end{array}$ & $\begin{array}{l}22^{\circ} 43^{\prime} 59.5 " \mathrm{~S} ; \\
41^{\circ} 57^{\prime} 26.1^{\prime \prime} \mathrm{W}\end{array}$ & - & $\mathrm{X}$ \\
\hline $\begin{array}{c}\text { MM } \\
107\end{array}$ & $\begin{array}{l}\text { "Híncksia” } \\
\text { conifera }\end{array}$ & Praia Rasa & $\begin{array}{c}\text { Armação } \\
\text { dos Búzios, } \\
\text { RJ }\end{array}$ & 08/03/2015 & $\begin{array}{l}\text { M. Mungioli; V. } \\
\text { Cassano }\end{array}$ & $\begin{array}{l}22^{\circ} 43^{\prime} 59.5^{\prime \prime S} \\
41^{\circ} 57 ' 26.1^{\prime \prime} \mathrm{W}\end{array}$ & - & $\mathrm{X}$ \\
\hline $\begin{array}{c}\text { MM } \\
108\end{array}$ & $\begin{array}{l}\text { “Híncksia” } \\
\text { conifera }\end{array}$ & Praia Rasa & $\begin{array}{c}\text { Armação } \\
\text { dos Búzios, } \\
\text { RJ }\end{array}$ & 08/03/2015 & $\begin{array}{l}\text { M. Mungioli; V. } \\
\text { Cassano }\end{array}$ & $\begin{array}{l}22^{\circ} 43^{\prime} 59.5 " \mathrm{~S} ; \\
41^{\circ} 57^{\prime} 26.1 " \mathrm{~W}\end{array}$ & $\mathrm{X}$ & $\mathrm{X}$ \\
\hline $\begin{array}{c}\text { MM } \\
109\end{array}$ & $\begin{array}{l}\text { "Feldmannia" } \\
\text { mitchelliae }\end{array}$ & Praia Rasa & $\begin{array}{c}\text { Armação } \\
\text { dos Búzios, } \\
\text { RJ }\end{array}$ & 08/03/2015 & $\begin{array}{l}\text { M. Mungioli; V. } \\
\text { Cassano }\end{array}$ & $\begin{array}{l}22^{\circ} 43^{\prime} 59.5 " \mathrm{~S} \\
41^{\circ} 57^{\prime} 26.1^{\prime \prime} \mathrm{W}\end{array}$ & - & $\mathrm{X}$ \\
\hline $\begin{array}{c}\text { MM } \\
110\end{array}$ & $\begin{array}{c}\text { Asteronema } \\
\text { breviarticulatu } \\
m\end{array}$ & Praia Rasa & $\begin{array}{c}\text { Armação } \\
\text { dos Búzios, } \\
\text { RJ }\end{array}$ & 08/03/2015 & $\begin{array}{l}\text { M. Mungioli; V. } \\
\text { Cassano }\end{array}$ & $\begin{array}{l}22^{\circ} 43^{\prime} 59.5^{\prime \prime S} \\
41^{\circ} 57^{\prime} 26.1^{\prime \prime} \mathrm{W}\end{array}$ & - & - \\
\hline $\begin{array}{c}\text { MM } \\
111\end{array}$ & $\begin{array}{l}\text { "Híncksia" } \\
\text { conifera }\end{array}$ & Praia Rasa & $\begin{array}{c}\text { Armação } \\
\text { dos Búzios, } \\
\text { RJ }\end{array}$ & 08/03/2015 & $\begin{array}{l}\text { M. Mungioli; V. } \\
\text { Cassano }\end{array}$ & $\begin{array}{l}22^{\circ} 43^{\prime} 59.5^{\prime \prime S} \\
41^{\circ} 57 ' 26.1^{\prime \prime} \mathrm{W}\end{array}$ & $\mathrm{X}$ & $\mathrm{X}$ \\
\hline $\begin{array}{c}\text { MM } \\
112\end{array}$ & $\begin{array}{c}\text { "Feldmannia" } \\
\text { mitchelliae }\end{array}$ & Praia Rasa & $\begin{array}{c}\text { Armação } \\
\text { dos Búzios, } \\
\text { RJ }\end{array}$ & 08/03/2015 & $\begin{array}{l}\text { M. Mungioli; V. } \\
\text { Cassano }\end{array}$ & $\begin{array}{l}22^{\circ} 43^{\prime} 59.5 " \mathrm{~S} \\
41^{\circ} 57 ' 26.1^{\prime \prime} \mathrm{W}\end{array}$ & $\mathrm{X}$ & $\mathrm{X}$ \\
\hline $\begin{array}{c}\text { MM } \\
113\end{array}$ & $\begin{array}{c}\text { "Feldmannia" } \\
\text { mitchelliae }\end{array}$ & Praia Rasa & $\begin{array}{c}\text { Armação } \\
\text { dos Búzios, } \\
\text { RJ }\end{array}$ & 08/03/2015 & $\begin{array}{l}\text { M. Mungioli; V. } \\
\text { Cassano }\end{array}$ & $\begin{array}{l}22^{\circ} 43^{\prime} 59.5 " \mathrm{~S} ; \\
41^{\circ} 57^{\prime} 26.1^{\prime \prime} \mathrm{W}\end{array}$ & $\mathrm{X}$ & $\mathrm{X}$ \\
\hline $\begin{array}{c}\text { MM } \\
114\end{array}$ & $\begin{array}{l}\text { "Feldmannia } \\
\text { irregularis" }\end{array}$ & $\begin{array}{l}\text { Praia do } \\
\text { Geribá }\end{array}$ & $\begin{array}{c}\text { Armação } \\
\text { dos Búzios, } \\
\text { RJ }\end{array}$ & 09/03/2015 & $\begin{array}{l}\text { M. Mungioli; V. } \\
\text { Cassano }\end{array}$ & $\begin{array}{l}22^{\circ} 46^{\prime} 49.4^{\prime \prime S} \\
41^{\circ} 54^{\prime} 14.6 " \mathrm{~W}\end{array}$ & $\mathrm{X}$ & $\mathrm{X}$ \\
\hline $\begin{array}{c}\text { MM } \\
115\end{array}$ & $\begin{array}{c}\text { Feldmannia } \\
\text { mitchelliae }\end{array}$ & $\begin{array}{c}\text { Praia do } \\
\text { Geribá }\end{array}$ & $\begin{array}{c}\text { Armação } \\
\text { dos Búzios, } \\
\text { RJ }\end{array}$ & 09/03/2015 & $\begin{array}{l}\text { M. Mungioli; V. } \\
\text { Cassano }\end{array}$ & $\begin{array}{c}22^{\circ} 46^{\prime} 49.4^{\prime \prime S} \\
41^{\circ} 54^{\prime} 14.6^{\prime \prime W}\end{array}$ & - & $\mathrm{CH} 2 \mathrm{O}$ \\
\hline $\begin{array}{c}\mathrm{MM} \\
116\end{array}$ & $\begin{array}{c}\text { "Feldmannia” } \\
\text { irregularis }\end{array}$ & $\begin{array}{c}\text { Praia da } \\
\text { Ferradurinha }\end{array}$ & $\begin{array}{c}\text { Armação } \\
\text { dos Búzios, } \\
\text { RJ }\end{array}$ & 09/03/2015 & $\begin{array}{l}\text { M. Mungioli; V. } \\
\text { Cassano }\end{array}$ & $\begin{array}{c}22^{\circ} 46^{\prime} 27.5^{\prime \prime S} \\
41^{\circ} 53^{\prime} 16.3^{\prime \prime W}\end{array}$ & $\mathrm{X}$ & $\mathrm{X}$ \\
\hline
\end{tabular}


Tabela 2. Continuação

\begin{tabular}{|c|c|c|c|c|c|c|c|c|}
\hline $\begin{array}{l}\text { Código } \\
\text { de } \\
\text { Coleta }\end{array}$ & Amostra & $\begin{array}{l}\text { Local de } \\
\text { Coleta }\end{array}$ & Cidade & Data & $\begin{array}{l}\text { Coletor } \\
\text { (s) }\end{array}$ & $\begin{array}{l}\text { Latitude / } \\
\text { Longitude }\end{array}$ & $\begin{array}{l}\text { COI- } \\
5 P\end{array}$ & $r b c \mathbf{L}$ \\
\hline $\begin{array}{c}\mathrm{MM} \\
117\end{array}$ & $\begin{array}{l}\text { "Feldmannia } \\
\text { irregularis" }\end{array}$ & $\begin{array}{l}\text { Praia da } \\
\text { Ferradurinha }\end{array}$ & $\begin{array}{c}\text { Armação } \\
\text { dos Búzios, } \\
\text { RJ }\end{array}$ & 09/03/2015 & $\begin{array}{l}\text { M. Mungioli; V. } \\
\text { Cassano }\end{array}$ & $\begin{array}{l}22^{\circ} 46^{\prime} 27.5^{\prime \prime S} \\
41^{\circ} 53 ' 16.3^{\prime \prime W}\end{array}$ & - & $\mathrm{X}$ \\
\hline $\begin{array}{c}\mathrm{MM} \\
118\end{array}$ & $\begin{array}{c}\text { Acinetospora } \\
\text { filamentosa }\end{array}$ & $\begin{array}{c}\text { Praia da } \\
\text { Ferradurinha }\end{array}$ & $\begin{array}{c}\text { Armação } \\
\text { dos Búzios, } \\
\text { RJ }\end{array}$ & 09/03/2015 & $\begin{array}{l}\text { M. Mungioli; V. } \\
\text { Cassano }\end{array}$ & $\begin{array}{l}22^{\circ} 46^{\prime} 27.5^{\prime \prime S} \\
41^{\circ} 53^{\prime} 16.3^{\prime \prime} \mathrm{W}\end{array}$ & $\mathrm{X}$ & $\mathrm{X}$ \\
\hline $\begin{array}{c}\mathrm{MM} \\
119\end{array}$ & $\begin{array}{c}\text { Levringia } \\
\text { brasiliensis }\end{array}$ & $\begin{array}{c}\text { Praia da Foca } \\
\text { - Pta da } \\
\text { Lagoinha }\end{array}$ & $\begin{array}{c}\text { Armação } \\
\text { dos Búzios, } \\
\text { RJ }\end{array}$ & 09/03/2015 & $\begin{array}{l}\text { M. Mungioli; V. } \\
\text { Cassano }\end{array}$ & $\begin{array}{l}22^{\circ} 45^{\prime} 53^{\prime \prime S} ; \\
41^{\circ} 52^{\prime} 41^{\prime \prime} \mathrm{W}\end{array}$ & - & - \\
\hline $\begin{array}{c}\mathrm{MM} \\
120\end{array}$ & $\begin{array}{c}\text { “Feldmannia” } \\
\text { irregularis }\end{array}$ & $\begin{array}{c}\text { Praia da Foca } \\
\text { - Pta da } \\
\text { Lagoinha }\end{array}$ & $\begin{array}{c}\text { Armação } \\
\text { dos Búzios, } \\
\text { RJ }\end{array}$ & 09/03/2015 & $\begin{array}{l}\text { M. Mungioli; V. } \\
\text { Cassano }\end{array}$ & $\begin{array}{l}22^{\circ} 45^{\prime} 53^{\prime \prime S} ; \\
41^{\circ} 52^{\prime} 41^{\prime \prime} \mathrm{W}\end{array}$ & $\mathrm{X}$ & $\mathrm{X}$ \\
\hline $\begin{array}{c}\mathrm{MM} \\
121\end{array}$ & $\begin{array}{c}\text { Levringia } \\
\text { brasiliensis }\end{array}$ & $\begin{array}{l}\text { Praia da } \\
\text { Ferradurinha }\end{array}$ & $\begin{array}{c}\text { Armação } \\
\text { dos Búzios, } \\
\text { RJ }\end{array}$ & 09/03/2015 & $\begin{array}{l}\text { M. Mungioli; V. } \\
\text { Cassano }\end{array}$ & $\begin{array}{l}22^{\circ} 46^{\prime} 53.3^{\prime \prime S} ; \\
41^{\circ} 53^{\prime} 59.1^{\prime \prime} \mathrm{W}\end{array}$ & - & $\mathrm{X}$ \\
\hline $\begin{array}{c}\mathrm{MM} \\
122\end{array}$ & $\begin{array}{l}\text { Feldmannia } \\
\text { irregularis }\end{array}$ & $\begin{array}{c}\text { Praia da Foca } \\
\text { - Pta da } \\
\text { Lagoinha }\end{array}$ & $\begin{array}{c}\text { Armação } \\
\text { dos Búzios, } \\
\text { RJ }\end{array}$ & 09/03/2015 & $\begin{array}{l}\text { M. Mungioli; V. } \\
\text { Cassano }\end{array}$ & $\begin{array}{l}22^{\circ} 45^{\prime} 53^{\prime \prime S} \\
41^{\circ} 52^{\prime} 41^{\prime \prime} \mathrm{W}\end{array}$ & $\mathrm{CH} 2 \mathrm{O}$ & $\mathrm{CH} 2 \mathrm{O}$ \\
\hline $\begin{array}{c}\text { MM } \\
123\end{array}$ & $\begin{array}{c}\text { Feldmannia } \\
\text { irregularis }\end{array}$ & $\begin{array}{c}\text { Praia da } \\
\text { Ferradurinha }\end{array}$ & $\begin{array}{c}\text { Armação } \\
\text { dos Búzios, } \\
\text { RJ }\end{array}$ & 09/03/2015 & $\begin{array}{l}\text { M. Mungioli; V. } \\
\text { Cassano }\end{array}$ & $\begin{array}{l}22^{\circ} 46^{\prime} 53.3^{\prime \prime} \mathrm{S} ; \\
41^{\circ} 53^{\prime} 59.1^{\prime \prime} \mathrm{W}\end{array}$ & $\mathrm{CH} 2 \mathrm{O}$ & $\mathrm{CH} 2 \mathrm{O}$ \\
\hline $\begin{array}{c}\mathrm{MM} \\
124\end{array}$ & $\begin{array}{c}\text { Acinetospora } \\
\text { filamentosa }\end{array}$ & $\begin{array}{l}\text { Praia da } \\
\text { Ferradurinha }\end{array}$ & $\begin{array}{c}\text { Armação } \\
\text { dos Búzios, } \\
\text { RJ }\end{array}$ & 09/03/2015 & $\begin{array}{l}\text { M. Mungioli; V. } \\
\text { Cassano e } \\
\text { C.A.A.Azevedo. }\end{array}$ & $\begin{array}{l}22^{\circ} 46^{\prime} 53.3^{\prime \prime} \mathrm{S} \\
41^{\circ} 53^{\prime} 59.1^{\prime \prime W}\end{array}$ & $X$ & $\mathrm{X}$ \\
\hline $\begin{array}{c}\mathrm{MM} \\
125\end{array}$ & $\begin{array}{l}\text { Feldmannia } \\
\text { mitchelliae }\end{array}$ & $\begin{array}{c}\text { Praia da } \\
\text { Ferradurinha }\end{array}$ & $\begin{array}{c}\text { Armação } \\
\text { dos Búzios, } \\
\text { RJ }\end{array}$ & 09/03/2015 & $\begin{array}{l}\text { M. Mungioli; V. } \\
\text { Cassano e } \\
\text { C.A.A.Azevedo. }\end{array}$ & $\begin{array}{l}22^{\circ} 46^{\prime} 53.3^{\prime \prime} \mathrm{S} ; \\
41^{\circ} 53^{\prime} 59.1^{\prime \prime W}\end{array}$ & $\mathrm{CH} 2 \mathrm{O}$ & $\mathrm{CH} 2 \mathrm{O}$ \\
\hline $\begin{array}{c}\mathrm{MM} \\
126\end{array}$ & $\begin{array}{l}\text { "Feldmannia } \\
\text { irregularis" }\end{array}$ & $\begin{array}{l}\text { Praia do } \\
\text { Cibratel II }\end{array}$ & $\begin{array}{l}\text { Itanhaém, } \\
\text { SP }\end{array}$ & 20/03/2015 & $\begin{array}{l}\text { M. Mungioli; } \\
\text { C.A.A. Azevedo }\end{array}$ & $\begin{array}{l}24^{\circ} 12^{\prime} 06.5^{\prime \prime} \text {; } \\
46^{\circ} 48^{\prime} 40.1^{\prime \prime W}\end{array}$ & - & $\mathrm{X}$ \\
\hline $\begin{array}{c}\text { MM } \\
127\end{array}$ & $\begin{array}{l}\text { "Feldmannia } \\
\text { irregularis" }\end{array}$ & $\begin{array}{l}\text { Praia do } \\
\text { Cibratel II }\end{array}$ & $\begin{array}{l}\text { Itanhaém, } \\
\text { SP }\end{array}$ & 20/03/2015 & $\begin{array}{l}\text { M. Mungioli; } \\
\text { C.A.A. Azevedo }\end{array}$ & $\begin{array}{l}24^{\circ} 12^{\prime} 06.5^{\prime \prime} \mathrm{S} \\
46^{\circ} 48^{\prime} 40.1^{\prime \prime} \mathrm{W}\end{array}$ & - & $\mathrm{X}$ \\
\hline $\begin{array}{c}\mathrm{MM} \\
128\end{array}$ & $\begin{array}{l}\text { “Asteronema” } \\
\text { breviarticulatum }\end{array}$ & $\begin{array}{l}\text { Praia do } \\
\text { Cibratel II }\end{array}$ & $\begin{array}{l}\text { Itanhaém, } \\
\text { SP }\end{array}$ & 20/03/2015 & $\begin{array}{l}\text { M. Mungioli; } \\
\text { C.A.A. Azevedo }\end{array}$ & $\begin{array}{l}24^{\circ} 12^{\prime} 06.5^{\prime \prime} \mathrm{S} \\
46^{\circ} 48^{\prime} 40.1^{\prime \prime} \mathrm{W}\end{array}$ & - & $\mathrm{X}$ \\
\hline $\begin{array}{c}\text { MM } \\
129\end{array}$ & $\begin{array}{l}\text { "Feldmannia } \\
\text { irregularis" }\end{array}$ & $\begin{array}{l}\text { Praia do } \\
\text { Cibratel II }\end{array}$ & $\begin{array}{l}\text { Itanhaém, } \\
\text { SP }\end{array}$ & 20/03/2015 & $\begin{array}{l}\text { M. Mungioli; } \\
\text { C.A.A. Azevedo }\end{array}$ & $\begin{array}{l}24^{\circ} 12^{\prime} 06.5^{\prime \prime S} ; \\
46^{\circ} 48^{\prime} 40.1^{\prime \prime} \mathrm{W}\end{array}$ & - & $\mathrm{X}$ \\
\hline $\begin{array}{c}\text { MM } \\
130\end{array}$ & $\begin{array}{l}\text { “Feldmannia } \\
\text { irregularis” }\end{array}$ & $\begin{array}{l}\text { Praia do } \\
\text { Cibratel II }\end{array}$ & $\begin{array}{l}\text { Itanhaém, } \\
\text { SP }\end{array}$ & 20/03/2015 & $\begin{array}{l}\text { M. Mungioli; } \\
\text { C.A.A. Azevedo }\end{array}$ & $\begin{array}{l}24^{\circ} 12^{\prime} 06.5^{\prime \prime S} \\
46^{\circ} 48^{\prime} 40.1^{\prime \prime W}\end{array}$ & - & $X$ \\
\hline $\begin{array}{c}\text { MM } \\
131\end{array}$ & $\begin{array}{c}\text { "Feldmannia" } \\
\text { mitchelliae }\end{array}$ & $\begin{array}{l}\text { Praia do } \\
\text { Cibratel II }\end{array}$ & $\begin{array}{l}\text { Itanhaém, } \\
\text { SP }\end{array}$ & 20/03/2015 & $\begin{array}{l}\text { M. Mungioli; } \\
\text { C.A.A. Azevedo }\end{array}$ & $\begin{array}{l}24^{\circ} 12^{\prime} 06.5^{\prime \prime S} \\
46^{\circ} 48^{\prime} 40.1^{\prime \prime} \mathrm{W}\end{array}$ & $\mathrm{X}$ & $X$ \\
\hline $\begin{array}{c}\mathrm{MM} \\
132\end{array}$ & $\begin{array}{l}\text { Feldmannia } \\
\text { mitchelliae }\end{array}$ & $\begin{array}{l}\text { Praia do } \\
\text { Cibratel II }\end{array}$ & $\begin{array}{l}\text { Itanhaém, } \\
\text { SP }\end{array}$ & 20/03/2015 & $\begin{array}{l}\text { M. Mungioli; } \\
\text { C.A.A. Azevedo }\end{array}$ & $\begin{array}{l}24^{\circ} 12^{\prime} 06.5^{\prime \prime} \mathrm{S} \\
46^{\circ} 48^{\prime} 40.1^{\prime \prime} \mathrm{W}\end{array}$ & - & - \\
\hline $\begin{array}{c}\text { MM } \\
133\end{array}$ & $\begin{array}{l}\text { Feldmannia } \\
\text { mitchelliae }\end{array}$ & $\begin{array}{l}\text { Praia do } \\
\text { Cibratel II }\end{array}$ & $\begin{array}{l}\text { Itanhaém, } \\
\text { SP }\end{array}$ & 20/03/2015 & $\begin{array}{l}\text { M. Mungioli; } \\
\text { C.A.A. Azevedo }\end{array}$ & $\begin{array}{l}24^{\circ} 12^{\prime} 06.5^{\prime \prime S} \\
46^{\circ} 48^{\prime} 40.1^{\prime \prime} \mathrm{W}\end{array}$ & - & - \\
\hline $\begin{array}{c}\mathrm{MM} \\
134\end{array}$ & $\begin{array}{c}\text { "Hincksia" } \\
\text { conifera }\end{array}$ & $\begin{array}{l}\text { Praia Saco do } \\
\text { Ribeira }\end{array}$ & $\begin{array}{l}\text { Ubatuba, } \\
\text { SP }\end{array}$ & 28/11/2012 & J. C. De-Paula. & $\begin{array}{l}23^{\circ} 30^{\prime} 04.4^{\prime} \mathrm{S} \\
45^{\circ} 07^{\prime} 21.8^{\prime} \mathrm{W}\end{array}$ & $\mathrm{X}$ & $\mathrm{X}$ \\
\hline $\begin{array}{c}\text { MM } \\
135\end{array}$ & $\begin{array}{l}\text { "Feldmannia } \\
\text { irregularis" }\end{array}$ & $\begin{array}{c}\text { Praia } \\
\text { Vermelha }\end{array}$ & Paraty, RJ & $18 / 10 / 2013$ & J. C. De-Paula. & $\begin{array}{l}23^{\circ} 11^{\prime} 28.4^{\prime} \mathrm{S} \\
44^{\circ} 38^{\prime} 44.1^{\prime} \mathrm{W}\end{array}$ & - & - \\
\hline $\begin{array}{c}\mathrm{MM} \\
136\end{array}$ & $\begin{array}{l}\text { "Feldmannia } \\
\text { irregularis" }\end{array}$ & $\begin{array}{l}\text { Praia das } \\
\text { Cigarras }\end{array}$ & $\begin{array}{l}\text { São } \\
\text { Sebastião, } \\
\text { SP }\end{array}$ & 2013 & J. C. De-Paula. & $\begin{array}{c}23^{\circ} 43^{\prime} 40.8^{\prime \prime S} \\
45^{\circ} 23^{\prime} 54.4^{\prime \prime} \mathrm{W}\end{array}$ & - & - \\
\hline
\end{tabular}


Tabela 2. Continuação

\begin{tabular}{|c|c|c|c|c|c|c|c|c|}
\hline $\begin{array}{c}\text { Código } \\
\text { de } \\
\text { Coleta }\end{array}$ & Amostra & $\begin{array}{l}\text { Local de } \\
\text { Coleta }\end{array}$ & Cidade & Data & Coletor (s) & $\begin{array}{l}\text { Latitude / } \\
\text { Longitude }\end{array}$ & $\begin{array}{l}\text { COI- } \\
5 P\end{array}$ & $r b c \mathbf{L}$ \\
\hline $\begin{array}{c}\mathrm{MM} \\
137\end{array}$ & $\begin{array}{l}\text { "Feldmannia } \\
\text { irregularis" }\end{array}$ & $\begin{array}{c}\text { Praia das } \\
\text { Cigarras }\end{array}$ & $\begin{array}{l}\text { São } \\
\text { Sebastião, } \\
\text { SP }\end{array}$ & 2013 & J. C. De-Paula. & $\begin{array}{l}23^{\circ} 43^{\prime} 40.8^{\prime \prime S} \\
45^{\circ} 23^{\prime} 54.4^{\prime \prime} \mathrm{W}\end{array}$ & - & - \\
\hline $\begin{array}{c}\mathrm{MM} \\
138\end{array}$ & $\begin{array}{c}\text { Asteronema } \\
\text { breviarticulatum }\end{array}$ & $\begin{array}{c}\text { Praia dos } \\
\text { Emissários }\end{array}$ & $\begin{array}{l}\text { Camaçari, } \\
\text { BA }\end{array}$ & $14 / 10 / 2012$ & J. C. De-Paula. & $\begin{array}{c}12^{\circ} 44^{\prime} 28.7 " \mathrm{~S} \\
38^{\circ} 09^{\prime} 02.5^{\prime \prime W}\end{array}$ & - & - \\
\hline $\begin{array}{c}\text { MM } \\
139\end{array}$ & $\begin{array}{c}\text { Asteronema } \\
\text { breviarticulatum }\end{array}$ & $\begin{array}{c}\text { Praia dos } \\
\text { Emissários }\end{array}$ & $\begin{array}{l}\text { Camaçari, } \\
\text { BA }\end{array}$ & $14 / 10 / 2012$ & V. Cassano & $\begin{array}{c}12^{\circ} 44^{\prime} 28.7 " \mathrm{~S} \\
38^{\circ} 09^{\prime} 02.5^{\prime \prime} \mathrm{W}\end{array}$ & - & - \\
\hline $\begin{array}{c}\mathrm{MM} \\
140\end{array}$ & $\begin{array}{l}\text { Bachelotia } \\
\text { antillarum }\end{array}$ & $\begin{array}{c}\text { Praia da } \\
\text { Pedra do Sal }\end{array}$ & $\begin{array}{l}\text { Cidade do } \\
\text { Parnaíba, } \\
\text { PI }\end{array}$ & $26 / 06 / 2013$ & D. Milsten. & $\begin{array}{c}2^{\circ} 48 ' 21.2^{\prime \prime S} \\
41^{\circ} 43^{\prime} 48.8 " \mathrm{~W}\end{array}$ & - & $\mathrm{X}$ \\
\hline $\begin{array}{c}\mathrm{MM} \\
141\end{array}$ & $\begin{array}{l}\text { Bachelotia } \\
\text { antillarum }\end{array}$ & $\begin{array}{l}\text { Praia da } \\
\text { Costa } \\
\text { Dourada }\end{array}$ & Itaúnas, ES & $25 / 07 / 2014$ & - & $\begin{array}{c}18^{\circ} 15^{\prime} 46.0^{\prime} \mathrm{S} \\
39^{\circ} 38^{\prime} 40.7^{\prime} \mathrm{W}\end{array}$ & - & $\mathrm{X}$ \\
\hline $\begin{array}{c}\mathrm{MM} \\
142\end{array}$ & $\begin{array}{c}\text { "Feldmannia" } \\
\text { mitchelliae }\end{array}$ & $\begin{array}{l}\text { Praia da } \\
\text { Costa } \\
\text { Dourada }\end{array}$ & Itaúnas, ES & $25 / 07 / 2014$ & J. C. De-Paula. & $\begin{array}{c}18^{\circ} 15^{\prime} 46.0^{\prime} \mathrm{S} \\
39^{\circ} 38^{\prime} 40.7^{\prime} \mathrm{W}\end{array}$ & - & $\mathrm{X}$ \\
\hline $\begin{array}{c}\mathrm{MM} \\
143\end{array}$ & $\begin{array}{c}\text { Levringia } \\
\text { brasiliensis }\end{array}$ & Praia Rasa & $\begin{array}{c}\text { Armação } \\
\text { dos Búzios, } \\
\text { RJ }\end{array}$ & 06/05/2012 & J. C. De-Paula. & $\begin{array}{c}22^{\circ} 44^{\prime} 01.9 " \mathrm{~S} \\
41^{\circ} 57^{\prime} 29.1^{\prime \prime W}\end{array}$ & - & - \\
\hline $\begin{array}{c}\mathrm{MM} \\
144\end{array}$ & $\begin{array}{l}\text { Bachelotia } \\
\text { antillarum }\end{array}$ & Praia Rasa & $\begin{array}{c}\text { Armação } \\
\text { dos Búzios, } \\
\text { RJ }\end{array}$ & 06/05/2012 & J. C. De-Paula. & $\begin{array}{l}22^{\circ} 44^{\prime} 01.9 " \mathrm{~S} \\
41^{\circ} 57^{\prime} 29.1 " \mathrm{~W}\end{array}$ & - & - \\
\hline $\begin{array}{c}\mathrm{MM} \\
145\end{array}$ & $\begin{array}{c}\text { Sphacelaria } \\
\text { brachgonia }\end{array}$ & Praia Rasa & $\begin{array}{c}\text { Armação } \\
\text { dos Búzios, } \\
\text { RJ }\end{array}$ & 06/05/2012 & J. C. De-Paula. & $\begin{array}{l}22^{\circ} 44^{\prime} 01.9 " \mathrm{~S} \\
41^{\circ} 57^{\prime} 29.1^{\prime \prime} \mathrm{W}\end{array}$ & - & - \\
\hline $\begin{array}{c}\mathrm{MM} \\
146\end{array}$ & $\begin{array}{c}\text { "Feldmannia" } \\
\text { mitchelliae }\end{array}$ & Praia de Fora & $\begin{array}{c}\text { Baía de } \\
\text { Guanabara, } \\
\text { RJ }\end{array}$ & $18 / 12 / 2012$ & J. C. De-Paula. & $\begin{array}{c}22^{\circ} 56^{\prime} 43.4^{\prime \prime S} \\
43^{\circ} 09^{\prime} 19.3^{\prime \prime W}\end{array}$ & - & - \\
\hline $\begin{array}{c}\mathrm{MM} \\
147\end{array}$ & $\begin{array}{c}\text { "Feldmannia" } \\
\text { mitchelliae }\end{array}$ & Praia de Fora & $\begin{array}{c}\text { Baía de } \\
\text { Guanabara, } \\
\text { RJ }\end{array}$ & $18 / 12 / 2012$ & J. C. De-Paula. & $\begin{array}{l}22^{\circ} 56^{\prime} 43.4^{\prime \prime S} \\
43^{\circ} 09^{\prime} 19.3 " \mathrm{~W}\end{array}$ & - & - \\
\hline $\begin{array}{c}\mathrm{MM} \\
148\end{array}$ & $\begin{array}{c}\text { "Feldmannia" } \\
\text { mitchelliae }\end{array}$ & Praia de Fora & $\begin{array}{c}\text { Baía de } \\
\text { Guanabara, } \\
\text { RJ }\end{array}$ & $18 / 12 / 2012$ & J. C. De-Paula. & $\begin{array}{l}22^{\circ} 56^{\prime} 43.4^{\prime \prime S} \\
43^{\circ} 09^{\prime} 19.3^{\prime \prime W}\end{array}$ & - & - \\
\hline $\begin{array}{c}\mathrm{MM} \\
149\end{array}$ & $\begin{array}{c}\text { "Feldmannia" } \\
\text { mitchelliae }\end{array}$ & Praia de Fora & $\begin{array}{c}\text { Baía de } \\
\text { Guanabara, } \\
\text { RJ }\end{array}$ & $18 / 12 / 2012$ & J. C. De-Paula. & $\begin{array}{l}22^{\circ} 56^{\prime} 43.4^{\prime \prime S} \\
43^{\circ} 09^{\prime} 19.3^{\prime \prime} \mathrm{W}\end{array}$ & - & - \\
\hline $\begin{array}{c}\mathrm{MM} \\
150\end{array}$ & $\begin{array}{c}\text { "Feldmannia" } \\
\text { mitchelliae }\end{array}$ & Praia de Fora & $\begin{array}{c}\text { Baía de } \\
\text { Guanabara, } \\
\text { RJ }\end{array}$ & $18 / 12 / 2012$ & J. C. De-Paula. & $\begin{array}{l}22^{\circ} 56^{\prime} 43.4^{\prime \prime S} \\
43^{\circ} 09^{\prime} 19.3 " \mathrm{~W}\end{array}$ & - & - \\
\hline $\begin{array}{c}\text { MM } \\
151\end{array}$ & $\begin{array}{c}\text { “Feldmannia" } \\
\text { mitchelliae }\end{array}$ & Praia de Fora & $\begin{array}{c}\text { Baía de } \\
\text { Guanabara, } \\
\text { RJ }\end{array}$ & 18/12/2012 & J. C. De-Paula. & $\begin{array}{l}22^{\circ} 56^{\prime} 43.4^{\prime \prime S} \\
43^{\circ} 09^{\prime} 19.3 " \mathrm{~W}\end{array}$ & - & - \\
\hline $\begin{array}{c}\text { MM } \\
152\end{array}$ & $\begin{array}{c}\text { "Feldmannia" } \\
\text { mitchelliae }\end{array}$ & Praia de Fora & $\begin{array}{c}\text { Baía de } \\
\text { Guanabara, } \\
\text { RJ }\end{array}$ & $18 / 12 / 2012$ & J. C. De-Paula. & $\begin{array}{l}22^{\circ} 56^{\prime} 43.4^{\prime \prime S} \\
43^{\circ} 09^{\prime} 19.3^{\prime \prime W}\end{array}$ & - & - \\
\hline $\begin{array}{c}\text { MM } \\
153\end{array}$ & $\begin{array}{c}\text { “Feldmannia" } \\
\text { mitchelliae }\end{array}$ & Praia de Fora & $\begin{array}{c}\text { Baía de } \\
\text { Guanabara, } \\
\text { RJ }\end{array}$ & $18 / 12 / 2012$ & J. C. De-Paula. & $\begin{array}{c}22^{\circ} 56^{\prime} 43.4^{\prime \prime S} \\
43^{\circ} 09^{\prime} 19.3 " \mathrm{~W}\end{array}$ & - & - \\
\hline $\begin{array}{c}\mathrm{MM} \\
154\end{array}$ & $\begin{array}{c}\text { "Feldmannia" } \\
\text { mitchelliae }\end{array}$ & Praia de Fora & $\begin{array}{c}\text { Baía de } \\
\text { Guanabara, } \\
\text { RJ }\end{array}$ & 18/12/2012 & J. C. De-Paula. & $\begin{array}{l}22^{\circ} 56^{\prime} 43.4^{\prime \prime S} \\
43^{\circ} 09^{\prime} 19.3^{\prime \prime W}\end{array}$ & - & - \\
\hline
\end{tabular}


Tabela 2. Continuação

\begin{tabular}{|c|c|c|c|c|c|c|c|c|}
\hline $\begin{array}{c}\text { Código } \\
\text { de } \\
\text { Coleta }\end{array}$ & Amostra & $\begin{array}{l}\text { Local de } \\
\text { Coleta }\end{array}$ & Cidade & Data & Coletor (s) & $\begin{array}{l}\text { Latitude / } \\
\text { Longitude }\end{array}$ & $\begin{array}{l}\text { COI- } \\
5 P\end{array}$ & $r b c \mathrm{~L}$ \\
\hline $\begin{array}{c}\mathrm{MM} \\
155\end{array}$ & $\begin{array}{c}\text { "Feldmannia" } \\
\text { mitchelliae }\end{array}$ & Praia de Fora & $\begin{array}{c}\text { Baía de } \\
\text { Guanabara, } \\
\text { RJ }\end{array}$ & $18 / 12 / 2012$ & J. C. De-Paula. & $\begin{array}{l}22^{\circ} 56^{\prime} 43.4^{\prime \prime S} \\
43^{\circ} 09^{\prime} 19.3^{\prime \prime W}\end{array}$ & - & - \\
\hline $\begin{array}{c}\mathrm{MM} \\
156\end{array}$ & $\begin{array}{c}\text { “Feldmannia” } \\
\text { mitchelliae }\end{array}$ & Praia de Fora & $\begin{array}{c}\text { Baía de } \\
\text { Guanabara, } \\
\text { RJ }\end{array}$ & $18 / 12 / 2012$ & J. C. De-Paula. & $\begin{array}{l}22^{\circ} 56^{\prime} 43.4^{\prime \prime S} \\
43^{\circ} 09^{\prime} 19.3^{\prime \prime} \mathrm{W}\end{array}$ & - & - \\
\hline $\begin{array}{c}\text { MM } \\
157\end{array}$ & $\begin{array}{c}\text { “Feldmannia” } \\
\text { mitchelliae }\end{array}$ & Praia de Fora & $\begin{array}{c}\text { Baía de } \\
\text { Guanabara, } \\
\text { RJ }\end{array}$ & $18 / 12 / 2012$ & J. C. De-Paula. & $\begin{array}{l}22^{\circ} 56^{\prime} 43.4^{\prime \prime S} \\
43^{\circ} 09^{\prime} 19.3^{\prime \prime} \mathrm{W}\end{array}$ & - & - \\
\hline $\begin{array}{c}\mathrm{MM} \\
158\end{array}$ & $\begin{array}{l}\text { "Feldmannia } \\
\text { irregularis" }\end{array}$ & Praia de Fora & $\begin{array}{c}\text { Baía de } \\
\text { Guanabara, } \\
\text { RJ }\end{array}$ & $18 / 12 / 2012$ & J. C. De-Paula. & $\begin{array}{l}22^{\circ} 56^{\prime} 43.4^{\prime \prime S} \\
43^{\circ} 09^{\prime} 19.3^{\prime \prime W}\end{array}$ & - & - \\
\hline $\begin{array}{c}\text { MM } \\
159\end{array}$ & $\begin{array}{l}\text { "Feldmannia } \\
\text { irregularis" }\end{array}$ & Praia de Fora & $\begin{array}{c}\text { Baía de } \\
\text { Guanabara, } \\
\text { RJ }\end{array}$ & $18 / 12 / 2012$ & J. C. De-Paula. & $\begin{array}{l}22^{\circ} 56^{\prime} 43.4^{\prime \prime S} \\
43^{\circ} 09^{\prime} 19.3^{\prime \prime} \mathrm{W}\end{array}$ & - & - \\
\hline $\begin{array}{c}\mathrm{MM} \\
160\end{array}$ & $\begin{array}{l}\text { "Feldmannia } \\
\text { irregularis" }\end{array}$ & Praia de Fora & $\begin{array}{c}\text { Baía de } \\
\text { Guanabara, } \\
\text { RJ }\end{array}$ & 18/12/2012 & J. C. De-Paula. & $\begin{array}{l}22^{\circ} 56^{\prime} 43.4^{\prime \prime S} \\
43^{\circ} 09^{\prime} 19.3^{\prime \prime W}\end{array}$ & - & - \\
\hline $\begin{array}{c}\mathrm{MM} \\
161\end{array}$ & $\begin{array}{l}\text { "Feldmannia } \\
\text { irregularis" }\end{array}$ & Praia de Fora & $\begin{array}{c}\text { Baía de } \\
\text { Guanabara, } \\
\text { RJ }\end{array}$ & $18 / 12 / 2012$ & J. C. De-Paula. & $\begin{array}{l}22^{\circ} 56^{\prime} 43.4^{\prime \prime S} \\
43^{\circ} 09^{\prime} 19.3^{\prime \prime} \mathrm{W}\end{array}$ & - & - \\
\hline $\begin{array}{c}\mathrm{MM} \\
162\end{array}$ & $\begin{array}{l}\text { "Feldmannia } \\
\text { irregularis" }\end{array}$ & Praia de Fora & $\begin{array}{c}\text { Baía de } \\
\text { Guanabara, } \\
\text { RJ }\end{array}$ & $18 / 12 / 2012$ & J. C. De-Paula. & $\begin{array}{l}22^{\circ} 56^{\prime} 43.4^{\prime \prime S} \\
43^{\circ} 09^{\prime} 19.3^{\prime \prime} \mathrm{W}\end{array}$ & - & - \\
\hline $\begin{array}{c}\text { MM } \\
163\end{array}$ & $\begin{array}{l}\text { "Feldmannia } \\
\text { irregularis" }\end{array}$ & Praia de Fora & $\begin{array}{c}\text { Baía de } \\
\text { Guanabara, } \\
\text { RJ }\end{array}$ & $19 / 12 / 2012$ & J. C. De-Paula. & $\begin{array}{l}22^{\circ} 56^{\prime} 43.4^{\prime \prime S} \\
43^{\circ} 09^{\prime} 19.3^{\prime \prime W}\end{array}$ & - & - \\
\hline $\begin{array}{c}\mathrm{MM} \\
164\end{array}$ & $\begin{array}{l}\text { "Feldmannia } \\
\text { irregularis" }\end{array}$ & Praia de Fora & $\begin{array}{c}\text { Baía de } \\
\text { Guanabara, } \\
\text { RJ }\end{array}$ & 20/12/2012 & J. C. De-Paula. & $\begin{array}{l}22^{\circ} 56^{\prime} 43.4^{\prime \prime S} \\
43^{\circ} 09^{\prime} 19.3 " \mathrm{~W}\end{array}$ & - & - \\
\hline $\begin{array}{c}\mathrm{MM} \\
165\end{array}$ & $\begin{array}{c}\text { “Feldmannia” } \\
\text { mitchelliae }\end{array}$ & Praia de Fora & $\begin{array}{c}\text { Baía de } \\
\text { Guanabara, } \\
\text { RJ }\end{array}$ & $21 / 12 / 2012$ & J. C. De-Paula. & $\begin{array}{l}22^{\circ} 56^{\prime} 43.4^{\prime \prime S} \\
43^{\circ} 09^{\prime} 19.3^{\prime \prime} \mathrm{W}\end{array}$ & - & $\mathrm{X}$ \\
\hline $\begin{array}{c}\mathrm{MM} \\
166\end{array}$ & $\begin{array}{c}\text { "Feldmannia" } \\
\text { mitchelliae }\end{array}$ & Praia de Fora & $\begin{array}{c}\text { Baía de } \\
\text { Guanabara, } \\
\text { RJ }\end{array}$ & $22 / 12 / 2012$ & J. C. De-Paula. & $\begin{array}{l}22^{\circ} 56^{\prime} 43.4^{\prime \prime S} \\
43^{\circ} 09^{\prime} 19.3 " \mathrm{~W}\end{array}$ & - & - \\
\hline $\begin{array}{c}\mathrm{MM} \\
167\end{array}$ & $\begin{array}{c}\text { "Feldmannia" } \\
\text { mitchelliae }\end{array}$ & Praia de Fora & $\begin{array}{c}\text { Baía de } \\
\text { Guanabara, } \\
\text { RJ }\end{array}$ & 23/12/2012 & J. C. De-Paula. & $\begin{array}{c}22^{\circ} 56^{\prime} 43.4^{\prime \prime S} \\
43^{\circ} 09^{\prime} 19.3^{\prime \prime} \mathrm{W}\end{array}$ & - & - \\
\hline $\begin{array}{c}\mathrm{MM} \\
168\end{array}$ & $\begin{array}{c}\text { “Feldmannia" } \\
\text { mitchelliae }\end{array}$ & Praia de Fora & $\begin{array}{c}\text { Baía de } \\
\text { Guanabara, } \\
\text { RJ }\end{array}$ & $24 / 12 / 2012$ & J. C. De-Paula. & $\begin{array}{l}22^{\circ} 56^{\prime} 43.4^{\prime \prime S} \\
43^{\circ} 09^{\prime} 19.3 " \mathrm{~W}\end{array}$ & - & - \\
\hline $\begin{array}{c}\mathrm{MM} \\
169\end{array}$ & $\begin{array}{c}\text { "Feldmannia" } \\
\text { mitchelliae }\end{array}$ & Praia de Fora & $\begin{array}{c}\text { Baía de } \\
\text { Guanabara, } \\
\text { RJ }\end{array}$ & $25 / 12 / 2012$ & J. C. De-Paula. & $\begin{array}{l}22^{\circ} 56^{\prime} 43.4^{\prime \prime S} \\
43^{\circ} 09^{\prime} 19.3^{\prime \prime} \mathrm{W}\end{array}$ & - & - \\
\hline $\begin{array}{c}\mathrm{MM} \\
170\end{array}$ & $\begin{array}{c}\text { "Feldmannia" } \\
\text { mitchelliae }\end{array}$ & $\begin{array}{c}\text { Praia } \\
\text { Vermelha }\end{array}$ & Urca, RJ & 03/09/2012 & J. C. De-Paula. & $\begin{array}{l}22^{\circ} 57^{\prime} 15.2^{\prime \prime S} \\
43^{\circ} 09^{\prime} 50.5^{\prime \prime} \mathrm{W}\end{array}$ & - & - \\
\hline $\begin{array}{c}\mathrm{MM} \\
171\end{array}$ & $\begin{array}{c}\text { Feldmannia } \\
\text { mitchelliae }\end{array}$ & $\begin{array}{c}\text { Praia } \\
\text { Vermelha }\end{array}$ & Urca, RJ & 04/09/2012 & J. C. De-Paula. & $\begin{array}{l}22^{\circ} 57^{\prime} 15.2^{\prime \prime S} \\
43^{\circ} 09^{\prime} 50.5^{\prime \prime} \mathrm{W}\end{array}$ & - & - \\
\hline $\begin{array}{c}\mathrm{MM} \\
172\end{array}$ & Ectocarpales & $\begin{array}{l}\text { Praia dos } \\
\text { Emissários }\end{array}$ & $\begin{array}{c}\text { Camaçari, } \\
\text { BA }\end{array}$ & $14 / 10 / 2012$ & J. C. De-Paula. & $\begin{array}{c}12^{\circ} 44^{\prime 28.7 " S} \\
38^{\circ} 09^{\prime} 02.5^{\prime \prime W}\end{array}$ & - & - \\
\hline
\end{tabular}


Tabela 2. Continuação

\begin{tabular}{|c|c|c|c|c|c|c|c|c|}
\hline $\begin{array}{l}\text { Código } \\
\text { de } \\
\text { Coleta }\end{array}$ & Amostra & $\begin{array}{l}\text { Local de } \\
\text { Coleta }\end{array}$ & Cidade & Data & $\begin{array}{c}\text { Coletor } \\
\text { (s) }\end{array}$ & $\begin{array}{l}\text { Latitude / } \\
\text { Longitude }\end{array}$ & $\begin{array}{c}\text { COI- } \\
5 P\end{array}$ & $r b c \mathbf{L}$ \\
\hline $\begin{array}{c}\mathrm{MM} \\
173\end{array}$ & Ectocarpales & $\begin{array}{l}\text { Prainha de } \\
\text { Piratininga }\end{array}$ & Niterói, RJ & $17 / 04 / 2014$ & J. C. De-Paula. & $\begin{array}{l}22^{\circ} 57^{\prime} 16.8^{\prime \prime S} \\
43^{\circ} 05^{\prime} 53.6^{\prime \prime} \mathrm{W}\end{array}$ & - & - \\
\hline $\begin{array}{c}\mathrm{MM} \\
174\end{array}$ & Ectocarpales & $\begin{array}{l}\text { Prainha de } \\
\text { Piratininga }\end{array}$ & Niterói, RJ & $17 / 04 / 2014$ & J. C. De-Paula. & $\begin{array}{c}22^{\circ} 57^{\prime} 16.8 " \mathrm{~S} \\
43^{\circ} 05^{\prime} 53.6 " \mathrm{~W}\end{array}$ & - & - \\
\hline $\begin{array}{c}\mathrm{MM} \\
175\end{array}$ & Ectocarpales & $\begin{array}{c}\text { Praia } \\
\text { Vermelha }\end{array}$ & Urca, RJ & $11 / 08 / 2014$ & J. C. De-Paula. & $\begin{array}{l}22^{\circ} 57 ' 23.4^{\prime \prime S} \\
43^{\circ} 09^{\prime} 51.1^{\prime \prime W}\end{array}$ & - & - \\
\hline $\begin{array}{c}\mathrm{MM} \\
176\end{array}$ & Ectocarpales & $\begin{array}{c}\text { Praia } \\
\text { Vermelha }\end{array}$ & Urca, RJ & $12 / 08 / 2014$ & J. C. De-Paula. & $\begin{array}{l}22^{\circ} 57 ' 23.4^{\prime \prime S} \\
43^{\circ} 09^{\prime} 51.1^{\prime \prime W}\end{array}$ & - & - \\
\hline $\begin{array}{c}\text { MM } \\
177\end{array}$ & Ectocarpales & Ponta Grossa & $\begin{array}{c}\text { Ilha } \\
\text { Grande, RJ }\end{array}$ & - & J. C. De-Paula. & $\begin{array}{c}23^{\circ} 07^{\prime} 10.6^{\prime} \mathrm{S} \\
44^{\circ} 07^{\prime} 36.8^{\prime \prime} \mathrm{W}\end{array}$ & - & - \\
\hline $\begin{array}{c}\mathrm{MM} \\
178\end{array}$ & $\begin{array}{c}\text { Asteronema } \\
\text { breviarticulatu } \\
m\end{array}$ & $\begin{array}{l}\text { Ilha das } \\
\text { Palmas }\end{array}$ & $\begin{array}{l}\text { Ubatuba, } \\
\text { SP }\end{array}$ & $29 / 08 / 2011$ & $\begin{array}{l}\text { A. Medeiros; C. } \\
\text { Iha e M.C. } \\
\text { Oliveira. }\end{array}$ & $\begin{array}{c}24^{\circ} 00^{\prime} 30.3^{\prime \prime S} \\
46^{\circ} 19^{\prime} 25.6^{\prime \prime W}\end{array}$ & $\mathrm{CH} 2 \mathrm{O}$ & $\mathrm{CH} 2 \mathrm{O}$ \\
\hline $\begin{array}{c}\text { MM } \\
179\end{array}$ & Ectocarpales & Ilhote de Ubu & $\begin{array}{l}\text { Anchieta, } \\
\text { ES }\end{array}$ & $12 / 11 / 2012$ & $\begin{array}{l}\text { S. M. P. B. } \\
\text { Guimarães }\end{array}$ & $\begin{array}{l}20^{\circ} 48,367 \text { 's; } \\
40^{\circ} 36,014^{\prime \prime} \mathrm{W}\end{array}$ & - & - \\
\hline $\begin{array}{c}\text { MM } \\
180\end{array}$ & $\begin{array}{c}\text { Ectocarpales } \\
\text { sobre corda (b) }\end{array}$ & Ilhote de Ubu & $\begin{array}{c}\text { Anchieta, } \\
\text { ES }\end{array}$ & $12 / 11 / 2012$ & $\begin{array}{l}\text { S. M. P. B. } \\
\text { Guimarães }\end{array}$ & $\begin{array}{l}20^{\circ} 48,367^{\prime} \mathrm{S} ; \\
40^{\circ} 36,014^{\prime \prime} \mathrm{W}\end{array}$ & - & - \\
\hline $\begin{array}{c}\text { MM } \\
181\end{array}$ & Ectocarpales & Praia da Cruz & $\begin{array}{l}\text { Marataízes, } \\
\text { ES }\end{array}$ & $07 / 05 / 2012$ & M. C. Oliveira. & $\begin{array}{c}21^{\circ} 02,116^{\prime} \mathrm{S} \\
40^{\circ} 48,812^{\prime \prime} \mathrm{W}\end{array}$ & - & - \\
\hline $\begin{array}{c}\mathrm{MM} \\
182\end{array}$ & Ectocarpales & $\begin{array}{c}\text { Praia dos } \\
\text { Namorados }\end{array}$ & $\begin{array}{l}\text { Guarapari, } \\
\text { ES }\end{array}$ & 08/05/2012 & M. C. Oliveira. & $\begin{array}{c}20^{\circ} 40^{\prime} 18.5^{\prime \prime S} \\
40^{\circ} 29^{\prime} 41.9^{\prime \prime W}\end{array}$ & - & - \\
\hline $\begin{array}{c}\mathrm{MM} \\
183\end{array}$ & Ectocarpales & $\begin{array}{c}\text { Praia dos } \\
\text { Namorados }\end{array}$ & $\begin{array}{l}\text { Guarapari, } \\
\text { ES }\end{array}$ & $08 / 05 / 2012$ & M. C. Oliveira. & $\begin{array}{l}20^{\circ} 40^{\prime} 18.5^{\prime \prime S} \\
40^{\circ} 29^{\prime} 41.9^{\prime \prime} \mathrm{W}\end{array}$ & - & - \\
\hline $\begin{array}{c}\mathrm{MM} \\
184\end{array}$ & Ectocarpales & $\begin{array}{c}\text { Praia dos } \\
\text { Namorados }\end{array}$ & $\begin{array}{l}\text { Guarapari, } \\
\text { ES }\end{array}$ & 08/05/2012 & M. C. Oliveira. & $\begin{array}{c}20^{\circ} 40^{\prime} 18.5^{\prime \prime S} \\
40^{\circ} 29^{\prime} 41.9^{\prime \prime} \mathrm{W}\end{array}$ & - & - \\
\hline $\begin{array}{c}\text { MM } \\
185\end{array}$ & Ectocarpales & $\begin{array}{c}\text { Praia dos } \\
\text { Namorados }\end{array}$ & $\begin{array}{c}\text { Guarapari, } \\
\text { ES }\end{array}$ & 08/05/2012 & M. C. Oliveira. & $\begin{array}{c}20^{\circ} 40^{\prime} 18.5^{\prime} \mathrm{S} \\
40^{\circ} 29^{\prime} 41.9^{\prime \prime} \mathrm{W}\end{array}$ & - & - \\
\hline $\begin{array}{c}\text { MM } \\
186\end{array}$ & $\begin{array}{c}\text { “Feldmannia” } \\
\text { mitchelliae }\end{array}$ & $\begin{array}{l}\text { Saco do } \\
\text { Mamanguá }\end{array}$ & Paraty, RJ & $16 / 10 / 2013$ & M. C. Oliveira. & $\begin{array}{l}23^{\circ} 15^{\prime} 47.3^{\prime \prime S} \\
44^{\circ} 38^{\prime} 08.2^{\prime \prime} \mathrm{W}\end{array}$ & $\mathrm{X}$ & $\mathrm{X}$ \\
\hline $\begin{array}{c}\mathrm{MM} \\
187\end{array}$ & $\begin{array}{c}\text { “Feldmannia” } \\
\text { mitchelliae }\end{array}$ & $\begin{array}{c}\text { Praia de } \\
\text { Toque-Toque } \\
\text { Pequeno }\end{array}$ & $\begin{array}{c}\text { São } \\
\text { Sebastião }\end{array}$ & $29 / 01 / 2015$ & $\begin{array}{l}\text { M.Mungioli; } \\
\text { V.Cassano. }\end{array}$ & $\begin{array}{c}23^{\circ} 49^{\prime} 25.1^{\prime \prime S} \\
45^{\circ} 32^{\prime} 00.8^{\prime \prime} \mathrm{W}\end{array}$ & - & - \\
\hline $\begin{array}{c}\mathrm{MM} \\
188\end{array}$ & $\begin{array}{c}\text { “Feldmannia” } \\
\text { irregularis }\end{array}$ & $\begin{array}{c}\text { Praia de } \\
\text { Toque-Toque } \\
\text { Pequeno }\end{array}$ & $\begin{array}{c}\text { São } \\
\text { Sebastião }\end{array}$ & $30 / 01 / 2015$ & $\begin{array}{l}\text { M.Mungioli; } \\
\text { V.Cassano. }\end{array}$ & $\begin{array}{c}23^{\circ} 49^{\prime} 25.1^{\prime \prime S} \\
45^{\circ} 32^{\prime} 00.8^{\prime \prime W}\end{array}$ & - & - \\
\hline $\begin{array}{c}\mathrm{MM} \\
189\end{array}$ & $\begin{array}{l}\text { “Asteronema” } \\
\text { breviarticulatum }\end{array}$ & $\begin{array}{c}\text { Praia } \\
\text { Desertinha - } \\
\text { Reserva } \\
\text { Juréia-Itatins }\end{array}$ & Peruíbe, SP & $04 / 05 / 2015$ & $\begin{array}{l}\text { M.Mungioli e C. } \\
\text { A. A. Azevedo. }\end{array}$ & $\begin{array}{c}24^{\circ} 25^{\prime} 49.28^{\prime \prime} \\
\mathrm{S} ; \\
47^{\circ} 02^{\prime} 46.14^{\prime \prime} \\
\mathrm{W}\end{array}$ & - & $\mathrm{X}$ \\
\hline $\begin{array}{c}\text { MM } \\
190\end{array}$ & $\begin{array}{l}\text { “Asteronema” } \\
\text { breviarticulatum }\end{array}$ & $\begin{array}{c}\text { Praia } \\
\text { Desertinha - } \\
\text { Reserva } \\
\text { Juréia-Itatins }\end{array}$ & Peruíbe, SP & $04 / 05 / 2015$ & $\begin{array}{l}\text { M.Mungioli e C. } \\
\text { A. A. Azevedo. }\end{array}$ & $\begin{array}{c}24^{\circ} 25^{\prime} 49.28^{\prime \prime} \\
\mathrm{S} ; \\
47^{\circ} 02^{\prime} 46.14^{\prime \prime} \\
\mathrm{W}\end{array}$ & - & - \\
\hline $\begin{array}{c}\mathrm{MM} \\
191\end{array}$ & $\begin{array}{l}\text { “Asteronema”br } \\
\text { eviarticulatum }\end{array}$ & $\begin{array}{c}\text { Praia } \\
\text { Desertinha - } \\
\text { Reserva } \\
\text { Juréia-Itatins }\end{array}$ & Peruíbe, SP & 04/05/2015 & $\begin{array}{l}\text { M.Mungioli e C. } \\
\text { A. A. Azevedo. }\end{array}$ & $\begin{array}{c}24^{\circ} 25^{\prime} 49.28^{\prime \prime} \\
\mathrm{S} ; \\
47^{\circ} 02^{\prime} 46.14^{\prime \prime} \\
\mathrm{W}\end{array}$ & - & - \\
\hline $\begin{array}{c}\text { MM } \\
192\end{array}$ & $\begin{array}{l}\text { “Asteronema”br } \\
\text { eviarticulatum }\end{array}$ & $\begin{array}{c}\text { Praia } \\
\text { Desertinha - } \\
\text { Reserva } \\
\text { Juréia-Itatins }\end{array}$ & Peruíbe, SP & 04/05/2015 & $\begin{array}{l}\text { M.Mungioli e C. } \\
\text { A. A. Azevedo. }\end{array}$ & $\begin{array}{c}24^{\circ} 25^{\prime} 49.28^{\prime \prime} \\
\mathrm{S} ; \\
47^{\circ} 02^{\prime} 46.14^{\prime \prime} \\
\mathrm{W}\end{array}$ & - & - \\
\hline
\end{tabular}


Tabela 2. Continuação

\begin{tabular}{|c|c|c|c|c|c|c|c|c|}
\hline $\begin{array}{l}\text { Código } \\
\text { de } \\
\text { Coleta }\end{array}$ & Amostra & $\begin{array}{l}\text { Local de } \\
\text { Coleta }\end{array}$ & Cidade & Data & $\begin{array}{c}\text { Coletor } \\
\text { (s) }\end{array}$ & $\begin{array}{l}\text { Latitude / } \\
\text { Longitude }\end{array}$ & $\begin{array}{l}\text { COI- } \\
5 P\end{array}$ & $r b c \mathbf{L}$ \\
\hline $\begin{array}{c}\mathrm{MM} \\
193\end{array}$ & $\begin{array}{l}\text { “Asteronema”br } \\
\text { eviarticulatum }\end{array}$ & $\begin{array}{c}\text { Praia } \\
\text { Desertinha - } \\
\text { Reserva } \\
\text { Juréia-Itatins }\end{array}$ & Peruíbe, SP & $04 / 05 / 2015$ & $\begin{array}{l}\text { M.Mungioli e C. } \\
\text { A. A. Azevedo. }\end{array}$ & $\begin{array}{c}24^{\circ} 25^{\prime} 49.28^{\prime \prime} \\
\mathrm{S} ; \\
47^{\circ} 02^{\prime} 46.14^{\prime \prime} \\
\mathrm{W}\end{array}$ & - & - \\
\hline $\begin{array}{c}\mathrm{MM} \\
194\end{array}$ & $\begin{array}{l}\text { “Asteronema”br } \\
\text { eviarticulatum }\end{array}$ & $\begin{array}{c}\text { Praia } \\
\text { Desertinha - } \\
\text { Reserva } \\
\text { Juréia-Itatins }\end{array}$ & Peruíbe, SP & 04/05/2015 & $\begin{array}{l}\text { M.Mungioli e C. } \\
\text { A. A. Azevedo. }\end{array}$ & $\begin{array}{c}24^{\circ} 25^{\prime} 49.28^{\prime \prime} \\
\mathrm{S} ; \\
47^{\circ} 02^{\prime} 46.14^{\prime \prime} \\
\mathrm{W}\end{array}$ & - & - \\
\hline $\begin{array}{c}\mathrm{MM} \\
195\end{array}$ & $\begin{array}{l}\text { "Asteronema" } \\
\text { breviarticulatum }\end{array}$ & $\begin{array}{c}\text { Praia } \\
\text { Desertinha - } \\
\text { Reserva } \\
\text { Juréia-Itatins }\end{array}$ & Peruíbe, SP & $04 / 05 / 2015$ & $\begin{array}{l}\text { M.Mungioli e C. } \\
\text { A. A. Azevedo. }\end{array}$ & $\begin{array}{c}24^{\circ} 25^{\prime} 49.28^{\prime \prime} \\
\mathrm{S} ; \\
47^{\circ} 02^{\prime} 46.14^{\prime \prime} \\
\mathrm{W}\end{array}$ & - & $\mathrm{X}$ \\
\hline $\begin{array}{c}\mathrm{MM} \\
196\end{array}$ & $\begin{array}{c}\text { “Feldmannia”i } \\
\text { rregularis }\end{array}$ & $\begin{array}{c}\text { Praia } \\
\text { Desertinha - } \\
\text { Reserva } \\
\text { Juréia-Itatins }\end{array}$ & Peruíbe, SP & 04/05/2015 & $\begin{array}{l}\text { M.Mungioli e C. } \\
\text { A. A. Azevedo. }\end{array}$ & $\begin{array}{c}24^{\circ} 25^{\prime} 49.28^{\prime \prime} \\
\mathrm{S} ; \\
47^{\circ} 02^{\prime} 46.14^{\prime \prime} \\
\mathrm{W}\end{array}$ & - & $\mathrm{X}$ \\
\hline $\begin{array}{c}\mathrm{MM} \\
197\end{array}$ & $\begin{array}{c}\text { “Feldmannia"i } \\
\text { rregularis }\end{array}$ & $\begin{array}{c}\text { Praia } \\
\text { Desertinha - } \\
\text { Reserva } \\
\text { Juréia-Itatins }\end{array}$ & Peruíbe, SP & 04/05/2015 & $\begin{array}{l}\text { M.Mungioli e C. } \\
\text { A. A. Azevedo. }\end{array}$ & $\begin{array}{c}24^{\circ} 25^{\prime} 49.28^{\prime \prime} \\
\mathrm{S} ; \\
47^{\circ} 02^{\prime} 46.14^{\prime \prime} \\
\mathrm{W}\end{array}$ & - & $\mathrm{X}$ \\
\hline $\begin{array}{c}\mathrm{MM} \\
198\end{array}$ & $\begin{array}{c}\text { “Feldmannia” } \\
\text { irregularis }\end{array}$ & $\begin{array}{c}\text { Praia } \\
\text { Desertinha - } \\
\text { Reserva } \\
\text { Juréia-Itatins }\end{array}$ & Peruíbe, SP & 04/05/2015 & $\begin{array}{l}\text { M.Mungioli e C. } \\
\text { A. A. Azevedo. }\end{array}$ & $\begin{array}{c}24^{\circ} 25^{\prime} 49.28^{\prime \prime} \\
\mathrm{S} ; \\
47^{\circ} 02^{\prime} 46.14^{\prime \prime} \\
\mathrm{W}\end{array}$ & $\mathrm{X}$ & - \\
\hline $\begin{array}{c}\mathrm{MM} \\
199\end{array}$ & $\begin{array}{l}\text { “Feldmannia”i } \\
\text { rregularis }\end{array}$ & $\begin{array}{c}\text { Praia } \\
\text { Desertinha - } \\
\text { Reserva } \\
\text { Juréia-Itatins }\end{array}$ & Peruíbe, SP & 04/05/2015 & $\begin{array}{l}\text { M.Mungioli e C. } \\
\text { A. A. Azevedo. }\end{array}$ & $\begin{array}{c}24^{\circ} 25^{\prime} 49.28^{\prime \prime} \\
\mathrm{S} ; \\
47^{\circ} 02^{\prime} 46.14^{\prime \prime} \\
\mathrm{W}\end{array}$ & - & $\mathrm{X}$ \\
\hline $\begin{array}{c}\mathrm{MM} \\
200\end{array}$ & $\begin{array}{l}\text { "Asteronema" } \\
\text { breviarticulatum }\end{array}$ & $\begin{array}{c}\text { Praia de } \\
\text { Caramboré - } \\
\text { Reserva } \\
\text { Juréia-Itatins }\end{array}$ & Peruíbe, SP & 04/05/2015 & $\begin{array}{l}\text { M.Mungioli e C. } \\
\text { A. A. Azevedo. }\end{array}$ & $\begin{array}{l}24^{\circ} 25^{\prime} 56.9^{\prime \prime S} \\
47^{\circ} 03^{\prime} 11.2^{\prime \prime} \mathrm{W}\end{array}$ & - & - \\
\hline $\begin{array}{c}\text { MM } \\
201\end{array}$ & $\begin{array}{l}\text { "Asteronema" } \\
\text { breviarticulatum }\end{array}$ & $\begin{array}{c}\text { Praia de } \\
\text { Caramboré - } \\
\text { Reserva } \\
\text { Juréia-Itatins }\end{array}$ & Peruíbe, SP & 04/05/2015 & $\begin{array}{l}\text { M.Mungioli e C. } \\
\text { A. A. Azevedo. }\end{array}$ & $\begin{array}{l}24^{\circ} 25^{\prime} 56.9^{\prime \prime} \mathrm{S} \\
47^{\circ} 03^{\prime} 11.2^{\prime \prime} \mathrm{W}\end{array}$ & - & - \\
\hline $\begin{array}{c}\text { MM } \\
202\end{array}$ & $\begin{array}{l}\text { “Asteronema” } \\
\text { breviarticulatum }\end{array}$ & $\begin{array}{c}\text { Praia de } \\
\text { Caramboré - } \\
\text { Reserva } \\
\text { Juréia-Itatins }\end{array}$ & Peruíbe, SP & $04 / 05 / 2015$ & $\begin{array}{l}\text { M.Mungioli e C. } \\
\text { A. A. Azevedo. }\end{array}$ & $\begin{array}{l}24^{\circ} 25^{\prime} 56.9^{\prime \prime} \mathrm{S} \\
47^{\circ} 03^{\prime} 11.2^{\prime \prime} \mathrm{W}\end{array}$ & - & - \\
\hline $\begin{array}{c}\mathrm{MM} \\
203\end{array}$ & $\begin{array}{l}\text { Bachelotia } \\
\text { antillarum }\end{array}$ & $\begin{array}{c}\text { Praia de } \\
\text { Caramboré - } \\
\text { Reserva } \\
\text { Juréia-Itatins }\end{array}$ & Peruíbe, SP & 04/05/2015 & $\begin{array}{l}\text { M.Mungioli e C. } \\
\text { A. A. Azevedo. }\end{array}$ & $\begin{array}{l}24^{\circ} 25^{\prime} 56.9^{\prime \prime} \mathrm{S} \\
47^{\circ} 03^{\prime} 11.2^{\prime \prime} \mathrm{W}\end{array}$ & - & $\mathrm{X}$ \\
\hline $\begin{array}{c}\text { MM } \\
204\end{array}$ & $\begin{array}{l}\text { Bachelotia } \\
\text { antillarum }\end{array}$ & $\begin{array}{c}\text { Praia de } \\
\text { Caramboré - } \\
\text { Reserva } \\
\text { Juréia-Itatins }\end{array}$ & Peruíbe, SP & 04/05/2015 & $\begin{array}{l}\text { M.Mungioli e C. } \\
\text { A. A. Azevedo. }\end{array}$ & $\begin{array}{l}24^{\circ} 25^{\prime} 56.9^{\prime \prime S} \\
47^{\circ} 03^{\prime} 11.2^{\prime \prime} \mathrm{W}\end{array}$ & - & - \\
\hline $\begin{array}{c}\mathrm{MM} \\
205\end{array}$ & $\begin{array}{l}\text { Bachelotia } \\
\text { antillarum }\end{array}$ & $\begin{array}{c}\text { Praia de } \\
\text { Caramboré - } \\
\text { Reserva } \\
\text { Juréia-Itatins }\end{array}$ & Peruíbe, SP & $04 / 05 / 2015$ & $\begin{array}{l}\text { M.Mungioli e C. } \\
\text { A. A. Azevedo. }\end{array}$ & $\begin{array}{l}24^{\circ} 25^{\prime} 56.9^{\prime \prime S} \\
47^{\circ} 03^{\prime} 11.2^{\prime \prime} \mathrm{W}\end{array}$ & 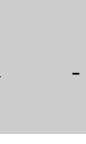 & - \\
\hline $\begin{array}{c}\text { MM } \\
206\end{array}$ & $\begin{array}{l}\text { Bachelotia } \\
\text { antillarum }\end{array}$ & $\begin{array}{c}\text { Praia de } \\
\text { Caramboré - } \\
\text { Reserva } \\
\text { Juréia-Itatins }\end{array}$ & Peruíbe, SP & 04/05/2015 & $\begin{array}{l}\text { M.Mungioli e C. } \\
\text { A. A. Azevedo. }\end{array}$ & $\begin{array}{l}24^{\circ} 25^{\prime} 56.9^{\prime \prime S} \\
47^{\circ} 03^{\prime} 11.2^{\prime \prime} \mathrm{W}\end{array}$ & - & $\mathrm{X}$ \\
\hline $\begin{array}{c}\mathrm{MM} \\
207\end{array}$ & $\begin{array}{l}\text { "Asteronema" } \\
\text { breviarticulatum }\end{array}$ & $\begin{array}{c}\text { Praia de } \\
\text { Caramboré - } \\
\text { Reserva } \\
\text { Juréia-Itatins }\end{array}$ & Peruíbe, SP & 04/05/2015 & $\begin{array}{l}\text { M.Mungioli e C. } \\
\text { A. A. Azevedo. }\end{array}$ & $\begin{array}{l}24^{\circ} 25^{\prime} 56.9^{\prime \prime} \mathrm{S} \\
47^{\circ} 03^{\prime} 11.2^{\prime \prime} \mathrm{W}\end{array}$ & 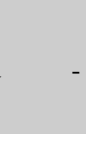 & - \\
\hline
\end{tabular}


Tabela 2. Continuação

\begin{tabular}{|c|c|c|c|c|c|c|c|c|}
\hline $\begin{array}{l}\text { Código } \\
\text { de } \\
\text { Coleta }\end{array}$ & Amostra & $\begin{array}{l}\text { Local de } \\
\text { Coleta }\end{array}$ & Cidade & Data & $\begin{array}{l}\text { Coletor } \\
\text { (s) }\end{array}$ & $\begin{array}{l}\text { Latitude / } \\
\text { Longitude }\end{array}$ & $\begin{array}{l}\text { COI- } \\
5 P\end{array}$ & $r b c \mathbf{L}$ \\
\hline $\begin{array}{c}\mathrm{MM} \\
208\end{array}$ & $\begin{array}{l}\text { "Asteronema"br } \\
\text { eviarticulatum }\end{array}$ & $\begin{array}{l}\text { Praia de } \\
\text { Guaraú }\end{array}$ & Peruíbe, SP & 05/05/2015 & $\begin{array}{l}\text { M.Mungioli e C. } \\
\text { A. A. Azevedo. }\end{array}$ & $\begin{array}{c}24^{\circ} 22^{\prime} 01.98^{\prime \prime} \\
\mathrm{S} ; \\
47^{\circ} 00^{\prime} 32.33^{\prime \prime} \\
\text { W }\end{array}$ & 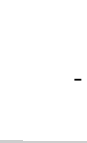 & - \\
\hline $\begin{array}{c}\text { MM } \\
209\end{array}$ & $\begin{array}{l}\text { “Asteronema"br } \\
\text { eviarticulatum }\end{array}$ & $\begin{array}{l}\text { Praia de } \\
\text { Guaraú }\end{array}$ & Peruíbe, SP & 05/05/2015 & $\begin{array}{l}\text { M.Mungioli e C. } \\
\text { A. A. Azevedo. }\end{array}$ & $\begin{array}{c}24^{\circ} 22^{\prime} 01.98^{\prime \prime} \\
\mathrm{S} ; \\
47^{\circ} 00^{\prime} 32.33^{\prime \prime} \\
\text { W }\end{array}$ & 更 & - \\
\hline $\begin{array}{c}\mathrm{MM} \\
210\end{array}$ & $\begin{array}{l}\text { "Asteronema"br } \\
\text { eviarticulatum }\end{array}$ & $\begin{array}{l}\text { Praia de } \\
\text { Guaraú }\end{array}$ & Peruíbe, SP & 05/05/2015 & $\begin{array}{l}\text { M.Mungioli e C. } \\
\text { A. A. Azevedo. }\end{array}$ & $\begin{array}{c}24^{\circ} 22^{\prime} 01.98^{\prime \prime} \\
\mathrm{S} ; \\
47^{\circ} 00^{\prime} 32.33^{\prime \prime} \\
\text { W }\end{array}$ & 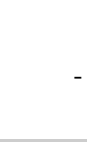 & - \\
\hline $\begin{array}{c}\mathrm{MM} \\
211\end{array}$ & $\begin{array}{l}\text { "Asteronema"br } \\
\text { eviarticulatum }\end{array}$ & $\begin{array}{l}\text { Praia de } \\
\text { Guaraú }\end{array}$ & Peruíbe, SP & 05/05/2015 & $\begin{array}{l}\text { M.Mungioli e C. } \\
\text { A. A. Azevedo. }\end{array}$ & $\begin{array}{c}24^{\circ} 222^{\prime} 01.98^{\prime \prime} \\
\mathrm{S} ; \\
47^{\circ} 00^{\prime} 32.33^{\prime \prime} \\
\text { W }\end{array}$ & 更 & - \\
\hline $\begin{array}{c}\mathrm{MM} \\
212\end{array}$ & $\begin{array}{l}\text { “Asteronema"br } \\
\text { eviarticulatum }\end{array}$ & $\begin{array}{l}\text { Praia de } \\
\text { Guaraú }\end{array}$ & Peruíbe, SP & 05/05/2015 & $\begin{array}{l}\text { M.Mungioli e C. } \\
\text { A. A. Azevedo. }\end{array}$ & $\begin{array}{l}24^{\circ} 22^{\prime} 01.98^{\prime \prime S} \\
47^{\circ} 00 ' 32.33^{\prime \prime} \mathrm{W}\end{array}$ & ; & - \\
\hline $\begin{array}{c}\mathrm{MM} \\
213\end{array}$ & $\begin{array}{l}\text { “Asteronema"br } \\
\text { eviarticulatum }\end{array}$ & $\begin{array}{l}\text { Praia de } \\
\text { Guaraú }\end{array}$ & Peruíbe, SP & 05/05/2015 & $\begin{array}{l}\text { M.Mungioli e C. } \\
\text { A. A. Azevedo. }\end{array}$ & $\begin{array}{c}24^{\circ} 22 ' 01.98^{\prime \prime} \\
\mathrm{S} ; \\
47^{\circ} 00^{\prime} 32.33^{\prime \prime} \\
\text { W }\end{array}$ & 更 & - \\
\hline $\begin{array}{c}\mathrm{MM} \\
214\end{array}$ & $\begin{array}{c}\text { "Feldmannia" } \\
\text { mitchelliae }\end{array}$ & $\begin{array}{l}\text { Praia de } \\
\text { Guaraú }\end{array}$ & Peruíbe, SP & 05/05/2015 & $\begin{array}{l}\text { M.Mungioli e C. } \\
\text { A. A. Azevedo. }\end{array}$ & $\begin{array}{c}24^{\circ} 22 ' 01.98^{\prime \prime} \\
\text { S; } \\
47^{\circ} 00^{\prime} 32.33^{\prime \prime} \\
\text { W }\end{array}$ & 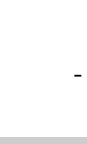 & $\mathrm{X}$ \\
\hline $\begin{array}{c}\mathrm{MM} \\
215\end{array}$ & $\begin{array}{c}\text { "Feldmannia" } \\
\text { mitchelliae }\end{array}$ & $\begin{array}{l}\text { Praia de } \\
\text { Guaraú }\end{array}$ & Peruíbe, SP & 05/05/2015 & $\begin{array}{l}\text { M.Mungioli e C. } \\
\text { A. A. Azevedo. }\end{array}$ & $\begin{array}{c}24^{\circ} 22 ' 01.98^{\prime \prime} \\
\mathrm{S} ; \\
47^{\circ} 00^{\prime} 32.33^{\prime \prime} \\
\text { W }\end{array}$ & 更 & $\mathrm{X}$ \\
\hline $\begin{array}{c}\mathrm{MM} \\
216\end{array}$ & $\begin{array}{c}\text { "Feldmannia" } \\
\text { mitchelliae }\end{array}$ & $\begin{array}{l}\text { Praia de } \\
\text { Guaraú }\end{array}$ & Peruíbe, SP & 05/05/2015 & $\begin{array}{l}\text { M.Mungioli e C. } \\
\text { A. A. Azevedo. }\end{array}$ & $\begin{array}{c}24^{\circ} 22 ' 01.98 " \\
\text { S; } \\
47^{\circ} 00^{\prime} 32.33^{\prime \prime} \\
\text { W }\end{array}$ & 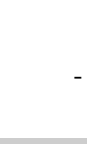 & - \\
\hline $\begin{array}{c}\mathrm{MM} \\
217\end{array}$ & $\begin{array}{c}\text { “Feldmannia" } \\
\text { mitchelliae }\end{array}$ & $\begin{array}{l}\text { Praia de } \\
\text { Guaraú }\end{array}$ & Peruíbe, SP & 05/05/2015 & $\begin{array}{l}\text { M.Mungioli e C. } \\
\text { A. A. Azevedo. }\end{array}$ & $\begin{array}{c}24^{\circ} 22^{\prime} 01.98^{\prime \prime} \\
\mathrm{S} ; \\
47^{\circ} 00^{\prime} 32.33^{\prime \prime} \\
\text { W }\end{array}$ & 更 & - \\
\hline $\begin{array}{c}\mathrm{MM} \\
218\end{array}$ & $\begin{array}{l}\text { "Feldmannia" } \\
\text { mitchelliae }\end{array}$ & $\begin{array}{l}\text { Praia de } \\
\text { Guaraú }\end{array}$ & Peruíbe, SP & 05/05/2015 & $\begin{array}{l}\text { M.Mungioli e C. } \\
\text { A. A. Azevedo. }\end{array}$ & $\begin{array}{c}24^{\circ} 222^{\prime} 01.98 " \\
\text { S; } \\
47^{\circ} 00^{\prime} 32.33^{\prime \prime} \\
\text { W }\end{array}$ & 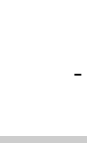 & - \\
\hline $\begin{array}{c}\text { MM } \\
219\end{array}$ & $\begin{array}{l}\text { Bachelotia } \\
\text { antillarum }\end{array}$ & Camburi & Vitória, ES & $12 / 03 / 2012$ & $\begin{array}{l}\text { S. M. P. B. } \\
\text { Guimarães }\end{array}$ & $\begin{array}{l}20^{\circ} 16^{\prime} 25.6^{\prime \prime S} \\
40^{\circ} 16^{\prime} 40.2^{\prime \prime} \mathrm{W}\end{array}$ & $\mathrm{X}$ & - \\
\hline $\begin{array}{c}\text { MM } \\
220\end{array}$ & $\begin{array}{l}\text { “Asteronema” } \\
\text { breviarticulatum }\end{array}$ & Camburi & Vitória, ES & 00/00/2012 & $\begin{array}{l}\text { S. M. P. B. } \\
\text { Guimarães }\end{array}$ & $\begin{array}{l}20^{\circ} 16^{\prime} 25.6^{\prime \prime S} \\
40^{\circ} 16^{\prime} 40.2^{\prime \prime} \mathrm{W}\end{array}$ & 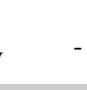 & - \\
\hline $\begin{array}{c}\text { MM } \\
221\end{array}$ & Ectocarpales & $\begin{array}{l}\text { Curva da } \\
\text { Jurema }\end{array}$ & Vitória, ES & 00/00/2012 & $\begin{array}{l}\text { S. M. P. B. } \\
\text { Guimarães }\end{array}$ & $\begin{array}{l}20^{\circ} 18^{\prime} 35.1^{\prime \prime S} \\
40^{\circ} 17^{\prime} 07.4^{\prime \prime} \mathrm{W}\end{array}$ & 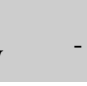 & - \\
\hline $\begin{array}{c}\text { MM } \\
222\end{array}$ & Ectocarpales & $\begin{array}{l}\text { Curva da } \\
\text { Jurema }\end{array}$ & Vitória, ES & 00/00/2012 & $\begin{array}{l}\text { S. M. P. B. } \\
\text { Guimarães }\end{array}$ & $\begin{array}{l}20^{\circ} 18^{\prime} 35.1 " \mathrm{~S} \\
40^{\circ} 17^{\prime} 07.4^{\prime \prime} \mathrm{W}\end{array}$ & 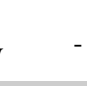 & - \\
\hline $\begin{array}{c}\text { MM } \\
223\end{array}$ & $\begin{array}{l}\text { Bachelotia } \\
\text { antillarum }\end{array}$ & Castanheiras & Vitória, ES & 00/00/2012 & $\begin{array}{l}\text { S. M. P. B. } \\
\text { Guimarães }\end{array}$ & $\begin{array}{l}20^{\circ} 40^{\prime} 28.9^{\prime \prime S} \\
40^{\circ} 29^{\prime} 48.9^{\prime \prime} \mathrm{W}\end{array}$ & 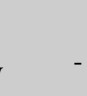 & $\mathrm{X}$ \\
\hline
\end{tabular}


Tabela 2. Continuação

\begin{tabular}{|c|c|c|c|c|c|c|c|c|}
\hline $\begin{array}{l}\text { Código } \\
\text { de } \\
\text { Coleta }\end{array}$ & Amostra & $\begin{array}{l}\text { Local de } \\
\text { Coleta }\end{array}$ & Cidade & Data & $\begin{array}{c}\text { Coletor } \\
\text { (s) }\end{array}$ & $\begin{array}{l}\text { Latitude / } \\
\text { Longitude }\end{array}$ & $\begin{array}{l}\text { COI- } \\
5 P\end{array}$ & $r b c \mathbf{L}$ \\
\hline $\begin{array}{l}\mathrm{MM} \\
226\end{array}$ & Ectocarpales & $\begin{array}{l}\text { Praia do } \\
\text { Lazaro - } \\
\text { Costão } \\
\text { esquerdo }\end{array}$ & $\begin{array}{l}\text { Ubatuba, } \\
\text { SP }\end{array}$ & $17 / 06 / 2015$ & C. A. A. Azevedo & $\begin{array}{c}23^{\circ} 30^{\prime} 31.12^{\prime} \mathrm{S} \\
; 45^{\circ} 08^{\prime} 09.72^{\prime \prime} \\
\mathrm{W}\end{array}$ & - & - \\
\hline $\begin{array}{l}\mathrm{MM} \\
227\end{array}$ & $\begin{array}{c}\text { "Feldmannia" } \\
\text { mitchelliae }\end{array}$ & $\begin{array}{c}\text { Ponta da } \\
\text { Cabeça, Praia } \\
\text { Grande }\end{array}$ & $\begin{array}{l}\text { Arraial do } \\
\text { Cabo, RJ }\end{array}$ & $11 / 11 / 2015$ & $\begin{array}{l}\text { M. Mungioli; V. } \\
\text { Cassano }\end{array}$ & $\begin{array}{l}22^{\circ} 58 ' 35.7 " \mathrm{~S} \\
42^{\circ} 02^{\prime} 05.6^{\prime \prime} \mathrm{W}\end{array}$ & $\mathrm{X}$ & $\mathrm{X}$ \\
\hline $\begin{array}{c}\mathrm{MM} \\
228\end{array}$ & $\begin{array}{l}\text { Levringia } \\
\text { brasiliensis }\end{array}$ & $\begin{array}{l}\text { Ponta da } \\
\text { Cabeça, Praia } \\
\text { Grande }\end{array}$ & $\begin{array}{l}\text { Arraial do } \\
\text { Cabo, RJ }\end{array}$ & $11 / 11 / 2015$ & $\begin{array}{l}\text { M. Mungioli; V. } \\
\text { Cassano }\end{array}$ & $\begin{array}{l}22^{\circ} 58 ' 35.7 " \mathrm{~S} \\
42^{\circ} 02^{\prime} 05.6^{\prime \prime} \mathrm{W}\end{array}$ & - & - \\
\hline $\begin{array}{c}\text { MM } \\
229\end{array}$ & $\begin{array}{c}\text { “Feldmannia" } \\
\text { mitchelliae }\end{array}$ & $\begin{array}{l}\text { Ponta da } \\
\text { Cabeça, Praia } \\
\text { Grande }\end{array}$ & $\begin{array}{l}\text { Arraial do } \\
\text { Cabo, RJ }\end{array}$ & $11 / 11 / 2015$ & $\begin{array}{l}\text { M. Mungioli; V. } \\
\text { Cassano }\end{array}$ & $\begin{array}{l}22^{\circ} 58 ' 35.7^{\prime \prime S} \\
42^{\circ} 02^{\prime} 05.6^{\prime \prime} \mathrm{W}\end{array}$ & $\mathrm{X}$ & $\mathrm{X}$ \\
\hline $\begin{array}{c}\mathrm{MM} \\
230\end{array}$ & $\begin{array}{c}\text { "Feldmannia" } \\
\text { mitchelliae }\end{array}$ & $\begin{array}{c}\text { Ponta da } \\
\text { Cabeça, Praia } \\
\text { Grande }\end{array}$ & $\begin{array}{l}\text { Arraial do } \\
\text { Cabo, RJ }\end{array}$ & $11 / 11 / 2015$ & $\begin{array}{l}\text { M. Mungioli; V. } \\
\text { Cassano }\end{array}$ & $\begin{array}{l}22^{\circ} 58 ' 35.7^{\prime \prime S} \\
42^{\circ} 02^{\prime} 05.6^{\prime \prime} \mathrm{W}\end{array}$ & $\mathrm{CH} 2 \mathrm{O}$ & $\mathrm{CH} 2 \mathrm{O}$ \\
\hline $\begin{array}{c}\mathrm{MM} \\
231\end{array}$ & $\begin{array}{c}\text { "Feldmannia" } \\
\text { irregularis }\end{array}$ & $\begin{array}{l}\text { Ponta da } \\
\text { Cabeça, Praia } \\
\text { Grande }\end{array}$ & $\begin{array}{l}\text { Arraial do } \\
\text { Cabo, RJ }\end{array}$ & $11 / 11 / 2015$ & $\begin{array}{l}\text { M. Mungioli; V. } \\
\text { Cassano }\end{array}$ & $\begin{array}{l}22^{\circ} 58 ' 35.7^{\prime \prime S} \\
42^{\circ} 02^{\prime} 05.6^{\prime \prime} \mathrm{W}\end{array}$ & $\mathrm{X}$ & $X$ \\
\hline $\begin{array}{c}\mathrm{MM} \\
232\end{array}$ & $\begin{array}{c}\text { Elachistiella } \\
\text { leptonematoides }\end{array}$ & $\begin{array}{c}\text { Ponta da } \\
\text { Cabeça, Praia } \\
\text { Grande }\end{array}$ & $\begin{array}{l}\text { Arraial do } \\
\text { Cabo, RJ }\end{array}$ & $11 / 11 / 2015$ & $\begin{array}{l}\text { M. Mungioli; V. } \\
\text { Cassano }\end{array}$ & $\begin{array}{l}22^{\circ} 58 ' 35.7 " \mathrm{~S} \\
42^{\circ} 02^{\prime} 05.6^{\prime \prime} \mathrm{W}\end{array}$ & $\mathrm{X}$ & $\mathrm{X}$ \\
\hline $\begin{array}{c}\mathrm{MM} \\
233\end{array}$ & $\begin{array}{c}\text { "Feldmannia" } \\
\text { mitchelliae }\end{array}$ & $\begin{array}{l}\text { Ponta da } \\
\text { Cabeça, Praia } \\
\text { Grande }\end{array}$ & $\begin{array}{l}\text { Arraial do } \\
\text { Cabo, RJ }\end{array}$ & $11 / 11 / 2015$ & $\begin{array}{l}\text { M. Mungioli; V. } \\
\text { Cassano }\end{array}$ & $\begin{array}{l}22^{\circ} 58 ' 35.7^{\prime \prime S} \\
42^{\circ} 02^{\prime} 05.6^{\prime \prime} \mathrm{W}\end{array}$ & $\mathrm{CH} 2 \mathrm{O}$ & $\mathrm{CH} 2 \mathrm{O}$ \\
\hline $\begin{array}{c}\mathrm{MM} \\
234\end{array}$ & $\begin{array}{c}\text { “Feldmannia" } \\
\text { mitchelliae }\end{array}$ & $\begin{array}{l}\text { Ponta da } \\
\text { Cabeça, Praia } \\
\text { Grande }\end{array}$ & $\begin{array}{l}\text { Arraial do } \\
\text { Cabo, RJ }\end{array}$ & $11 / 11 / 2015$ & $\begin{array}{l}\text { M. Mungioli; V. } \\
\text { Cassano }\end{array}$ & $\begin{array}{l}22^{\circ} 58 ' 35.7 " \mathrm{~S} \\
42^{\circ} 02^{\prime} 05.6^{\prime \prime} \mathrm{W}\end{array}$ & $\mathrm{CH} 2 \mathrm{O}$ & $\mathrm{CH} 2 \mathrm{O}$ \\
\hline $\begin{array}{c}\mathrm{MM} \\
235\end{array}$ & $\begin{array}{c}\text { "Feldmannia" } \\
\text { mitchelliae }\end{array}$ & $\begin{array}{l}\text { Ponta da } \\
\text { Cabeça, Praia } \\
\text { Grande }\end{array}$ & $\begin{array}{l}\text { Arraial do } \\
\text { Cabo, RJ }\end{array}$ & $11 / 11 / 2015$ & $\begin{array}{l}\text { M. Mungioli; V. } \\
\text { Cassano }\end{array}$ & $\begin{array}{l}22^{\circ} 58 ' 35.7 " \mathrm{~S} \\
42^{\circ} 02^{\prime} 05.6^{\prime \prime} \mathrm{W}\end{array}$ & - & - \\
\hline $\begin{array}{c}\text { MM } \\
236\end{array}$ & $\begin{array}{c}\text { "Feldmannia" } \\
\text { mitchelliae }\end{array}$ & $\begin{array}{c}\text { Ponta da } \\
\text { Cabeça, Praia } \\
\text { Grande }\end{array}$ & $\begin{array}{c}\text { Arraial do } \\
\text { Cabo, RJ }\end{array}$ & $11 / 11 / 2015$ & $\begin{array}{l}\text { M. Mungioli; V. } \\
\text { Cassano }\end{array}$ & $\begin{array}{l}22^{\circ} 58 ' 35.7 " \mathrm{~S} \\
42^{\circ} 02^{\prime} 05.6^{\prime \prime} \mathrm{W}\end{array}$ & - & - \\
\hline $\begin{array}{c}\text { MM } \\
237\end{array}$ & $\begin{array}{c}\text { “Feldmannia" } \\
\text { irregularis }\end{array}$ & $\begin{array}{l}\text { Ponta da } \\
\text { Cabeça, Praia } \\
\text { Grande }\end{array}$ & $\begin{array}{l}\text { Arraial do } \\
\text { Cabo, RJ }\end{array}$ & $11 / 11 / 2015$ & $\begin{array}{l}\text { M. Mungioli; V. } \\
\text { Cassano }\end{array}$ & $\begin{array}{l}22^{\circ} 58 ' 35.7 " \mathrm{~S} \\
42^{\circ} 02^{\prime} 05.6^{\prime \prime} \mathrm{W}\end{array}$ & $\mathrm{CH} 2 \mathrm{O}$ & $\mathrm{CH} 2 \mathrm{O}$ \\
\hline $\begin{array}{c}\text { MM } \\
238\end{array}$ & $\begin{array}{c}\text { "Feldmannia" } \\
\text { mitchelliae }\end{array}$ & $\begin{array}{c}\text { Ponta da } \\
\text { Cabeça, Praia } \\
\text { Grande }\end{array}$ & $\begin{array}{l}\text { Arraial do } \\
\text { Cabo, RJ }\end{array}$ & $11 / 11 / 2015$ & $\begin{array}{l}\text { M. Mungioli; V. } \\
\text { Cassano }\end{array}$ & $\begin{array}{l}22^{\circ} 58 ' 35.7 " \mathrm{~S} \\
42^{\circ} 02^{\prime} 05.6^{\prime \prime} \mathrm{W}\end{array}$ & $\mathrm{CH} 2 \mathrm{O}$ & $\mathrm{CH} 2 \mathrm{O}$ \\
\hline $\begin{array}{c}\text { MM } \\
239\end{array}$ & $\begin{array}{c}\text { "Feldmannia" } \\
\text { mitchelliae }\end{array}$ & $\begin{array}{l}\text { Ponta da } \\
\text { Cabeça, Praia } \\
\text { Grande }\end{array}$ & $\begin{array}{l}\text { Arraial do } \\
\text { Cabo, RJ }\end{array}$ & $11 / 11 / 2015$ & $\begin{array}{l}\text { M. Mungioli; V. } \\
\text { Cassano }\end{array}$ & $\begin{array}{l}22^{\circ} 58 ' 35.7 " \mathrm{~S} \\
42^{\circ} 02^{\prime} 05.6^{\prime \prime} \mathrm{W}\end{array}$ & - & - \\
\hline $\begin{array}{c}\mathrm{MM} \\
240\end{array}$ & $\begin{array}{c}\text { “Feldmannia” } \\
\text { irregularis }\end{array}$ & Praia da Cruz & $\begin{array}{c}\text { Marataízes, } \\
\text { ES }\end{array}$ & 08/03/2016 & V. Cassano & $\begin{array}{l}21^{\circ} 02,116^{\prime} \mathrm{S} ; \\
40^{\circ} 48,812^{\prime \prime} \mathrm{W}\end{array}$ & - & - \\
\hline $\begin{array}{c}\mathrm{MM} \\
241\end{array}$ & $\begin{array}{c}\text { “Feldmannia" } \\
\text { mitchelliae }\end{array}$ & Praia da Cruz & $\begin{array}{c}\text { Marataízes, } \\
\text { ES }\end{array}$ & 08/03/2016 & V. Cassano & $\begin{array}{l}21^{\circ} 02,116^{\prime} \mathrm{S} ; \\
40^{\circ} 48,812^{\prime \prime} \mathrm{W}\end{array}$ & - & - \\
\hline $\begin{array}{c}\text { MM } \\
242\end{array}$ & $\begin{array}{c}\text { “Feldmannia” } \\
\text { irregularis }\end{array}$ & Praia da Cruz & $\begin{array}{c}\text { Marataízes, } \\
\text { ES }\end{array}$ & 08/03/2016 & V. Cassano & $\begin{array}{l}21^{\circ} 02,116^{\prime} \mathrm{S} \\
40^{\circ} 48,812^{\prime \prime} \mathrm{W}\end{array}$ & - & - \\
\hline $\begin{array}{c}\text { MM } \\
243\end{array}$ & $\begin{array}{c}\text { "Feldmannia" } \\
\text { irregularis }\end{array}$ & Praia da Cruz & $\begin{array}{c}\text { Marataízes, } \\
\text { ES }\end{array}$ & 08/03/2016 & V. Cassano & $\begin{array}{l}21^{\circ} 02,116^{\prime} \mathrm{S} ; \\
40^{\circ} 48,812^{\prime \prime W}\end{array}$ & - & - \\
\hline $\begin{array}{c}\mathrm{MM} \\
244\end{array}$ & $\begin{array}{c}\text { “Feldmannia” } \\
\text { irregularis }\end{array}$ & Praia da Cruz & $\begin{array}{c}\text { Marataízes, } \\
\text { ES }\end{array}$ & 08/03/2016 & V. Cassano & $\begin{array}{l}21^{\circ} 02,116^{\prime} \mathrm{S} \\
40^{\circ} 48,812^{\prime \prime} \mathrm{W}\end{array}$ & - & - \\
\hline $\begin{array}{c}\text { MM } \\
245\end{array}$ & $\begin{array}{c}\text { “Feldmannia" } \\
\text { irregularis }\end{array}$ & Praia da Cruz & $\begin{array}{c}\text { Marataízes, } \\
\text { ES }\end{array}$ & 08/03/2016 & V. Cassano & $\begin{array}{l}21^{\circ} 02,116^{\prime} \mathrm{S} \\
40^{\circ} 48,812^{\prime \prime} \mathrm{W}\end{array}$ & - & - \\
\hline
\end{tabular}


Tabela 2. Continuação

\begin{tabular}{|c|c|c|c|c|c|c|c|c|}
\hline $\begin{array}{c}\text { Código } \\
\text { de } \\
\text { Coleta }\end{array}$ & Amostra & $\begin{array}{l}\text { Local de } \\
\text { Coleta }\end{array}$ & Cidade & Data & $\begin{array}{l}\text { Coletor } \\
\text { (s) }\end{array}$ & $\begin{array}{l}\text { Latitude / } \\
\text { Longitude }\end{array}$ & $\begin{array}{l}\text { COI- } \\
5 P\end{array}$ & $r b c \mathbf{L}$ \\
\hline $\begin{array}{c}\text { MM } \\
246\end{array}$ & $\begin{array}{l}\text { Levringia } \\
\text { brasiliensis }\end{array}$ & Praia da Cruz & $\begin{array}{c}\text { Marataízes, } \\
\text { ES }\end{array}$ & 08/03/2016 & V. Cassano & $\begin{array}{l}21^{\circ} 02,116^{\prime} \mathrm{S} \\
40^{\circ} 48,812^{\prime \prime} \mathrm{W}\end{array}$ & - & - \\
\hline $\begin{array}{c}\text { MM } \\
247\end{array}$ & $\begin{array}{c}\text { "Feldmannia" } \\
\text { mitchelliae }\end{array}$ & Praia da Cruz & $\begin{array}{c}\text { Marataízes, } \\
\text { ES }\end{array}$ & 08/03/2016 & V. Cassano & $\begin{array}{l}21^{\circ} 02,116^{\prime} \mathrm{S} \\
40^{\circ} 48,812^{\prime \prime} \mathrm{W}\end{array}$ & - & - \\
\hline $\begin{array}{c}\mathrm{MM} \\
248\end{array}$ & $\begin{array}{c}\text { "Feldmannia" } \\
\text { irregularis }\end{array}$ & Praia da Cruz & $\begin{array}{c}\text { Marataízes, } \\
\text { ES }\end{array}$ & 08/03/2016 & V. Cassano & $\begin{array}{l}21^{\circ} 02,116^{\prime} \mathrm{S} \\
40^{\circ} 48,812^{\prime \prime} \mathrm{W}\end{array}$ & - & - \\
\hline $\begin{array}{l}\mathrm{MM} \\
249\end{array}$ & $\begin{array}{l}\text { Bachelotia } \\
\text { antillarum }\end{array}$ & Praia da Cruz & $\begin{array}{c}\text { Marataízes, } \\
\text { ES }\end{array}$ & 08/03/2016 & V. Cassano & $\begin{array}{l}21^{\circ} 02,116^{\prime} \mathrm{S} \\
40^{\circ} 48,812^{\prime \prime} \mathrm{W}\end{array}$ & - & - \\
\hline $\begin{array}{c}\text { MM } \\
250\end{array}$ & $\begin{array}{l}\text { Bachelotia } \\
\text { antillarum }\end{array}$ & Praia da Cruz & $\begin{array}{c}\text { Marataízes, } \\
\text { ES }\end{array}$ & 08/03/2016 & V. Cassano & $\begin{array}{l}21^{\circ} 02,116^{\prime} \mathrm{S} \\
40^{\circ} 48,812^{\prime \prime} \mathrm{W}\end{array}$ & - & - \\
\hline $\begin{array}{c}\mathrm{MM} \\
251\end{array}$ & $\begin{array}{l}\text { Bachelotia } \\
\text { antillarum }\end{array}$ & Praia da Cruz & $\begin{array}{c}\text { Marataízes, } \\
\text { ES }\end{array}$ & 08/03/2016 & V. Cassano & $\begin{array}{l}21^{\circ} 02,116^{\prime} \mathrm{S} \\
40^{\circ} 48,812^{\prime \prime} \mathrm{W}\end{array}$ & $\mathrm{CH} 2 \mathrm{O}$ & $\mathrm{CH} 2 \mathrm{O}$ \\
\hline $\begin{array}{c}\mathrm{MM} \\
252\end{array}$ & $\begin{array}{c}\text { “Feldmannia” } \\
\text { irregularis }\end{array}$ & Praia da Cruz & $\begin{array}{c}\text { Marataízes, } \\
\text { ES }\end{array}$ & 08/03/2016 & V. Cassano & $\begin{array}{l}21^{\circ} 02,116^{\prime} \mathrm{S} ; \\
40^{\circ} 48,812^{\prime \prime} \mathrm{W}\end{array}$ & - & - \\
\hline $\begin{array}{c}\mathrm{MM} \\
253\end{array}$ & $\begin{array}{c}\text { “Feldmannia" } \\
\text { irregularis }\end{array}$ & Praia da Cruz & $\begin{array}{c}\text { Marataízes, } \\
\text { ES }\end{array}$ & 08/03/2016 & V. Cassano & $\begin{array}{l}21^{\circ} 02,116^{\prime} \mathrm{S} ; \\
40^{\circ} 48,812^{\prime \prime} \mathrm{W}\end{array}$ & - & - \\
\hline $\begin{array}{c}\mathrm{MM} \\
254\end{array}$ & $\begin{array}{c}\text { “Feldmannia” } \\
\text { irregularis }\end{array}$ & Praia da Cruz & $\begin{array}{c}\text { Marataízes, } \\
\text { ES }\end{array}$ & 08/03/2016 & V. Cassano & $\begin{array}{l}21^{\circ} 02,116^{\prime} \mathrm{S} \\
40^{\circ} 48,812^{\prime \prime} \mathrm{W}\end{array}$ & - & - \\
\hline $\begin{array}{c}\mathrm{MM} \\
255\end{array}$ & $\begin{array}{c}\text { "Feldmannia" } \\
\text { irregularis }\end{array}$ & Praia da Cruz & $\begin{array}{c}\text { Marataízes, } \\
\text { ES }\end{array}$ & 08/03/2016 & V. Cassano & $\begin{array}{l}21^{\circ} 02,116^{\prime} \mathrm{S} \\
40^{\circ} 48,812^{\prime \prime} \mathrm{W}\end{array}$ & - & - \\
\hline $\begin{array}{c}\mathrm{MM} \\
256\end{array}$ & $\begin{array}{c}\text { “Feldmannia” } \\
\text { irregularis }\end{array}$ & Praia da Cruz & $\begin{array}{c}\text { Marataízes, } \\
\text { ES }\end{array}$ & 08/03/2016 & V. Cassano & $\begin{array}{l}21^{\circ} 02,116^{\prime} \mathrm{S} \\
40^{\circ} 48,812^{\prime \prime} \mathrm{W}\end{array}$ & - & - \\
\hline $\begin{array}{c}\text { MM } \\
257\end{array}$ & $\begin{array}{c}\text { “Feldmannia" } \\
\text { irregularis }\end{array}$ & Praia da Cruz & $\begin{array}{c}\text { Marataízes, } \\
\text { ES }\end{array}$ & 08/03/2016 & V. Cassano & $\begin{array}{l}21^{\circ} 02,116^{\prime} \mathrm{S} \\
40^{\circ} 48,812^{\prime \prime} \mathrm{W}\end{array}$ & - & - \\
\hline $\begin{array}{c}\text { MM } \\
258\end{array}$ & $\begin{array}{c}\text { “Feldmannia” } \\
\text { irregularis }\end{array}$ & Praia da Cruz & $\begin{array}{c}\text { Marataízes, } \\
\text { ES }\end{array}$ & 08/03/2016 & V. Cassano & $\begin{array}{l}21^{\circ} 02,116^{\prime} \mathrm{S} \\
40^{\circ} 48,812^{\prime \prime} \mathrm{W}\end{array}$ & - & - \\
\hline $\begin{array}{c}\text { MM } \\
259\end{array}$ & $\begin{array}{c}\text { “Feldmannia” } \\
\text { irregularis }\end{array}$ & Praia da Cruz & $\begin{array}{c}\text { Marataízes, } \\
\text { ES }\end{array}$ & 08/03/2016 & V. Cassano & $\begin{array}{l}21^{\circ} 02,116^{\prime} \mathrm{S} \\
40^{\circ} 48,812^{\prime \prime} \mathrm{W}\end{array}$ & - & - \\
\hline $\begin{array}{c}\mathrm{MM} \\
260\end{array}$ & $\begin{array}{c}\text { “Feldmannia” } \\
\text { irregularis }\end{array}$ & Praia da Cruz & $\begin{array}{c}\text { Marataízes, } \\
\text { ES }\end{array}$ & 08/03/2016 & V. Cassano & $\begin{array}{l}21^{\circ} 02,116^{\prime} \mathrm{S} ; \\
40^{\circ} 48,812^{\prime \prime} \mathrm{W}\end{array}$ & - & - \\
\hline $\begin{array}{c}\mathrm{MM} \\
261\end{array}$ & $\begin{array}{l}\text { Bachelotia } \\
\text { antillarum }\end{array}$ & Praia da Cruz & $\begin{array}{c}\text { Marataízes, } \\
\text { ES }\end{array}$ & 08/03/2016 & V. Cassano & $\begin{array}{l}21^{\circ} 02,116^{\prime} \mathrm{S} ; \\
40^{\circ} 48,812^{\prime \prime} \mathrm{W}\end{array}$ & - & - \\
\hline $\begin{array}{c}\mathrm{MM} \\
262\end{array}$ & $\begin{array}{l}\text { Bachelotia } \\
\text { antillarum }\end{array}$ & Praia da Cruz & $\begin{array}{c}\text { Marataízes, } \\
\text { ES }\end{array}$ & 08/03/2016 & V. Cassano & $\begin{array}{l}21^{\circ} 02,116^{\prime} \mathrm{S} ; \\
40^{\circ} 48,812^{\prime \prime W}\end{array}$ & $\mathrm{CH} 2 \mathrm{O}$ & $\mathrm{CH} 2 \mathrm{O}$ \\
\hline $\begin{array}{c}\mathrm{MM} \\
263\end{array}$ & $\begin{array}{c}\text { "Feldmannia" } \\
\text { mitchelliae }\end{array}$ & Praia da Cruz & $\begin{array}{c}\text { Marataízes, } \\
\text { ES }\end{array}$ & 08/03/2016 & V. Cassano & $\begin{array}{l}21^{\circ} 02,116^{\prime} \mathrm{S} ; \\
40^{\circ} 48,812^{\prime \prime} \mathrm{W}\end{array}$ & - & - \\
\hline $\begin{array}{c}\mathrm{MM} \\
264\end{array}$ & $\begin{array}{c}\text { "Feldmannia" } \\
\text { irregularis }\end{array}$ & $\begin{array}{l}\text { Praia de } \\
\text { Itaipava }\end{array}$ & $\begin{array}{l}\text { Itapemirim, } \\
\text { ES }\end{array}$ & 09/03/2016 & V. Cassano & $\begin{array}{l}21^{\circ} 00,439^{\prime} \mathrm{S} \\
40^{\circ} 48,563^{\prime \prime} \mathrm{W}\end{array}$ & - & - \\
\hline $\begin{array}{c}\mathrm{MM} \\
265\end{array}$ & $\begin{array}{c}\text { “Feldmannia" } \\
\text { irregularis }\end{array}$ & $\begin{array}{l}\text { Praia de } \\
\text { Itaipava }\end{array}$ & $\begin{array}{l}\text { Itapemirim, } \\
\text { ES }\end{array}$ & 09/03/2016 & V. Cassano & $\begin{array}{l}21^{\circ} 00,439^{\prime} \mathrm{S} \\
40^{\circ} 48,563^{\prime \prime} \mathrm{W}\end{array}$ & - & - \\
\hline $\begin{array}{c}\mathrm{MM} \\
266\end{array}$ & $\begin{array}{c}\text { "Feldmannia" } \\
\text { irregularis }\end{array}$ & $\begin{array}{l}\text { Praia de } \\
\text { Itaipava }\end{array}$ & $\begin{array}{l}\text { Itapemirim, } \\
\text { ES }\end{array}$ & 09/03/2016 & V. Cassano & $\begin{array}{l}21^{\circ} 00,439^{\prime} \mathrm{s} \\
40^{\circ} 48,563^{\prime \prime} \mathrm{W}\end{array}$ & - & - \\
\hline $\begin{array}{l}\text { MM } \\
267\end{array}$ & $\begin{array}{c}\text { “Feldmannia" } \\
\text { irregularis }\end{array}$ & $\begin{array}{l}\text { Praia de } \\
\text { Itaipava }\end{array}$ & $\begin{array}{l}\text { Itapemirim, } \\
\text { ES }\end{array}$ & 09/03/2016 & V. Cassano & $\begin{array}{l}21^{\circ} 00,439^{\prime} \mathrm{S} ; \\
40^{\circ} 48,563^{\prime \prime} \mathrm{W}\end{array}$ & - & - \\
\hline $\begin{array}{c}\mathrm{MM} \\
268\end{array}$ & $\begin{array}{c}\text { “Feldmannia” } \\
\text { irregularis }\end{array}$ & $\begin{array}{l}\text { Praia de } \\
\text { Itaipava }\end{array}$ & $\begin{array}{l}\text { Itapemirim, } \\
\text { ES }\end{array}$ & 09/03/2016 & V. Cassano & $\begin{array}{l}21^{\circ} 00,439^{\prime} \mathrm{S} ; \\
40^{\circ} 48,563^{\prime \prime} \mathrm{W}\end{array}$ & - & - \\
\hline
\end{tabular}


Tabela 2. Continuação

\begin{tabular}{|c|c|c|c|c|c|c|c|c|}
\hline $\begin{array}{c}\text { Código } \\
\text { de } \\
\text { Coleta }\end{array}$ & Amostra & $\begin{array}{l}\text { Local de } \\
\text { Coleta }\end{array}$ & Cidade & Data & $\begin{array}{l}\text { Coletor } \\
\text { (s) }\end{array}$ & $\begin{array}{l}\text { Latitude / } \\
\text { Longitude }\end{array}$ & $\begin{array}{l}\text { COI- } \\
5 P\end{array}$ & $r b c \mathbf{L}$ \\
\hline $\begin{array}{c}\text { MM } \\
269\end{array}$ & $\begin{array}{c}\text { "Feldmannia" } \\
\text { irregularis }\end{array}$ & $\begin{array}{l}\text { Praia de } \\
\text { Itaipava }\end{array}$ & $\begin{array}{l}\text { Itapemirim, } \\
\text { ES }\end{array}$ & 09/03/2016 & V. Cassano & $\begin{array}{l}21^{\circ} 00,439^{\prime} \mathrm{S} \\
40^{\circ} 48,563^{\prime \prime} \mathrm{W}\end{array}$ & - & - \\
\hline $\begin{array}{c}\mathrm{MM} \\
270\end{array}$ & $\begin{array}{c}\text { "Feldmannia" } \\
\text { mitchelliae }\end{array}$ & $\begin{array}{l}\text { Ilha do } \\
\text { Gambá }\end{array}$ & Piúma, ES & 09/03/2016 & V. Cassano & $\begin{array}{l}20^{\circ} 50,782^{\prime} \mathrm{S} \\
40^{\circ} 43,416^{\prime \prime} \mathrm{W}\end{array}$ & - & - \\
\hline $\begin{array}{c}\mathrm{MM} \\
271\end{array}$ & $\begin{array}{c}\text { "Feldmannia" } \\
\text { mitchelliae }\end{array}$ & $\begin{array}{l}\text { Ilha do } \\
\text { Gambá }\end{array}$ & Piúma, ES & 09/03/2016 & V. Cassano & $\begin{array}{l}20^{\circ} 50,782 \text { 'S; } \\
40^{\circ} 43,416^{\prime \prime} \mathrm{W}\end{array}$ & - & - \\
\hline $\begin{array}{l}\mathrm{MM} \\
272\end{array}$ & $\begin{array}{c}\text { "Feldmannia" } \\
\text { mitchelliae }\end{array}$ & $\begin{array}{l}\text { Ilha do } \\
\text { Gambá }\end{array}$ & Piúma, ES & 09/03/2016 & V. Cassano & $\begin{array}{l}20^{\circ} 50,782 ’ \mathrm{~S} \\
40^{\circ} 43,416^{\prime \prime} \mathrm{W}\end{array}$ & - & - \\
\hline $\begin{array}{c}\text { MM } \\
273\end{array}$ & $\begin{array}{c}\text { "Feldmannia" } \\
\text { mitchelliae }\end{array}$ & $\begin{array}{l}\text { Ilha do } \\
\text { Gambá }\end{array}$ & Piúma, ES & 09/03/2016 & V. Cassano & $\begin{array}{l}20^{\circ} 50,782 ’ \mathrm{~S} \\
40^{\circ} 43,416^{\prime \prime} \mathrm{W}\end{array}$ & - & - \\
\hline $\begin{array}{c}\mathrm{MM} \\
274\end{array}$ & $\begin{array}{c}\text { "Feldmannia" } \\
\text { mitchelliae }\end{array}$ & $\begin{array}{l}\text { Ilha do } \\
\text { Gambá }\end{array}$ & Piúma, ES & 09/03/2016 & V. Cassano & $\begin{array}{l}20^{\circ} 50,782 ’ \mathrm{~S} \\
40^{\circ} 43,416^{\prime \prime} \mathrm{W}\end{array}$ & - & - \\
\hline $\begin{array}{c}\mathrm{MM} \\
275\end{array}$ & $\begin{array}{c}\text { "Feldmannia" } \\
\text { mitchelliae }\end{array}$ & $\begin{array}{l}\text { Ilha do } \\
\text { Gambá }\end{array}$ & Piúma, ES & 09/03/2016 & V. Cassano & $\begin{array}{l}20^{\circ} 50,782 ’ \mathrm{~S} ; \\
40^{\circ} 43,416^{\prime \prime} \mathrm{W}\end{array}$ & - & - \\
\hline $\begin{array}{c}\mathrm{MM} \\
276\end{array}$ & $\begin{array}{c}\text { “Feldmannia” } \\
\text { mitchelliae }\end{array}$ & $\begin{array}{l}\text { Ilha do } \\
\text { Gambá }\end{array}$ & Piúma, ES & 09/03/2016 & V. Cassano & $\begin{array}{l}20^{\circ} 50,782 ’ \mathrm{~S} ; \\
40^{\circ} 43,416^{\prime \prime} \mathrm{W}\end{array}$ & - & - \\
\hline $\begin{array}{c}\mathrm{MM} \\
277\end{array}$ & $\begin{array}{c}\text { "Feldmannia" } \\
\text { irregularis }\end{array}$ & $\begin{array}{l}\text { Ilha do } \\
\text { Gambá }\end{array}$ & Piúma, ES & 09/03/2016 & V. Cassano & $\begin{array}{l}20^{\circ} 50,782 ’ \mathrm{~S} \\
40^{\circ} 43,416^{\prime \prime} \mathrm{W}\end{array}$ & - & - \\
\hline $\begin{array}{c}\mathrm{MM} \\
278\end{array}$ & $\begin{array}{c}\text { “Feldmannia” } \\
\text { irregularis }\end{array}$ & $\begin{array}{l}\text { Ilha do } \\
\text { Gambá }\end{array}$ & Piúma, ES & 09/03/2016 & V. Cassano & $\begin{array}{l}20^{\circ} 50,782 ’ \mathrm{~S} ; \\
40^{\circ} 43,416^{\prime \prime} \mathrm{W}\end{array}$ & - & - \\
\hline $\begin{array}{c}\text { MM } \\
279\end{array}$ & $\begin{array}{c}\text { "Feldmannia" } \\
\text { irregularis }\end{array}$ & $\begin{array}{l}\text { Ilha do } \\
\text { Gambá }\end{array}$ & Piúma, ES & 09/03/2016 & V. Cassano & $\begin{array}{l}20^{\circ} 50,782 ’ \mathrm{~S} \\
40^{\circ} 43,416^{\prime \prime} \mathrm{W}\end{array}$ & - & - \\
\hline $\begin{array}{c}\mathrm{MM} \\
280\end{array}$ & $\begin{array}{c}\text { "Feldmannia" } \\
\text { irregularis }\end{array}$ & $\begin{array}{l}\text { Ilha do } \\
\text { Gambá }\end{array}$ & Piúma, ES & 09/03/2016 & V. Cassano & $\begin{array}{l}20^{\circ} 50,782 ’ \mathrm{~S} \\
40^{\circ} 43,416^{\prime \prime} \mathrm{W}\end{array}$ & - & - \\
\hline $\begin{array}{c}\mathrm{MM} \\
281\end{array}$ & $\begin{array}{c}\text { "Feldmannia" } \\
\text { irregularis }\end{array}$ & $\begin{array}{l}\text { Ilha do } \\
\text { Gambá }\end{array}$ & Piúma, ES & 09/03/2016 & V. Cassano & $\begin{array}{l}20^{\circ} 50,782 ’ \mathrm{~S} ; \\
40^{\circ} 43,416^{\prime \prime} \mathrm{W}\end{array}$ & - & - \\
\hline $\begin{array}{c}\mathrm{MM} \\
282\end{array}$ & $\begin{array}{c}\text { "Feldmannia" } \\
\text { mitchelliae }\end{array}$ & $\begin{array}{l}\text { Ilha do } \\
\text { Gambá }\end{array}$ & Piúma, ES & 09/03/2016 & V. Cassano & $\begin{array}{l}20^{\circ} 50,782 ’ \mathrm{~S} ; \\
40^{\circ} 43,416^{\prime \prime} \mathrm{W}\end{array}$ & - & - \\
\hline $\begin{array}{c}\mathrm{MM} \\
283\end{array}$ & $\begin{array}{c}\text { "Feldmannia" } \\
\text { mitchelliae }\end{array}$ & $\begin{array}{l}\text { Ilha do } \\
\text { Gambá }\end{array}$ & Piúma, ES & 09/03/2016 & V. Cassano & $\begin{array}{l}20^{\circ} 50,782^{\prime} \mathrm{S} ; \\
40^{\circ} 43,416^{\prime \prime} \mathrm{W}\end{array}$ & - & - \\
\hline $\begin{array}{c}\mathrm{MM} \\
284\end{array}$ & $\begin{array}{c}\text { “Feldmannia” } \\
\text { mitchelliae }\end{array}$ & $\begin{array}{l}\text { Ilha do } \\
\text { Gambá }\end{array}$ & Piúma, ES & 09/03/2016 & V. Cassano & $\begin{array}{l}20^{\circ} 50,782 ’ \mathrm{~S} \\
40^{\circ} 43,416^{\prime \prime} \mathrm{W}\end{array}$ & - & - \\
\hline $\begin{array}{l}\mathrm{MM} \\
285\end{array}$ & $\begin{array}{c}\text { "Feldmannia" } \\
\text { mitchelliae }\end{array}$ & $\begin{array}{l}\text { Ilha do } \\
\text { Gambá }\end{array}$ & Piúma, ES & 09/03/2016 & V. Cassano & $\begin{array}{l}20^{\circ} 50,782 \text { ’s; } \\
40^{\circ} 43,416^{\prime \prime} \mathrm{W}\end{array}$ & - & - \\
\hline $\begin{array}{l}\mathrm{MM} \\
286\end{array}$ & $\begin{array}{l}\text { Levringia } \\
\text { brasiliensis }\end{array}$ & $\begin{array}{l}\text { Ilha do } \\
\text { Gambá }\end{array}$ & Piúma, ES & 09/03/2016 & V. Cassano & $\begin{array}{l}20^{\circ} 50,782 ’ \mathrm{~s} \\
40^{\circ} 43,416^{\prime \prime} \mathrm{W}\end{array}$ & - & - \\
\hline $\begin{array}{c}\mathrm{MM} \\
287\end{array}$ & $\begin{array}{l}\text { Levringia } \\
\text { brasiliensis }\end{array}$ & $\begin{array}{l}\text { Ilha do } \\
\text { Gambá }\end{array}$ & Piúma, ES & 09/03/2016 & V. Cassano & $\begin{array}{l}20^{\circ} 50,782^{\prime} \mathrm{S} ; \\
40^{\circ} 43,416^{\prime \prime} \mathrm{W}\end{array}$ & - & - \\
\hline $\begin{array}{c}\mathrm{MM} \\
288\end{array}$ & $\begin{array}{c}\text { Levringia } \\
\text { brasiliensis }\end{array}$ & $\begin{array}{l}\text { Ilha do } \\
\text { Gambá }\end{array}$ & Piúma, ES & 09/03/2016 & V. Cassano & $\begin{array}{l}20^{\circ} 50,782 ’ \mathrm{~S} \\
40^{\circ} 43,416^{\prime \prime} \mathrm{W}\end{array}$ & - & - \\
\hline $\begin{array}{c}\text { MM } \\
289\end{array}$ & $\begin{array}{c}\text { "Feldmannia" } \\
\text { mitchelliae }\end{array}$ & $\begin{array}{l}\text { Ilha do } \\
\text { Gambá }\end{array}$ & Piúma, ES & 09/03/2016 & V. Cassano & $\begin{array}{l}20^{\circ} 50,782^{\prime} \mathrm{s} ; \\
40^{\circ} 43,416^{\prime \prime} \mathrm{W}\end{array}$ & - & - \\
\hline $\begin{array}{c}\mathrm{MM} \\
290\end{array}$ & Ectocarpales & $\begin{array}{l}\text { Ilha do } \\
\text { Gambá }\end{array}$ & Piúma, ES & 09/03/2016 & V. Cassano & $\begin{array}{l}20^{\circ} 50,782 ’ \mathrm{~S} ; \\
40^{\circ} 43,416^{\prime \prime} \mathrm{W}\end{array}$ & $\mathrm{CH} 2 \mathrm{O}$ & $\mathrm{CH} 2 \mathrm{O}$ \\
\hline $\begin{array}{l}\text { MM } \\
291\end{array}$ & $\begin{array}{c}\text { "Feldmannia" } \\
\text { mitchelliae }\end{array}$ & $\begin{array}{l}\text { Ilha do } \\
\text { Gambá }\end{array}$ & Piúma, ES & 09/03/2016 & V. Cassano & $\begin{array}{l}20^{\circ} 50,782^{\prime} \mathrm{S} ; \\
40^{\circ} 43,416^{\prime \prime} \mathrm{W}\end{array}$ & - & - \\
\hline
\end{tabular}


Tabela 2. Continuação

\begin{tabular}{|c|c|c|c|c|c|c|c|c|}
\hline $\begin{array}{l}\text { Código } \\
\text { de } \\
\text { Coleta }\end{array}$ & Amostra & $\begin{array}{l}\text { Local de } \\
\text { Coleta }\end{array}$ & Cidade & Data & $\begin{array}{l}\text { Coletor } \\
\text { (s) }\end{array}$ & $\begin{array}{l}\text { Latitude / } \\
\text { Longitude }\end{array}$ & $\begin{array}{l}\text { COI- } \\
5 P\end{array}$ & $\operatorname{rbc} \mathbf{L}$ \\
\hline $\begin{array}{c}\text { MM } \\
292\end{array}$ & $\begin{array}{c}\text { "Feldmannia" } \\
\text { mitchelliae }\end{array}$ & $\begin{array}{l}\text { Ilha do } \\
\text { Gambá }\end{array}$ & Piúma, ES & 09/03/2016 & V. Cassano & $\begin{array}{l}20^{\circ} 50,782 ' \mathrm{~S} ; \\
40^{\circ} 43,416^{\prime \prime} \mathrm{W}\end{array}$ & T & - \\
\hline $\begin{array}{c}\text { MM } \\
293\end{array}$ & $\begin{array}{c}\text { "Feldmannia" } \\
\text { mitchelliae }\end{array}$ & $\begin{array}{l}\text { Ilha do } \\
\text { Gambá }\end{array}$ & Piúma, ES & 09/03/2016 & V. Cassano & $\begin{array}{l}20^{\circ} 50,782^{\prime} \mathrm{S} ; \\
40^{\circ} 43,416^{\prime \prime} \mathrm{W}\end{array}$ & $T$ & - \\
\hline $\begin{array}{c}\mathrm{MM} \\
294\end{array}$ & $\begin{array}{c}\text { "Feldmannia" } \\
\text { mitchelliae }\end{array}$ & $\begin{array}{l}\text { Ilha do } \\
\text { Gambá }\end{array}$ & Piúma, ES & 09/03/2016 & V. Cassano & $\begin{array}{l}20^{\circ} 50,782 ’ \mathrm{~S} ; \\
40^{\circ} 43,416^{\prime \prime} \mathrm{W}\end{array}$ & T & - \\
\hline $\begin{array}{c}\text { MM } \\
295\end{array}$ & $\begin{array}{c}\text { "Feldmannia" } \\
\text { mitchelliae }\end{array}$ & $\begin{array}{l}\text { Ilha do } \\
\text { Gambá }\end{array}$ & Piúma, ES & 09/03/2016 & V. Cassano & $\begin{array}{l}20^{\circ} 50,782^{\prime} \mathrm{S} ; \\
40^{\circ} 43,416^{\prime \prime} \mathrm{W}\end{array}$ & 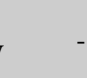 & - \\
\hline $\begin{array}{c}\text { MM } \\
298\end{array}$ & $\begin{array}{l}\text { Ectocarpus } \\
\text { siliculosus }\end{array}$ & $\begin{array}{l}\text { Masonboro } \\
\text { Sound, } \\
\text { Condado de } \\
\text { New Hanover }\end{array}$ & $\begin{array}{l}\text { Wilmington } \\
\text {, NC, EUA }\end{array}$ & 09/02/2016 & $\begin{array}{l}\text { D.W. Freshwater; } \\
\text { M LaCroce }\end{array}$ & $\begin{array}{c}34^{0} 08.416^{\prime} \mathrm{N} \\
077^{0} 51.806^{\prime \prime} \\
\mathrm{W}\end{array}$ & - & $\mathrm{X}$ \\
\hline $\begin{array}{c}\text { MM } \\
299\end{array}$ & $\begin{array}{l}\text { Ectocarpus } \\
\text { siliculosus }\end{array}$ & $\begin{array}{l}\text { Pier CMS, } \\
\text { Masonboro } \\
\text { Sound, } \\
\text { Condado de } \\
\text { New Hanover }\end{array}$ & $\begin{array}{l}\text { Wilmington } \\
\text {, NC, EUA }\end{array}$ & $09 / 02 / 2016$ & $\begin{array}{l}\text { M LaCroce; D.W. } \\
\text { Freshwater }\end{array}$ & $\begin{array}{c}34^{0} 08.416^{\prime} \mathrm{N} \\
077^{0} 51.806^{\prime \prime} \\
\text { W }\end{array}$ & - & $\mathrm{X}$ \\
\hline $\begin{array}{c}\text { MM } \\
300\end{array}$ & $\begin{array}{c}\text { “Feldmannia" } \\
\text { mitchelliae }\end{array}$ & $\begin{array}{c}\text { Ponte da Praia } \\
\text { de } \\
\text { Wrightsville } \\
\text { Condado de } \\
\text { New Hanover }\end{array}$ & $\begin{array}{l}\text { Wilmington } \\
\text {, NC, EUA }\end{array}$ & 09/02/2016 & D.W. Freshwater. & $\begin{array}{c}34^{0} 13.090 ' \mathrm{~N} \\
077^{0} 48.786^{\prime \prime} \\
\text { W }\end{array}$ & - & $\mathrm{X}$ \\
\hline $\begin{array}{c}\text { MM } \\
301\end{array}$ & $\begin{array}{l}\text { Ectocarpus } \\
\text { siliculosus }\end{array}$ & $\begin{array}{c}\text { Ponte da Praia } \\
\text { de } \\
\text { Wrightsville } \\
\text { Condado de } \\
\text { New Hanover }\end{array}$ & $\begin{array}{l}\text { Wilmington } \\
\text {, NC, EUA }\end{array}$ & 09/02/2016 & D.W. Freshwater. & $\begin{array}{c}34^{0} 13.090 \mathrm{~N} \\
077^{0} 48.786^{\prime \prime} \\
\text { W }\end{array}$ & - & - \\
\hline $\begin{array}{c}\text { MM } \\
302\end{array}$ & $\begin{array}{c}\text { “Feldmannia" } \\
\text { mitchelliae }\end{array}$ & $\begin{array}{c}\text { Wynne Plaza } \\
\text { Park, Condado } \\
\text { de New } \\
\text { Hanover }\end{array}$ & $\begin{array}{l}\text { Wilmington } \\
\text {, NC, EUA }\end{array}$ & $11 / 02 / 2016$ & $\begin{array}{l}\text { M LaCroce; D.W. } \\
\text { Freshwater }\end{array}$ & $\begin{array}{c}34^{0} 12.501^{\prime} \mathrm{N} ; \\
077^{0} 47.815^{\prime \prime} \\
\text { W }\end{array}$ & ; & - \\
\hline $\begin{array}{c}\text { MM } \\
303\end{array}$ & $\begin{array}{l}\text { Acinetospora } \\
\text { filamentosa(co } \\
\text { mo A. crinita) }\end{array}$ & $\begin{array}{c}\text { Wynne Plaza } \\
\text { Park, Condado } \\
\text { de New } \\
\text { Hanover }\end{array}$ & $\begin{array}{l}\text { Wilmington } \\
\text {, NC, EUA }\end{array}$ & $11 / 02 / 2016$ & $\begin{array}{l}\text { D.W. Freshwater; } \\
\text { M LaCroce }\end{array}$ & $\begin{array}{c}34^{0} 12.501^{\prime} \mathrm{N} ; \\
077^{0} 47.815^{\prime} \\
\mathrm{W}\end{array}$ & ; & $\mathrm{X}$ \\
\hline $\begin{array}{c}\text { MM } \\
304\end{array}$ & $\begin{array}{l}\text { Ectocarpus } \\
\text { rallsiae }\end{array}$ & $\begin{array}{c}\text { Wynne Plaza } \\
\text { Park, Condado } \\
\text { de New } \\
\text { Hanover }\end{array}$ & $\begin{array}{l}\text { Wilmington } \\
\text {, NC, EUA }\end{array}$ & $11 / 02 / 2016$ & $\begin{array}{l}\text { D.W. Freshwater; } \\
\text { M LaCroce }\end{array}$ & $\begin{array}{c}34^{0} 12.501 ' \mathrm{~N} \\
077^{0} 47.815^{\prime \prime} \\
\mathrm{W}\end{array}$ & - & - \\
\hline
\end{tabular}

Os organismos encontrados em epibiose foram coletados junto comseus hospedeiros e os espécimes foram imediatamente acondicionados e mantidos vivos em água do mar em frascos térmicos de 1 litro.

Logo após a coleta, o material foi submetido a uma triagem morfológica sob microscópio estereoscópio (American Optical Forty) e microscópio óptico (American Optical Fifty) para limpeza e separação de exemplares para posteriores estudos morfológicos e moleculares, além da observação da forma dos cloroplastos, feita apenas em material vivo e necessária para a delimitação de gêneros. Após a triagem, parte dos representantes foi separadae fixada em solução de formaldeído a 
4\% em água do mar para estudos morfológicos. Para os estudos moleculares, porções destes organismos, livres de epibiontes, foram separados, secos com papel absorvente, acondicionados em sacos de papel filtro e identificados em frascos individuais com sílica-gel dessecante. Quando coletados táxons com problemas de identificação ou com pouca biomassa, os mesmos foram mantidos em frascos em água do mar para o cultivo in vitroem laboratório.

\subsection{Estudos Morfológicos}

O material foi submetido a uma análise detalhada sob microscópio estereoscópico (Leica Wild M3C, Alemanha) e microscópio óptico (Nikon Eclipse E200, Japão). Medidas dos caracteres vegetativos e reprodutivos foram feitas usando-se ocular micrométrica para um conjunto de 15 medidas para cada estrutura analisada a partir de um adez exemplares escolhidos aleatoriamente, quando possível. Para as medidas morfométricas são fornecidos os valores mínimo e máximo para cada estrutura. As ilustrações de cada táxon foram feitas usando-se câmera digital (Sony Cyber Short,W570)representando o hábito mais comum do talo e suas variações morfológicas e a variaçãona forma das estruturas de reprodução. Após análise, o material foi depositado no herbário do Instituto de Biociências da Universidade de São Paulo (SPF) em coleçãode laminário, uma vez que os exemplares são,em sua maioria, diminutos. Quando possível, as lâminas foram associadas às exsicatas, que seguiram os métodos de herborização conforme o protocolo usual para algas marinhas.

\subsection{Cultivo}

Para garantir o sucesso na amplificação e sequenciamento de DNA algumas espécies coletadas com pouca biomassa foram submetidas ao desenvolvimento in vitro,seguindo-se os métodos adotados no Laboratório de Algas Marinhas Édison José de Paula, do Departamento de Botânica da Universidade de São Paulo.

As espécies (Tabela 3 ) foram cultivadas emágua do mar filtrada e esterilizada por radiação UVC e enriquecida com solução de nutrientes Von Stosch (Ursi \&Plastino 
2001) à 25\% com troca semanal, aeração com alternância a cada 30 minutos, temperatura de $25^{\circ} \mathrm{C}+1{ }^{\circ} \mathrm{C}$ e o fotoperíodo de $14 \mathrm{~h}$ claro / $10 \mathrm{~h}$ escuro.

Tabela 3.Espécies cultivadas no Laboratório de Algas Marinhas Édison José de Paula.

\begin{tabular}{|c|c|c|c|c|}
\hline $\begin{array}{l}\text { Código de } \\
\text { Coleta }\end{array}$ & Amostra & Local de Coleta & Cidade & Data \\
\hline MM 023 & $\begin{array}{l}\text { Ectocarpus } \\
\text { fasciculatus }\end{array}$ & $\begin{array}{l}\text { Ponta da Cabeça, Praia } \\
\text { Grande }\end{array}$ & $\begin{array}{l}\text { Arraial do Cabo, } \\
\text { RJ }\end{array}$ & $16 / 04 / 2014$ \\
\hline MM 025 & $\begin{array}{l}\text { Hincksia } \\
\text { sandriana }\end{array}$ & $\begin{array}{l}\text { Ponta da Cabeça, Praia } \\
\text { Grande }\end{array}$ & $\begin{array}{l}\text { Arraial do Cabo, } \\
\text { RJ }\end{array}$ & $16 / 04 / 2014$ \\
\hline MM 043 & $\begin{array}{l}\text { Bachelotia } \\
\text { antillarum }\end{array}$ & Praia do Cibratel II & Itanhaém, SP & 05/11/2014 \\
\hline MM 054 & $\begin{array}{l}\text { Feldmannia } \\
\text { mitchelliae* }\end{array}$ & Praia das Cigarras & $\begin{array}{l}\text { São Sebastião, } \\
\text { SP }\end{array}$ & 27/01/2015 \\
\hline MM 062 & $\begin{array}{l}\text { Feldmannia } \\
\text { mitchelliae* }\end{array}$ & $\begin{array}{l}\text { Ponta da Cabeça, Praia } \\
\text { Grande }\end{array}$ & $\begin{array}{l}\text { Arraial do Cabo, } \\
\text { RJ }\end{array}$ & 05/03/2015 \\
\hline
\end{tabular}

* Identificada em campo como F. indica.

\subsection{Estudos Moleculares}

As algas pardas filamentosas mostraram-se desafiadoras quanto ao sucesso na extração, amplificação e sequenciamento de DNA e necessitaram de inúmeros testes para garantir o êxito e qualidade dos nossos resultados. As amostras coletadas são diminutas e, em sua maioria, possuem grande quantidade de organismos epífitos, como diatomáceas. Para garantir que os filamentos destinados às análises moleculares fossem de um mesmo tufo destinado às análises morfológicas e, ainda, que estes estariam livres de contaminantes, a biomassa destinada à extração foi comprometida, resultando em porções de 0,005 g a 0,020 g.

Vários métodos de extração foram testados, de acordo com o manual do fabricante, e não resultaram em qualidade e quantidade de DNA suficientes para o avanço das análises, foram eles: Chelex ${ }^{\circledR} 100$ Resin (Bio-Rad,Hercules, EUA); Phire Plant Direct PCR(Finnzymes, Thermo Scientific, Waltham, EUA);QuickExtract Plant DNA Extraction Solution (Epicentre) eextração de DNA através de Método Manual 
(Faugeron et al. 2001). O kit de extração de tecidos vegetais NucleoSpin Plant II (Macherey-Nagel, Düren, Alemanha) foi o que apresentou melhor resultado. Assim, fragmentos de talo, foram submetidos à extração pelo o kit NucleoSpin Plant I/de acordo com o protocolo do fornecedor.

Após a extração, o DNA total foi submetido à eletroforese em gel de agarose 0,7\%, em tampão tris-borato-EDTA, corado com GelRedNucleic Acid Gel Stain (BiotiumHayward, CA, EUA), para averiguação da qualidade e quantidade de DNA extraído (Sambrook et al. 1989). Caso o procedimento tenha sido interrompido nesta etapa, as amostras de DNA foram armazenadas à $-20^{\circ} \mathrm{C}$.

Como marcador do tipo DNA Barcoding para algas pardas foi utilizada a região 5' do gene mitocondrial (cox1) que codifica a subunidade I da enzima citocromoc-oxidase (COI-5P) (Lane et al. 2007) e para as análises filogenéticas foi usado o gene codificante da subunidade grande da ribulose-1, 5-bifosfato carboxilase/oxigenase- Rubisco - o rbcL (Draisma et al. 2001, Bittner et al. 2008, Burrowes et al. 2003).

Apartir do DNA extraído, asamostras foram submetidas à amplificação através da técnica de PCR (Polymerase Chain Reaction) com a utilização do kitillustra ${ }^{\mathrm{TM}}$ puReTaq Ready-To-Go PCR Beads (GE Healthcare, Buckinghamshire, Inglaterra), sob as condições de $20 \mu \mathrm{L}$ de água, $1 \mu \mathrm{L}$ de cada amostra de DNA total e $1 \mu \mathrm{L}$ de cada oligonucleotídeos direto e reverso - F e $\mathrm{R}$, respectivamente (Tabela 4).

Tabela 4. Oligonucleotídeos dos marcadores mitocondrial (COI-5P) e plastidial ( $r b c \mathrm{~L})$ utilizados na amplificação e no sequenciamento deste estudo.

\begin{tabular}{|c|c|c|c|}
\hline Marcador & Oligonucleotídeo & Sequência $5^{\prime} \rightarrow 3^{\prime}$ & Referência \\
\hline COI-5P & Gaz F2 & CCAACCAYAAAGATATWGGTAC & Lane et al., 2007 \\
\hline COI-5P & Gaz R2 & GGATGACCAAARAACCAAAA & Lane et al.,2007 \\
\hline rbcL & $68 \mathrm{~F}$ & GCNAAAATGGGNWAYTGGGATGC & $\begin{array}{c}\text { Draisma et al., } \\
2001\end{array}$ \\
\hline rbcL & $708 \mathrm{R}$ & TTAAGNTAWGAACCYTTAACTTC & Bittner et al.,2008 \\
\hline rbcL & $543 F$ & CCWAAATTAGGTCTTTCWGGWAAAAA & Bittner et al., 2008 \\
\hline rbcL & 1381R & ATATCTTTCCATARRTCTAAWGC & $\begin{array}{c}\text { Burrowes et al., } \\
2003\end{array}$ \\
\hline
\end{tabular}


Os termocicladores MiniCycler (MJ Research) e TC-512 Thermal Cycler (Techne Barlworld Scientific) foram os utilizados nesta etapa através dos seguintes ciclos:

- COI-5P: $94^{\circ} \mathrm{C}$ por $4 \mathrm{~min}$, seguido por 40 ciclos de $94^{\circ} \mathrm{C}$ por $1 \mathrm{~min}, 50^{\circ} \mathrm{C}$ por $30 \mathrm{~s}$, $72^{\circ} \mathrm{C}$ por 2 min., com extensão final de $72^{\circ} \mathrm{C}$ por 8 minutos.

- rbcL: $94^{\circ} \mathrm{C}$ por $3 \mathrm{~min}$, seguido por 28 ciclos de $94^{\circ} \mathrm{C}$ por $1 \mathrm{~min}$., $52^{\circ} \mathrm{C}$ por $1 \mathrm{~min}$., $72^{\circ} \mathrm{C}$ por $2 \mathrm{~min}$., com extensão final de $72^{\circ} \mathrm{C}$ por 10 minutos.

Outros marcadores foram testados com base em literatura, porém nenhum resultou em amplificação (Tabela 5).

Tabela 5. Oligonucleotídeos testados para a amplificação e para o sequenciamento de cada marcador molecular.

\begin{tabular}{|c|c|c|c|}
\hline Oligonucleotídeo & Marcador & Sequência & Referência \\
\hline nad1-113F & nad1 & 5`CGWAAAATTATGGCNGGTATTCA 3` & $\begin{array}{c}\text { Silberfeld et al., } \\
2010\end{array}$ \\
\hline nad1-895R & nad1 & 3`AGNGGYAARAAACAYTTCCAACC 5` & $\begin{array}{c}\text { Silberfeld et al., } \\
2010\end{array}$ \\
\hline atp9-22F & atp9 & 5`ATGTTAGTTCAAGCTGCTAAAC 3` & $\begin{array}{c}\text { Silberfeld et al., } \\
2010\end{array}$ \\
\hline atp9-190R & atp9 & 3`ATYAARAAAGCCATCATYAAAGC 5` & $\begin{array}{c}\text { Silberfeld et al., } \\
2010\end{array}$ \\
\hline $\operatorname{cox} 3-44 \mathrm{~F}$ & $\cos 3$ & 5` CAACGNCAYCCWTTTCATTT 3` & $\begin{array}{c}\text { Silberfeld et al., } \\
2010\end{array}$ \\
\hline $\operatorname{cox} 3-739 R$ & $\operatorname{cox} 3$ & 3` CATCNACAAAATGCCAATACCA $5{ }^{\circ}$ & $\begin{array}{c}\text { Silberfeld et al., } \\
2010\end{array}$ \\
\hline $\operatorname{cox} 3-67 \mathrm{~F}$ & $\operatorname{cox} 3$ & 5`TTRGTTGAYCCNAGYCCNTGGC 3` & $\begin{array}{c}\text { Silberfeld et al., } \\
2010\end{array}$ \\
\hline $\operatorname{cox} 3-623 R$ & $\operatorname{cox} 3$ & 3` CATGAAANCCATGRAANCCNGTAG 5` & $\begin{array}{c}\text { Silberfeld et al., } \\
2010\end{array}$ \\
\hline UPA F & UPA & 5' GGACAGAAAGACCCTATGAA 3' & Presting, 2006 \\
\hline UPA R & UPA & 5' TCAGCCTGTTATCCCTAGAG 3' & Presting, 2006 \\
\hline
\end{tabular}

Após a amplificação da PCR, as amostras foram submetidas à eletroforese em gel de agarose (0,7\%).A quantificação do DNA amplificado foi feita por uma estimativa visual comparando-se a concentração do DNA amplificado e purificado 
com a concentração de DNA da banda de 1,6Kb do marcador "1Kb DNA ladder" (Invitrogen), seguindo as especificações fornecidas pelo fabricante.

Para a purificação foi utilizado o kit GFX ${ }^{\mathrm{TM}}$ PCR DNA and Gel Band Purification (GE Healthcare, Buckinghamshire, UK) sob protocolo do fabricante. Em seguida, as mesmas as amostrasforam quantificadas utilizando $1 \mathrm{uL}$ da amostra do DNA purificado para a análise da concentração de ácido nucleico (DNA/ $\mu \mathrm{L}$ ), através do equipamentoNanoDrop 2000 Spechtophotometer (Thermo Scientific, Waltham, EUA) e,então, encaminhadas para a reação de sequenciamento.

O sequenciamento foi feito com aproximadamente $2 \mathrm{uL}$ de produto purificado. As amostras foram então submetidas ao sequenciamento através dos sequenciadores automáticos ABI PRISM 3130DNA e 3730xI, com uso do kit Cycle Sequencing Big-Dye Terminator v3.1 (Applied Biosystems, Life Technologies, Grand Island, EUA), e com os mesmos oligonucleotídeos empregados na amplificação da PCR.

As sequências obtidas foram comparadas com as sequências de algas pardas filamentosas depositadas no banco de dados GenBank (http://www.ncbi.nlm.nih.gov), usando o algoritmo BlastN, e BOLD, The Barcode of Life Data System (www.barcodinglife.org) (Ratnasingham \& Hebert 2007).As sequências direta e reversa foram alinhadas manualmente usando-se o programa

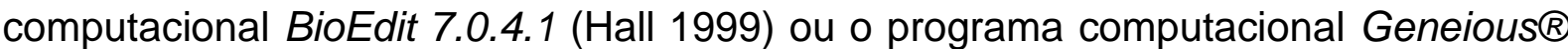
9.1.2, para gerar as sequências consenso. Incongruências nas sequências e posições ambíguas foram checadas manualmente analisando-se os cromatogramas.

Para o COI-5P foi feita análise de distância pelo método Neighbor-Joining (NJ) com 2000 réplicas de bootstrap, usando-se o programa PAUP 4.0b8 (Swofford 2002). Para o marcador $r b c L$, além da análise de NJ (2000 réplicas), foram utilizados os métodos de Máxima Verossimilhança (ML) e Inferência Bayesiana (BI) para as inferências filogenéticas. O modelo evolutivo utilizado foi o $G T R+I+G$, onde assumese o modelo Geral de Reversão ao longo do Tempo (GTR), com proporção de sítios invariáveis (I) e distribuição gamma $(G)$. O modelo foi selecionado pelo programa MrModeltest 2.2 (Nylander 2004) com um nível de significância de 0,01 usando-se o Akaike Information Criterion (AIC). A análise de ML, com 100 réplicas de bootstrap, foi feita pelo programa PhyML através do programa TOPALi v2.5 (Milne et al. 2009). A Inferência Bayesiana $(\mathrm{BI})$ foi feita utilizando-se o programa Mr.Bayes v.3.1.2 
(Huelsenbeck \& Ronquist 2001), com duas corridas com quatro cadeias de Markov, 4.000.000 de gerações com amostragem a cada 100 gerações. Foram descartadas as primeiras 50.000 gerações como "burn-in", determinado com a ajuda de um gráfico construído com as colunas de gerações e valores de máxima verossimilhança no programa Excel 2007. Após eliminar as árvores associadas ao "burn-in", uma árvore consenso foi construída para a análise do $r b c \mathrm{~L}$. Em todas as análises os "gaps" foram considerados dados ausentes. As porcentagens de divergência genética foram calculadas usando-se uncorrected ' $p$ ' distances no PAUP.

As árvores foram construídas a partir alinhamentos das sequências obtidas neste estudo e das sequências disponíveis no GenBank (Tabelas 6 e 7).

Tabela 6. Sequências obtidas do banco de dados GenBank com seus respectivos códigos de acesso utilizadas nas análises moleculares de COI-5P.

\begin{tabular}{|c|c|c|}
\hline Espécie & Local de Coleta & COI-5P \\
\hline Macrocystis integrifolia. & Canadá, Colúmbia Britânica. & FJ409174 \\
\hline Undaria pinnatifida & Itália & GQ368267 \\
\hline Spongonema tomentosum & Alemanha, Heligoland. & LM994974 \\
\hline Ectocarpus fasciculatus & França, Roscoff. & LM995264 \\
\hline Ectocarpus sp.1 siliculosus & Massachusetts, Glócester. & KF281133 \\
\hline Ectocarpus crouaniorum & França, Roscoff. & LM995245 \\
\hline Ectocarpus siliculosus & $\begin{array}{l}\text { Estados Unidos, Carolina do Norte, } \\
\text { Masonboro Som. }\end{array}$ & KF367762 \\
\hline Ectocarpus subulatus & France, Bretanha, Terenez. & LM995284 \\
\hline Kuckuckia spinosa & Croácia, Split. & LM995001 \\
\hline Myrionema strangulans & Estados Unidos, Maine, Bear Cove. & LM994985 \\
\hline Hecatonema maculans & Estados Unidos, Maine, Bear Cove. & LM994994 \\
\hline Acinetosporaceae sp.12 & Itália, Nápoles, Mergellina & LM995324 \\
\hline Acinetosporaceae sp. 11 & Coréia do Sul, Jeju, Seogwipo. & LM995439 \\
\hline Feldmannia irregularis & Itália, Nápoles, Mergellina & LM995322 \\
\hline Feldmannia irregularis & $\begin{array}{l}\text { Grécia, Golfo de Evoikos, porto de Porto } \\
\text { Rafti }\end{array}$ & LM995387 \\
\hline
\end{tabular}


Tabela 6. Continuação

\begin{tabular}{|c|c|c|}
\hline Espécie & Local de Coleta & COI-5P \\
\hline Hincksia mitchelliae & Itália: Napoli, Mergellina & LM995323 \\
\hline Hincksia mitchelliae & França, Bretanha, Le Caro & LM994975 \\
\hline Hincksia mitchelliae & $\begin{array}{c}\text { França, Bretanha, Roscoff, Santec, } \\
\text { Perharidy }\end{array}$ & LM994976 \\
\hline Feldmannia globifera & $\begin{array}{l}\text { França, Bretanha, Roscoff, Santec, } \\
\text { Perharidy }\end{array}$ & LM995281 \\
\hline Feldmannia globifera & $\begin{array}{l}\text { França, Bretanha, Roscoff, Santec, Roc'h } \\
\text { ar Bleiz }\end{array}$ & LM995197 \\
\hline Feldmannia globifera & Itália, Napoli, Castel dell'Ovo. & LM995330 \\
\hline $\begin{array}{l}\text { Acinetospora filamentosa (como } \\
\text { Ectocarpus filamentosus). }\end{array}$ & Japão, Niigata Pref., Murakami, Iwagasaki & LC060609 \\
\hline $\begin{array}{l}\text { Acinetospora filamentosa (como } \\
\text { Ectocarpus filamentosus). }\end{array}$ & Japão, Niigata Pref., Murakami, Iwagasaki & LC060608 \\
\hline Acinetospora crinita & $\begin{array}{l}\text { França, Bretanha, Roscoff, Santec, Roc'h } \\
\text { ar Bleiz }\end{array}$ & LM995175 \\
\hline Acinetospora crinita. & Grécia, Nea Peramos, Vrasida & LM995426 \\
\hline Acinetospora crinita. & Grécia: Saronida, Ilha de Koudounes & LM995405 \\
\hline Pylaiella littoralis. França & Bretanha, Roscoff, Santec, Roc'h ar Bleiz & LM995046 \\
\hline Hincksia granulosa & $\begin{array}{l}\text { França, Bretanha, Roscoff, Santec, Roc'h } \\
\text { ar Bleiz }\end{array}$ & LM995246 \\
\hline Hincksia granulosa & $\begin{array}{l}\text { França, Bretanha, Roscoff, Santec, Roc'h } \\
\text { ar Bleiz }\end{array}$ & LM995250 \\
\hline Hincksia granulosa & $\begin{array}{l}\text { França, Bretanha, Roscoff, Santec, Roc'h } \\
\text { ar Bleiz }\end{array}$ & LM995122 \\
\hline Hincksia sandriana & $\begin{array}{l}\text { Chile: América do Sul, Reloncavi, Puerto } \\
\text { Montt }\end{array}$ & LN828738 \\
\hline Hincksia hincksiae & $\begin{array}{l}\text { França, Bretanha, Roscoff, Santec, Roc'h } \\
\text { ar Bleiz }\end{array}$ & LM995208 \\
\hline Hincksia hincksiae & $\begin{array}{l}\text { França, Bretanha, Roscoff, Santec, Roc'h } \\
\text { ar Bleiz }\end{array}$ & LM995159 \\
\hline Hincksia hincksiae & $\begin{array}{l}\text { França, Bretanha, Roscoff, Santec, Roc'h } \\
\text { ar Bleiz }\end{array}$ & LM995199 \\
\hline Hincksia hincksiae & $\begin{array}{l}\text { França, Bretanha, Roscoff, Santec, Roc'h } \\
\text { ar Bleiz }\end{array}$ & LM995147 \\
\hline Feldmannia simplex & Itália: Napoli, Ischia & LM995288 \\
\hline
\end{tabular}




\begin{tabular}{lll} 
Feldmannia simplex & Itália: Napoli, Ischia & LM995286 \\
Feldmannia lebelii & França: Bretanha, Plougonvelin, Traezh Hir & LM994979 \\
\hline
\end{tabular}

Tabela 7. Sequências obtidas do banco de dados GenBank com seus respectivos códigos de acesso utilizadas nas análises filogenéticas de $r b c L$.

\begin{tabular}{|c|c|c|}
\hline Local de Coleta & rbcL & \\
\hline $\begin{array}{l}\text { Chorda Japão, Oshoro, Hokkaido } \\
\text { filum }\end{array}$ & AY372983 & \\
\hline Undaria pinnatifida & França & GQ368325 \\
\hline Punctaria plantaginea & Japão: Hokkaido, Akkeshi & AB302316 \\
\hline Leathesia sphaerocephala & Japão: Hokkaido, Akkeshi & AB302155 \\
\hline Cladosiphon umezakii & Coreia do Sul: Seokduri, Chujado & FJ805437 \\
\hline Elachista fucicola & - & AF055398 \\
\hline Myrionema strangulans. & - & AF055407 \\
\hline Elachista flaccida. & - & JF796583 \\
\hline Elachista scutulata & - & JF796584 \\
\hline Phaeostroma pustulosum & - & AF207808 \\
\hline Ectocarpus siliculosus & - & 11543 \\
\hline Ectocarpus siliculosus. & Austrália & AY307410 \\
\hline Ectocarpus siliculosus. & França: Bretanha, Santec, Perharidy & FN564467 \\
\hline Pylaiella littoralis & - & FN56446 \\
\hline Acinetospora sp. & $\begin{array}{l}\text { Japan, Hiroshima Pref., Innoshima, } \\
\text { Oohamacho }\end{array}$ & LC060517 \\
\hline Acinetospora sp. & $\begin{array}{l}\text { Japan, Hiroshima Pref., Innoshima, } \\
\text { Yaekojima }\end{array}$ & LC060516 \\
\hline Acinetospora sp. & Japan, Hokkaido, Muroran & LC060509 \\
\hline Acinetospora sp. & Japan, Hokkaido, Otaru, Oshoro & LC060507 \\
\hline Acinetospora sp. & Japan, Hokkaido, Otaru, Oshoro & LC060506 \\
\hline Hincksia mitchelliae. & - & U38753 \\
\hline Hincksia granulosa & - & EU681596 \\
\hline $\begin{array}{l}\text { Acinetospora filamentosa (como Ectocarpus } \\
\text { filamentosus) }\end{array}$ & Japão, Niigata Pref., Murakami, Iwagasaki & LC060490 \\
\hline
\end{tabular}


Acinetospora filamentosa (como Ectocarpus filamentosus).

Acinetospora filamentosa (como Ectocarpus filamentosus).

Tabela 7. Continuação

\begin{tabular}{lcc}
\hline Espécie & Local de Coleta $\quad$ rbcL & \\
\hline Asterocladon lobatum. & Brasil; São Paulo, Costa da Praia Brava. & FM956109 \\
Asteronema ferruginea. & - & AJ295818
\end{tabular}

Japão, Niigata Pref., Murakami, Iwagasaki LC060496

Japão, Niigata Pref., Murakami, Iwagasaki

LC060494 


\subsection{Sinopse dos táxons identificados}

Ochrophyta

Phaeophyceae

Fucophycidae

Ectocarpales

Acinetosporaceae

Acinetospora Bornet

Acinetospora filamentosa(Noda) Yaegashi, Uwai \& K. Kogame* Feldmannia Hamel

"Feldmannia" irregularis (Kützing) Hamel

"Feldmannia irregularis" 1

"Feldmannia irregularis" 2

"Feldmannia" mitchelliae (Harvey) H.-S. Kim

Hincksia J.E. Gray

"Hincksia" conifera (Børgesen) I.A. Abbott

Hincksiasandriana(Zanardini) P.C. Silva* ${ }^{1}$

Ectocarpaceae

Ectocarpus Lyngbye

Ectocarpusfasciculatus Harvey

Scytothamnales

Asteronemataceae

Asteronema Delépine \& Asensi

"Asteronema" breviarticulatum (J. Agardh) Ouriques \& Bouzon

\section{Bachelotiaceae \\ Bachelotia (Bornet) Kuckuck ex Hamel \\ Bachelotia antillarum(Grunow) Gerloff}

* Nova ocorrência para o Oceano Atlântico.

${ }^{*}$ Nova ocorrência para o Brasil.

Gêneros e espécies grafados entre aspas não foram confirmados molecularmente. 
Foram coletados, no presente estudo, um total de 302amostras de algas pardas filamentosas destinadas às análises morfológicas e moleculares, dentre as quais sete foram gentilmente cedidas pelo Prof. Dr. D.W. Freshwater, coletadas no Condado de New Hanover, Wilmington, Carolina do Norte, EUA. Dez táxons de algas pardas filamentosas foram identificados neste estudo. Destes, um constitui nova ocorrência para o Brasil, Hincksiasandriana(Zanardini) P.C. Silva e outro, nova ocorrência para o Oceano Atlântico, Acinetospora filamentosa(Noda) Yaegashi, Uwai \&K. Kogame.

A partir de 302amostras destinadas à biologia molecular foi obtidoum total de 145 novas sequências (Tabela 5), das quais 64 correspondem ao marcador mitocondrial do tipo Barcode COI-5P e 81 ao gene plastidialrbcL.

\subsection{Análises moleculares}

\subsubsection{Análise do marcador do rbcL}

Para análise com o rbcL foi gerada uma matriz com 126 sequências com um alinhamento final de 1288 pares de base (pb), incluindo 81 sequências geradas neste estudo e 45 obtidas do GenBank. Duas sequências de Laminariales foram usadas como grupos externos às Ectocarpales sensu lato: Chorda filum (Linnaeus) Stackhouse (AY372983) e Undaria pinnatifida (Harvey) Suringar(GQ368325). Para a matriz do $r b c \mathrm{~L}$ foram geradas árvores de distância (neighbor-joining, NJ), máxima verossimilhança $(\mathrm{ML})$ e de análise bayesiana $(\mathrm{BI})$. A árvore consenso de $\mathrm{NJ}$ é mostrada na Figura8. Nessa análise foram formados três clados principais: i) um clado formado pela ordem Scytothamnales com duas famílias Asteronemataceae e Bachelotiaceae, com suporte alto para ML (96\%) e PP (1.00); ii) um clado formado pelas ordens Asterocladales e Scytothamnales, com alto suporte em todas as análises, e iii) um clado formado pela ordem Ectocarpales com três famílias, Acinetosporaceae, Ectocarpaceae e Chordariaceae, com suporte moderado para ML (87\%) e alto para $\mathrm{PP}(1.00)$.

O clado formado apenas por Scytothamnales agrupou Asteronema ferruginea(Harvey) Delépine \& Asensi (Asteronemataceae) da Austrália e Bachelotia 
antillarum(Bachelotiaceae) do Brasil e da Nova Zelândia. A divergência intraespecífica entre as sequências de $B$. antillarum do Brasil,incluindo uma amostra do nordeste (Piauí), variou de $0 \%$ a $1,2 \%$, sendo a maior divergência observada entre amostras do Rio de Janeiro e Espírito Santo. A sequência de B. antillarum da Nova Zelândia divergiu de $1,4 \%$ a 1,6\% das amostras brasileiras.

O segundo clado com representantes das ordens Asterocladales e Scytothamnales se dividiu em dois subclados agrupando: i) duas espécies de Asterocladon, A. rhodochortonoides(Børgesen) Uwai, Nagasato, Motomura \& K. Kogame (Japão e Ilhas Canárias) e A. interjectum Uwai, Nagasato, Motomura \& K. Kogame (Japão), com alto suporte apenas para PP e ii) "Asteronema" breviarticulatum (Brasil, este estudo)(Scytothamnales) e Asterocladon lobatum D.G. Müller, E.R. Parodi \& A.F. Peters (Brasil, FM956109) (Asterocladales), com suporte total. As sequências brasileiras de "Asteronema" breviarticulatum (100\% idênticas) se agruparam com aespécie tipo de Asterocladon, Asterocladon lobatum, cuja localidade tipo é o Brasil, Praia Brava, São Paulo, e da qual divergiram em 5,9\%. Nossos espécimes divergiram de $A$. rhodochortonoidesde $8,5 \%$ a $8,6 \%$ e deA. interjectumem 9,3\%. Não há sequências de $A$. breviarticulatum (localidade tipo México) nos bancos de dados para comparação. Nossos resultados mostraram que o gênero Asteronema não é monofilético. Os espécimes brasileiros de "Asteronema" breviarticulatumdivergiram da outra espécie de Asteronema, A. ferruginea, disponível no banco de dados em $12,8 \%$.

O terceiro e maior clado foi formado pelas Ectocarpales. Dentro das Chordariaceae,duas amostras de espécies cuja localidade tipo é o Rio de Janeiro, Brasil, foram sequenciadas estudo: Elachistiella leptonematoides Cassano, Yoneshigue-Valentin \& M.J. Wynne e Levringia brasiliensis (Montagne) A.B. Joly. Essas espécies se agruparam com os demais representantes da família, embora com alto suporte apenas para PP (0.97). Duas sequências do banco de dados: Myriactula clandestina (P. Crouan \& H. Crouan) Feldmann e Myrionemapapillosum Sauvageau foram as mais divergentes dentre as Chordariaceae incluídas nas análises (Fig. 08). Phaeostroma pustulosum Kuckuck também pertencente à família Chordariaceae, se agrupou com representes de Ectocarpaceae, porém sem suporte. Nossos resultados parecem indicar que a família Chordariaceae não é monofilética. 
A família Ectocarpaceae, com suporte moderado para NJ (84\%) e alto para ML (100\%) e PP (1.00), incluiu duas sequências de Ectocarpussiliculosus (100\% idênticas) geradas neste estudo, provenientes dos EUA. As amostras sequenciadas de E. siliculosus formaram um subclado, com suporte moderado a alto, com duas amostras do banco de dados, uma procedente da Austrália e outra com localidade não identificada. A divergência intraespecífica entre as amostras desse subclado variou de $0 \%$ a $0,4 \%$, indicando que se trata de um mesmo táxon. Um segundo subclado agrupou amostras de E. siliculosus do Japão, França e Peru e divergiu do primeiro de 1,8\% a 2,8\%. Ectocarpus crouaniorum Thuret se agrupou neste segundo subclado com amostras de $E$. siliculosus, das quais divergiu de $0,8 \%$ a $0,9 \%$, variação que pode ser considerada intraespecífica. A amostra de E. fasciculatus da França divergiu de E. siliculosus de 1,2\% a 2,9\%. A maior divergência observada entre os subclados de E. siliculosus indica que pode haver diversidade críptica. Não há sequências disponíveis de $E$. siliculosus nos bancos de dados da localidade tipo, Inglaterra, para comparação.

A espécie Ectocarpus siliculosus foi citada para o Brasil em referências antigas como Martius et al. (1833) e Martens (1870) (Oliveira Filho 1977). Posteriormente, a espécie foi referida para o Rio de Janeiro por Taylor (1930) e para o Rio Grande do Sul por Coutinho (1982). Não há referências mais recentes de $E$. siliculosus para o litoral brasileiro e essa espécie não foi novamente coletada no presente estudo. Uma única amostra de Ectocarpus, E. fasciculatus foi coletada em Arraial do Cabo, Rio de Janeiro, porém não foi possível gerar sequências de $r b c L$ para essa amostra.

A família Acinetosporaceae foi dividida em dois clados principais com suporte moderado para ML (85\%) e alto para PP (1.00): Acinetosporaceae 1 e 2 (Fig. 8). O clado Acinetosporaceae 2, com baixo suporte (PP0.64), foi formado pelos gêneros Hincksia, Herponema J. Agardh e Pylaiella Bory e suas respectivas espécies tipo, $H$. hincksiae (Harvey) P.C. Silva(= $H$. ramulosa J.E. Gray, nom. illeg.), $H$. velutinum(Greville) J.Agardhe Pylaiella littoralis (Linnaeus) Kjellman. A amostra brasileira de Hincksiasandriana (Arraial do Cabo, RJ) se agrupou com $H$. hincksiae da qual divergiu em 2,3\%, indicando que são táxons distintos. A divergência entre H.sandriana e H. granulosa (Smith) P.C. Silva foi de 3,6\%. Hincksiasandriana é o único táxon encontrado neste estudo que pertence ao autêntico gênero Hincksia. 
O clado Acinetosporaceae 1 foi dividido em dois subclados principais formados por: i) Acinetospora filamentosa e $A$. crinita com alto suporte, e ii) "Feldmannia" irregularis, "F.irregularis" 1, "F.irregularis" 2, "F". mitchelliae, "Hincksia" conifera e Acinetospora asiatica Yaegashi, Yamagishi \& K. Kogame,também com alto suporte.

Duas amostras brasileiras (Rio de Janeiro) e uma dos EUA (Carolina do Norte) de $A$. filamentosageradas nesse estudo eidentificadas primeiramente como $A$. crinita, se agruparam com cinco amostras de $A$. filamentosa do Japão, localidade tipo da espécie. As amostras do Brasil e dos EUA apresentaram baixa divergência intraespecífica, 0\% a 0,15\%, e estas divergiram das amostras do Japão de 0\% a 0,6\%. As duas amostras brasileiras são $100 \%$ idênticas à amostra de $A$. filamentosa (LC060490) de Hokkaido, Japão. A amostra de A. crinita (AF207795), cuja procedência não foi especificada, divergiu de $A$. filamentosa de 2,9\% a 3,4\%. A espécie tipo de Acinetospora é Acinetospora pusilla (A.W. Griffiths ex Harvey) De Toni, atualmente considerada sinônimo de A. crinita (Guiry \& Guiry 2017). Portanto, A. crinita representa a espécie tipo do gênero.

Acinetospora asiatica não se agrupou com as outras duas espécies do gênero e se manteve como grupo irmão de "Feldmanniairregularis" 1 e "F.irregularis" 2, porém com suporte baixo (PP 0.73). As amostras de $A$. asiatica divergiram entre si de $0 \%$ a $0,2 \%$. A divergência entre $A$. asiatica e $A$. filamentosa variou de $4,4 \%$ a $5,0 \%$ e entre $A$. asiatica e $A$. crinita de 4,8\% a4,9\%. Enquanto que a divergência entre $A$. asiatica e " $F$. irregularis" 1 foi mais baixa, variando de 1,9\% a 2,3\%, e com " $F$ ". irregularis" 2 foi de 2,8\% a 2,9\%. A divergência entre $A$. asiatica e " $F$ ". irregularis foi de $2,5 \%$ a $3,2 \%$.

As amostras de " $F$ ". irregularis sequenciadas este estudo, procedentes do Rio de Janeiro e São Paulo, se agruparam com a única sequência de $r b c L$ dessa espécie disponível nos bancos de dados (AF207800, Ilha da Madeira, Portugal). As amostras brasileiras apresentaram baixa divergência intraespecífica (0\% a 0,16\%) e divergiram da amostra de Portugal de 1,1\% a 1,3\%.

As amostras denominadas como "F". irregularis" 1 (MM006, MM008 e MM009 - 100\% idênticas) formaram um clado com suporte total e se mantiveram distantes filogeneticamente de " $F$ ". irregularis, da qual divergiram de 2,3\% a 2,4\%. O mesmo foi verificado para clado formado por "F.irregularis" 2 (MM063, MM065, MM066 e 
MM068 - 100\% idênticas) que divergiu de " $F$ ". irregularis de 2,2\% a 2,8\%. "Feldmanniairregularis" 1 e "F".irregularis" 2 divergiram entre si de 1,7\% a 1,8\%. Não há sequências de $r b c L$ de $F$. irregularis da localidade tipo, Mar Adriático, disponíveis nos bancos de dados para comparação.

As amostras de "F". mitchelliae do Brasil, EUA (MM300) e Japão (AB302306, como Hincksia sp.) formaram um clado com suporte moderado a alto (88\% NJ, 74\% ML, 0.98 PP) (Fig.8). Hincksia sp. do Japão foi a sequência mais divergente variando de 0,4\% a 0,8\% em relação as sequências do Brasil e EUA.

Dois subclados de "F". mitchelliae foram formados: um com amostras apenas do Brasil (Rio de Janeiro, São Paulo e Espírito Santo) com divergência intraespecífica de 0\% a 0,23\%; e outro com amostras do Brasil (Rio de Janeiro e São Paulo), dos EUA (MM300), sequenciada neste estudo, e do Japão. As sequências brasileiras desse subclado foram 100\% idênticas e divergiram das do primeiro em até 0,5\%. Feldmanniamitchelliae tem como localidade tipo os EUA (Nantucket, Massachusetts). A amostra dos EUA (MM300) é procedente de Wilmington, Carolina do Norte, área muito próxima à localidade tipo. A divergência intraespecífica entre a amostra dos EUA e as brasileiras foi de 0,08\% a 0,4\%. 0 posicionamento das sequências analisadas e a baixa divergência genética do $r b c L$ sugerem que todas as amostras do Brasil, EUA e Japão correspondem ao mesmo táxon "F". mitchelliae.

O clado formado por "Hincksia" conifera, com alto suporte em todas as análises, foi recuperado como grupo irmão de "F." irregularis, embora com suporte alto apenas para PP (0.98). As amostras brasileiras de " $H$." conifera apresentaram baixa divergência intraespecífica variando de $0 \%$ a 0,8\%. "Hincksia" conifera divergiu do clado " $F$ ". irregularis de $1,7 \%$ a 2,1\%, enquanto a divergência com a espécie tipo do gênero, $H$. hincksiaefoi de 4,2 a 4,7\%.

A divergência genética verificada para o gene $r b c L$ está sumarizada na Tabela 8. Nossos resultados mostram uma clara sobreposição entre os valores de divergência entre gêneros, entre espécies e dentro de uma mesma espécie. A divergência intergenérica entre Acinetospora, Feldmannia, Hincksia e Ectocarpus foram baixas, indicando não apenas que esses gêneros são proximiamente relacionados, mas que necessitam de uma ampla revisão e de mudanças nomenclaturais visando acomodar algumas de suas espécies. A divergência entre 
Acinetospora asiatica, posicionada próximo ao gênero "Feldmannia", foi a mais baixa observada (1,9\%). As maiores divergências intraespecíficas encontradas para Ectocarpus e Feldmannia(2,8\%) reforça a necessidade de revisão desses gêneros.

Igualmente houve sobreposição entre os valores de divergência intergenérica e interespecífica entre Asteronema e Asterocladon. A divergência interespecífica entre espécies de Asterocladon ( $A$. lobatum, $A$. rhodochortonoides e A. interjectum) foi a mais alta observada $(7,7 \%$ a $8,9 \%)$. A baixa divergência verificada entre Asterocladone "Asteronema"breviarticulatum(5,9\%) demonstra que essa espécie deve ser alocada dentro do gênero Asterocladon. Isso é reforçado pela alta divergência interespecífica entre "Asteronema"breviarticulatum e Asteronema ferruginea $(12,8 \%)$, estando esse valor claramente na faixa de divergência entre gêneros para o marcador rbcL.

A maior divergência intraespecífica encontrada para o gênero Bachelotiafoi 1,6\% (Brasil vs. Nova Zelândia). A sequência de $r b c L$ da Nova Zelândia é a única disponível nos bancos de dados para comparação e, portanto, uma maior amostragem desse gênero é necessária, incluindo sequenciamento de espécime da localidade tipo (Guadalupe), para um melhor entendimento da variação genética dentro de Bachelotia. Entretanto, nossas análises indicam que $B$. antillarum é uma espécie críptica. 
Tabela 8. Amplitude de divergência genética entre os gêneros estudados para o gene $r b c L$.

\begin{tabular}{|c|c|c|c|c|}
\hline Gêneros/marcador & & & & \\
\hline Divergência intergenérica ( & & Interespecífic & & Intraespecífica(\%) \\
\hline Acinetospora e Asteronema & $10,4-12,6$ & Acinetospora & $\begin{array}{l}2,9- \\
5,0 * 3\end{array}$ & $0-0,6$ \\
\hline Acinetospora eAsterocladon & $8,7-12,4$ & Asteronema & $12,8^{*} 4$ & 0 \\
\hline Acinetospora e Bachelotia & $9,2-12,9$ & Asterocladon & $7,7-8,9$ & 0,1 \\
\hline Acinetospora e Ectocarpus & $7,4-9,2$ & Bachelotia & - & $0-1,6^{\star 5}$ \\
\hline Acinetospora e Feldmannia & $1,9^{*}-3,2$ & Ectocarpus & $1,2-2,9$ & $0-2,8^{* 6}$ \\
\hline Acinetospora e Hincksia ${ }^{\star 1}$ & $4,8-6,1$ & Feldmannia & $1,1-2,7$ & $0-2,8^{* 7}$ \\
\hline Asteronema e Asterocladon & $5,9^{* 2}-12,8$ & Hincksia $^{* 1}$ & $2,3-3,6$ & - \\
\hline Asteronema e Bachelotia & $10,9-13,3$ & & & \\
\hline Asteronema e Ectocarpus & $9,8-11,4$ & & & \\
\hline Asteronema e Feldmannia & $9,1-12,4$ & & & \\
\hline Asteronema e Hincksia ${ }^{* 1}$ & $10,2-11,9$ & & & \\
\hline Asterocladon e Bachelotia & $12,2-13,8$ & & & \\
\hline Asterocladon eEctocarpus & $8,7-11,6$ & & & \\
\hline Asterocladon e Feldmannia & $8,3-10,7$ & & & \\
\hline Asterocladon e Hincksia ${ }^{\star 1}$ & $9,3-11,9$ & & & \\
\hline Bachelotia e Ectocarpus & $9,5-13,4$ & & & \\
\hline Bachelotia e Feldmannia & $8,7-13,2$ & & & \\
\hline Bachelotia e Hincksia ${ }^{* 1}$ & $11,6-12,9$ & & & \\
\hline Ectocarpus e Feldmannia & $6,2-8,3$ & & & \\
\hline Ectocarpus e Hincksia ${ }^{* 1}$ & $5,1-7,6$ & & & \\
\hline Feldmannia e Hincksia ${ }^{* 1}$ & $3,7-5,5$ & & & \\
\hline $\begin{array}{l}\text { *Menor divergência entre Aci } \\
{ }^{*} \text { Valores relativos ao clado c } \\
{ }^{* 2} \text { Menor divergência entre“As } \\
{ }^{* 3} \text { Maior divergência entre Aci } \\
{ }^{*} \text { Divergência entre "Asterone } \\
{ }^{* 5} \text { Maior valor observado entr } \\
{ }^{*} \text { Maior valor observado entre } \\
{ }^{*} \text { Maior valor observado entr }\end{array}$ & $\begin{array}{l}\text { ospora asia } \\
\text { pposto por re } \\
\text { ronema" bre } \\
\text { tospora asia } \\
\text { a" breviartic } \\
\text { Bachelotia d } \\
\text { ois subcladc } \\
\text { Feldmannia }\end{array}$ & $\begin{array}{l}\text { "Feldmannia ir } \\
\text { entantes autên } \\
\text { Alatum e Aste } \\
\text { A. filamentos } \\
n \text { e Asteronem } \\
\text { sil e da Nova Z } \\
\text { E. siliculosus. } \\
\text { ularis e "F"irres }\end{array}$ & $\begin{array}{l}\text { laris" } 1 . \\
\text { do gêner } \\
\text { don lobatı } \\
\text { ruginea. } \\
\text { dia. } \\
\text { is" } 2 \text {. }\end{array}$ & $\begin{array}{l}\text { Hincksia. } \\
\text { m. }\end{array}$ \\
\hline
\end{tabular}


Figura 8. Árvore consenso gerada a partir da análise de Neighbor-Joining (NJ) para sequências do rbcL. Valores de bootstrap indicados nos ramos são referentes a NJ (2000 réplicas), Máxima Verossimilhança (ML) (100 réplicas) e probabilidade a posteriori (PP), respectivamente. Valores de bootstrap inferiores a 50 não apresentadors Amostras geradas neste estudo estão destacadas em negrito; indica falta de suporte; * indica suporte total do ramo (valor de bootstrap $=100 \% \mathrm{e}$ $\mathrm{PP}=1.00)$. 


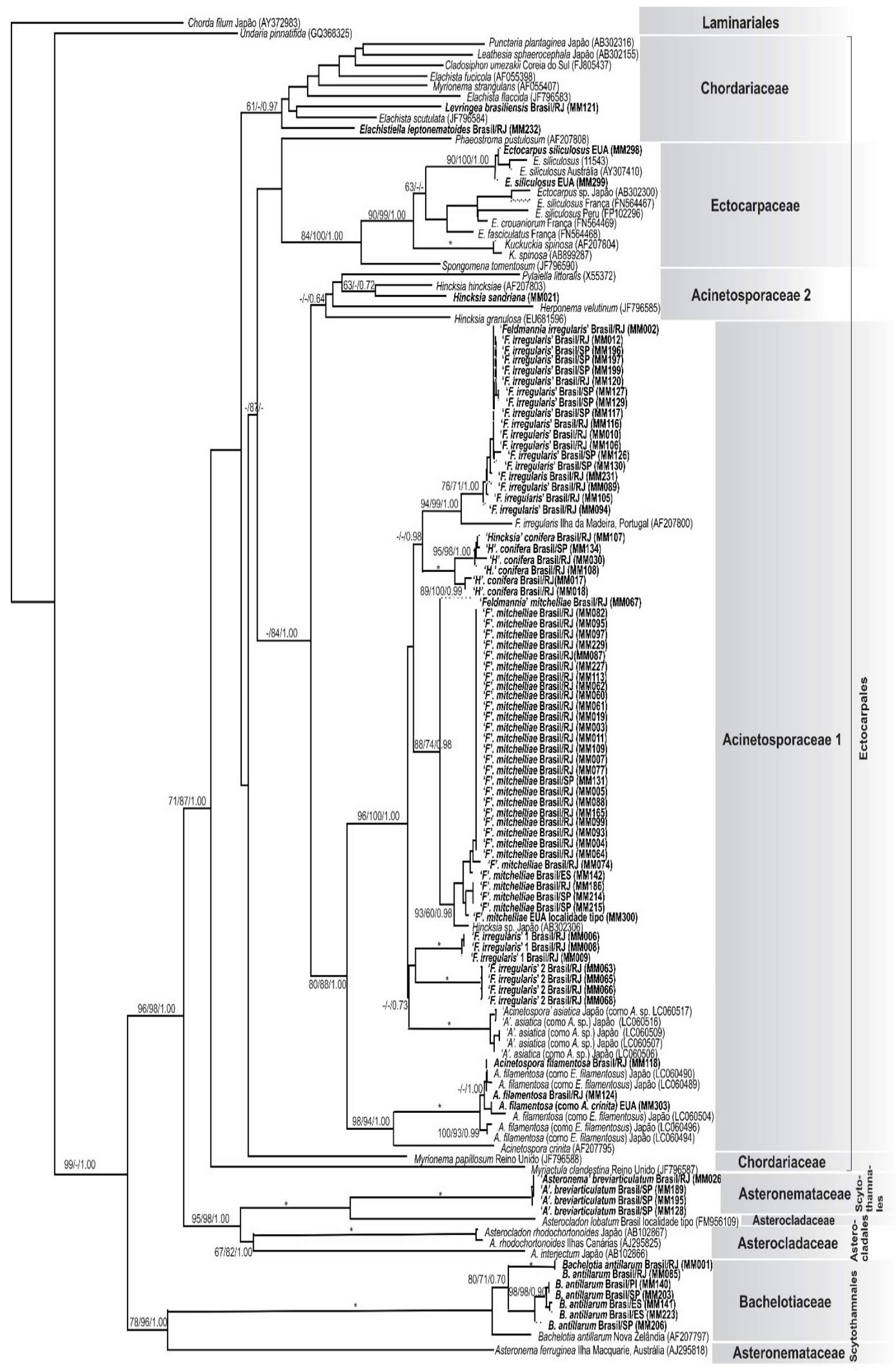




\subsubsection{Análise do Marcador COI-5P}

A Figura 9mostra a árvore referente à análise de Neighbor-Joining (NJ) para 0 marcador COI-5P. A matriz desse marcador foi formada com 107 sequências, sendo 63 geradas neste estudo e 44 extraídas do GenBank. O alinhamento final consistiu de 658 pb. Duas sequências de Laminariales foram usadas como grupos externos às Ectocarpales sensu lato: Macrocystis integrifolia Bory(FJ409174) e Undaria pinnatifida (Harvey) Suringar(GQ368267). Duas ordens de algas pardas com representantes filamentosos estão representadas nessa análise, Ectocarpales e Scytothamnales. A ordem Ectocarpales formou os dois agrupamentos, embora não sustentados pela análise de NJ: Acinetosporaceae 1 e Acinetosporaceae 2 (Fig. 9).

A família Ectocarpaceae formou um agrupamento com suporte baixo (68\%). A única sequência do gênero Ectocarpusobtida neste estudo, E. fasciculatus, procedente de Arraial do Cabo, Rio de Janeiro, divergiu da sequência da França (LM995264) em 1\%, indicando que se correspondemao mesmo táxon. Não há sequências de E. fasciculatus da localidade tipo (Irlanda) para comparação. A divergência intraespecífica entre as amostras de E. siliculosusfoi alta (0\% a 6,5\%). Ectocarpus fasciculatus do Brasil e da França divergiram da espécie tipo do gênero, E. siliculosus(Dillwyn) Lyngbye dos EUA e da França [como E. subulatus $($ LM995284) $=$ E. siliculosus var. dasycarpus (Kuckuck) Gallardo], de 6,3\% a 9,4\%, e de $E$. crouaniorum Thuret de 8,6 a 8,8\%. A divergência interespecífica entre $E$. siliculosus e E. crouaniorum variou de 5,7\% a 7,2\%.A divergência entreos gêneros Kuckuckia Hamele Ectocarpus(7,1\% - 9,0\%) se sobrepõe àdivergência interespecíficadeespécies de Ectocarpus, indicando que E. siliculosus pode representar uma espécie críptica. Portanto, uma revisão das espécies de Ectocarpus e Kuckuckia é necessária para esclarecer a posição taxonômica desses gêneros.

Representantes da família Chordariaceae se agruparam com suporte moderado (79\%). As amostras da espécie endêmica do Brasil, Elachistiella leptonematoides, sem divergência intraespecífica, se agruparam com Myrionemastrangulans Greville da qual divergiram em 11,5\%. Não foi possível obter sequências de Levringia brasiliensis para o COI-5P.Embora sem suporte, Hecatonema terminale(Kützing) Kylin (Chordariaceae) não se agrupou com os 
demais representantes da família Chordariaceae.Como nos dados obtidos com o $r b c L$, a família Chordariaceae parece não ser monofilética.

Dois agrupamentos foram formados por representantes da família Acinetosporaceae, embora sem suporte para NJ. O primeiro e maior agrupamento, Acinetosporaceae 1 incluiu o gênero tipo da família, Acinetospora, além do gênero "Feldmannia" e "Hincksia" conifera. O segundo agrupamento Acinetosporaceae 2 incluiu o gênero Hincksia e sua espécie tipo, H.hincksiae, o gênero Feldmannia e sua espécie tipo, F. lebelii (Areschoug ex P.Crouan \& H.Crouan) Hamel e o gênero Pylaiella e sua espécie tipo, $P$. littoralis. Neste agrupamento, se posicionaram as amostras de Hincksiasandrianado Brasil com uma divergência intraespecífica de $0,01 \%$. As amostras brasileiras se agruparam com $H$. sandriana do Chile com $100 \%$ de valor de bootstrap, divergindo da amostra chilena de 2,1\% a 2,2\%.A localidade tipo de $H$. sandriana é a Croácia e não há sequências disponíveis da localidade tipo para comparação.Hincksia sandriana formou um agrupamento com H.hincksiae com alto suporte (98\%). A divergência intraespecífica entre as amostras de H.hincksiae variou de $0 \%$ a $0,07 \%$. Os dois táxons divergiram entre si de 8,0 a $9,7 \%$.

Amostras de Hincksia granulosamostraramdivergência intraespecífica de 0\% a 0,06\%. A divergência interespecífica entre as espécies do agrupamento que contém o autêntico gênero Hincksia foi alta. A espécie tipo, $H$. hincksiaedivergiu de $H$. granulosa de $12,6 \%$ a $12,9 \%$, enquanto $H$. granulosa e $H$. sandrianadivergiram de $12,7 \%$ a 13,9\%. Essas divergências estão na faixa de amplitude observada entre diferentes gêneros de algas pardas filamentosas (Tabela 9).

No agrupamento Acinetosporaceae 1, o gênero Acinetospora foi o mais divergente e foi sustentado por $96 \%$ de valor de bootstrap. As amostras brasileiras de A.filamentosa, sem divergência intraespecífica, se agruparam, com alto suporte (100\%), com amostras dessa espécie procedentes da localidade tipo, Japão, das quais divergiram em apenas $0,01 \%$. A divergência intraespecífica de $A$. crinita variou de $0 \%$ a $0,7 \%$, enquanto que dentro de $A$. asiatica a variação foi de $0,7 \%$ a $2,6 \%$. A divergência interespecífica entre A.crinita e $A$. filamentosa foialta (11,3\% a 11,5\%). Maior amplitude de variação foi observada entre A.crinitae $A$. asiatica $(14,5 \%$ $15,8 \%)$ e entre $A$. filamentosa e $A$. asiatica $(14,4 \%-15,9 \%)$. Os resultados obtidos com o COI-5P foram semelhantes aos do $r b c \mathrm{~L}$, confirmando a ocorrência de $A$. filamentosa no litoral brasileiro. Como nos resultados obtidos como o $r b c L, A$. 
asiaticanão se agrupou com as demais espécies do gênero e se manteve como grupo irmão de "Feldmanniairregularis" 1, porém com suporte baixo (53\%). Nossos resultados para os dois marcadores indicam que $A$. asiatica não pertence ao gênero Acinetospora.

Dentro de Acinetosporaceae 1, o gênero "Feldmannia" está representado pelas espécies F. globifera (Kützing) Hamel, "F". irregularis, "F.irregularis" 1,"F. irregularis" 2 e " $F$ ". mitchelliae.As amostras brasileiras de " $F$ ". irregularis se agruparam com amostras dessa espécie procedentes daltália e Grécia com alto suporte (100\%). A divergência intraespecífica entre as amostras brasileiras foi de $0 \%$ a $0,6 \%$.A divergência entre as amostras brasileiras e a da Itália procedente de Nápoles (LM995322) foi de 4,8\% a 5,0\% e com as da Grécia de 4,7\% a 4,9\%. A amostra da Itália e as da Grécia divergiram entre si em apenas 0,01\%.

A localidade tipo de $F$. irregularis é o Mar Adriático, que banha o lado oriental da Itália. A amostra da Itália (LM995322)pode ser considera próxima à localidade tipo, já que Nápoles se localiza no Mar Tirreno, que banha o lado ocidental da Península Itálica. A divergência verificada entre as amostras brasileiras e a da Itália e Gréciaé alta, o que indica que correspondem a entidades taxonômicas distintas.

Os espécimes denominados como "F.irregularis" 1, coletados em Búzios e Arraial do Cabo, Rio de Janeiro, formaram um agrupamento com 100\% de bootstrap. Dois subgrupos foram formados, ambos com alto suporte (100\%): um com as amostras MM037 e MM038, procedentes de Arraial do Cabo e idênticas entre si; e outro com as amostras MM006, MM008 e MM009 coletadas em Búzios, também sem variação intraespecífica. Esses dois subgrupos mostraram variação genética de $2,5 \%$, indicando que podem pertencer a um mesmo táxon.

Os táxons denominados como "F.irregularis" 2, procedentes de São Paulo e Rio de Janeiro, formaram um agrupamento com alto suporte (100\%). As amostras brasileiras não apresentaram variação intraespecífica e foram mais próximas de uma amostra da Itália obtida do GB, nomeada como Acinetosporaceae sp. 12 (LM995324). A divergência entre as amostras brasileiras e Acinetosporaceae sp. 12 foi de $3,6 \%$, indicando que indicando que esse táxon é distinto das amostras brasileiras. 
O agrupamento de " $F$ ". irregularis mostrou alta divergência genética com"F.irregularis" 1 (9,9\% - 11,2\%) e com"F.irregularis" 2 (10,7\% - 11,2\%). "Feldmanniairregularis" 1 e "F.irregularis" 2 divergiram entre si de 9,4\% a 9,8\%. As altas divergências observadas sugerem que há três entidades taxonômicas independentespara o que anteriormente era considerado um único táxon, denominado deF. irregularis. Os dados obtidos para esses táxons com o marcador $r b c \mathrm{~L}$ foram corroborados pelo COI-5P.

As amostras brasileiras de "Hincksia" conifera coletadas em São Paulo e Rio de Janeiro formaram um agrupamento com alto suporte (100\%). Dois subgrupos foram formados: um com 100\% de bootstrap, agrupouduas amostras de Búzios, Rio de Janeiro (MM017 e MM018) e uma amostra identificada como Acinetosporaceae sp. 11 da Coreia do Sul (LM995439); e outro, como 99\% de bootstrap, agrupou as demais amostras brasileiras. O subgrupo formado pelas amostras MM017, MM018 e Acinetosporaceae sp. 11 apresentou baixa divergência genética, 0,3\%, o que indica que esses espécimes correspondem a um mesmo táxon. O segundo subgrupo teve uma maior amplitude de variação genética de $0,01 \%$ a 2,9\%. A divergência entre os dois subgrupos foi de $3,9 \%$ a 4,4\%. A amostra MM030 (Búzios, RJ) foi a mais divergente variando de $2,3 \%$ a $4,4 \%$ em relação às demais amostras do agrupamento. A divergência genética entre os dois subgrupos de " $H$." coniferaindica que podem se tratar de táxons distintos. A amplitude de variação intraespecífica do agrupamento" $\mathrm{H}$." conifera para o COI-5P foi muito mais elevada do que a obtidapara o rbcL, cuja amostra MM030 variou de 0,01\% a 0,8\% das demais, estando claramente dentro dafaixa de variação intraespecífica encontrada para esse marcador.

"Hincksia" conifera foi recuperada como grupo irmão de "F". irregularis com suporte moderado (84\%). Os dois táxons divergiram entre si de $7,7 \%$ a $9,8 \%$. A divergência genética entre " $H$." conifera e "F. irregularis" 1 variou de 9,9\% a 11,6\% e entre "F. irregularis" 2 de 9,3\% a 10,5\%.As amostras brasileiras de "H." coniferase mantiveram separadas das sequências da espécie tipo do gênero,de H.hincksiae,espécie tipo do gênero, das quais divergiram de $13,6 \%$ a $15,1 \%$. A localidade tipo de H.hincksiaeé Ballycastle, Irlanda do Norte. Não há sequências disponíveis da localidade tipo nos bancos de dados, porém todas as sequências dessa espécie são procedentes do Atlântico Norte (Roscoff, França).Os resultados 
obtidos para os dois marcadores utilizados nesse estudo claramente sustentam que o epíteto específico conifera não deve ser alocado no gênero Hincksia.

As amostras de " $F$ ". mitchelliae formaram um agrupamento com alto suporte (100\%). Três subgrupos foram recuperados, todos com alto suporte (100\%). O subgrupo mais divergente foi formado por duas amostras procedentes da França, idênticas entre si. Os dois outros subgruposforam formadospor:i) representantes do Brasil (Rio de Janeiro e São Paulo) e Itália eii) por representantes do Brasil (Rio de Janeiro e São Paulo).No primeiro subgrupo a divergência observada foi de $0 \%$ 0,9\%. Esse resultado indica que todas as amostras brasileiras e italianas correspondem a um mesmo táxon. A divergência no segundo subgrupoigualmente foi de $0 \%$ a $0,9 \%$. Esses dois subgrupos divergiram de 2,2\% a 3,4\%, enquanto as amostras da Françadivergiram destes de 4,9\% a 5,6\%,indicando que as amostras francesas são umaespécie distinta. Os dados obtidos com o COI-5P indicam que " $F$ ". mitchelliaeforma um complexo que poderia ser dividido em três táxons distintos.

Não há sequências de COI-5P de F. mitchelliaeda localidade tipo (EUA, Massachusetts) nos bancos de dados para comparação, e todas as tentativas de amplificação da amostra dos EUA (MM300)falharam para esse marcador. Os resultados do $r b c \mathrm{~L}$ não foram corroborados pelo COI-5P, cuja divergência para o primeiro marcador para todas as sequências de F. mitchelliaedo Brasil, EUA e Japão não ultrapassou $0,8 \%$.

A amostra deFeldmannialebelii (LM994979), espécie tipo do gênero Feldmannia, é procedente da sua localidade tipo (Bretanha, França). Nenhuma sequência de material brasileiro gerada neste estudo se agrupou com a espécie tipo do gênero Feldmannia. Apenas F. simplex(P. Crouan\& H.Crouan) Hameldo banco de dados formou um agrupamento com F.lebelii, porém com baixo suporte (69\%). A divergência entre essas duas espécies foi alta, variando de 12,6\% a 12,8\%. Feldmannialebeliidivergiu de " $F$ ". irregularis, "F.irregularis" 1 e "F.irregularis" 2 de $12,7 \%$ a $15,6 \%$ e de " $F$ ". mitchelliae de 13,6\% a 14,5\%. A divergência entre $F$. lebeliie F. globifera foi ainda mais alta $(15,9 \%$ - 16,1\%). A maior amplitude de variação genética verificada ocorreu entre $F$. simplexe " $F$ ". irregularisdo Brasil $(14,4 \%-17,3 \%)$.

A ordem Scytothamnales está representada nessa análise pela espécie Bachelotia antillarum, cujas amostras provenientes do Rio de Janeiro, Espírito Santo 
e São Paulo se agruparam com alto suporte (100\%). As amostras do Rio de Janeiro e São Paulo apresentaram baixa divergência genética, $0 \%$ a 0,01\%, enquanto a amostra do Espírito Santo divergiu de 5,8\% a 6,0\% das demais, sugerindo que essa é uma espécie críptica.

Para "Asteronema" breviarticulatumnão foi possível obter sequências do COI5P devido à dificuldade de amplificação desse marcador.

A Tabela 9 sumariza adivergência genética verificada para o gene COI-5P. Devido às distâncias genéticas observadas entre os agrupamentos formados pelos autênticos gêneros Hincksia e Feldmannia e os demais representantes previamente identificados sob esses gêneros, os valores de divergência foram considerados separadamente.Há sobreposição dos valores de divergência intergenérica, inter- e intraespecífica para os gêneros proximamente relacionados Acinetospora, Feldmannia sensu lato, Hincksiasensu latoe Ectocarpus.A disponibilidade de sequências das espécies tipo de Hincksia ( $r b c \mathrm{~L}$ e COI-5P) e de Feldmannia (COI$5 \mathrm{P})$ para as análises revelou que nenhuma das sequências obtidas neste estudo, com exceção de $H$. sandriana, correspondem a autênticos representantes de Feldmannia e Hincksia.Um novo gênero deverá ser estabelecido para acomodar os táxons pertencentes a Acinetosporaceae 1: "Feldmannia" irregularis, "F. irregularis" 1, F. irregularis 2, " $F$ ". mitchelliae, F. globifera, "Hincksia" conifera e Acinetospora asiatica. Contudo, a alta divergência genética encontrada não descarta a possibilidade da proposição de mais gêneros dentro de Acinetosporaceae 1, o que ainda demandará maiores análises para a sua efetivação. Duas espécies novas para a ciência deverão ser propostas para acomodar os táxons " $F$. irregularis 1" e" $F$. irregularis 2". 
Tabela 9.Amplitude de divergência genética entre os gêneros estudados para o gene COI$5 P$.

\begin{tabular}{|c|c|c|c|c|}
\hline Gêneros/marcador & & & OI-5P & \\
\hline Divergência intergenérica (\%) & & Interesp & cífica (\%) & Intraespecífica \\
\hline Acinetospora e Bachelotia & $16,1-17,8$ & Acinetospora & $11,3-15,9^{\star 3}$ & $0-2,6$ \\
\hline Acinetospora e Ectocarpus & $13,2-15,6$ & Bachelotia & - & $0,01-6,0^{* 6}$ \\
\hline Acinetospora e Feldmannia ${ }^{*}$ & $14,7-17,6$ & Ectocarpus & $5,7-9,4$ & $0-6,5^{\star 7}$ \\
\hline Acinetospora e Feldmannia & $9,3^{* 2}-16,2$ & Feldmannia ${ }^{*}$ & $12,6-12,8$ & 0,6 \\
\hline Acinetospora e Hincksia ${ }^{* 1}$ & $14,2-17,4$ & Feldmannia & $9,4-14,4^{* 4}$ & $0-5,6^{* 8}$ \\
\hline $\begin{array}{l}\text { Acinetospora e"Hincksia" } \\
\text { conifera }\end{array}$ & $11,3-14,7$ & Hincksia $^{{ }^{* 1}}$ & $8,0-13,9^{* 5}$ & $0-2,2$ \\
\hline Bachelotia e Ectocarpus & $15,1-17,2$ & "H." conifera & - & $0,01-4,4$ \\
\hline Bachelotia e Feldmannia* & $16,7-18,1$ & & & \\
\hline Bachelotia e Feldmannia & $14,4-17,6$ & & & \\
\hline Bachelotia e Hincksia ${ }^{* 1}$ & $16,3-18,7$ & & & \\
\hline $\begin{array}{l}\text { Bachelotia e "Hincksia" } \\
\text { conifera }\end{array}$ & $13,8-15,9$ & & & \\
\hline
\end{tabular}

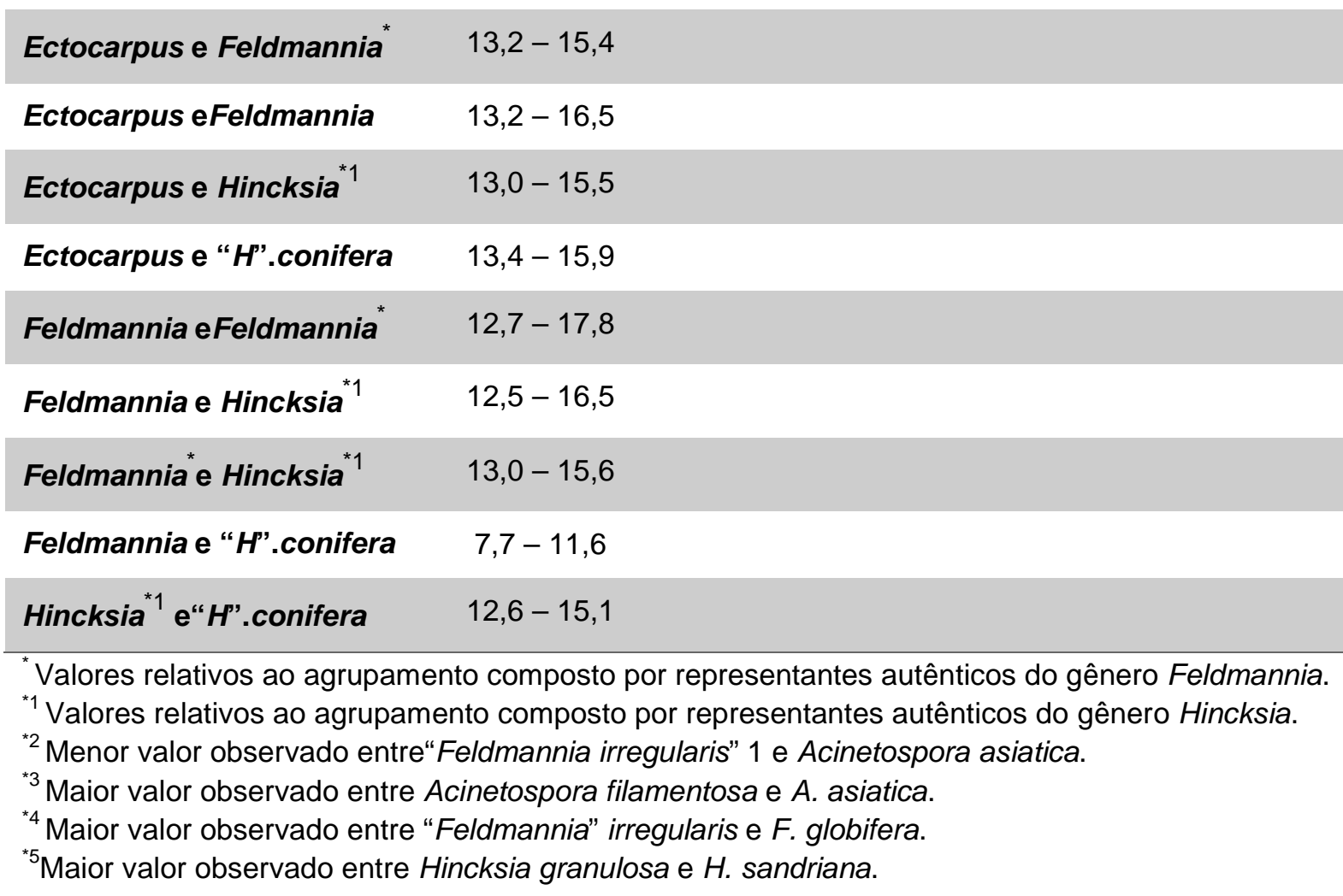


${ }^{* 6}$ Maior valor observado entre Bachelotia do Espírito Santo e demais amostras brasileiras.

${ }^{*}$ Maior valor observado entre amostras de Ectocarpus siliculosus.

${ }^{\star 8}$ Maior valor observado entre "Feldmannia" mitchelliae Brasil/Itália e França.

A Tabela 10 compila a amplitude de variação genética entre as sequências do $r b c$ Le doCOI-5P verificadas nesse estudo.

Tabela 10. Comparação da amplitude de variação da divergência genéticaentre os marcadores estudados.

Marcadores / \% de divergência

$r b c L$

COI-5P

Intergenérica

$\left(1,9^{*}\right) 3,7-13,8$

$\left(9,3^{*}\right) 12,5-18,7$

Interespecífica

$1,1-8,9\left(12,8^{*}\right)$

$5,7-15,9$

Intraespecífica

$0-2,8$

$0-6,5^{* 3}$

*Menor divergência entre "Acinetospora" asiatica e"Feldmannia irregularis" 1.

${ }^{*}$ Maior divergência entre "Asteronema" breviarticulatum e Asteronema ferruginea.

*2Menor divergência entre"Acinetospora" asiatica e"Feldmanniairregularis" 1.

${ }^{\star 3}$ Maior divergência entreespécies de Ectocarpus siliculosus.

As sequências do COI-5P foram mais variáveis em nível intergenérico, inter- e intraespecífico do que as do $r b c \mathrm{~L}$, como mencionado em estudos anteriores de algas pardas (Yaegashi et al. 2015) e, principalmente, de algas vermelhas (Geraldino et al.2006, Yang et al.2007, Cassano 2009, Nauer et al. 2014, 2015, Jesus et al. 2016), uma vez que o genoma mitocondrial apresenta taxas maiores de mutação no DNA do que o genoma do cloroplasto (Avise 1994). 
Figura 9. Árvore de Neighbor-Joining (NJ) para sequências do COI-5P. Valores de bootstrap estão indicados nos ramos (2000 réplicas). Valores de bootstrap inferiores a 50 não apresentados. Amostras geradas neste estudo estão destacadas em negrito. 


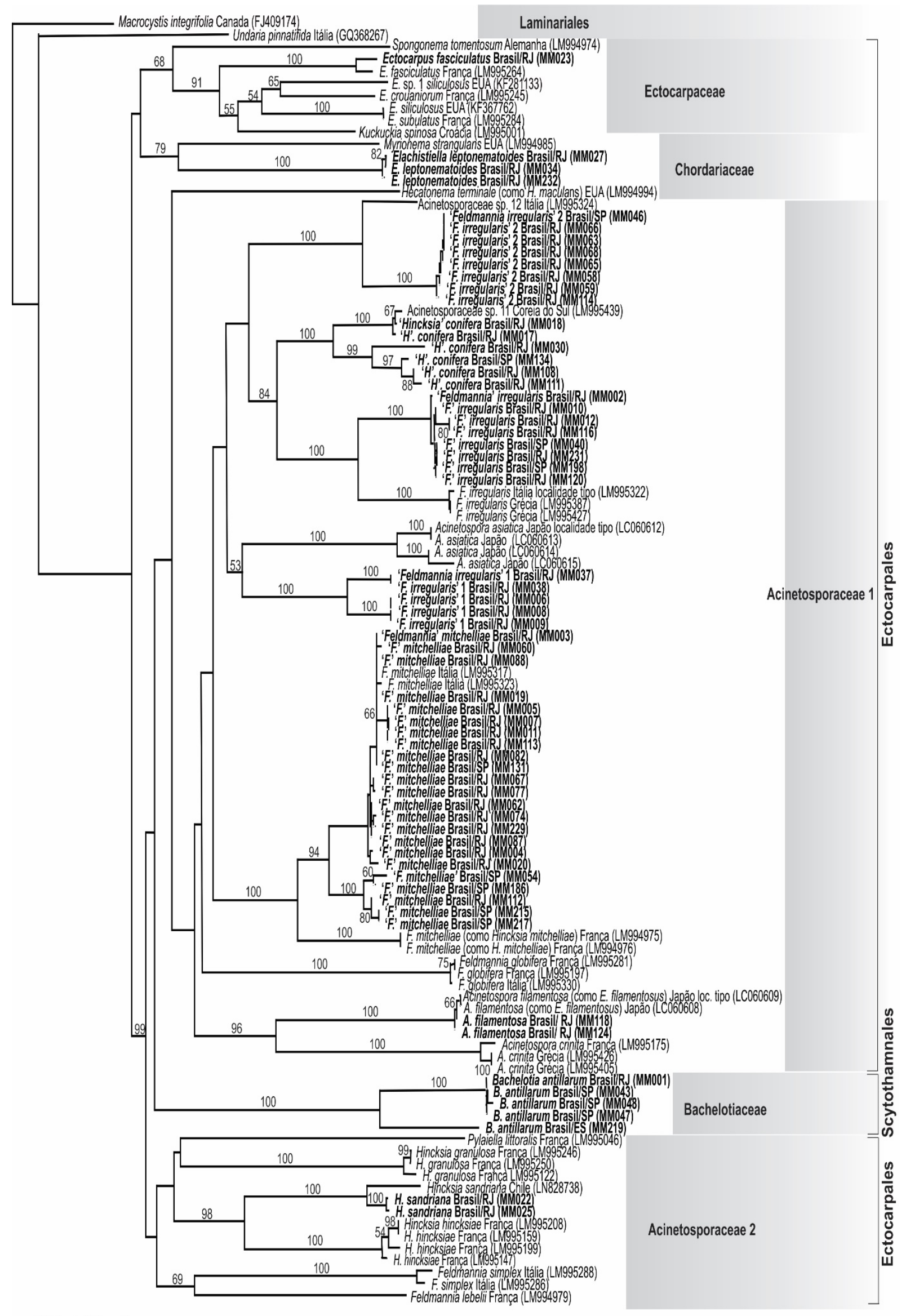

-0.005 substitutions/site 


\subsection{Análise Morfológica}

\section{Ordem Ectocarpales \\ Família Acinetosporaceae \\ Gênero Acinetospora Bornet}

Talos em tufos, eretos, epífitos ou epilíticos, filamentos unisseriados esparsamente ramificados, sem distinção de filamento principal, formando massas emaranhadas, fixos por rizoides produzidos a partir de células inferiores do talo ou por curtos ramos denominados "crampons". Filamentos terminados por células arredondadas ou em pseudopêlos. Crescimento difuso no talo e com regiões meristemáticas definidas na base dos ramos laterais. Ramos laterais e râmulos curtos ("crampons") usualmente dispostos em ângulo reto. Cloroplastos discoides, numerosos por célula contendo um pirenoide. Reprodução por estruturas uniloculares (meiosporângios), esporângios pluriloculares e gametângios pluriloculares, ou ainda por acinetosporângios ou monosporângios, ambos produzindo células imóveis. Esporângios pluriloculares cônicos alongados, usualmente com pedicelos de uma célula dispostos em ângulo reto no filamento. Esporângiosuniloculares estritamente esféricos, normalmente sésseis sobre o filamento principal. Histórico de vida diplo-haplôntico isomórfico (Kim 2010, Cormaci et al. 2012).

\section{Acinetospora filamentosa (Noda) Yaegashi, Uwai \&K. Kogame in Yaegashi et al. 2015: 334, fig. 2 A-G.}

Figuras $10-16$

\section{Basiônimo:}

Ectocarpus filamentosus Noda. 
Talo filamentoso unisseriado formando densos tufos de aspecto emaranhado, medindo 1-1,5 cm de altura (Figs 10, 11). Talo esparsamente ramificado, sem eixo principal definido. Filamentos eretos com ramificação irregular portando ramos laterais curtos originados em ângulo aberto a reto, retos ou curvados (crampons), com ápices arredondados (Figs 13-15). Células dos filamentos eretos medindo 17,5$30 \mu$ mde diâmetro nas porções medianas do talo, contendonumerosos cloroplastos discoides com um pirenoide por cloroplasto. Pseudopêlos não observados. Crescimento difuso, com zona meristemática curtas localizadas preferencialmente nas porções superiores do talo (Fig. 12). Estruturas pluriloculares cônicas, sésseis, algumas dispostas em ângulo reto ao filamento principal medindo 40-65 $\mu \mathrm{m}$ de comprimento e 20-32,5 $\mu \mathrm{m}$ de diâmetro (Fig. 16). Estruturas uniloculares não observadas.

Habitat:Crescendo do médiolitoral ao infralitoral raso, epilítica em costões rochosos ou em poças-de-maré ocupando uma superfície mais ou menos extensa do costão.

Material Examinado:Brasil, Rio de Janeiro, Município de Armação de Búzios, Praia Rasa, 08/03/2015, col. M. Mungioli; V. Cassano \& C.A.A. Azevedo(MM105), Praia da Ferradurinha, 09/03/2015, col. M. Mungioli; V. Cassano \& C.A.A. Azevedo(MM118 e MM124). Estados Unidos, Carolina do Norte, Wilmington,Wynne Plaza Park, Condado de New Hanover, 11/02/2016, col. D.W. Freshwater \& M LaCroce (MM303).

\section{Comentários}

O gênero Acinetosporafoi estabelecido por Bornet (1891) para acomodar plantas que possuíam estruturas pluriloculares (acinetosporângios) que produziam grandes esporos imóveis (acinetósporos) (Pedersen \& Kristiansen 2001, Yaegashi et al. 2015). A circunscrição do gênero foi ampliada em diversos trabalhos posteriores e, atualmente, o gênero é caracterizado por apresentar filamentos unisseriados pouco ramificados, formando tufos emaranhados, ramos laterais curtos em ângulo reto, com extremidade reta ou recurvada formando ganchos chamados "crampons", 
zona meristemática difusa, cloroplastos discoides a ligeiramente alongados, presença de estruturas pluriloculares cônicas em ângulo reto, estruturas uniloculares e monosporângios (Yoneshigue \& Figueiredo 1983, Széchy \& Cordeiro-Marino 1991, Kim \& Lee 1994, Pedersen \& Kristiansen 2001, Yaegashi et al. 2015).

A independência genérica de Acinetosporafoi questionada por vários autores com base em trabalhos de cultivo (Kornmann 1953,Knoepffler-Pèguy 1972, 1974, 1977). Acinetospora crinitafoi considerada por Kornmann (1953) como uma fase do ciclo de vida de espécies de Feldmannia, no qual $A$. crinitacorresponderia ao esporófito diploide. Ou ainda, o gênero foi considerado meramente como uma fase morfológica alternante de Feldmannia ou Hincksia (como Giffordia Batters) por Knoepffler-Pèguy $(1972,1974,1977)$, cuja passagem, reversível de um morfo a outro, seria influenciada por fatores ambientais (Knoepffler-Pèguy 1972, 1977).De acordo com Knoepffler-Pèguy (1972), o aparecimento da forma Acinetospora seria induzido por baixas temperaturas, enquanto a forma Feldmannia seria induzida por temperaturas mais altas, independentemente da alternância gametófito-esporófito. Estudos posteriores de morfogênese desenvolvidos por Kim \& Lee (1994) atestaram que plantas esporofíticas de $A$. crinita não eram as mesmas de Feldmannia, e os gêneros Acinetosporae Feldmanniaforam mantidos como independentes, seguindo os estudos prévios de Pedersen (1983) e Amsler \& Kapraun (1985). Formas alternantes entre Feldmannia e Acinetospora também foram observadas em cultura de F. irregularis por Cassano (1997). Porém, devido à falta de estudos específicos com o gênero Acinetospora proveniente do campo (espécimes desse gênero não foram encontrados nos locais de coleta), e, consequentemente, a impossibilidade do estabelecimento de cultivo, Feldmannia e Acinetospora não foram considerados cogenéricos por Cassano (1997) até que estudos mais aprofundados fossem realizados com espécimes brasileiros. Os dados moleculares obtidos nesse estudo, assim como os de Yaegashi et al. (2015), claramente sustentam a independência genérica desses táxons.

Acinetosporafilamentosa foi descrita como Ectocarpus filamentosusNoda(1970) para a costa de Iwagasaki, Província de Echigo, Japão (Silva et al. 1996). A espécie foi transferida para o gênero Acinetospora por Yaegashi et al. (2015) com base em dados morfológicos e moleculares, usando sequências de $r b c \mathrm{~L}$ e COI-5P. A espécie é caracterizada pela presença de 
estruturas pluriloculares e uniloculares nos filamentos prostrados e nas porções inferiores dos filamentos eretos (Yaegashi et al. 2015). O material brasileiro de $A$. filamentosa se enquadra na descrição fornecida por esses autores quanto ao diâmetro do filamento ereto (17,5-30 $\mu \mathrm{m}$, presente estudo vs. 18-28 $\mu \mathrm{m}$, Yaegashi et al. 2015); presença de zonas meristemáticas difusas, ramos laterais formando "crampons" e ausência de monosporângios. Entretanto, não foram observadas estruturas uniloculares ou pluriloculares em filamentos prostrados, uma vez que estes, assim como estruturas de fixação, não foram encontrados no material estudado.

O gênero Acinetospora foi citado pela primeira vez para o Brasil quando Yoneshigue \& Figueiredo (1983) reportaram A. crinita para Cabo Frio, Rio de Janeiro, cuja ocorrência foi associada ao fenômeno de ressurgência na região. Além do Rio de Janeiro (Yoneshigue \& Figueiredo 1983, Széchy \& Cordeiro-Marino 1991), a espécie tem citação para Santa Catarina (Bouzon et al. 2006) e São Paulo (Széchy \& De-Paula 2015), sendo restrita as regiões sudeste e sul do Brasil.

A espécie A. crinitaé distinta deA.filamentosapela presença de monosporângios e estruturas do tipo acinetosporângios (produzem células imóveis), megasporângios (produzem células móveis) e estruturas pluriloculares com grandes e pequenos lóculos(Pedersen \& Kristiansen 2001, Yaegashi et al. 2015). A espécie A. asiatica, estabelecida por Yaegashi et al. (2015),difere de $A$. crinita pelas mesmas características citadas acima e de $A$. filamentosa pela ausência de estruturas uniloculares. Yoneshigue \& Figueiredo (1983) e Széchy \& Cordeiro-Marino (1991) descreveram a presença de monosporângios nos espécimes do Rio de Janeiro de $A$. crinita, estruturas que não são descritas para $A$. filamentosa e não foram encontradas nos nossos exemplares examinados desta espécie.Além disso, as estruturas pluriloculares descritas como ovoides para A. crinitapor Yoneshigue \& Figueiredo (1983) são muito distintas das observadas no material de A. filamentosa do presente estudo.

Exemplares de A. crinita não foram novamente coletados no presente estudo, embora o mesmo local onde a espécie foi encontrada pela primeira vez (Ponta da Cabeça, Arraial do Cabo, RJ) tenha sido visitado em três diferentes coletas em 2014 e 2015. Portanto, a ocorrência de A. crinita para o litoral brasileiro não pôde ser confirmada por dados moleculares. 
Os dados moleculares tanto para o rbcL como para o COI-5Pdemonstraram que os espécimes coletados neste estudo, assim como a amostra proveniente dos EUA correspondem, sem dúvida, à $A$. filamentosa, cuja divergência intraespecífica com os espécimes da localidade tipo foi baixa para ambos os marcadores, 0\% a 0,6\% para o rbcLe apenas 0,01\% para o COI-5P. Essa é a primeira citação de $A$. filamentosa para o Oceano Atlântico. A espécie havia sido citada anteriormente apenas para a sua localidade tipo, Japão, e Grécia, onde foi considerada como uma introdução recente (Yaegashi et al. 2015, Guiry \& Guiry 2017). 
Figuras 10 - 16. Acinetospora filamentosa. Anatomia vegetativa e reprodutiva de material fixado.

Figs 10 - 11. Aspecto geral do talo mostrando filamentos frouxamente emaranhados.

Fig. 12. Filamento ereto exibindo zona meristemática curta (seta).

Figs 13 - 15. Ramos laterais curtos perpendiculares ao eixo principal.

Fig. 16. Estruturas pluriloculares cônicas sésseis. 

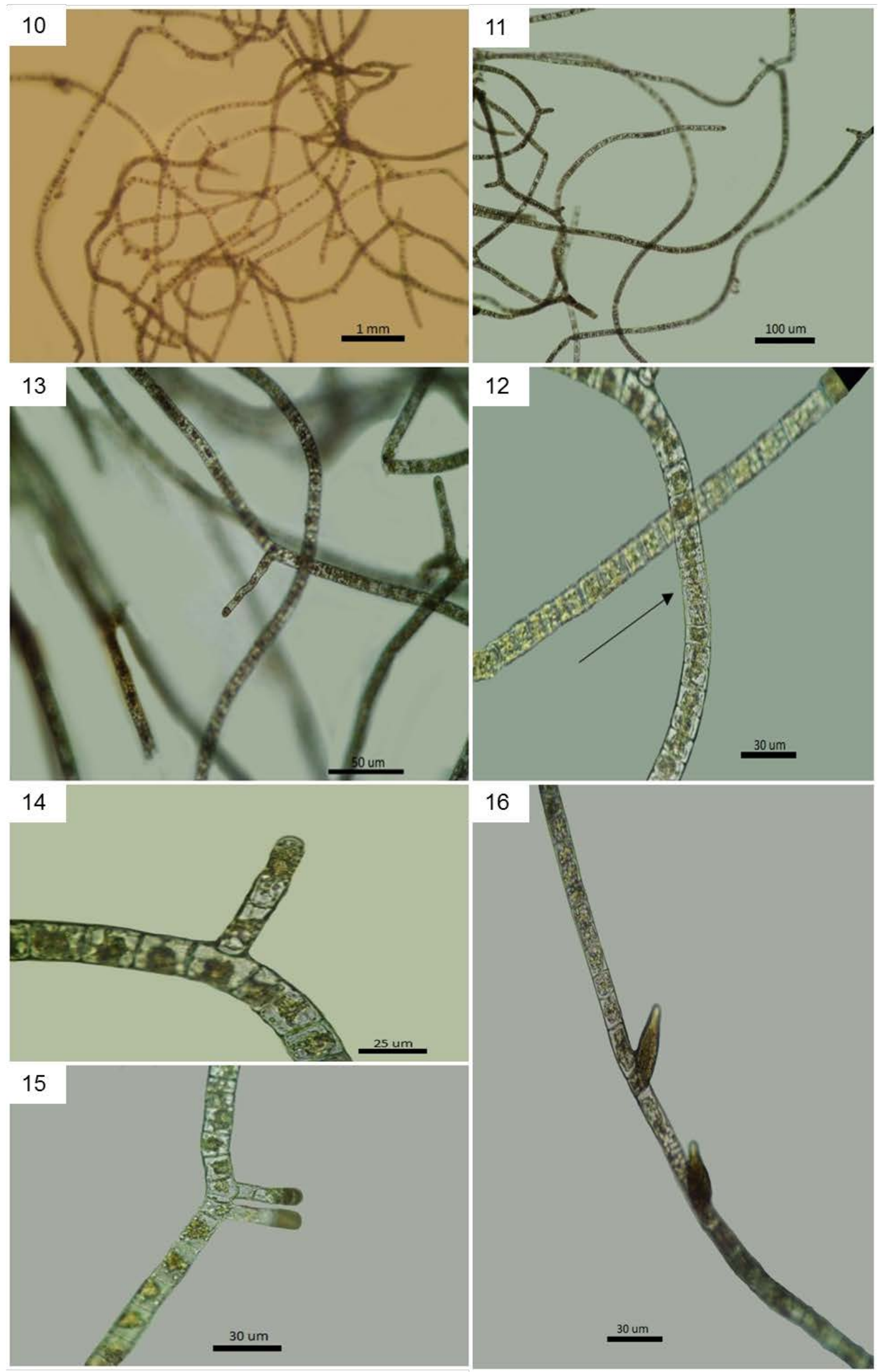


\section{Gênero Feldmannia Hamel}

Optou-se pela descrição do gênero Feldmannia aqui apenas para fins comparativos, uma vez que nossos resultados moleculares demonstraram que o material analisado não corresponde ao autêntico gênero Feldmannia.

Talos em tufos, eretos, epífitos, epilíticos ou com filamentos basais endifíticos, filamentos unisseriados ramificados, com organização heterotríquia, fixos por rizoides. Crescimento localizado, principalmente por zonas meristemáticas basais nos filamentos principais; em algumas espécies desenvolvimento de meristemas secundários entre os internós (intervalos entre ramos laterais). Filamentos eretos, normalmente ramificados de forma alterna ou oposta, abaixo da zona meristemática e com um longo filamento simples acima; ou com 2-3 ramos laterais juntos, emitidos em séries mais ou menos regulares abaixo do meristema secundário formando repetidas ramificações acima do meristema secundário, frequentemente terminadas em pseudopêlos. Cloroplastos discoides, numerosos por célula contendo um pirenoide. Esporângios pluriloculares cônicos alongados a globulares cilíndricos, sésseis ou pedicelados desenvolvidos abaixo das zonas meristemáticas, ou em séries nas porções basais dos râmulos em espécies que produzem meristemas secundários. Esporângiosuniloculares ovoides a elipsoides, sésseis desenvolvidos na mesma posição que os pluriloculares. Histórico de vida diplo-haplôntico isomórfico (Kim 2010, Cormaci et al. 2012).

\section{"Feldmannia" irregularis(Kützing) Hamel 1939: xvii}

Figuras17 - 23

\section{Basiônimo:}

Ectocarpus irregularis Kützing

\section{Sinônimos homotípicos:}

Giffordia irregularis (Kützing) Joly

Hincksia irregularis (Kützing) C. Amsler 
Talo filamentoso, unisseriado, heterótrico, habitualmente epífito, formandotufos densos de coloração marrom amarelada a marrom esverdeada, quando vivos, atingindo $0,5-0,7 \mathrm{~cm}$ de altura (Fig. 17), fixo ao substrato por filamentosrizoidais que partem dos filamentos prostrados. Filamentos eretos longos,simples ou pouco ramificados de forma irregular na sua porção basal, sem ramificação ou estruturas reprodutivas produzidas acima da zona meristemática (Figs 18, 19).Porção apical dos filamentos eretos terminados empseudopêlos (Fig. 19). Células dos filamentos principais medindo 20-27 $\mu \mathrm{m}$ de diâmetro nas porções medianas do taloe contendo numerosos cloroplastos discoides com um pirenoide por cloroplasto, evidenciados em material vivo (Fig. 23). Zona meristemática definida, localizada na porção basal dos filamentos eretos. Estruturas pluriloculares cônicas com base alargada e ápice atenuado a fusiformes, sésseis ou pediceladas com até uma célula (Figs 20-22),

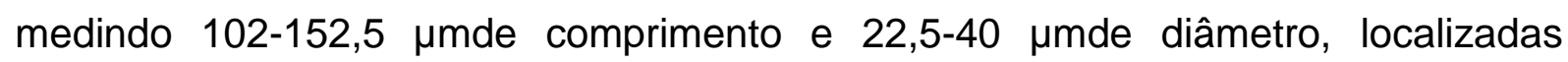
sempre abaixo da zona meristemática.Estruturas uniloculares não observadas.

Habitat:Crescendo na zona entremarés, usualmente epizóica em cirripédios do gênero Chthamalus, gastrópodos do gêneroLittorina e do gênero Brachidontes. Comumente associada a "Feldmannia" mitchelliae.

Material examinado:Brasil, Rio de Janeiro, Município de Armação dos Búzios, Ponta da Lagoinha, Praia da Foca, 15/04/2014, col. M. Mungioli; V. Cassano, J. C. De-Paula \& C.A.A.Azevedo (MM002, MM010,MM012), 09/03/2015, col. M. Mungioli; V. Cassano \& C.A.A. Azevedo (MM120), Praia Rasa, 08/03/2015, col. M. Mungioli; V. Cassano \& C.A.A. Azevedo (MM106), Praia da Ferradurinha, 09/03/2015, col. M. Mungioli; V. Cassano \& C.A.A. Azevedo (MM116, MM117); Município de Arraial do Cabo, Pontal do Atalaia, Prainhas, 06/03/2015, col. M. Mungioli; V. Cassano \& C.A.A. Azevedo (MM089); Município de Cabo Frio, Praia das Conchas, 07/03/2015, col. M. Mungioli; V. Cassano \& C.A.A. Azevedo (MM094). São Paulo, Município de Itanhaém, Praia do Cibratel II, 20/03/2015, col. M. Mungioli; C.A.A. Azevedo \&F. F. C. Ho (MM126, MM127, MM129, MM130); Município de São Sebastião, Praia de Toque-Toque Pequeno, 30/01/2015, col. M. Mungioli \& V. Cassano (MM188); Município de Peruíbe, Reserva Juréia-Itatins,04/05/2015, Praia Desertinha, col. M. Mungioli \& C.A.A. Azevedo (MM196, MM197 e MM198). 


\section{Comentários}

A espécie Ectocarpus irregularis foi originalmente descrita por Kützing (1845) a partir de material coletado no Mar Adriático. Kützing (1855) ilustrou o espécime tipo mostrando filamentos eretos simples, estruturas pluriloculares cônicas, localizadas próximo à base da planta, posicionadas abaixo ou no início da zona meristemática basal, definida, seguida de pseudopêlos (Cassano 1997). De acordo Clayton (1974), o material tipo não foi localizado e é possível que esteja depositado em L (Nacional Herbarium Nederland) (Guiry \& Guiry 2017).

"Feldmannia" irregularis tem ampla distribuição no litoral brasileiro se estendendo do Rio Grande do Sul a Pernambuco (Széchy \& De-Paula 2015). Entretanto, uma ampla revisão deve ser feita para esse táxon cujas citações podem representar mais de uma espécie ou ser um nome mal aplicado para "H". conifera.

A história taxonômica de Feldmannia irregularis é longa e problemática devido a diferentes circunscrições e entendimentos descritos na literatura para esse táxon, tendo o epíteto irregularis sido atribuído a diferentes gêneros.

Hamel (1939), ao propor o gênero Feldmannia, efetuou a nova combinação Feldmannia irregularis (Kützing) Hamel e colocou Ectocarpus coniferus Börgesen (= Ectocarpus conifer) como sinônimo da primeira, seguindo Sauvageau (1933). A descrição de F. irregularisde Hamel (1939) incluiu plantas com estruturas pluriloculares sempre sésseis, adaxiais, seriadas nos ramos laterais, típicas de "H." conifera (= E. coniferus) e, embora não mencionadas, a sua ilustração mostra zonas de crescimento intercalares no talo (Cassano 1997). Assim, Hamel (1939) ao incluir Ectocarpus coniferus sob o gênero Feldmannia, ampliou a sua circunscrição genérica, estabelecida por ele mesmo, na qual o gênero Feldmanniaagrupava plantas com zonas meristemáticas localizadas na base dos filamentos e com ramificações e estruturas pluriloculares (opostas, geralmente pediceladas) localizadas abaixo dos meristemas.

Taylor (1960) deu uma diferente interpretação para esses táxons e considerou E. coniferus como uma espécie independente, transferida para o gênero Giffordia Batters, para a qual propôs a nova combinação Giffordia conifera (Börgesen) Taylor.

O gênero Giffordia foi criado por Batters em 1893 para acomodar a espécie Ectocarpus secundus Kützing que produzia estruturas de reprodução de tamanhos 
diferentes, provavelmente gametas anisogâmicos (Russell 1966, Clayton 1974). Hamel (1939) ampliou a circunscrição do gêneroGiffordia, transferindo todas as espécies de Ectocarpuscom cloroplastos discoides, estruturas pluriloculares sempre sésseis, frequentemente em série, em geral, não opostas, com presença de pseudopelos e ausência de zonas meristemáticas basais e definidas para o gênero Giffordia.

Joly (1965) julgou que a combinação de Giffordia conifera feita por Taylor (1960) era desnecessária, uma vez que o próprio autor da espécie Ectocarpus coniferBörgesen (1914) admitiu mais tardeque sua espécie era coespecífica de $E$. irregularis (Börgesen 1941). Assim, Joly (1965) propôs a nova combinação Giffordia irregularis (Kützing) Joly, com G. conifera como sinônimo.A combinação de Joly (1965) foi seguida por mais de duas décadas por muitos autores, muitos dos quais brasileiros.

Silva et. al. (1987) transferiram 21 espécies de GiffordiaBatters (1893) para o gênero Hincksia Gray (1864) com base em prioridade de publicação. De acordo com Silva et. al.(1987), Gray propôs o gênero Hincksia com uma única espécie, $H$. ramulosaJ.E. Gray, nom. illeg., baseado em Ectocarpus hincksiae Harvey (1841). Entretanto, Silva et al. (1987) mantiveram o epíteto irregularis no gênero Feldmannia e não mencionaram o posicionamento de G. conifera.

Abbott (1989) considerou G. conifera como um táxon independente de F.irregularis e propôs a nova combinação Hincksia conifera (Börgesen) I.A. Abbott.

A despeito do tratamento taxonômico dado por Silva et al. (1987) para Feldmannia irregularis, Széchy \& Cordeiro-Marino (1991) e, ao mesmo tempo, Amsler in Schneider \& Searles (1991) transferiram Ectocarpus irregularis para o gênero Hincksia propondo a nova combinação Hincksiairregularis (Kützing) C. Amsler, mantendo $H$. conifera como sinônimo.

A divergência quanto à circunscrição desta espécie persistiu em publicações posteriores. Müller \& Ramirez (1994) consideraram Feldmannia irregularis e Hincksia conifera como entidades taxonômicas distintas, baseados em estudos de campo e cultivo. Assim como Kim \& Lee (1994),que por meio de estudos de morfogênese em material de campo e de cultura, reconheceram que 'a forma coniferus' de $F$. irregularis constituía uma espécie independente, colocada também sob o 
gêneroHincksia.Em oposição, Wynne (1998) na primeira revisão do seu checklist para o Atlântico ocidental, considerou Hincksia coniferaeHincksiairregulariscomo sinônimos de F. irregularis.

Cassano (1997), em seu estudo de campo e cultivo de algas pardas filamentosas do Rio de Janeiro, considerou $F$. irregularis e $H$. conifera comotáxons independentes, principalmente pela posição da zona meristemática, difusa em $H$. conifera e localizada em $F$. irregularis. Com base na ilustração do espécime tipo de Ectocarpus irregularis de Kützing (1855) a autora considerou que o epíteto específico irregularis seria melhor alocado no gênero Feldmannia pelo posicionamento basal e localizado da zona meristemática e $E$. coniferus foi reconhecida como uma espécie independente sob o gênero Hincksia, por apresentar zona meristemática difusa.

A maioria dos autores brasileiros seguiu o tratamento de Wynne (1998) para esses táxons, que foi mantido na segunda revisão do seu checklist (Wynne 2005). Entretanto, Wynne (2011) aceitou os argumentos de Kraft (2009) para a manutenção de $F$. irregularise $H$. coniferacomo táxons distintos e adotou esse tratamento na terceira revisão do seu checklist.

"Feldmannia" irregularis tem ampla distribuição no litoral brasileiro se estendendo do Rio Grande do Sul a Pernambuco (Széchy \& De-Paula 2015). Entretanto, uma ampla revisão deve ser feita para esse táxon cujas citações podem representar mais de uma espécie ou ser um nome mal aplicado para " $H$ ". conifera.

O epíteto irregularis foi atribuído aqui aos espécimes sequenciados no presente estudo que se agruparam com sequências de $r b c L$ do banco de dados e de COI-5P procedentes de locais próximos à sua localidade tipo, e que possuem as seguintes características morfológicas: filamentos eretos simples ou pouco ramificados na base, zona meristemática basal, localizada, estruturas pluriloculares basais e ramos laterais produzidos abaixo dos meristemas e presença de pseudopelos. Plantas com estas características se assemelham à ilustração do espécime tipo de Kützing (1855) e às descrições e ilustrações de plantas epífitas em Codium spp. e FucusLinnaeus dadas por Sauvageau (1933), Ercegovic (1955), Cardinal (1964), Kim \& Lee (1994), Müller \& Ramirez (1994), Cassano (1997) e Kim (2010). Portanto, nossos espécimes concordam com as descrições desses autores 
no hábito, forma de crescimento, diâmetro do filamento principal e dimensões das estruturas pluriloculares.

Os dados moleculares obtidos nesse estudo demonstraramque, indubitavelmente, $F$. irregularis e $H$. conifera não correspondem à mesma entidade taxonômica, como definido em estudos anteriores com base em morfologia e cultura (Müller \& Ramirez 1994, Kim \& Lee 1994, Cassano 1997, Kraft 2009). Além disso, o posicionamento filogenético e a alta divergência genética entre essas espécies e suas respectivas espécies-tipo apontam que os epítetos irregularis e conifera devem ser atribuídos a novos gêneros. 
Figuras 17-23. "Feldmannia" irregularis. Anatomia vegetativa e reprodutiva.

Fig. 17. Aspecto geral de tufos epífitos em Sargassum sp.

Fig. 18. Detalhe de um tufo mostrando filamentos eretos longos sem ramificação ou estrutura reprodutiva acima da zona meristemática.

Fig. 19. Detalhe da porção apical dos filamentos eretos mostrando pseudopelos.

Figs 20 - 22. Estruturas pluriloculares sésseis ou pediceladas com até uma célula, localizadas abaixo da zona meristemática.

Fig. 23. Detalhe das células mostrando numerosos cloroplastos discoides com um pirenoide, evidenciados em material vivo. 


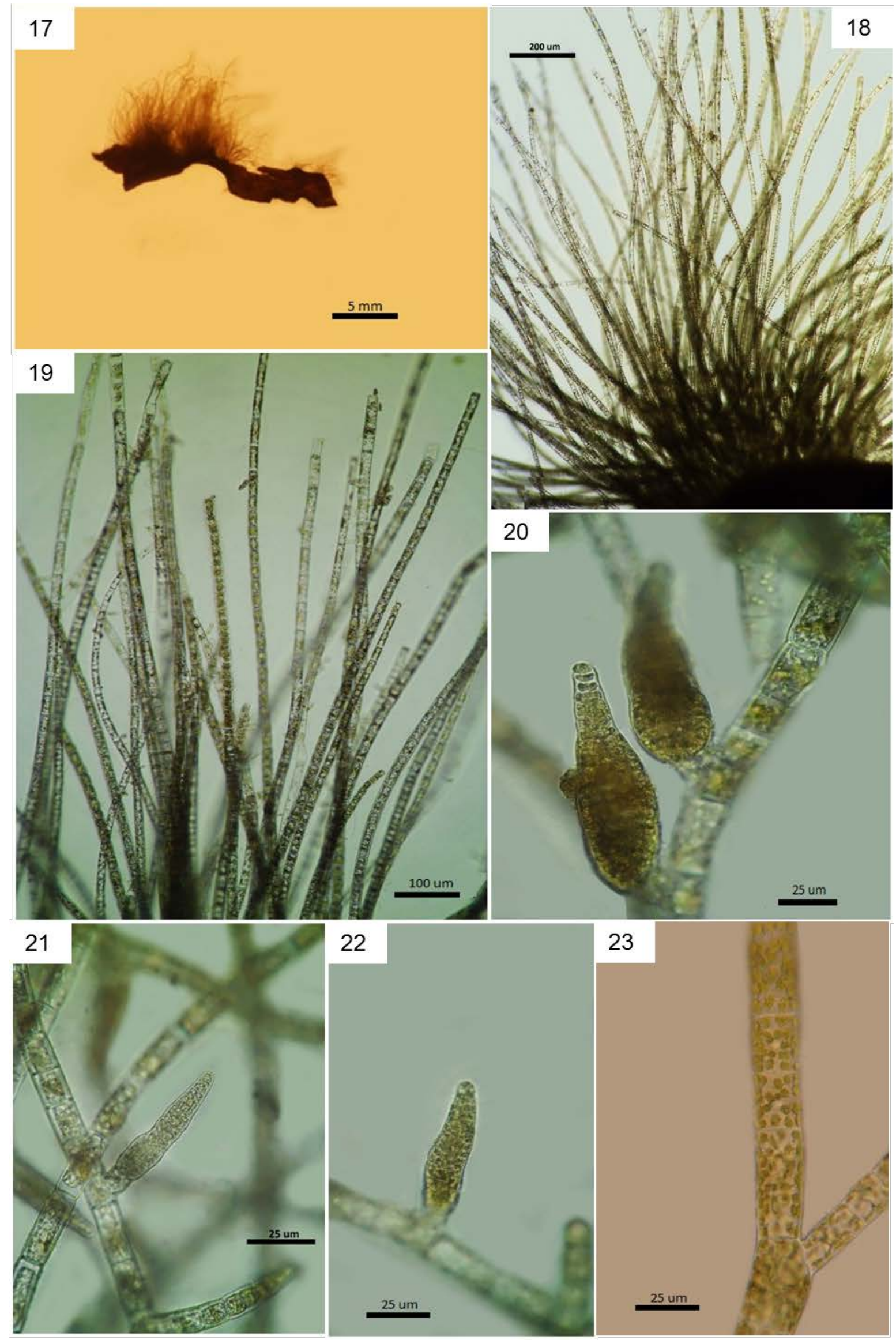




\section{"Feldmanniairregularis" 1}

Figuras $24-33$

Talofilamento, unisseriado, heterótrico, formando densos tufos de coloração amarronzada, quando vivos, medindo 1-1,5 cm de altura (Fig. 24), fixo ao substrato por filamentos rizoidais originados das porções inferiores dos filamentos eretos. Filamentos eretos com ramificação esparsa, irregular a alterna (Fig. 25). Porção apical dos filamentos eretos terminados empseudopelos. Células dos filamentos principais medindo 20-27,5 $\mu \mathrm{m}$ de diâmetro nas porções medianas do talo e contendonumerosos cloroplastos discoides com um pirenoide por cloroplasto, evidenciados em material vivo. Zona meristemática definida, localizada nas regiões superiores do talo (Figs 25, 26), acima da qual não são formados ramos laterais ou estruturas reprodutivas. Estruturas pluriloculares cônicas-lineares a cônicas com base alargada e ápice atenuado, sésseis ou pediceladas com até quatro células(Figs 27-32), normalmente formando longas séries ao longo dos filamentos principais e dos ramos laterais (Figs 25 e 30), medindo 40-85 $\mu$ mde comprimento e 20-40 $\mu$ mde diâmetro. Estrutura unilocular ovoide, séssil, medindo 31 umde comprimento e 25 $\mu$ mde diâmetro(Fig. 33).

Habitat:Crescendo na zona entremarés, usualmente epizóica em cirripédios do gênero Chthamalus, gastrópodos do gêneroLittorina e do gênero Brachidontes. Comumente associada a "Feldmannia" mitchelliae.

Material examinado:Brasil, Rio de Janeiro, Município de Armação dos Búzios, Ponta da Lagoinha, Praia da Foca, 15/04/2014, col. M. Mungioli; V. Cassano, J. C. De-Paula \& C.A.A.Azevedo (MM006, MM008, MM009), Município de Arraial do Cabo, Pontal do Atalaia, Prainhas, 16/04/2014, col. M. Mungioli; V. Cassano \& C.A.A.Azevedo. (MM037, MM038). 


\section{Comentários}

Cassano (1997) descreveu dois morfotipos para Feldmannia irregularis. O primeiro incluiu espécimes epífitos com morfologia semelhante às plantas típicas de Ectocarpus irregularis e que foram tratadas no presente trabalho como "Feldmannia" irregularis, descrita acima. O segundo morfotipo incluiu plantas que foram denominadas pela autora de 'formas variantes' de F. irregularis, nas quais os talos eram maiores em comprimento, os filamentos eretos com maior diâmetro e mais ramificados e as estruturas pluriloculares, sésseis ou pediceladas, distribuídas ao longo do filamento principal e nos ramos laterais. As zonas meristemáticas nessas plantas maioreseram, em geral, nítidas, localizadas nas regiões mais superiores do talo, acima dos ramos laterais e estruturas de reprodução. Geralmente com presença de zonas meristemáticas secundárias curtas, distribuídas no talo, abaixo da zona meristemática primária. Neste morfotipo incluem-se os espécimes denominados no presente estudo como "Feldmanniairregularis" 1.

Embora nitidamente os dois morfotipos pudessem ser distintos pelas suas características morfológicas, os resultados de cultivo de Cassano (1997) não permitiram a separação de $F$. irregularis em dois táxons independentes, pois plantas típicas de F. irregularis, epífitas em Codium, foram cultivadas e tiveram sua morfologia típica descaracterizada, passando a exibir zonas meristemáticas nas regiões mais superiores do talo e zonas meristemáticas secundárias curtas; em fases adiantadas do cultivo as plantas passaram a apresentar morfologia semelhante à Acinetospora. Essas diferenças morfológicas foram interpretadas pela autora como variação de um mesmo táxon.

Os dados moleculares comprovaram tanto pelo $r b c \mathrm{~L}$ quanto pelo COI-5P que a 'forma variante' de F. irregularissensuCassano (1997) corresponde a um táxon distinto denominado aqui de "F. irregularis" 1. Esse táxon deverá ser descrito como uma espécie nova para a ciência. 
Figuras 24 - 33. "Feldmannia irregularis" 1. Anatomia vegetativa e reprodutiva.

Fig. 24. Aspecto geral da planta formando denso tufo.

Fig. 25. Detalhe dos filamentos mostrando zonas meristemáticas localizadas nas regiões mais superiores do talo (setas) e estruturas pluriloculares em séries ao longo dos filamentos principais e ramos laterais.

Fig. 26. Detalhe de um filamento mostrando zona meristemática (seta).

Figs. 27 - 32. Detalhes da variação das estruturas pluriloculares (cônicas estreitas a cônicas com base alargada), sésseis ou pedicelados com até quatro células.

Fig. 33. Detalhe de estrutura unilocular ovoide, séssil. 


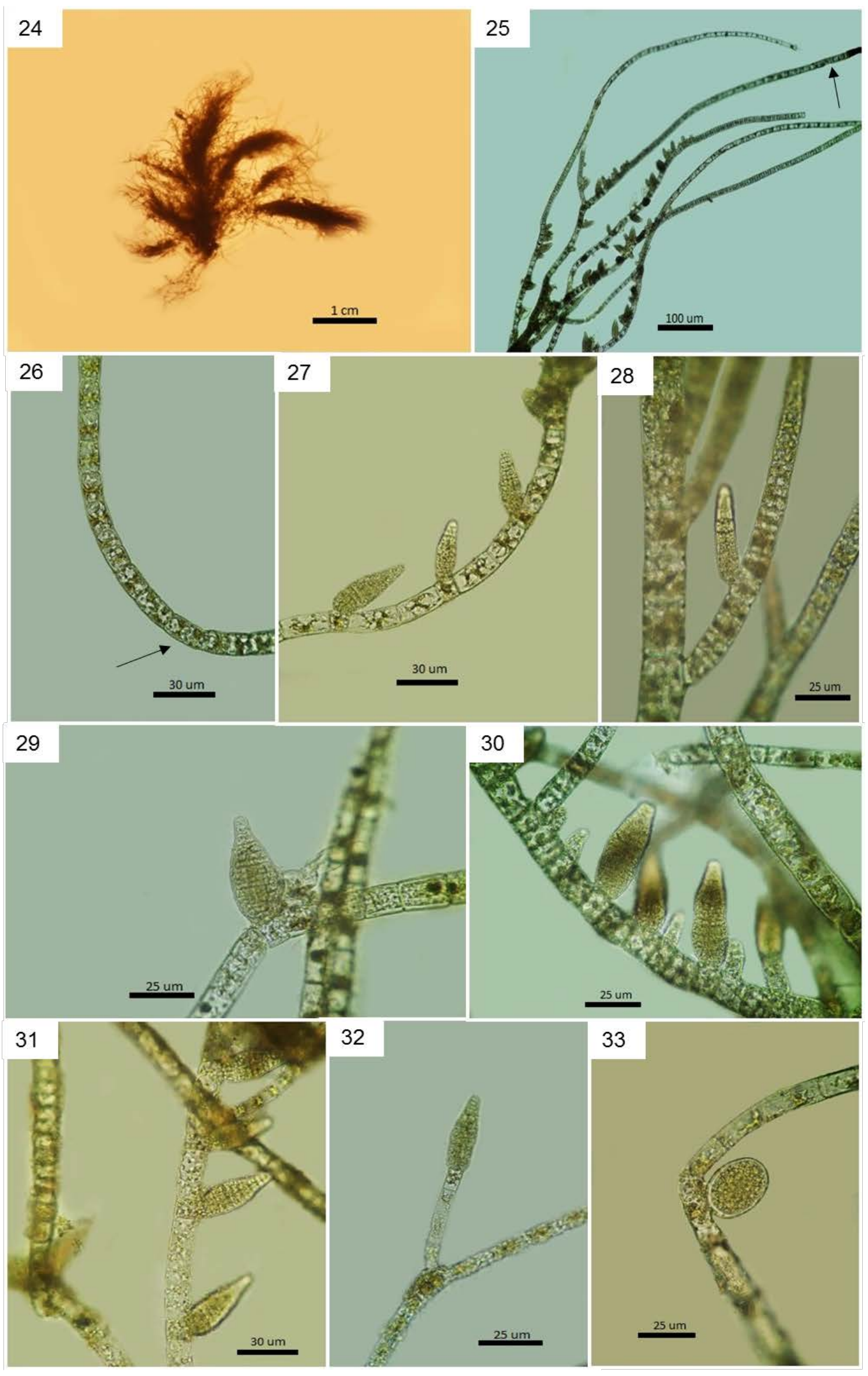




\section{"Feldmanniairregularis" 2}

Figuras $34-41$

Talo filamentoso, unisseriado, heterótrico, formando tufos delicados de coloração marrom amarelada a marrom esverdeada, quando vivos, medindo até 0,5 cm de altura (Fig. 34), fixo ao substrato por filamentos rizoidais de contorno irregular, originados do terço inferior dos filamentos eretos(Fig. 35). Filamentos eretoscom ramificação escassa, irregular (Fig. 35). Células dos filamentos principais medindo 32,5-42,5 $\mu \mathrm{m}$ de diâmetro nas porções medianas do talo e contendo numerosos cloroplastos discoides com um pirenoide por cloroplasto, evidenciados em material vivo. Zona meristemática definida, localizada nas porções superiores do talo semramificação ou estruturas reprodutivas produzidas acima dela.Estruturaspluriloculares cônicas a fusiformes (Figs 37-41), sésseis, distribuídos de forma esparsa nos filamentos principais e ramos laterais, sem formação de longas séries nos filamentos, medindo 75-130 $\mu \mathrm{m}$ de comprimento e 27,5-35 $\mu \mathrm{m}$ de diâmetro. Estruturas uniloculares não observadas.

Habitat:Crescendo na zona entremarés, usualmente epizóica em cirripédios do gênero Chthamalus, gastrópodos do gêneroLittorina e do gênero Brachidontes. Comumente associada a "Feldmannia" mitchelliae.

Material Examinado:Brasil, Rio de Janeiro, Município de Armação dos Búzios, Praia do Geribá, 09/03/2015, col. M. Mungioli; V. Cassano \& C.A.A. Azevedo (MM114); Município de Arraial do Cabo, 05/03/2015, col. M. Mungioli; V. Cassano \&C.A.A. Azevedo (MM058, MM059, MM063, MM065, MM066, MM068). São Paulo, Município de Itanhaém, Praia do Cibratel II, 05/11/2014, col. M. Mungioli; C. A. A. Azevedo \& F. F. C. Ho (MM046).

\section{Comentários}

Os espécimes denominados "Feldmanniairregularis" 2 diferem morfologicamente de "F. irregularis" 1 por apresentar talos menos ramificados e estruturas pluriloculares distribuídas de forma mais esparsa sem formação de longas séries nos filamentos. Essas características morfológicas são de tênue separação entre "F. irregularis" 1 e "F. irregularis" 2. Plantas com caracteres de "F. irregularis" 2 foram também incluídas na 'forma variante' de F. irregularis sensu Cassano (1997), 
tendo sido interpretadas como plasticidade fenotípica. O posicionamento filogenético e a divergência genética entre esses dois táxons confirmaram que estes devem ser tratados como espécies distintas. Contudo, a identificação desses táxons com base exclusivamente em caracteres morfológicos é bastante difícil e, portanto, uma identificação segura deve ser baseada em dados moleculares. 
Figuras 34-41. "Feldmannia irregularis" 2. Anatomia vegetativa e reprodutiva.

Fig. 34. Aspecto geral do talo.

Fig. 35. Detalhe da porção basal do talo evidenciando rizoides unisseriados, de contorno irregular originados da terço inferior dos filamentos eretos.

Figs 36 - 37. Detalhe de porções medianas de filamentos eretos mostrando estruturas pluriloculares esparsas ou em séries curtas nos filamentos, zona meristemática localizada nas porções superiores do talo semramificação ou estruturas reprodutivas produzidas acima dela.

Figs 38 - 41. Detalhes da variação das estruturas pluriloculares sésseis, cônicas a fusiformes. 


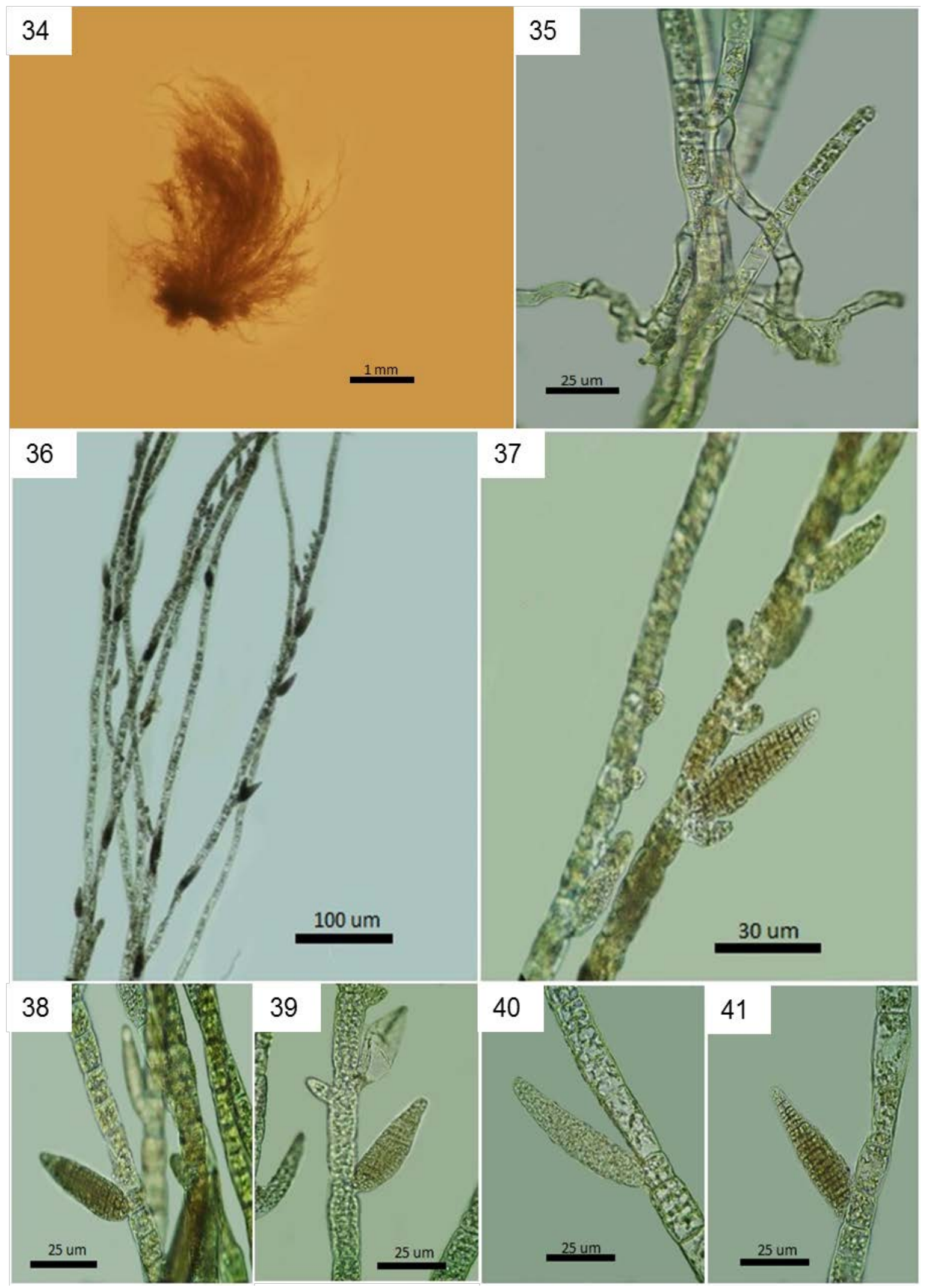




\section{"Feldmannia" mitchelliae (Harvey) H.-S.Kim \\ 2010: 51,figs 21-22.}

Figuras $42-50$

\section{Basiônimo:}

Ectocarpusmitchelliae Harvey

\section{Sinônimos homotípicos:}

Giffordia mitchelliae (Harvey) Hamel

Hincksia mitchelliae (Harvey) P.C. Silva

Talo filamentoso, unisseriado, heterótrico, formando espessos tufos de coloração marrom amarelada a marrom esverdeada, quando vivos, medindo 1-3,5 cm de altura (Fig. 42), fixo ao substrato por filamentos rizoidais emitidos da porção prostrada do talo (Fig. 43) ou do terço inferior dos filamentos eretos, muitas vezes entrelaçados. Filamentos eretos com ramificação irregular e abundante em todos os planos, principalmente na porção superior do talo (Fig. 44). Ramos laterais alongados, menores que o filamento principal, inseridos em ângulo aberto e frequentemente terminados em pseudopelos (Figs 45, 46), ou mais curtos e, neste caso,pseudopelos estão ausentes (Fig. 47). Células do filamento principal medindo 20-50 $\mu \mathrm{m}$ de diâmetro nas porções medianas do talo com ramos de última ordem curtos de aspecto espinescente (Figs 48, 49). Numerosos cloroplastos por célula, pequenos e discoides, com um pirenoide por cloroplasto, evidenciados em material vivo (Fig. 50). Zona meristemática dispersaem sériescurtas nos filamentos principais.Estruturas pluriloculares cilíndricas oblongas com ápices arredondados (Figs 48, 49), normalmente sésseis ou sobre pedicelos de até 3 células, medindo 30$102,5 \mu \mathrm{m}$ de comprimento e 15-27,5 $\mu \mathrm{m}$ de diâmetro, frequentemente dispostas em séries curtas adaxiais ou isoladas nos ramos laterais. Estruturas uniloculares não observadas. 
Habitat:Crescendo na zona entremarés, usualmente epizóica em espécies de cirripédios do gênero Chthamalus, gastrópodos do gêneroLittorina e espécies do gênero Brachidontes. Comumente associada a"Feldmannia" irregularis.

Material Examinado:Brasil, Município do Rio de Janeiro, Urca, Praia Vermelha, 03/09/2012, col. J. C. De-Paula (MM170, MM171). Município de Armação dos Búzios, Praia da Foca, Ponta da Lagoinha, 15/04/2014, col. M. Mungioli; V. Cassano, J.C. De-Paula \& C.A.A. Azevedo (MM003, MM004, MM005, MM007, MM011, MM015),Praia do Forno, 15/04/2014, col. M. Mungioli; V. Cassano, J.C. DePaula \& C.A.A. Azevedo (MM019, MM020), 06/03/2015, col. M. Mungioli; V. Cassano \& C.A.A.Azevedo (MM083),Praia Rasa, 17/04/2014, col. M. Mungioli; V. Cassano, J.C. De-Paula \& C.A.A. Azevedo (MM032),08/03/2015, col. M. Mungioli; V. Cassano \& C.A.A.Azevedo (MM109, MM112, MM113), Praia do Geribá, 09/03/2015, col. M. Mungioli; V. Cassano \& C.A.A.Azevedo (MM115), Praia da Ferradurinha, 09/03/2015, col. M. Mungioli; V. Cassano \& C.A.A.Azevedo (MM125). Município de Arraial do Cabo, Ponta da Cabeça, Praia Grande, 16/04/2014, col. M. Mungioli; V. Cassano, J.C. De-Paula \& C.A.A. Azevedo (MM039), 05/03/2015, col. M. Mungioli; V. Cassano \& C.A.A. Azevedo (MM056, MM057, MM064, MM069, MM072, MM073, MM074, MM076), 11/11/2015, col. M. Mungioli \&V. Cassano (MM227, MM229, MM230, MM233, MM234, MM235, MM236, MM238), Pontal do Atalaia, Prainhas, 06/03/2015, col.M. Mungioli; V. Cassano \& C.A.A.Azevedo (MM077, MM080, MM088, MM090, MM091),Praia das Conchas, 07/03/2015, col. M. Mungioli; V. Cassano \& C.A.A.Azevedo (MM093, MM095, MM097, MM098, M099, MM100). São Paulo, Município de Itanhaém, Praia do Cibratel II, 05/11/2014, col. M. Mungioli; C.A.A. Azevedo e F. F. C. Ho (MM050),20/03/2015, col. M. Mungioli; C.A.A. Azevedo \& F. F. C. Ho (MM131, MM132, MM133). Município de São Sebastião, Praia de Toque-Toque Pequeno, 29/01/2015, col. M.Mungioli\& V. Cassano (MM055),29/01/2015, col. M.Mungioli\& V. Cassano (MM187). Município de Peruíbe, 05/05/2015, col. M. Mungioli \& C.A.A. Azevedo (MM214, MM215, MM216, MM217,MM 218). Espírito Santo, Município de Marataízes, Praia da Cruz, 08/03/2016, col. V. Cassano (MM241, MM247, MM263). Município de Piúma, Illha do Gambá, 09/03/2016, col. V. Cassano (MM270, MM271, MM272, MM274, MM275, MM276, MM289, MM291, MM292, MM293, MM294, MM295). Estados Unidos, 
Carolina do Norte, Wilmington, Ponte da Praia de Wrightsville e Área de doca, Condado de New Hanover, 11/02/2016, col. D.W. Freshwater (MM300), Wynne Plaza Park, Condado de New Hanover, 11/02/2016, col. M. LaCroce\& D.W. Freshwater (MM302).

\section{Comentários}

Ectocarpus mitchelliae foi descrita por Harvey (1851) tendo como localidade tipoNantucket, Massachusetts, EUA (Clayton 1974).

Essa espécie cosmopolita (Kim 2010) é uma das mais comuns no litoral brasileiro se estendendo do Rio Grande do Sul ao Ceará (Széchy \& De-Paula 2015). "Feldmannia" mitchelliae é de fácil reconhecimento pelo seu aspecto arborescente devido a sua ramificação abundante, principalmente no terço superior do talo, estruturas pluriloculares cilíndricas e zonas meristemáticas difusas (Cassano 1997). O material estudado está de acordo com as descrições fornecidas por Joly (1965), Széchy \& Cordeiro-Marino (1991), Kim \& Lee (1992), Müller \& Ramirez (1994), Cassano (1997), Kim (2010) e Guimarães et al. (2016).

Kim (2010) transferiu Hincksia mitchelliae para o gênero Feldmanniacom base em análises moleculares com o gene rbcL (dados não publicados), nas quais $H$. mitchelliae formou um clado monofilético bem suportado com outras espécies de Feldmannia. Os gêneros Hincksia e Feldmannia são separados, principalmente, pela diferença na posição da zona meristemática, difusa em Hincksiae localizada em Feldmannia. A princípio, a presença de zona meristemática difusa em Feldmanniamitchelliaepode tornar o valor diagnóstico dessa característica questionável. Contudo, de acordo com Kim (2010), o gênero Feldmannia é caracterizado, principalmente, por crescimento por meristema basal nos filamentos principais e, em algumas espécies, também por meristemas secundários localizados nos 'internós', i.e., no intervalo entre os ramos laterais. Meristemas secundários são descritos ou ilustrados para o gênero Feldmannia desde Oltmanns (1922), e foram também referidos por Hamel (1931), Sauvageau (1933), Rosenvinge \&Lund. (1941), Ercegovic (1955), Cardinal (1964) e Cassano (1997); todas essas referências para F. irregularis. Desta forma, Kim (2010) argumentou que os meristemas secundários 
localizados nos intervalos de ramos em F. mitchelliaesão homólogos aos encontrados em outras espécies de Feldmannia. Por outro lado, o gênero Hincksia é caracterizado por possuir crescimento difuso, sem uma zona meristemática localizada discernível na base dos filamentos (Kim 2010).

Ainda de acordo, com Kim (2010), o padrão de ramificação de $F$. mitchelliae, com ramos abundantes nas porções superiores do talo, é mais próximo de Hincksia do que de Feldmannia, mas é característico o bastante para diferenciá-la de outras espécies de Hincksia, na qual há formação de 2 a 3 ramos laterais juntos nos filamentos principais em intervalos mais ou menos regulares. As estruturas pluriloculares de F. mitchelliae também são mais próximas do gênero Feldmannia, sendo alongadas cilíndricas ou cônicas alongadas, simétricas sem ápice curvado para o eixo e, frequentemente, pediceladas, enquanto no gênero Hincksia são cônicas curtas a ovoides com base alargada, assimétricas, curvadas para o eixo e,frequentemente, sésseis (Kim 2010).

Apesar de fácil identificação, os espécimes de " $F$ ". mitchelliae examinados nesse estudo apresentaram nitidamente variações morfológicas nos talos semelhantes às descritas por Cassano (1997) para plantas sujeitas à forte arrebentação. Cassano (1997) relacionou as variações morfológicas observadas nessa espécie a condições ambientaisparticulares, nas quais plantas de ambiente batido apresentavam menor altura do talo, ramos laterais curtos fortemente recurvados para o eixo principal e sem pseudopelos e estruturas pluriloculares menores, enquanto plantas coletadas em poças de maré muitas vezes se assemelhavam mais à $F$. indica e possuíam ramificação mais esparsa e estruturas pluriloculares variando de cilíndricas lineares até clavadas e pediceladas, muitas vezes germinando fixas à planta mãe.

Os espécimes de "F". mitchelliae sequenciados no presente estudo formaram dois agrupamentos que divergiram entre si em até 5,6\% pelo COI-5P. O subgrupo formado pelas amostras MM112, MM186, MM214, MM215 e MM217 nas análises do COI-5P e rbcL incluiu espécimes que apresentavam variações morfológicas descritas para aqueles de ambiente batido (ausência de pseudopelos, estruturas pluriloculares menores), porém no presente estudo não foi possível relacioná-los a um ambiente específico como feito por Cassano (1997), pois neste subgrupo 
também se juntaram espécimes procedentes de ambientes calmos, mas que mantinham as mesmas características descritas acima.

Embora os dois agrupamentos também tenham sido formados pelas análises com o rbcL, a divergência para esse marcador não ultrapassou 0,8\%, estando dentro da faixa de variação intraespecífica. A alta divergência verificada pelo COI-5P poderia indicar " $F$ ". mitchelliae como uma espécie críptica, porém pelas variações morfológicas observadas consideramos de " $F$ ". mitchelliae forma um complexo que ainda deve ser melhor estudado por uma maior amostragem no litoral brasileiro.

Os espécimes brasileiros se agruparam com uma amostra de " $F$ ". mitchelliae procedente da localidade tipo (EUA), sequenciada no presente estudo, confirmando que se tratam do mesmo táxon. Contudo, nossos resultados moleculares demonstraram que " $F$." mitchelliaedeve ser transferida para um novo gênero, uma vez que não se agrupou com a espécie tipo de Feldmannia, F. lebelli. 
Figura 42-50. "Feldmannia" mitchelliae. Anatomia vegetativa e reprodutiva.

Fig. 42. Aspecto geral da planta.

Fig. 43. Detalhe da porção prostrada do talo evidenciando filamentos rizoidais unisseriados emitidos da porção prostrada.

Fig. 44. Detalhe da terço superior do talo mostrando ramificação abundante e irregular em vários planos.

Figs. 45 - 46. Detalhe da porção apical de plantas típicas com filamentos terminados em pseudopelos. Note râmulos de última ordem espinescentes (MM082, Fig. 46).

Fig. 47. Detalhe da variação morfológica de "F." mitchelliae " evidenciando o terço superior de filamentos eretos com ramificações curtas, esparsas e espinescentes, ausência de pseudopelos e estruturas pluriloculares de menores dimensões, mais frequentemente pediceladas (MM214).

Figs.48 - 49. Estruturas pluriloculares cilíndricas, sésseis, adaxiais nos ramos laterais.

Fig. 50. Detalhe das células mostrando numerosos cloroplastos discoides com um pirenoide por cloroplasto, evidenciados em material vivo. 

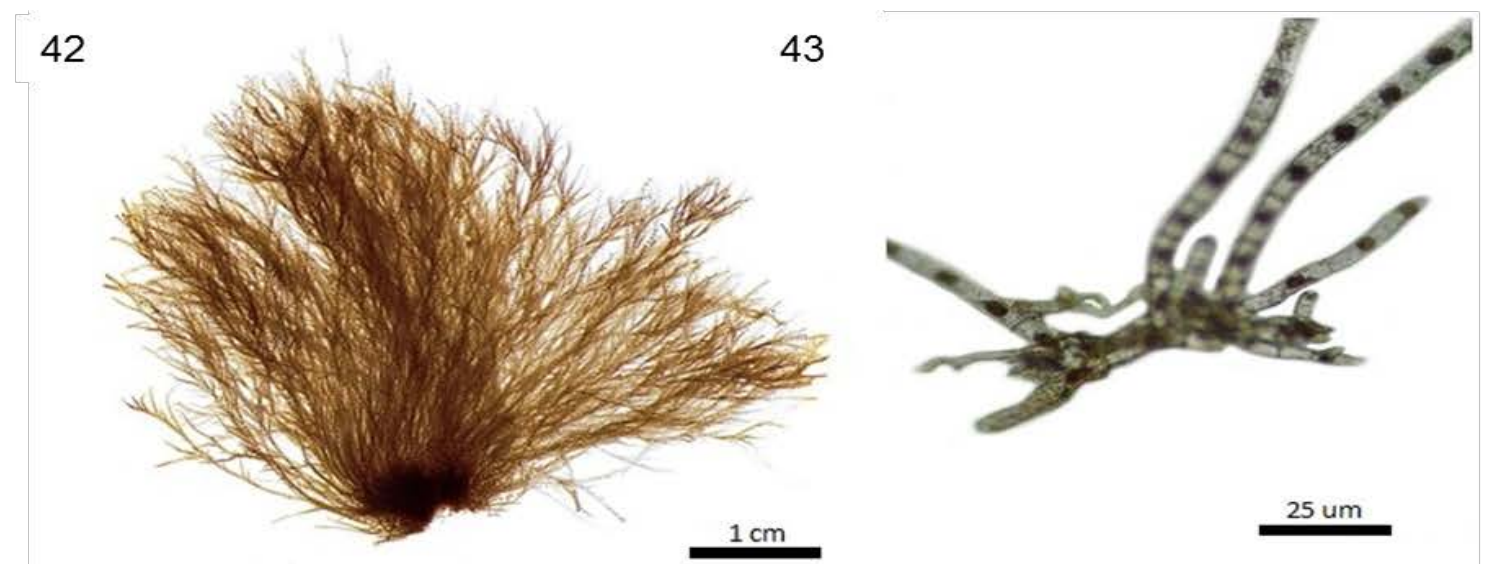

44

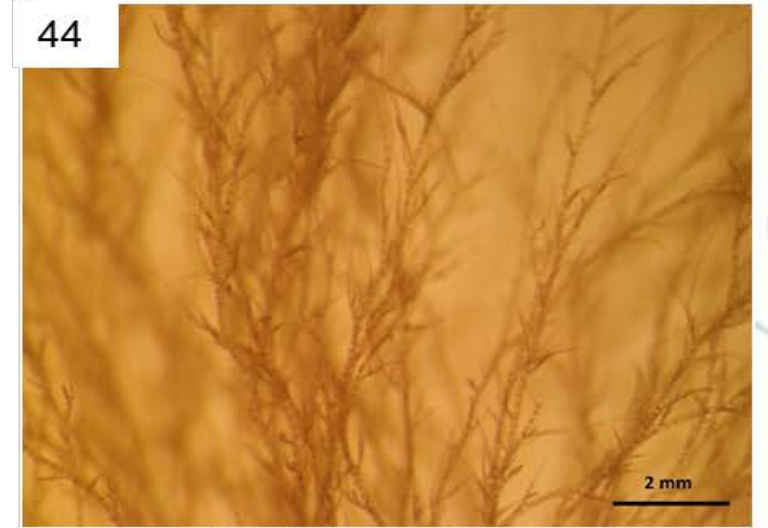

45
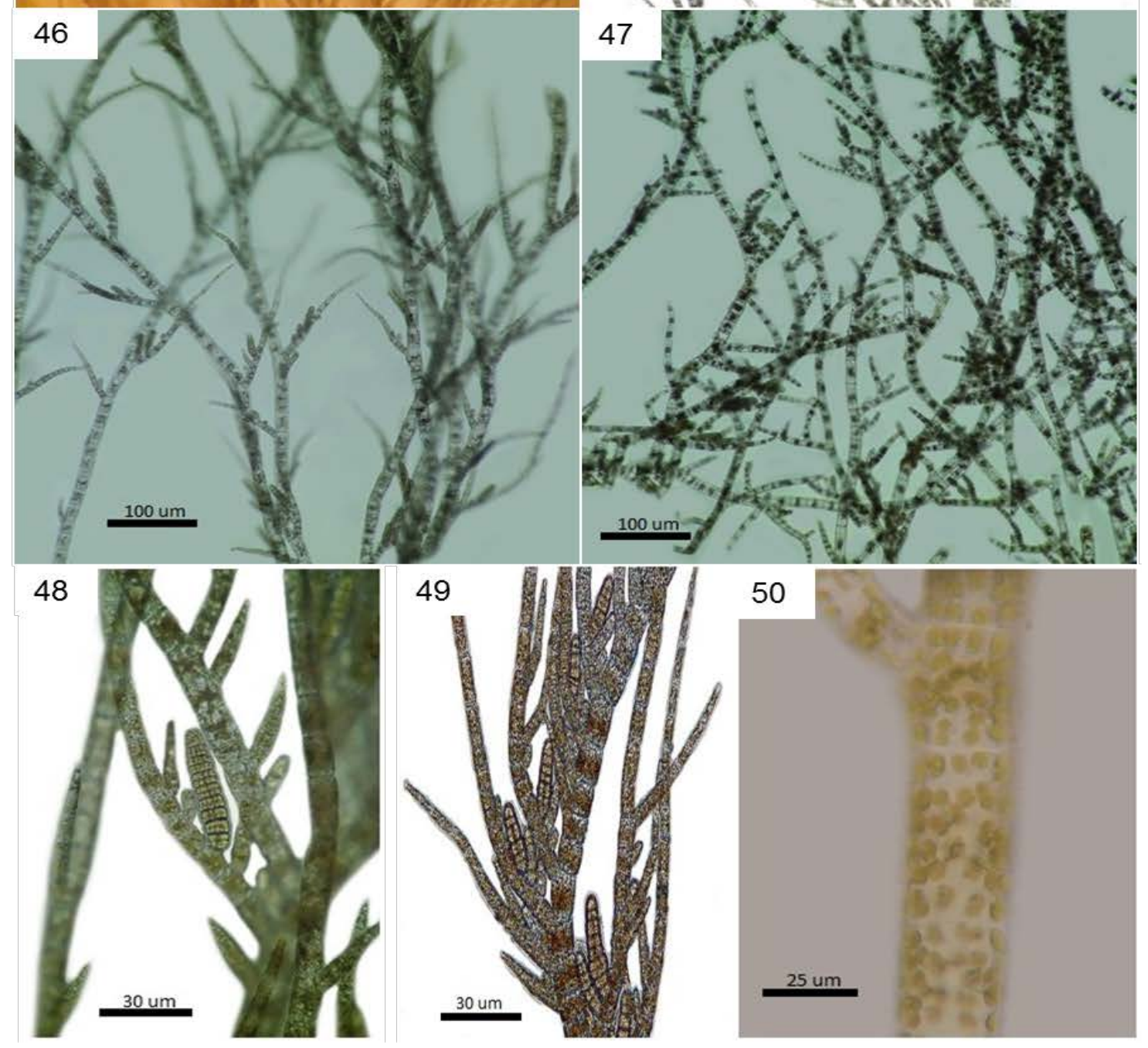


\section{Gênero Hincksia J.E. Gray}

Talos em tufos, eretos, epífitos, epilíticos, filamentos unisseriados muito ramificados, com organização heterotríquia, fixos por rizoides. Crescimento difuso, sem zona meristemática discernível nas regiões basais do talo. Ramificação irregular a subdicotômica, frequentemente secunda nos râmulos (frequentes séries unilaterais de râmulos) a oposta em intervalos mais ou menos regulares, normalmente filamentos terminados por pseudopelos. Células frequentemente curtas a moderadamente alongadas cilíndricas. Cloroplastos discoides, numerosos por célula contendo um pirenoide. Esporângios pluriloculares sésseis, raramente pedicelados, relativamente menores que em Feldmannia,ovoides a elipsoides globulares, normalmente assimétricos, curvados para o eixo no lado adaxial ou abaxial dos ramos. Esporângiosuniloculares sésseis, raramente pedicelados elipsoides largos a subesféricos. Histórico de vida diplo-haplôntico isomórfico (Kim 2010, Cormaci et al. 2012, este estudo).

\section{“Hincksia" conifera (Børgesen) I.A.Abbott 1989: 226, 231}

Figuras $51-59$

\section{Basiônimo:}

Ectocarpus conifer Børgesen

\section{Sinônimo homotípico:}

Giffordia conifera (Børgesen) W.R. Taylor

Talo filamentoso, unisseriado, heterótrico, formando tufos delicados, de aspecto emaranhado, medindo até $1,0 \mathrm{~cm}$ de altura (Fig. 51), fixo ao substrato por filamentos rizoidais originados do terço inferior dos filamentos eretos (Fig. 52). Filamentos eretos com ramificação irregular em vários planos, alterna a unilateral (Fig. 53). Células dos filamentos principais medindo 27,5-32,5 $\mu \mathrm{m}$ de diâmetro nas 
porções medianas do talo e contendo numerosos cloroplastos discoides com um pirenoide por cloroplasto, evidenciados em material vivo. Zona meristemática difusa no filamento principal e nos ramos laterais longos, com crescimento intercalar próximo à saída dos ramos.Porção apical dos filamentos eretos normalmente terminando em pseudopelos (Fig. 53).Em plantas típicas, estruturas pluriloculares cônicas, oblongo-ovoides, sésseis,em séries curtas localizadas nas axilas dos ramos laterais (Figs 55-58). Em plantas variantes, estruturas plurilocularesdistribuídas na parte superior dos filamentos principaisou ao longo dos ramos laterais, normalmente não dispostas em séries na axila dos ramos. Estruturas pluriloculares medindo62,5$100 \mu \mathrm{m}$ de comprimento e 20-40 $\mu \mathrm{m}$ de diâmetro. Estrutura unilocular ovoide em pedicelo bicelular, medindo $75 \mu \mathrm{m}$ de comprimento e 62,5 $\mu \mathrm{m}$ de diâmetro (Fig. 59).

Habitat: Crescendo do médiolitoral ao infralitoral raso, epilítica em costões rochosos, habitualmente na parte mais protegida do costão rochoso.

Material Examinado:Brasil, Rio de Janeiro, Município de Armação dos Búzios, Praia do Forno, 15/04/2014, col. M. Mungioli; V. Cassano, J.C. De-Paula \& C.A.A. Azevedo. (MM017, MM018), Praia Rasa, 17/04/2015, col. M. Mungioli; V. Cassano \& C.A.A.Azevedo (MM030), 08/03/2015, col. M. Mungioli; V. Cassano \& C.A.A.Azevedo (MM108, MM111). São Paulo, Município de Ubatuba, Praia Saco do Ribeira, 28/11/2012, col. não identificado (MM134).

\section{Comentários}

A espécie Ectocarpus coniferus(= E. conifer) foi descrita por Børgesen(1914) para as llhas Virgens. A história taxonômica de E. coniferus é conturbada e está atrelada à sua espécie morfologicamente relacionada, " $F$ ". irregularis, como já descrito anteriormente.

Børgesen(1914), ao descrever E. coniferus, admitiusua proximidade com $E$. irregularis Kützing, reconhecendo que sua espécie poderia ser simplesmente uma forma desta última. A característica distintiva na qual Børgesen(1914) baseou seu argumento para propor uma nova espécie foi o posicionamento adaxial das estruturas plurilocularesnos ramos laterais, sempre próximas ao ângulo entre o 
filamento principal e o ramo, raramente dispostas no filamento principal. De acordo com Børgesen(1914), em E. irregularisasestruturas pluriloculares se distribuem mais irregularmente ao longo do filamento não estando estritamente confinadas ao lado superior dos ramos.

Börgesen (1926) forneceu diferenças adicionais para separação das duas espécies, como o diâmetro do filamento principal (maior em E. coniferus) e as dimensões e forma das estruturas pluriloculares (mais largas na base em $E$. coniferus).

Sauvageau (1933) discutiu as variações morfológicas de E. irregularis e incluiu nestas variações, plantas de E. coniferus e E. rallsiae Vickers, salientando que pelas diferenças muito sutis entre elas, E. coniferus e E. rallsiae deveriam ser reduzidas a sinônimos de E. irregularis. A partir do trabalho de Sauvageau (1933), Börgesen (1941) reviu sua posição quanto à independência específica das três espécies e forneceu uma considerável lista de sinônimos para E. irregularis, entre eles E. coniferus e E. rallsiae. Börgesen (1941), não reconheceu o gênero Feldmanniade Hamel (1939) e a nova combinação Feldmannia irregularis (Kützing) Hamel, e manteve este táxon sob o nome mais antigo: E. irregularis.

Várias mudanças nomenclaturais foram feitas para o epíteto coniferus(Taylor 1960, Joly 1965, Abbott 1989, Silva et al. 1987, Schneider \& Searles 1991, Széchy \& Cordeiro-Marino 1991), que já foram mencionadas anteriormente nos comentários de "F." irregularis.

"Hincksia"coniferafoi reconhecida como um táxon independente por Cassano (1997). A autora verificou que citações desse táxon para o Rio de Janeiro como Giffordia irregularis(Széchy 1986, Figueiredo 1989, Reis-Santos 1990) ou como Hincksia irregularis (Széchy\& Cordeiro-Marino 1991) correspondiam a plantas típicas de " $H$ ". conifera. O material estudado está de acordo com as descrições de Børgesen(1914, 1926), Cassano (1997) e Guimarães et al. (2016).

Széchy \& De-Paula (2015) registram " $H$ ". conifera apenas para o Rio de Janeiro com base nos estudos de Cassano (1997). Contudo, a espécie possivelmente foi referida para outros locais da costa brasileira sob outro nome e deve ter maior distribuição geográfica. Guimarães et al. (2016) descreveram plantas típicas de Hincksia conifera citando o táxon pela primeira vez para o litoral de São 
Paulo, a despeito de Joly (1965) ter ilustrado uma planta típica de " $H$ ". conifera (como Giffordia irregularis, prancha VIII, Fig. 111) para o norte de São Paulo e arredores.

De acordo com Cassano (1997), a posição característica das estruturas pluriloculares e a presença de pseudopelos em todos os filamentos, tanto principais quanto laterais, parecem constituir características constantes nas plantas típicas. Porém, uma ampla variação morfológica foi observada pela autora que foi interpretada como plasticidade fenotípica, reforçada pelos seus resultados de cultura. As mesmas variações morfológicas descritas por Cassano (1997) foram observadas no material analisado no presente estudo, sendo elas: alteração da posição adaxial característica das estruturas pluriloculares que se distribuem com maior incidência ao longo do filamento principal, as séries curtas adaxiais de estruturas pluriloculares são menos frequentes e há maior incidência de estruturas pluriloculares pediceladas, os talos são menos ramificados e pseudopelos estão ausentes na maioria das plantas. As zonas meristemáticassão difusasou não em plantas típicas ou não, às vezes inconspícuas, mas nunca localizadas como em "Feldmannia"irregularis, "F. irregularis" 1 e "F. irregularis" 2. As variações morfológicas descritas acima também foram observadas em cultura feita a partir de plantas típicas, o que levou Cassano (1997) a considerar um caso de plasticidade fenotípica.

Os dados moleculares obtidos com o COI-5P e com o rbcL evidenciaram dois agrupamentos referentes aos espécimes denominados "H." conifera. Um deles agrupou plantas típicas e o outro, plantas variantes. A divergência do COI-5P entre esses agrupamentos foi de 3,9\% a 4,4\%, o que sugere que podem ser táxons distintos. Por outro lado, a divergência do rbcL foi mais baixa, $0 \%$ a $0,8 \%$ amplitude que está dentro da faixa de variação intraespecífica desse marcador. Mais estudos são necessários para a definição de qual tratamento dar a esse táxon. Porém, os resultados moleculares confirmaram que " $H$ ".coniferanão pertence ao autêntico gênero Hincksiae que o epíteto específico conifera deve ser transferido para um novo gênero. 
Figuras 51- 59. "Hincksia" conifera. Anatomia vegetativa e reprodutiva.

Fig. 51. Aspecto geral da planta.

Fig. 52. Detalhe da porção basal do talo mostrando filamentos rizoidais unisseriados e de contorno irregular originados do terço inferior dos filamentos eretos.

Fig. 53. Detalhe da porção mediana de um filamento principal de uma planta típica mostrando estruturas pluriloculares em séries curtas localizadas nas axilas dos ramos laterais (MM108).

Fig. 54.Detalhe da variação morfológica de "H." conifera evidenciando o terço superior de filamentos eretos com estruturas pluriloculares distribuídas ao longo dos ramos laterais (MM017). Note poucas estruturas pluriloculares adaxiais nos ramos laterais.

Figs 55 - 58. Detalhes das variações na forma das estruturas pluriloculares adaxiais.

Fig. 59. Detalhe de uma estrutura unilocular ovoide, pedicelada (MM017). 


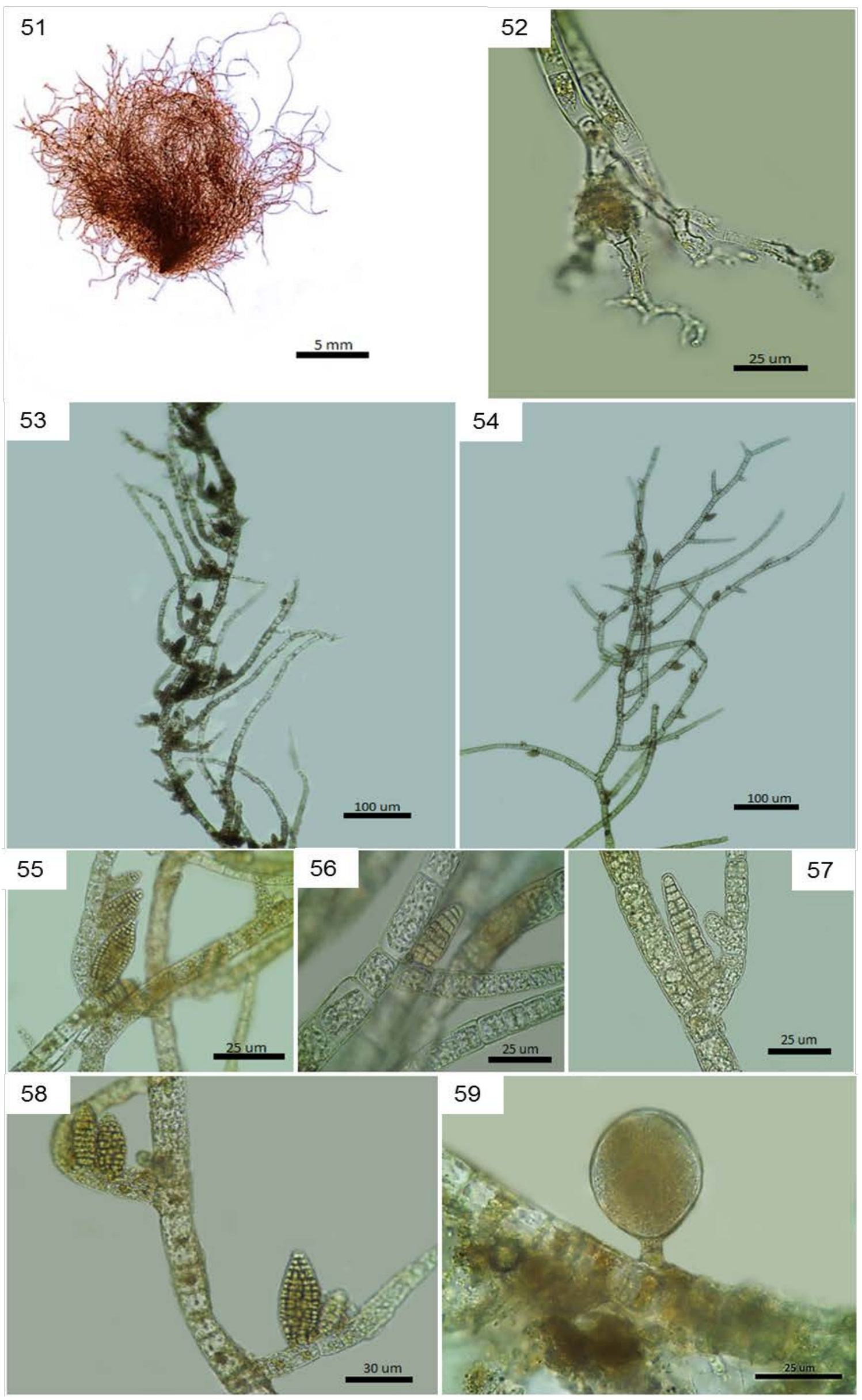




\section{Hincksiasandriana (Zanardini) P.C. Silva in Silva \\ et al. 1987: 130}

Figuras $60-69$

\section{Basiônimo:}

Ectocarpus sandrianus Zanardini

Sinônimo homotípico:

Giffordia sandriana (Zanardini) Hamel

\section{Descrição:}

Talo filamentoso, unisseriado, heterótrico, formando tufos flácidos de coloração marrom clara, quando vivos, constituídos por um emaranhado delicado de filamentos, atingindo 1-1,5 cm de altura (Fig. 61). Filamentos eretos abundantemente ramificados (Figs 62-64), com eixo principal definido (Fig. 64). Filamento principal com ramificação alterna (Fig. 64), portando ramos laterais recurvados em direção ao eixo principal com ramificação unilateral em séries de râmulos adjacentes (Figs 64, 65). Células do filamento principal quadráticas, mais largas que altas, medindo 57,5-70 $\mu \mathrm{m}$ de diâmetro, com numerosos cloroplastos discoides, com um pirenoide por cloroplasto, evidenciados em material vivo (Fig. 66). Pseudopelos não observados. Crescimento por zona meristemática difusa. Estruturas pluriloculares cônicas alongadas, assimétricas, normalmente com porção mediana alargada medindo57,5-70 $\mu \mathrm{m}$ de comprimento e 22,5-30 $\mu \mathrm{m}$ de diâmetro, frequentemente sésseis podendo formar séries adaxiais de 2-5 estruturas nos ramos laterais ou pediceladas com até 3 células. Estruturas uniloculares não observadas.

Habitat:Crescendo na franja do infralitoral, na região mais protegida do costão rochoso, associada a "Feldmannia" irregularise "Feldmannia" mitchelliae.

Material examinado:Brasil, Rio de Janeiro, Município de Arraial do Cabo, Ponta da Cabeça, Praia Grande, 16/04/2014, col. M. Mungioli; V. Cassano, J. C. De-Paula \& C.A.A. Azevedo (MM021, MM022, MM025). 


\section{Comentários}

Hincksiasandrianafoi descrita originalmente como Ectocarpus sandrianus Zanardini a partir de material coletado em Zadar, Croácia(Silva et al. 1987). A espécie é caracterizada por suas estruturas pluriloculares ovoides, cônicas a alongadas com porção mediana alargada, sésseis, frequentemente assimétricas, ligeiramente recurvadas, formando longas séries adaxiais, não contínuas, de 2 a 5 estruturas; talo flácido, abundantemente ramificado e meristemáticas difusas (Cardinal 1964, Kim \& Lee 1992, Kim 2010, Cormaci et al. 2012, Boraso de Zaixso 2013, Mystikou et al. 2016, este estudo). O material analisado está de acordo, de forma geral, com as descrições fornecidas pelos autores supracitados, entretanto nossos espécimes apresentaram maior diâmetro do filamento (57,5-70 $\mu \mathrm{m})$ quando comparado às descrições da literatura, cuja amplitude de variação foi bem menor (15-50 m, Cardinal 1964, Kim \& Lee 1992, Kim 2010, Cormaci et al. 2012, Boraso de Zaixso 2013). As séries adaxiais de estruturas pluriloculares foram mais curtas no material brasileiro (até 5), enquanto para espéciems do Mar Mediterrâneo as séries adaxias são mais longas podendo chegar até 15 estuturas pluriloculares (Cormaci et al. 2012). Entretanto, as dimensões das estruturas pluriloculares estudadas (22,5-30 $\mu \mathrm{m}$ de diâmetro), vão de acordo com os autores (20-30 $\mu \mathrm{m}$,Kim e Lee 1992; 22-

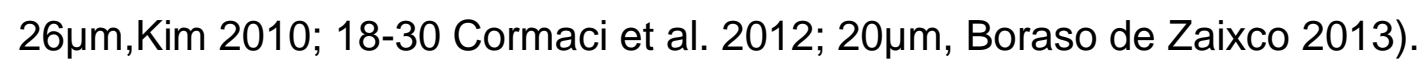

Hincksiasandrianatem ampla distribuição em mares tropicais, subtropicais e temperados (Kim \& Lee 1992, Guiry \& Guiry 2017). Cardinal (1964) referiu a espécie para a América do Sul e sua distribuição se estende do Atlântico Sul (Argentina) (Asensi \& Küpper 2012, Boraso de Zaixso 2013) ao Pacífico Sul (Ilhas Galápagos) (Ruiz \& Ziemmeck 2011) e Chile (Mystikou et al. (2016).

Morfologicamente, H.sandrianaé proximamente relacionada com $H$. hincksiae e $H$. secunda(Kützing) P.C.Silva pela presença de estruturas pluriloculares em séries adaxias. Entretanto, de acordo com Cormaci et al. (2012), H. hincksiaepossui estruturas pluriloculares em séries muito densas, pectinadas, com as estruturas em contato ou parcialmente sobrepostas umas às outras e, ainda, as estruturas plurloculares se distribuem também em séries nos eixos principais. Já $H$. secundapossui estruturas pluriloculares em séries curtas de 3 a 5 pluriloculares, enquanto que em $H$. sandriana as séries são longas de 5 a 15 pluriloculares. Esse aspecto nossos espécimes se sobrepõem com $H$. secunda. 
Os dados moleculares obtidos com o rbcL e COI-5P mostraram que $H$. sandriana é próxima de $H$. hincksiae da qual diverge por altos valores 8,0-9,7\% pelo COI-5P e por $2,3 \%$ pelo $r b c L$, estando na faixa de divergência interespecífica para os dois marcadores.

Hincksiasandrianaé citada pela primeira vez para o Brasil a partir de material coletado na Ponta da Cabeça, Arraial do Cabo, Rio de Janeiro. A flora da Ponta da Cabeça foi exaustivamente inventariada por Yoneshigue (1985) e Cassano (1997). O local foi visitado em diferentes épocas do ano pelas duas autoras e $H$. sandriana jamais foi encontrada nesses estudos prévios. Desta forma, H.sandriana é considerada aqui como uma espécie recentemente introduzida. 
Figuras 60-69.Hincksia sandriana. Anatomia vegetativa e reprodutiva.

Fig. 60. Aspecto geral da planta formando tufo denso.

Fig. 61. Detalhe da porção apical do talo mostrando ramificação abundante com ramos laterais recurvados para o eixo principal e ramificados unilateralmente.

Fig. 62. Detalhe da zona meristemática difusa (seta).

Fig. 63. Detalhe da ramificação alterna na porção mediana do filamento principal e séries de râmulos unilaterais sobre ramos recurvados de segunda ordem,

Fig. 64. Detalhe da ramificação unilateral de células adjacentes.

Fig. 65. Detalhe das células mostrando numerosos cloroplastos discoides com um pirenoide por cloroplasto, evidenciados em material vivo.

Figs 66 - 67. Estruturas pluriloculares em pedicelos de uma a três células.

Figs 68 - 69. Estruturas pluriloculares sésseis localizadas no lado adaxial dos ramos em séries de até cinco estruturas. 


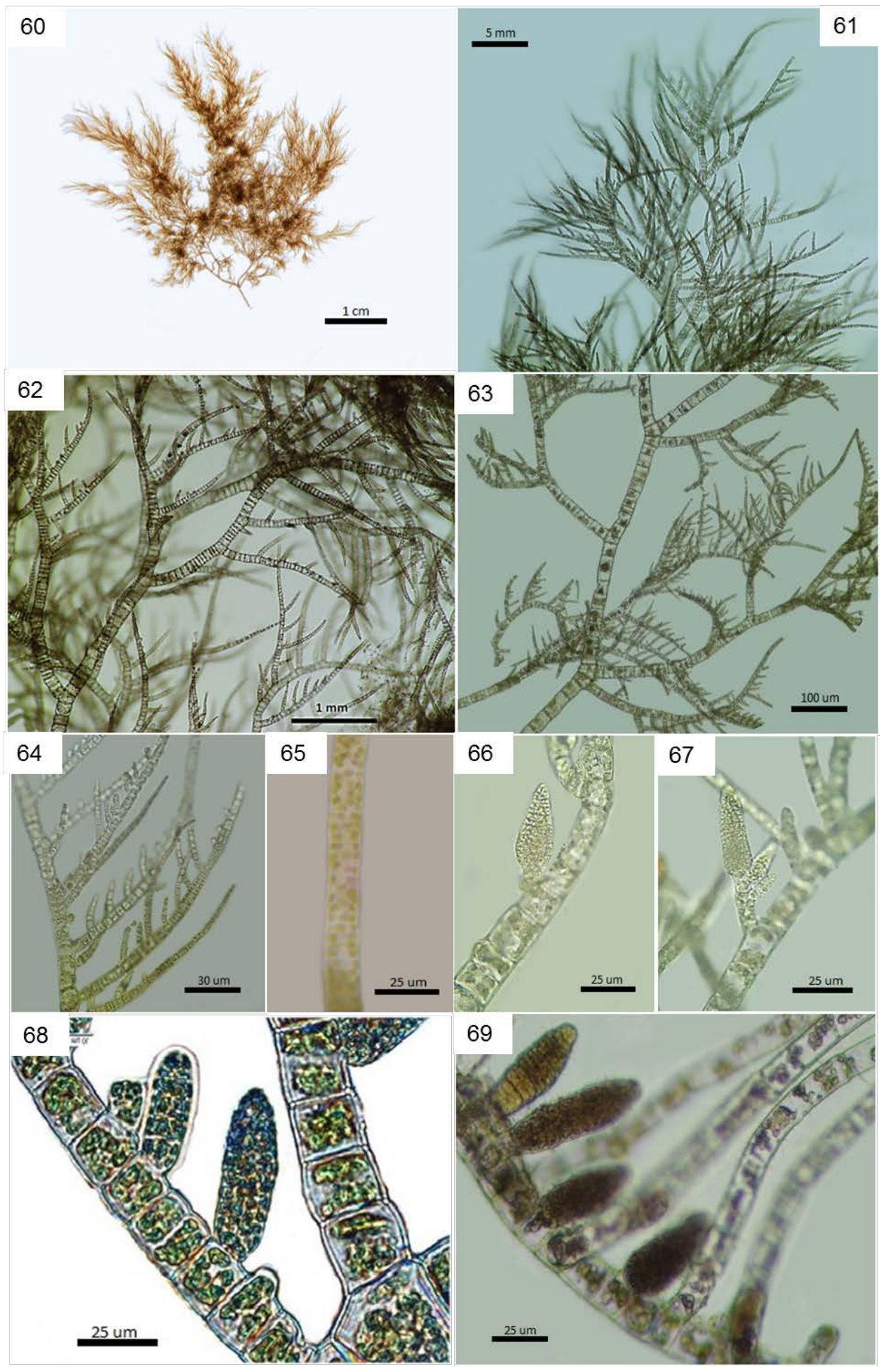




\section{Família Ectocarpaceae Gênero Ectocarpus Lyngbye}

Talos em tufos, eretos, epífitos, epilíticos, filamentos unisseriados muito ramificadossubdicotomicamente ou irregularmente, com organização heterotríquia, fixos por rizoides. Crescimento difuso com meristemas inconspícuos espalhados no talo. Ramos laterais normalmente subdicotômicos a alternos, produzindo 2-3 ordens de râmulos, usualmente terminados por pseudopelos. Células usualmente alongadas a cilíndricas. Cloroplastos parietais em forma de fita, um a vários por célula, contendo um a vários pirenoides. Esporângios pluriloculares normalmente pedicelados, raramente sésseis, originados das células do filamento principal ou adaxialmente nos ramos laterais, fusiformes a cônicos. Esporângiosuniloculares sésseis, raramente pedicelados, subesféricos a ovoides. Reprodução isogâmica. Histórico de vida diplo-haplôntico isomórfico ou com gerações ligeiramente heteromórficas, reprodução meiosporângios uniloculares e gametângios pluriloculares ou assexuadamente por partenogênese (Kim 2010, Cormaci et al. 2012).

\section{Ectocarpus fasciculatus Harvey 1841: 40}

Figuras $70-77$

Talo filamentoso, unisseriado, heterótrico, epífito, formando tufos delicados de coloração marrom amarelada, quando vivos, atingindo até $0,5 \mathrm{~cm}$ de altura(Fig. 71),fixo ao substrato por um disco basal reforçado por numerosos rizoides diminutos, medindo 5-7 $\mu \mathrm{m}$ de comprimento. Filamentos principais distintos, eretos, desnudos ou com ramos curtos esparsos na porção basal do talo eportando râmulos fasciculados acima, dispostos de maneira alterna a unilateral no filamento principal (Figs 72-74). Células do filamento principalcilíndricas, mais altas que largas, medindo 22,5-30 $\mu \mathrm{m}$ de diâmetrona porção mediana do talo, a doliformes com numerosos cloroplastos em forma de fita com vários pirenoides por cloroplasto, evidenciados em material vivo (Fig. 75).Pseudopêlos não observados. Talo com 
crescimento difuso (Fig. 74). Estruturas pluriloculares de formato cônico a fusiforme com pedicelos de 1-3 células(Figs 76 - 78), raramente sésseis, isoladas no filamento principal ou em séries curtas adaxiais nos ramos lateraisfasciculados, medindo 75$120 \mu \mathrm{m}$ de comprimento e 17,5-25 $\mu \mathrm{m}$ de diâmetro. Estruturas uniloculares não observadas.

Habitat:Crescendo na franja do infralitoral, epífita em Pterocladiella capillacea(S.G. Gmelin) Santelices \& Hommersand, na região protegida do costão rochoso.

Material Examinado:Brasil, Rio de Janeiro, Município de Arraial do Cabo, Ponta da Cabeça, Praia Grande, 16/04/2014, epífita em Pterocladiella capillacea(S.G.Gmelin) Santelices \& Hommersand, col. M. Mungioli; V. Cassano, J.C. De-Paula \& C.A.A.Azevedo (MM023).

\section{Comentários}

A espécie Ectocarpus fasciculatus foi descrita por Harvey (1841) tendo como localidades síntipas a Irlanda (Mangan's Bay, Co. Waterford), a Irlanda do Norte (Strangford Lough) e o Reino Unido(Torquay) (Guiry \& Guiry 2017).

A espécie foi citada pela primeira vez para o Brasil por Yoneshigue \& Figueiredo (1983), a partir de material coletado no Rio de Janeiro em Arraial do Cabo (Ponta da Cabeça), epífita em Pterocladiella capillacea.Posteriormente foi referida por Yoneshigue (1985) para a região de Cabo Frio (Saco do Inglês), para o Espírito Santo, por Crispino (2000) e para São Paulo (Ilha Anchieta) por Pereira (2007).

Oito categorias infraespecíficas de Ectocarpus fasciculatus são listadas por Guiry \& Guiry (2017), sendo sete variedades e uma forma. Destas, apenas E.fasciculatus var. refractus (Kützing) Ardissone, E. fasciculatus var. macrosporusAskenasy e E. fasciculatusf. polyrhizus Collinssão aceitas atualmente. Ectocarpusfasciculatus var. pigmaeusAreschoug foi citada pela primeira vez para o Brasil na mesma publicação que reporta a variedade típica (Yoneshigue \& 
Figueiredo 1983). Contudo, a variedade pigmaeus foi transferida para $E$. siliculosuspor Gallardo (1992), sendo, então, designadaE. siliculosus(Dillwyn) Lyngbye var. pigmaeus(Areschoug) Gallardo. Diferenças no padrão de ramificação têm sido consideradas de valor diagnóstico para separação das duas espécies. Ectocarpus fasciculatuspossui ramos laterais fasciculados e filamento principal conspícuo e mais estreito, enquanto E. siliculosuspossui ramificação subdicotômica (Russell 1966, 1967, Peters et al. 2010).Ectocarpussiliculosusvar. pigmaeusé caracterizada por seu talo essencialmente prostrado com ramos eretos nunca ramificados ou com apenas uma ordem de ramos e estruturas pluriloculares frequentemente terminais (Yoneshigue \& Figueiredo 1983, Yoneshigue 1985, Cormaci et al. 2010). Ectocarpussiliculosusvar. pigmaeusnão foi novamente coletada no presente estudo.

A espécie E. fasciculatus é caracterizada principalmente pela presença de ramos fasciculados muito evidentes, esparsos, com fascículos de ramos dispostos de forma alterna ou unilateral no filamento, além de filamentos principais bem distintos, desnudos nas porções basais (Cardinal 1964, Yoneshigue \& Figueiredo 1983, Kim \& Lee 1992, Cormaci et al. 2012). Nossos exemplares concordam de forma geral com as descrições fornecidas por Yoneshigue \& Figueiredo (1983) e Yoneshigue (1985). Entretanto, os fascículos de ramos foram menos conspícuos, com muitos ramos curtos isolados dispostos de forma alterna nas porções superiores do filamento, muitas vezes entremeados com estruturas pluriloculares isoladas, majoritariamente dispostas sobre longos pedicelos de até 5 células, e não exclusivamente sésseis, como descrito por Yoneshigue \& Figueiredo (1983) e Yoneshigue (1985). Nesses aspectos o material estudado é mais semelhante ao descrito por Boraso de Zaixso (2013) para espécimes da Argentina e por Kim \& Lee (1992) para a Coreia, embora nossos exemplares sejam menos ramificados. Eventuais pseudopelos descritos por Cormaci et al. (2012) para espécimes do Mar Mediterrâneo, não foram observados no material analisado.

Yoneshigue (1985) reportouE. fasciculatus como uma espécie rara para a região de Cabo Frio. No presente estudo apenas uma amostra de E. fasciculatus foi coletada no mesmo local de sua primeira citação para o Brasil (Praia Grande, Ponta da Cabeça, Arraial do Cabo), igualmente crescendo sobre P. capillacea. Devido ao seu tamanho diminuto e pouca biomassa, essa espécie foi cultivada e o êxito no seu 
sequenciamento se deu exclusivamente pela obtenção detalos crescidos em cultura. Foi obtida uma única sequência de COI-5P para essa espécie. As tentativas de obtenção de sequências de $r b c L$ não tiveram sucesso devido a falhas na amplificação. Os dados do COI-5P confirmaram que nossos espécimes correspondem a E. fasciculatus os quais divergiram de uma amostra da França em $1 \%$. 
Figuras 70-77. Ectocarpus fasciculatus. Anatomia vegetativa e reprodutiva.

Fig. 70. Aspecto geral da planta formando tufos delicados pouco ramificados.

Fig. 71. Detalhe dos filamentos eretos pouco ramificados com estruturas pluriloculares esparsas no filamento.

Fig. 72. Detalhe mostrando terço inferior do talo pouco ramificado e fascículos de ramos acima.

Fig. 73. Detalhe da porção mediana do filamento principal mostrando zona meristemática.

Fig. 74. Detalhe das células mostrando cloroplastos em forma de fita com vários pirenoides por cloroplasto, evidenciados em material vivo.

Figs 75 - 77. Estruturas pluriloculares cônicas e pediceladas com até três células. 


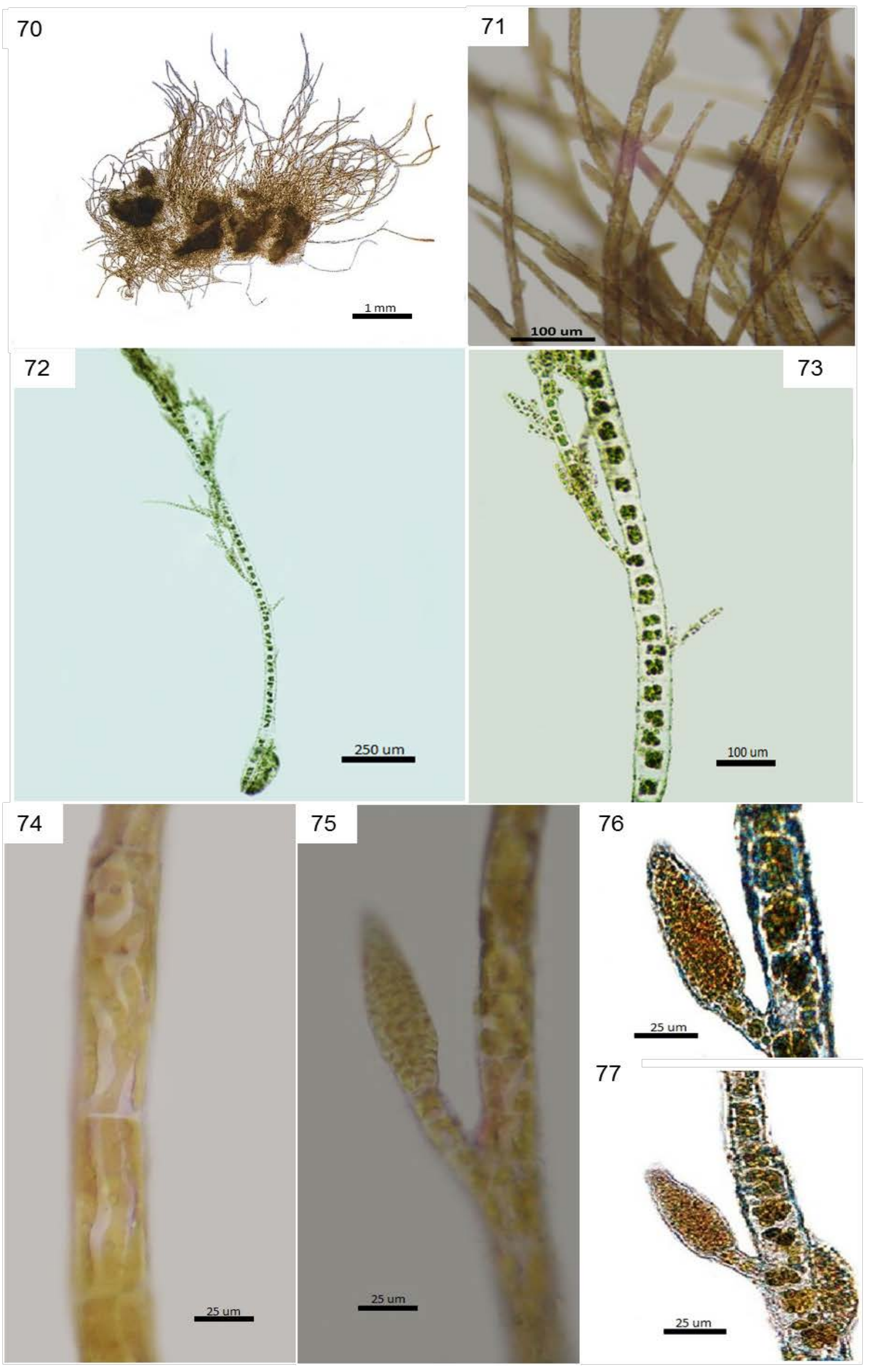




\section{Ordem Scytothamnales \\ Família Asteronemataceae \\ Gênero Asteronema Delépine \&Asensi}

Optou-se pela descrição do gênero Asteronemaaqui para fins comparativos, uma vez que nossos resultados moleculares tenham demonstraram que o material analisado não corresponde ao autêntico gênero Asteronema.

Talos em tufos, eretos, epífitos ou epilíticos, organização heterotríquia, filamentos unisseriados com bases coalescentes a partir das quais se desenvolvem filamentos rizoidais e filamentos eretos com ramificação escassa, às vezes, unilateral. Crescimento intercalar. Vários cloroplastos alongados com arranjo estrelado, associados pelos pólos dos seus pirenoides. Um único pirenoidepor cloroplasto em posição lateral em relação aos tilacoides. Pirenoides voltados para a região central da célula. Invaginações tubulares citoplasmáticas presentes nos pirenoides. Esporângios uniloculares e pluriloculares, sésseis ou em pedicelos de 1 a 2 células.Monósporos são formados em $A$. australeDelépine \&Asensi (Delépine \& Asensi 1975, Silberfeld et al. 2011, Boraso de Zaixso 2013).

\section{"Asteronema" breviarticulatum (J.Agardh) Ouriques \& Bouzon 2000: 271.}

Figs $78-84$

Basiônimo:

Ectocarpus breviarticulatus J. Agardh(1847)

\section{Sinônimos homotípicos:}

Giffordia breviarticulata (J.Agardh) Doty \& I.A. Abbott

Feldmannia breviarticulata (J.Agardh) Pham-Hoàng Hô

Hincksia breviarticulata (J.Agardh) P.C. Silva 
Talo filamentoso, unisseriado, heterótrico, formando densos tufos eretos, entrelaçados em espiral de aspecto digitiforme, com consistência esponjosa e coloração marrom esverdeada quando vivos, atingindo 1,5-4 cm de altura (Fig. 79), fixos ao substrato por abundantes filamentos rizoidais (Fig. 80). Ramificação irregular (Fig. 81) com muitos ramos laterais curtos dispostos em ângulo aberto a reto no filamento e com ápices recurvados formando gavinhas (Figs 81-84), que promovem maior entrelaçamento dos filamentos. Células do filamento principal medindo 27,5-32,5 $\mu \mathrm{m}$ de diâmetro com vários cloroplastos alongados com arranjo estrelado. Zonas meristemáticas intercalares curtas distribuídas ao longo do talo. Ausência de pseudopelos. Estruturas pluriloculares laterais com formato esférico a oblongo, medindo 42,5-67,5 $\mu \mathrm{m}$ de comprimento e 15- $30 \mu \mathrm{m}$ de diâmetro, em pedicelo curto (1-2 células) ou esporadicamente sésseis. Estruturas uniloculares não observadas.

Habitat:Crescendo na zona entremarés, comumente epizóicos em espécies de cirripédios do gênero Chthamalus, gastrópodos do gêneroLittorina e espécies do gênero Brachidontes. Espécimes epilíticos crescendo emcostões sujeitos à arrebentação ou em poças-de-maré, associados a Bachelotia antillarum.

Material Examinado:Brasil, Rio de Janeiro: Município de Arraial do Cabo, Pontal do Atalaia, Prainhas, 16/04/2014, col. M. Mungioli; V. Cassano, J. C. De-Paula \& C.A.A.Azevedo (MM026),Município de Armação dos Búzios, Praia Rasa, 08/03/2015, col. M. Mungioli; V. Cassano \& C.A.A.Azevedo (MM110). São Paulo: Município de Itanhaém, Praia do Cibratel II, 05/11/2014 e 20/03/2015, col. M. Mungioli; C.A.A.Azevedo \&F. F. C. Ho. (MM045, MM128). Bahia: Município de Camaçari, Praia dos Emissários, 14/10/2012, col. V. Cassano, (MM138, MM139). São Paulo, Município de Ubatuba, Ilha das Palmas, 29/08/2011, col. A. Medeiros; C. Iha \& M.C. Oliveira (MM178), Município de Peruíbe, Reserva Juréia-Itatins, Praia da Desertinha, 04/05/2015, col. M.Mungioli \&C. A. A. Azevedo (MM189, MM190, MM191, MM192, MM193, MM194, MM195, MM200, MM201, MM202, MM207), Praia do Guaraú, 05/05/2015, col. M.Mungioli \&C. A. A. Azevedo (MM208, MM209, MM210, MM211, MM212, MM213). Espírito Santo, Município de Vitória, Praia do Camburi, 2012, col. S. M. P. B. Guimarães (MM220). 


\section{Comentários}

Asteronema breviarticulatum foi descrita originalmente como Ectocarpus breviarticulatus por J. Agardh (1847) para San Agustín, Oaxaca, México (Silva et al. 1996). A espécie é facilmente reconhecida pelos seus filamentos entrelaçados, dando aspecto digitiforme ao talo, pela sua consistência esponjosa, estruturas pluriloculares globosas e râmulos em forma de ganchos (Cassano 1997). Entretanto, durante décadas a posição genérica deste táxon permaneceu problemática devido à imprecisão em delimitar a forma dos cloroplastos em microscopia óptica, característica de valor diagnóstico que separa Ectocarpus, com cloroplastos em fita, de gêneros próximos, como Hincksia, com cloroplastos discoides (Cassano 1997). A espécie foi citada pela primeira vez para o Atlântico sul americano como $E$. breviarticulatus por Joly (1957) e é comum no litoral brasileiro, se estendendo de Santa Catarina ao Ceará (Széchy \& De-Paula 2015).

Ectocarpus breviarticulatus foi transferida para o gênero Hincksia por Silva in Silva et al. (1987) devido à prioridade de publicação, entretanto a forma dos cloroplastos não foi mencionada pelos autores. Cassano (1997) manteve o táxon sob seu nome original devido à observação de cloroplastos em fita em células jovens de plantas cultivadas e, também em populações naturais, embora raros. A predominância de cloroplastos discoides em populações naturais foi atribuída pela autora a condições ambientais estressantes como longos períodos de dessecação. A mudança na forma dos cloroplastos também foi observada em plantas cultivadas, cujas células possuíam cloroplastos em fita nos estádios iniciais de desenvolvimento que passavam a discoides com o seu envelhecimento (Cassano 1997). Ouriques \& Bouzon (2000) transferiram a espécie para o gênero Asteronema com base em estudos de microscopia eletrônica que revelaram que os cloroplastos de $A$. breviarticulatum são dispostos de forma estrelada, pouco numerosos, orientados para um pirenoide central. Os resultados moleculares obtidos no presente estudo indicam que Asteronema breviarticulatum deve ser transferida para o gênero Asterocladon.

O gênero Asterocladon foi estabelecido por Müller et al. (1999) com base em sequências do rDNA nuclear (LSU, SSU e ITS) para acomodar a espécie A. lobatum descrita a partir de material brasileiro cultivado. O gênero Asterocladon é distinto de Asteronema pela presença de pêlos com meristema basal e de divisões longitudinais 
no filamento, porém compartilham a presença de cloroplastos estrelados com pirenoides, agrupados no centro da célula (Müller et al 1999). Contudo, Uwai et al. (2005) ampliaram a circunscrição do gênero Asterocladon quando estabeleceram a espécie nova Asterocladon interjectum e transferiram Asteronema rhodochortonoides (Børgesen) D.G. Müller\& Parodi para Asterocladon rhodochortonoides (Børgesen) Uwai, Nagasato, Motomura \& K.Kogame. As análises filogenéticas moleculares realizadas por Uwai et al. (2005) baseadas nos marcadores rbcL e SSU mostraram que $A$. interjectum, $A$. lobatum e $A$. rhodochortonoides formavam um clado monofilético bem suportado. Com base nisso, os autores emendaram o gênero Asterocladon incluindo espécies que apresentavam as seguintes características: filamentos com crescimento apical, com ou sem pêlos laterais e filamentos eretos; divisões celulares longitudinais presentes ou ausentes; células com vários cloroplastos em um a vários arranjos estrelados e pirenoides agregados para formar um corpo esférico próximo ao núcleo; e invaginação citoplasmática ausente nos pirenoides. Essa última característica foi apontada como uma sinapomorfia para o clado Asterocladon spp. Com a circunscrição mais ampla estabelecida por Uwai et al. (2005), Asteronema breviarticulatum se enquadra perfeitamente na circunscrição genérica de Asterocladon, incluindo a ausência de invaginação citoplasmática nos pirenoides (Ouriques \& Bouzon 2000).

A parafilia do gênero Asteronema já foi verificada anteriormente por Draisma et al. (2001), Peters \& Ramírez (2001), Rousseau et al. (2001) e Uwai et al. (2005) assim como no presente estudo, uma vez que Asteronema ferruginea não se agrupou com Asteronemabreviarticulatum em nenhuma análise. A possibilidade de coespecificidade da espécie tipo de Asteronema, A. australe Delépine \& Asensi (1975) com A. ferruginea (Cladophora ferruginea Harvey 1859) foi levantada por vários autores (Delépine \& Asensi 1975, Womersley 1987, Müller \& Parodi 1994), e Uwai et al. (2005) reforçaram essa possibilidade, embora a coespecificidade não tenha sido efetivada. Asteronema australe difere de Asterocladon spp. pela ultraestrutura do cloroplasto na qual os pirenoides possuem invaginações citoplasmáticas (Reviers \& Rousseau 1999, Uwai et al. 2005).

A circunscrição genérica atual de Asterocladon separa este gênero de Asteronema ferruginea/australe e esses táxons foram claramente separados em nossas análises moleculares, assim como nas de Uwai et al. (2005). Embora não haja sequências de $A$. breviarticulatum nos bancos de dados para comparação, a separação em duas linhagens de Asteronema, A. ferruginea e A. breviarticulatum, indica que uma mudança nomenclatural de 
Asteronema breviarticulatum para o gênero Asterocladon é necessária para resolver o posicionamento taxonômico dessa espécie. 
Figuras 78- 84. "Asteronema" breviarticulatum. Anatomia vegetativa e reprodutiva.

Fig. 78. Aspecto geral da planta formando densos tufos digitiformes de consistência esponjosa.

Fig. 79. Detalhe da porção basal do talo.

Fig. 80. Detalhe de uma porção do talo mostrando ramificação abundante e irregular formada por ramos curtos com ápice recurvado em forma de gavinha.

Fig. 81. Detalhe do ápice de um ramo em forma de gavinha.

Figs 82 - 84. Estruturas pluriloculares laterais esféricas em pedicelo unicelular. 


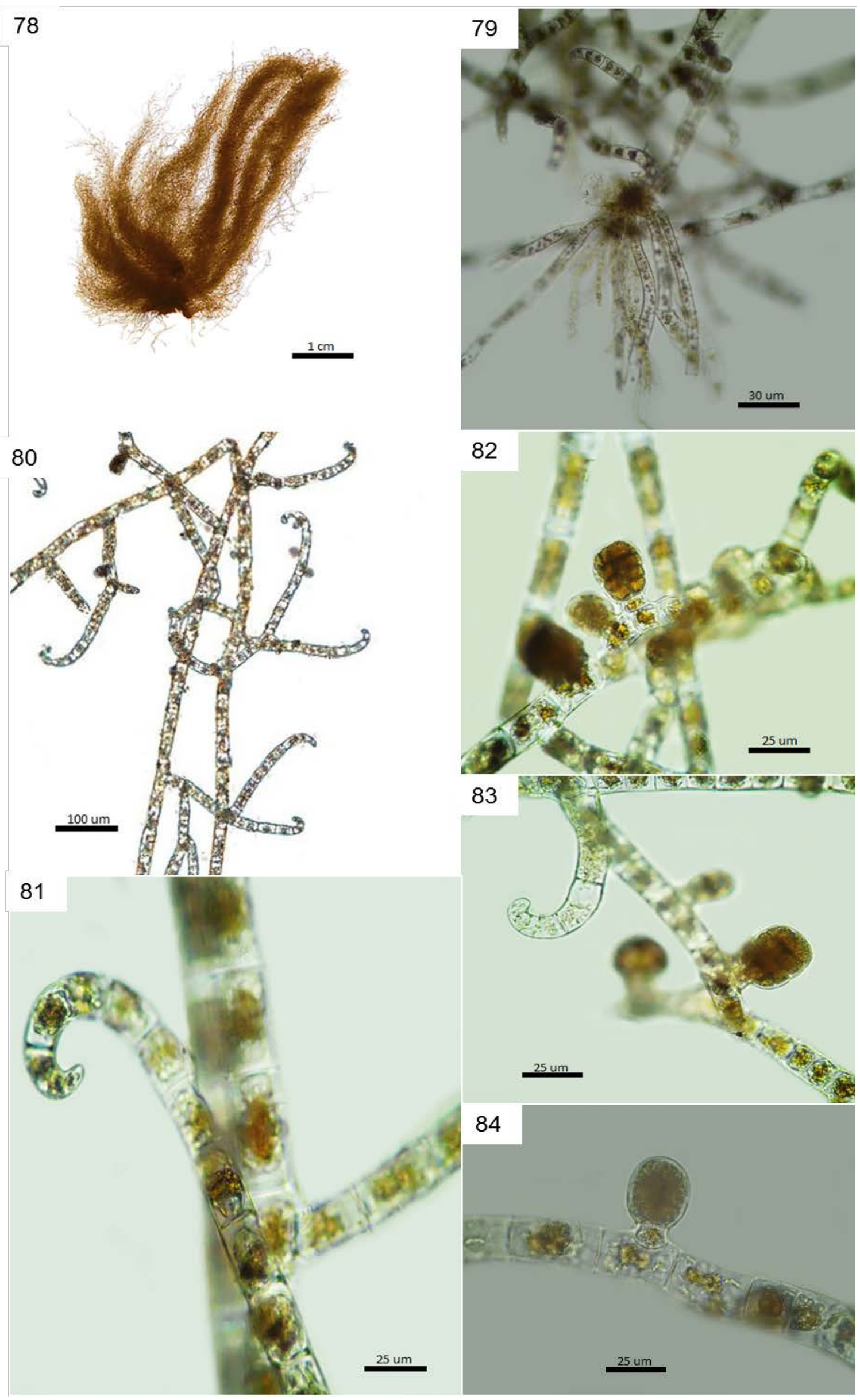




\section{Família Bachelotiaceae \\ GêneroBachelotia (Grunow) Gerloff}

Talos em tufos, eretos, epilíticos, organização heterotríquia, filamentos unisseriados emaranhados fixos por filamentos rizoidais. Filamentos eretos simples ou pouco ramificados na base de forma irregular. Pseudopelos ausentes. Crescimento intercalar. Divisões longitudinais ocasionais apenas nas regiões férteis. Cada célula com vários cloroplastos alongados com arranjo estrelado, associados pelos pólos dos seus pirenoides. Um único pirenoide por cloroplasto em posição terminal em relação aos tilacoides. Pirenoides voltados para a região central da célula. Invaginações tubulares citoplasmáticas ausentes nos pirenoides. Esporângios uniloculares intercalares, estruturas pluriloculares desconhecidas (Silberfeld et al. 2011, Boraso de Zaixso 2013).

\section{Bachelotia antillarum (Grunow) Gerloff 1959: 38}

Figuras $85-91$

\section{Basiônimo:}

Ectocarpus antillarum Grunow

Sinônimo homotípico:

Pylaiella antillarum (Grunow) De Toni

\section{Descrição}

Talo filamentoso,unisseriado, heterótrico, formando densos tufos de coloração marrom escura a marrom amarelada, atingindo 1-2,5 cm de altura, fixos ao substrato por filamentos rizoidais. Filamentos eretos simples ou com ramificação rara e irregular na porção basal dos filamentos. Filamentos principais com células medindo 27,5 $\mu \mathrm{m}$ a 47,5 $\mu \mathrm{m}$ de diâmetro na porção mediano do taloe comnumerosos cloroplastosalongados de configuração estrelada, formando 1 a 2 agrupamentos por 
célula.Crescimento difuso com zona meristemática bem definida. Estruturas uniloculares intercalares nos filamentos eretos,em séries contínuas, muitas vezes aos pares por divisão longitudinal da célula, dando aspecto inflado ao filamento e medindo 15-30 $\mu \mathrm{m}$ de comprimento e 42,5-60 $\mu \mathrm{m}$ de diâmetro.

Habitat:Crescendo do médiolitoral ao infralitoral raso, epilítica emcostões protegidos ou expostos somente aos borrifos d'água ou, ainda, em poças-de-maré. Epizoicas em espécies do gênero Brachidontes ou em Codium fragile (Suringar) Hariot. Muitas vezes associadas a "Asteronema" breviarticulatum, Cladophora vagabunda (Linnaeus) Hoek, "Feldmannia" irregularis e "Feldmannia" mitchelliae.

Material examinado: Brasil, Rio de Janeiro: Município de Armação dos Búzios, Praia da Foca, Ponta da Lagoinha, 15/04/2014, col. M. Mungioli; V. Cassano, J.C, De-Paula \& C.A.A.Azevedo (MM001), Praia Rasa, 17/04/2015, col. M. Mungioli; V. Cassano \& C.A.A.Azevedo (MM033), 08/03/2015, col. M. Mungioli; V. Cassano \& C.A.A.Azevedo (MM102, MM103, MM104, MM144), Município de Arraial do Cabo, Pontal do Atalaia, Prainhas, 06/03/2015, col. M. Mungioli; V. Cassano \& C.A.A.Azevedo (MM084, MM085, MM086), Município de Cabo Frio, Praia das Conchas, 07/03/2015, col. M. Mungioli; V. Cassano \& C.A.A.Azevedo (MM092, MM096). São Paulo: Município de Itanhaém, Praia do Cibratel II, 05/11/2014, col. M. Mungioli; C.A.A.Azevedo \& F. F. C. Ho (MM043, MM044, MM047, MM048), Município de São Sebastião, Praia de Paúba, 27/11/2014, col. M. Mungioli \&V. Cassano (MM052, MM053), Município de Peruíbe, Reserva Juréia-Itatins, Praia de Caramboré, 04/05/2015, col. M. Mungioli \& C. A. A. Azevedo (MM203, MM204, MM205, MM206). Espírito Santo, Município de Marataízes, Praia da Cruz, 08/03/2016, col. V. Cassano (MM249, MM250, MM251 MM261, MM262).

\section{Comentários}

O gênero Bachelotia é monoespecífico e a espécie tipo Bachelotia fulvescens foi reduzida a sinônimo deBachelotia antillarum.

Bachelotia antillarum foi descrita como Ectocarpus antillarum Grunow, cuja localidade tipo é Guadalupe, Caribe (Silva et al. 1987). A espécie é facilmente reconhecida por seus vários cloroplastos com configuração estrelada formando um 
ou dois grupos por célula, cada um com um pirenoide terminal voltado para o centro da célula, filamentos simples ou pouco ramificados de forma esparsa e irregular e estruturas uniloculares intercalares nos filamentos eretos; estruturas pluriloculares são desconhecidas (Silberfeld et al.2011, Széchy \& Cordeiro-Marino 1991, Guimarães et al. 2016).

O primeiro registro de citação da espécie para o litoral brasileiro (Jaquaranga) foi feito por Schmidt (1924) como Pylaiella fulvescens Bornet(Taylor 1930). Mais tarde, a espécie foi referida por Joly (1957) para a Baía de Santos e Joly (1965), no seu estudo no litoral norte de São Paulo, como Bachelotia fulvencens (Bornet) Kuckuck exHamel. De acordo com Wynne (1998), B. fulvencens foi considerada como sinônimo de B. antillarumpor Blomquist (1958), tratamento seguido por Earle (1969)e, posteriormente, pelos autores brasileiros.Atualmente, B. antillarum tem ampla distribuição no litoral brasileiro se estendendo do Rio Grande do Sul ao Ceará (Széchy \& De-Paula 2015).

Morfologicamente, nossos espécimes estão de acordo com as descrições fornecidas por Joly (1965), Széchy \& Cordeiro-Marino (1991), Nunes (1999), Guimarães et al. (2016).

A despeito da facilidade de identificação de $B$. antillarum, nossas as análises moleculares revelaram alta divergência intraespecífica para o COI-5P, até 6,0\% entre uma amostra do Espírito Santo (MM219) e as demais do Rio de Janeiro e São Paulo, e até 1,6\% para o rbcL, entre amostras do sudeste e nordeste (PI) do Brasil e da Nova Zelândia. Para a amostra mais divergente (MM219) não foi possível obter sequências do $r b c L$ para comparação. Nossos resultados indicam que $B$. antillarum é uma espécie críptica. 
Figuras 85-91. Bachelotia antillarum. Anatomia vegetativa e reprodutiva.

Fig. 85. Aspecto geral da planta evidenciando longos filamentos simples.

Fig. 86. Detalhe da porção basal do talo mostrando rizoides originados do terço inferior dos filamentos eretos.

Fig. 87. Detalhe dos filamentos eretos unisseriados.

Fig. 88. Detalhe dos filamentos evidenciando zonas meristemáticas (setas);

Figs. 89 - 90. Detalhes dos filamentos vegetativos mostrando um (Fig. 89) ou dois grupos (Fig. 90) de cloroplastos alongados por célula com configuração estrelada.

Fig. 91. Porção mediana do talo mostrando estruturas uniloculares intercalares no filamento em série contínua. Note divisão longitudinal da célula reprodutiva (seta). 

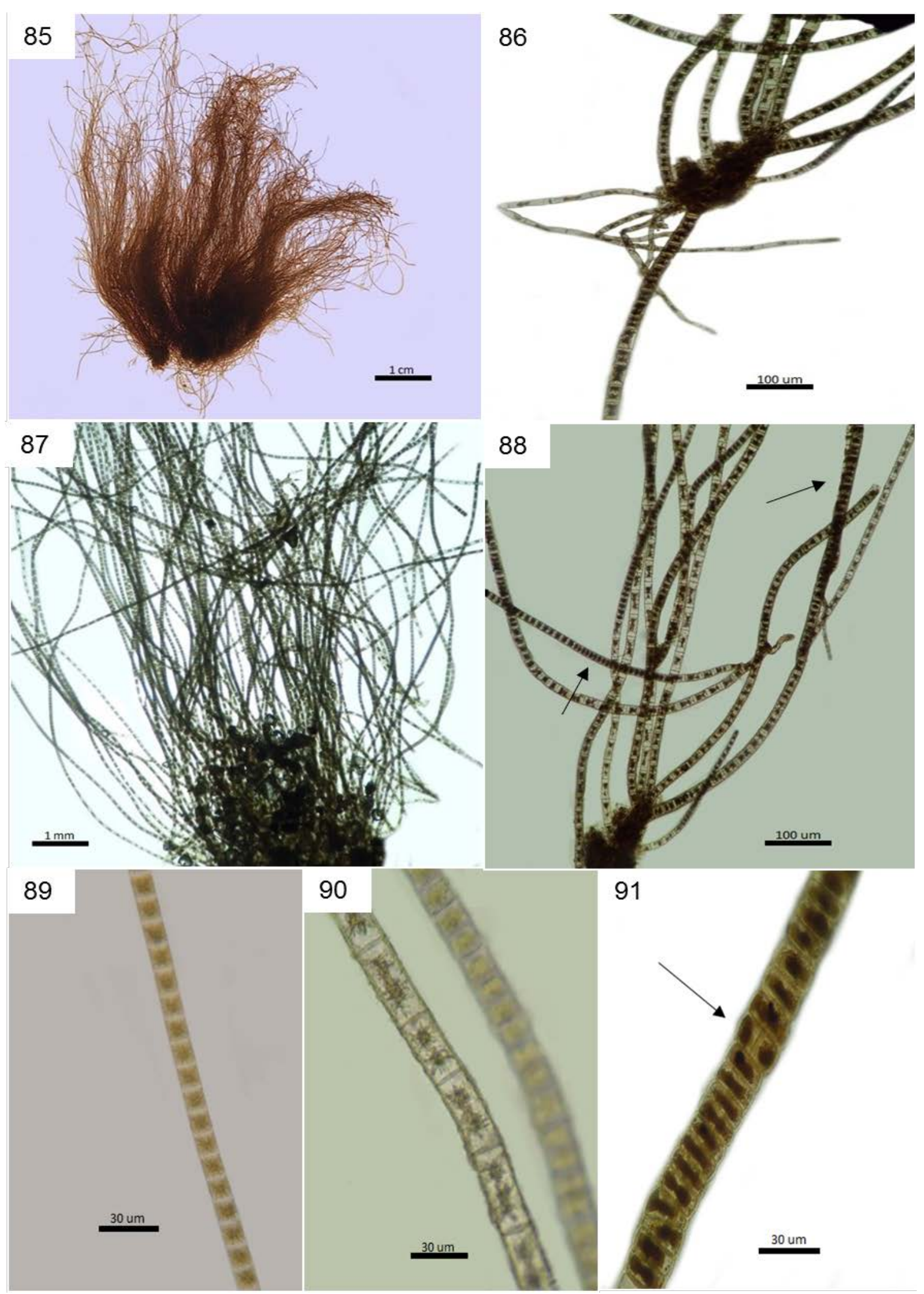


\section{DISCUSSÃO GERAL}

Os dados moleculares obtidos nesse estudo para as algas pardas filamentosas são pioneiros para a costa brasileira e demonstraram que a sua diversidade estava subestimada. Nossos resultados revelaram a ocorrência de espécies crípticas e complexo de espécies, a necessidade de mudanças nomenclaturais e de proposição de gêneros e espécies novas para acomodar táxons atualmente incluídos nas famílias Acinetosporaceae e Asteronemataceae.

Uma alta diversidade foi evidenciada especialmente dentro da família Acinetosporaceae. A família não é monofilética e foi dividida em dois maiores agrupamentos pelo COI-5P, um contendo sequências dos gêneros Feldmannia e Hincksia e suas respectivas espécies-tipo, e outro contendo o gênero Acinetospora, e sua espécie tipo, e os demais táxons encontrados no litoral brasileiro. Embora uma maior amostragem no nosso litoral e mais análises moleculares sejam necessárias, sobretudo análises multigênicas e sequenciamento das espécies-tipo utilizando-se outros marcadores, como o $r b c \mathrm{~L}$, nossos dados sugerem que a proposição de uma nova família seria necessária para acomodar os autênticos gêneros Hincksia, Feldmannia e Pylaiella, enquanto que a família Acinetosporaceae seria retida para o agrupamento que contém Acinetospora crinita, a espécie tipo da família, e demais táxons.

A alta diversidade em Acinetosporaceae foi recentemente revelada por Peters et al. (2015) ao aplicaram a técnica de DNA Barcoding usando o COI-5P (568 pb), na qual houve a formação de dois agrupamentos, o grupo Pylaiella-Hincksia-Feldmannia e o grupo Acinetospora. Peters et al. (2015) estimaram o valor máximo de divergência intraespecífica pela análise de distribuição de "pairwise Kimura-2-parameter (K2P) distances", sendo considerada uma mesma espécie aquela cujo valor está abaixo de 1,8\%. O "barcode gap" foi indicado entre 1,5\% de distância intraespecífica e >2,5\% de distância interespecífica.

Nossos valores de divergência intraespecífica para o COI-5P foram comparáveis aos encontrados por Peters et al. (2015) para os gêneros Acinetospora (0-2,6\%), Feldmannia s.s. (0,6\%) e Hincksia s.s. (0-2,2\%). A divergência intraespecífica para o gênero Acinetospora verificada neste estudo está perfeitamente dentro da faixa de variação considerada por Yaegashi et al. (2015) para espécies desse gênero $(<2,7 \%)$. Igualmente, Hincksia sandriana se manteve dentro da faixa de variação intraespecífica $(2,1-2,2 \%)$ verificada por Peters et al. (2015) e Yaegashi et al. (2015). Para os demais táxons estudados (Bachelotia, Ectocarpus, Feldmannia e "H." conifera) foram observados valores de divergência 
intraespecífica muito mais elevados, o que pode indicar uma diversidade críptica ou complexo de espécies.

De acordo com Peters et al. (2015), o COl-5P revelou especiação críptica para F. mitchelliae entre amostras do Atlântico (Bretanha, França) e amostras do Mar Mediterrâneo (Itália e Grécia) que possuem morfologia similar, porém apresentam uma divergência de 5,3\% a 5,7\% entre os agrupamentos. Nossas análises moleculares foram similares às descritas por Peters et al. (2015), cujas amostras de F. mitchelliae divergiram entre si em até 5,6\%, incluindo 23 novas sequências de material brasileiro. Além dos dois agrupamentos de Peters et al. (2015) referidos acima, um terceiro agrupamento com amostras de F. mitchelliae foi verificado nas nossas análises, incluindo apenas amostras brasileiras (Fig. 09). A divergência entre esse agrupamento e aquele formado pelas demais amostras brasileiras e duas amostras da Itália foi menor (2,2-3,4\%), porém a divergência máxima $(3,4 \%)$ está fora da faixa de divergência intraespecífica observada para outros táxons nesse estudo (espécies de Acinetospora e $H$. sandriana). Morfologicamente, os dois agrupamentos com amostras brasileiras mostraram diferenças quanto à presença e ausência de pseudopelos que altera o hábito do talo e quanto às dimensões das estruturas pluriloculares, tornando os ramos laterais e suas ramificações mais longas quando comparadas aos talos sem pseudopelos. $O$ menor agrupamento formado pelas amostras MM112, MM186, MM214, MM215 e MM217 nas análises do COI-5P e rbcL inclui exemplares sem pseudopelos e menores dimensões das estruturas pluriloculares (Fig.47). Essas variações morfológicas estão de acordo com as descritas para F. mitchelliae (como Hincksiamitchelliae) por Cassano (1997). Para o gene rbcL dois subclados de $F$. mitchelliae foram formados, porém a divergência entre as amostras não ultrapassou 0,8\%. A amostra dos EUA, que representa a localidade tipo da espécie, sequenciada nesse estudo, confirmou que as amostras brasileiras devem ser atribuídas ao epíteto mitchelliae. Entretanto, F. mitchelliae se manteve distante da espécie tipo de Feldmannia, F. lebelli pela análise do COI-5P, indicando que o epíteto mitchelliae deve ser atribuído a um gênero novo para a ciência.

Ainda dentro da família Acinetosporaceae, "H." conifera também apresentou valor mais elevado de divergência intraespecífica, até 4,4\%. O agrupamento de "H." conifera incluiu plantas típicas com estruturas pluriloculares sésseis, cônicas, mais 
largas na base e ápice atenuado, dispostas adaxialmente em séries curtas nos ramos, sempre no ângulo entre os ramos laterais e o filamento principal, ou próximo a ele (Børgesen 1914, 1926, Cassano 1997). O agrupamento incluiu também plantas com variações morfológicas conforme as descritas por Cassano (1997) nas quais as plantas são menos ramificadas e, portanto, as estruturas pluriloculares alteram sua posição característica e se distribuem com mais frequência ao longo do filamento principal e não adaxialmente nos ramos, quando adaxiais, as séries curtas são menos frequentes e há maior incidência de estruturas pluriloculares pediceladas. $\mathrm{O}$ maior subgrupo formado pelas amostras MM030, MM108, MM111 e MM134 incluiu plantas variantes (Figs $X X$ ), indicando "H." conifera forma um complexo. Por outro lado, o gene $r b c L$ agrupou molecularmente as amostras de "H." conifera como um único táxon, cuja divergência das amostras não ultrapassou 0,8\%. Mais estudos são necessários para compreender a divergência genética dentro de " $H$." conifera. Contudo, esse táxon se posicionou distante filogeneticamente da espécie tipo de Hincksia, $\mathrm{H}$. hincksiae tanto para o $r b c \mathrm{~L}$ quanto para o COI-5P, indicando que o epíteto conifera deve ser transferido para um novo gênero.

A maioria dos estudos moleculares com algas pardas filamentosas não fornece dados de divergência genética entre gêneros e espécies que possibilite uma comparação com os nossos resultados. As divergências interespecífica e intergenérica verificadas nesse estudo para o COI-5P se sobrepuseram para a maioria dos táxons, com exceção de Ectocarpus, cuja divergência interespecífica variou em uma faixa de amplitude menor (Tab. 9). Os gêneros Feldmannia s.s. e Hincksia s.s., que correspondem aos agrupamentos que contêm as suas respectivas espécies-tipo, mostraram alta divergência interespecífica: 12,6-12,8\% entre $F$. lebelli e $F$. simplex, e até $13,9 \%$ entre $H$. granulosa e $H$. sandriana. Alta divergência interespecífica também foi verificada para Feldmannia s.l., entre $F$. irregularis e $F$. globifera (14,4\%). Para o gênero Acinetospora, Yaegashi et al. (2015) verificaram uma divergência interespecífica para o COI-5P entre 11,3-16,3\%,divergência comparável aos nossos resultados (11,3-15,9\%), nos quais duas sequências de Acinetospora filamentosa do Brasil foram acrescidas à análise. A divergência entre espécies de Acinetospora é alta, sendo elevada mesmo dentro do agrupamento que contém a espécie tipo do gênero, $A$. crinita $(11,3-11,5 \%$, entre $A$. crinita e $A$. filamentosa). Contudo, a maior divergência observada $(15,9 \%)$ ocorreu entre $A$. 
filamentosa e $A$. asiatica, esta última não se agrupou ao autêntico gênero Acinetospora.

O mesmo resultado foi obtido com o gene $r b c L$, com $A$. asiatica não se agrupando com o autêntico clado de Acinetospora. A divergência entre as espécies de Acinetospora observada nesse trabalho foi de 2,9-5,0\%, sendo que a mais alta divergência ocorreu entre $A$. asiatica e $A$. filamentosa. Essa amplitude de variação para o rbcL está na faixa de divergênciaverificada por Yaegashi et al. (2015), 3,0$4,7 \%$, sendo a mais alta divergência observada entre $A$. asiatica e $A$. crinita.

Embora A. asiatica nos resultados de Yaegashi et al. (2015) não tenha se agrupado com espécie tipo do gênero se mantendo mais próxima de sequências nomeadas como Acinetosporaceae sp. do banco de dados, os autores argumentaram que além dos dados moleculares que a sustentavam como uma espécie nova, $A$. asiatica poderia ser atribuída ao gênero Acinetospora devido a características morfológicas como a ramificação esparsa, presença de "crampons" e zonas meristemáticas difusas. Apesar de $A$. asiatica possuir características típicas de Acinetospora, nossos resultados moleculares para os dois marcadores utilizados claramente demonstraram que $A$. asiatica não deve ser posicionada sob o gênero Acinetospora. Os próprios autores, Yaegashi et al. (2015), reconheceram que $A$. asiatica é mais proximamente relacionada com $F$. irregularis e $F$. mitchelliae do que $\operatorname{com} A$. crinita, porém optaram em descrever $A$. asiatica sob o gênero Acinetospora não apenas com base em características morfológicas, mas também devido a espécie ser distantemente relacionada ao grupo Pylaiella-Hincksia-Feldmannia de Peters et al. (2015) que contém as espécies tipo desses gêneros. Yaegashi et al. (2015) salientaram que uma revisão da circunscrição de Acinetospora, Feldmannia e Hincksia é necessária para melhor delimitar os táxons em nível genérico.

Os táxons nomeados como " $F$ ". irregularis, "F.irregularis" 1 e "F.irregularis" 2, todos identificados primeiramente como um mesmo táxon ( $F$. irregularis) apresentaram alta divergência genética para o COI-5 e, embora com divergência mais baixa, porém dentro da faixa de variação para táxons distintos, os três agrupamentos também foram recuperados pelo $r b c \mathrm{~L}$. Diferenças morfológicas são reconhecidas entre os três táxons. O agrupamento de "F". irregularis incluiu plantas com morfologia típica da espécie, cujos talos são pequenos e possuem, estruturas pluriloculares cônicas, fusiformes, normalmente sésseis, localizadas na base do talo 
e zonas meristemáticas localizadas na porção basal dos filamentos acima das quais não são formados ramos laterais nem estruturas de reprodução. Nos exemplares de "F.irregularis" 1, as plantas são maiores em altura (até 1,5 cm), mais ramificadas e as estruturas pluriloculares não são restritas à base dos filamentos, muitas delas, sésseis ou pediceladas, se distribuem ao longo dos filamentos principais e ramos laterais em séries longas (Fig. 25). As estruturas pluriloculares são cônicas alongadas com o ápice atenuado, porém muitas são mais alargadas na base. Em "F.irregularis" 2 as estruturas pluriloculares igualmente não se restringem às porções basais dos filamentos eretos, porém diferem de "F. irregularis" 1 na forma de distribuição mais esparsa das estruturas pluriloculares sem formar séries longas nos filamentos, sendo em sua maioria sésseis e os talos são menos ramificados que em "F. irregularis" 1. Morfologicamente, a separação entre "F.irregularis" 1 e "F.irregularis" 2 é muito tênue, porém nossos resultados moleculares demonstraram que esses táxons são distintos e correspondem a espécies novas para a ciência, não pertencentes ao gênero Feldmannia, uma vez que não são proximamente relacionados à espécie tipo do gênero, F. lebelii. O epíteto irregularis deve ser retido para " $F$ ". irregularis, porémsob novo gênero.

Alta diversidade genética também foi evidenciada dentro da família Bachelotiaceae. Bachelotia antillarum mostrou a mais alta divergência intraespecífica entre os táxons brasileiros para o marcador COI-5P (5,8-6,0\%, entre uma amostra do Espírito Santo e amostras do Rio de Janeiro e São Paulo). Para o $r b c L$ as amostras brasileiras divergiram em até 1,2\%, o que poderia ser considerado um valor dentro da chamada "zona cinza" de divergência genética no limite entre a divergência intraespecífica e interespecífica. A divergência intraespecífica foi mais elevada entre as amostras brasileiras e da Nova Zelândia (1,6\%). Bachelotia antillarum é uma espécie de fácil identificação e os exemplares analisados mostraram morfologia semelhante. A alta divergência verificada para o COI-5P evidencia que $B$. antillarum constitui uma espécie críptica.

Nossos resultados com o rbcL demonstraram que a ordem Scytothamnales é parafilética. "Asteronema" breviarticulatum se agrupou com a espécie tipo de Asterocladon lobatum, cuja localidade tipo é o Brasil, e se manteve filogeneticamente distante da outra espécie de Asteronema disponível nos bancos de dados, A. ferruginea. A transferência de "Asteronema" breviarticulatum para o gênero Asterocladon é necessária para resolver o posicionamento taxonômico dessa espécie. 


\section{CONSIDERAÇÕES FINAIS}

O estudo molecular e morfológico de algas pardas filamentosas dos gêneros Acinetospora, Asteronema, Bachelotia, Ectocarpus, Hincksia e Feldmannia nos permitiu confirmar dez táxons de pardas filamentosas para o litoral sudeste do Brasil. De acordo com a classificação atual das algas pardas, sete deles pertencem à ordem Ectocarpales, família Acinetosporaceae: Acinetospora filamentosa(Noda) Yaegashi, Uwai \& K. Kogame, "Feldmannia" irregularis (Kützing) Hamel, "Feldmannia irregularis" 1, "Feldmannia irregularis" 2, "Feldmannia" mitchelliae (Harvey) H.-S. Kim, "Hincksia" conifera (Børgesen) I.A. Abbott e Hincksiasandriana (Zanardini) P.C. Silva, e um pertence à família Ectocarpaceae: Ectocarpusfasciculatus Harvey; dois táxons pertencem à ordem Scytothamnales, família Asteronemataceae: "Asteronema" breviarticulatum (J. Agardh) Ouriques \& Bouzon e um à família Bachelotiaceae: Bachelotia antillarum(Grunow) Gerloff.

A família Asteronemataceae não foi resolvida como monofilética pelas análises com o $r b c L$. Nossos resultados mostraram que o táxon "Asteronema" breviarticulatum deve ser alocado na família Asterocladaceae e transferido para o gênero Asterocladon propondo-se uma combinação nova para resolver o posicionamento taxonômico dessa espécie, tornando a família Asteronemataceae monofilética.

Os dados gerados com os marcadores rbcL e COI-5P demonstraram que Bachelotia antillarum é uma espécie críptica.

A família Ectocarpaceae foi representada por apenas uma espécie, Ectocarpusfasciculatus confirmada pela primeira vez por meio de dados moleculares.

A família Acinetosporaceae não foi resolvida como monofilética pelas análises com o rbcL e COI-5P. Dois agrupamentos foram resolvidos e denominados como Acinetosporaceae 1 e Acinetosporaceae 2. O agrupamento formado por representantes de Acinetosporaceae 1 incluiu a espécie tipo da família, Acinetospora crinita, e, portanto, a família Acinetosporaceae deve ser retida para os táxons desse agrupamento. O agrupamento Acinetosporaceae 2 incluiu os autênticos gêneros Feldmannia Hamel (1939), Hincksia J.E. Gray (1864) e Pylaiella Bory (1823), uma vez que agrupou suas respectivas espécies-tipo, i.e, Feldmannia lebelli, Hincksia hincksiae e Pylaiella litorallis. Para o agrupamento Acinetosporaceae 2 uma nova família deve ser estabelecida.

Hincksia sandriana foi a única espécie que se agrupou em Acinetosporaceae 2, clado que contém o autêntico gênero Hincksia. Essa espécie é citada pela primeira vez para o Brasil a partir de material coletado no Rio de Janeiro (Ponta da Cabeça, Arraial do Cabo) e é considerada aqui um caso de introdução recente. 
Os táxons nomeados como "Feldmannia" irregularis, "Feldmannia irregularis" 1 e "Feldmannia irregularis" 2 não pertencem ao autêntico gênero Feldmannia, uma vez que não se agruparam com a espécie tipo do gênero pela análise com o COI-5P. Sequências do COI-5P de F. irregularis da Itália, considerada próxima à localidade tipo (Mar Adriático), disponíveis nos bancos de dados, confirmaram que parte do material analisado deve ser mantido sob o epíteto irregularis para o qual um gênero novo para a ciência deverá ser proposto.

Análises com os marcadores moleculares $r b c \mathrm{~L}$ e COI-5P demonstraram que os táxons nomeados como "Feldmannia" irregularis, "Feldmannia irregularis" 1 e "Feldmannia irregularis" 2, previamente citados sob uma única espécie - F. irregularis, representam três entidades taxonômicas independentes e, portanto, duas novas espécies para a ciência devem ser propostas para acomodar "F. irregularis" 1 e "F. irregularis" 2.

Análises com os marcadores moleculares rbcL e COI-5P igualmente demonstraram que "Feldmannia" mitchelliae não pertence ao autêntico gênero Feldmannia, uma vez que não se agrupou com a espécie tipo do gênero pelas análises com ambos os marcadores. Uma sequência de "F." mitchelliae gerada no presente estudo procedente dos EUA (Carolina do Norte), próxima à localidade tipo (Massachusetts), confirmou que o material brasileiro deve ser descrito sob o epíteto mitchelliae, porém acomodado sob um novo gênero.

As variações morfológicas de " $F$." mitchelliae demonstram que a espécie representa um complexo. Portanto, "F." mitchelliae não é interpretada aqui como uma espécie críptica como salientaram outros autores. Os três agrupamentos formados pelo COI-5P para "F." mitchelliae que poderiam ser descritos como táxons distintos não foram recuperados pelo $r b c L$ que constitui um gene mais conservado.

Análises com os marcadores moleculares $r b c \mathrm{~L}$ e COI-5P também demonstraram que táxon "Hincksia" conifera não pertence ao autêntico gênero Hincksia, já que não se agrupou com a espécie tipo do gênero,e, portanto, o epíteto conifera deve ser transferido para um novo gênero ainda a ser descrito. As análises com o marcador COI-5P mostraram a formação de dois subgrupos que poderiam ser descritos como entidades taxonômicas distintas. Maiores estudos moleculares e morfológicos são necessários para melhor delimitar "H." conifera ou como um único táxon muito plástico ou como, pelo menos, dois táxons diferentes. Por outro lado, o rbcL, gene mais conservado, resolveu " $H$." conifera como uma única entidade taxonômica. A possibilidade de um caso de especiação incipiente não é descartada.

Nossos resultados moleculares demonstraram claramente que o gênero Acinetospora não é monofilético e que a espécie " $A$ ". asiatica é mais relacionada com "Feldmannia" do que com A. crinita, espécie tipo do gênero. Desta forma, "A". asiatica deve ser alocada sob um novo gênero. Nossos dados moleculares para os dois marcadores utilizados demonstraram, pela primeira vez, a ocorrência de Acinetospora filamentosa no Oceano Atlântico. Os espécimes 
coletados foram primeiramente identificados, em campo, como A. crinita, espécie já referida para o litoral brasileiro para os estados do Rio de Janeiro e São Paulo. Entretanto, a análise morfológica dos nossos espécimes revelou a ausência de monosporângios, estando de acordo com a descrição de $A$. filamentosa, que não possui essas estruturas, descritas como típicas, apenas para $A$. crinita. A presença de monosporângios em $A$. crinita citada por Yoneshigue \& Figueiredo (1983) e por Széchy \& Cordeiro-Marino (1991) e a diferença na forma das estruturas pluriloculares entre as duas espécies nos levou a considerar que $A$. crinitra também ocorre no Brasil e não foi novamente coletada no presente estudo.

Seis táxons dos gêneros estudados, citados em trabalhos prévios para o litoral sudeste do Brasil, não foram recoletados no presente estudo, sendo eles: Acinetospora crinita, Ectocarpus rallsiae, E. siliculosus, E. siliculosus var. pigmaeus (como E. fasciculatus var. pigmaeus), Feldmannia indica e Hincksia onslowensis.Esta última é referida para águas profundas e nossas coletas foram restritas a zona entremarés até a franja do infralitoral. Os três táxons de Ectocarpus são diminutos e, em sua maioria, epífitos, o que pode dificultar a coleta. Contudo, esses táxons não têm sido referidos em trabalhos recentes para o litoral brasileiro. A citação de E. rallsiae para o Brasil requer uma reavaliação minuciosa. Esse táxon é extremamente problemático e já foi considerado um sinônimo de F. irregularis. O entendimento de E. rallsiae, assim como sua independência específica, é extremamente variado na literatura. Não há sequências de $E$. rallsiae nos bancos de dados para comparação com o nosso material e, lamentavelmente, não foi possível sequenciar a amostra dessa espécie procedente dos EUA fornecida pelo Dr. Wilson Freshwater devido à contaminação. A espécie F. indica foi citada por Cassano (1997) para a Praia Rasa, Búzios, $\mathrm{RJ}$, tendo sido encontrada em diferentes épocas do ano. Embora a Praia Rasa tenha sido revisitada em 2014 e 2015 no presente estudo, espécimes de F. indica não foram encontrados.

A citação de Feldmannia simplex sensu Széchy \& Cordeiro-Marino (1991) e Falcão et al. (1992) para o Rio de Janeiro foi questionada por Cassano (1997). Széchy \& Cordeiro-Marino (1991) referiram essa espécie pela primeira vez para o litoral brasileiro com base no trabalho de Clayton (1974), cujo conceito amplo dado por essa autora ao complexo F. simplex F.globifera, incluiu formas de F. irregularis. Cassano (1997) concluiu pela análise da literatura e de material de herbário que os espécimes citados como F. simplex para o litoral brasileiro foram confundidos com F. irregularis. Exemplares examinados de F. simplex procedentes do Herbário de Michigan (MICH 8764 - França e MICH 5505 - Alasca) eram muito distintos dos espécimes brasileiros. A localidade tipo de F. simplex é Bretanha, França, e o espécime $\mathrm{MICH} 8764$ pode ser considerado como um material de referência. Os espécimes identificados como F. simplex para o Rio de Janeiro depositados no Instituto de Botânica de São Paulo (SP187710 - Barra de São João) e 8152 - Ilha Grande (UFRJ, lâmina 
cedida pela Dra. Lísia Gestinari) eram idênticos à F. irregularis. Nenhuma amostra sequenciada no presente estudo se agrupou com sequências de $F$. simplex depositadas nos bancos de dados.

A utilização da ferramenta molecular no estudo de algas pardas filamentosas na região sudeste do Brasil foi fundamental para desvendar a sua diversidade, melhor delimitar seus gêneros e espécies e revelar espécies crípticas. Os dados aqui apresentados constituem uma fonte relevante de informação sobre a taxonomia e sistemática deste grupo.

A despeito dos táxons que não foram recoletados no presente estudo, nossos dados revelaram que a diversidade de algas pardas filamentosas estava subestimada. Uma ampla revisão, especialmente para os gêneros de Acinetosporaceae, ainda é requerida. Mais investigações ampliando a amostragem no litoral brasileiro e a inclusão de mais gêneros de algas pardas filamentosas nas análises podem ainda mudar o panorama da classificação desse grupo. 
Abbott, I.A. 1989. Marine algae of the northwest Hawaiian Islands. Pacific Science 43: 223-233.

Agardh, C.A. 1828. Species algarum rite cognitae, cum synonymis, differentiis specificis et descriptionibus succinctis. Voluminis secundi. Sectio prior. pp. [i]Ixxvi, [i]-189. Gryphiae [Greifswald]: sumptibus Ernesti Mauriti [Ernst Mauritius].

Agardh, J.G. (1847). Nya alger från Mexico. Öfversigt af Kongl. VetenskapsAdademiens Förhandlingar, Stockholm 4: 5-17.

Adl, S.M., Simpson, A.G.B., Farmer, M.A., Andersen, R.A., Anderson, O.R., Barta, J.R., Bowser, S.S., Brugerolle, G., Fensome, R.A., Fredericq, S., James, T.Y., Karpov, S., Kugrens, P., Krug, J., Lane, C.E., Lewis, L.A., Lodge, J., Lynn, D.H., Mann, D.G., McCourt, R.M., Mendoza, L., Moestrup, Ø., Mozley-Standridge, S.E., Nerad, T.A., Shearer, C.A., Smirnov, A.V., Speigel, F.W. \& Taylor, M.F.J.R. 2005. The new higher level classification of eukaryotes with emphasis on the taxonomy of protists. Journal of Eukaryotic Microbiology 52: 399-451.

Amado Filho, G.M. 1991. Algas marinhas bentônicas do litoral de Saquarema a Itacoatiara (RJ). Dissertação de mestrado. Museu Nacional, Universidade Federal do Rio de Janeiro, Rio de Janeiro, Brasil. 323 p.

Amado Filho, G.M. \& Yoneshigue-Valentin, Y. 1992. Feofíceas novas e raras para o litoral brasileiro. Rodriguesia 42/44: 39-46.

Amsler, C.D. and D.F. Kapraun. 1985. Giffordia onslowensis sp. Nov. (Phaeophyceae) from the North Carolina continental shelf and the relationship between Giffordia and Acinetospora. Journal of Phycology 21: 94-99.

Ardissone F. \& Strafforello J. 1877. Enumerazione delle Alghe di Liguria. Milano: Tipografia editrice Lombarda, $238 \mathrm{p}$.

Asensi, A.O. \& Küpper, F.C. 2012. Seasonal periodicity and reproduction of brown algae (Phaeophyceae) at Puerto Deseado (Patagonia). Botanica Marina 55: 217-228.

Balakrishnan, M.S. \& KInkar, V.N. 1981. A taxonomic account of Indian Ectocarpales and Ralfsiales. Seaweed Research and Utilization 4: 1 -57.

Blomquist, H.L. 1958. The taxonomy and chromatophores of Pylaiella antillarum (Grunow) De Toni. Journal of the Elisha Mitchell Science Society 74: 25-30.

Boraso de Zaixso, A.L. 2013. Elementos para el estudio de las macroalgas de Argentina. Con colaboración de J.M. Zaixso. pp. [1]-204. Comodoro Rivadavia: Universitaria de la Patagonia. 
Bessey, C.E. 1907. A synopsis of plant phyla. Nebraska University Studies 7: 275373.

Bittner, L., Payri, C.E., Couloux, A., Cruaud, C., Reviers, B. De \& Rousseau, F. 2008. Molecular phylogeny of the Dictyotales and their position within the brown algae, based on nuclear, plastidial and mitochondrial sequence data. Mol. Phylogenet. Evol. 49: 211-226.

Bornet, E. 1891. Note sur quelques Ectocarpus. Bull. Soc. Bot. France 38: 353-372.

Bouzon, J.L., Salles, J.P., Bouzon, Z., Horta, P.A. 2006. Aspectos florísticos e fitogeográficos das macroalgas marinhas das baías da Ilha de Santa Catarina, SC, Brasil. Insula 35: 68-84.

Brasileiro, P.S., Yoneshigue-Valentin, Y., Bahia, R.G., Reis, R.P. \& Amado-Filho, G.M. 2009. Algas marinhas bentônicas da Região de Cabo Frio e arredores: síntese do conhecimento. Rodriguesia 60: 39-66.

Bessey C.E. 1907. A synopsis of plant phyla. Nebraska university studies 7: 275-373.

Burrowes, R., Rousseau, F., Müller, D.G. \& Reviers, B. de. 2003. Taxonomic placement of Microzonia (Phaeophyceae) in Syringodermatales based on $r b c \mathrm{~L}$ and 28S nrDNA sequences. Cryptogamie, Algologie, 24: 63-73.

Cardinal, A. 1964. Étude sur les Ectocarpacées de la Mancha. Nova Hedwigia 15: 186.

Castro B.M. \& Miranda L.B. 1998. Physical oceanography of the western Atlantic continental shelf located between $4^{\circ} \mathrm{N}$ and $34^{\circ} \mathrm{S}$. In: The sea (A.R. Robinson \& K.H. Brink, eds), pp. 209-249. Wiley, New York.

Cassano, V. 1997. Taxonomia e morfologia de Ectocarpus breviarticulatus, Feldmannia indica, Feldmannia irregularis, Hincksia conifera, Hincksia mitchelliae (Ectocarpaceae, Phaeophyta) no estado do Rio de Janeiro. Dissertação de Mestrado. Museu Nacional, Universidade Federal do Rio de Janeiro. 211p.

Cassano V 2009. Taxonomia e filogenia do complexo Laurencia (Ceramiales, Rhodophyta), com ênfase no estado do Rio de Janeiro, Brasil. Tese de Doutorado, Instituto de Botânica de São Paulo. 328 p.

Cassano, V. \& Yoneshigue-Valentin, Y. 2001. Hincksiaonslowensis (Amsler \& Kapraun) Silva (Phaeophyta, Ectocarpaceae): New occurrence in deep waters for the South American Atlantic Coast. Hoehnea 28: 267-277.

Cassano, V., Yoneshigue-Valentin, Y. \& Wynne, M.J. 2004. Elachistiella leptonematoides gen. et sp. nov. (Elachistaceae, Phaeophyceae) from Brazil. Phycologia 43: 329-340.

Cavalier-Smith, T. 1986. The kingdom Chromista: origin and systematics. Progress in Phycological Research (eds. F.E. Round and D.J. Chapman), 4: 309-347. 
Cavalier-Smith, T. and Chao, E.E. 1996. 18S rRNA sequence of Heterosigma carterae (Raphidophyceae), and the phylogeny of heterokont algae (Ochrophyta). Phycologia, 35: 500-510.

Clayton, M.N. 1974. Studies on the development, life history and taxonomy of Ectocarpales (Phaeophyta) in southern Australia. Australian Journal of Botany 22: $743-813$.

Chase, M.W.; Salamin, N.; Wilkinson, M.; Dunwell, J.M.; Kesanakurthi, R.P.; Haidar, N.; Savolainen, V. 2005. Land plants and DNA barcoding: short-term and longterm goals. Philosophical Transactions of the Royal Society, B 360.

Clayton, M.N. 1974. Studies on the development, life history and taxonomy of the Ectocarpales (Phaeophyta) in Southern Australia. Australian Journal of Botany 22: $743-813$.

Cho, G.Y. \& Boo, S.M. 2006. Phylogenetic position of Petrospongium rugosum (Ectocarpales, Phaeophyceae): insights from the protein-coding plastid $r b c \mathrm{~L}$ and psaA gene sequences. Cryptogamie, Algologie 27: 3-15.

Cho, G.Y., Lee, S.H., and Boo, S.M. 2004. A new brown algal order, Ishigeales (Phaeophyceae), established on the basis of plastid protein-coding $r b c \mathrm{~L}, p s a \mathrm{~A}$, and psbA region comparisons. Journal of Phycology 40: 921-936.

Cock, J.M. et al. 2010. The Ectocarpus genome and the independent evolution of multicellularity in brown algae. Nature 465: 617-621.

Cordeiro-Marino, M. \& Guimarães, S.M.P.B. 1981. Novas referências para a flora marinha de profundidade do Brasil. Rickia 9: 61-70.

Cormaci, M. et al. 2012. Flora marina bentonica del Mediterraneo: Phaeophyceae. Bollettino Accademia Gioenia Sci. Nat.45, N. ${ }^{\circ} 375:$ 1-508 p.

Coutinho, R. 1982. Taxonomia, distribuição, crescimento sazonal, reprodução e biomassa das algas bentônicas do estuário da Lagoa dos Patos (RS). Dissertação de mestrado. Universidade do Rio Grande do Sul, 232p.

Crispino L.M.B. 2000. Feofíceas do litoral do Estado do Espírito Santo. Dissertação de mestrado. Universidade de São Paulo, Rio Claro, Brasil. 193 p.

Delépine, R. \& Asensi, A. 1975. Asteronemanov. gen. Nouveau genre de Phéophycée australe. Bull. Soc. Bot. Fr., 122: 295-304.

Draisma, S.G.A. and Prud'homme van Reine, W.F. 2001. Onslowiaceae fam. nov. (Phaeophyceae). Journal of Phycology 37: 647-649.

Draisma, S.G.A., Prud'homme van Reine, W.F., Stam W.T., and Olsen, J.A. (2001) A reassessment of phylogenetic relationships within the Phaeophyceae based on RUBISCO large subunit and ribosomal DNA sequences. Journal of Phycology 37: 586-603.

Earle, S.A. 1969. Phaeophyta of the eastern Gulf of Mexico. Phycologia 7: 71-254. 
Faugeron et al. 2001. Hierarquical spatial structure and discriminant analyses of genetic diversity in the red alga Mazzaella laminarioides (Gigartinales, Rhodophyta). Journal of Phycology37: 705-717

Feldmann J. 1937. Les algues marines de la côte des Albères. I-III. Cyanophycées, Chlorophycées, Phaéophycées. Revue algologique 9: 141(bis)-148(bis), 149335, pls 8-17.

Figueiredo M.A. DE O. 1989. Ficoflora marinha do Município de Parati, Rio de Janeiro. Dissertação de mestrado. Museu Nacional, Universidade Federal do Rio de Janeiro, Rio de Janeiro, Brasil. 236 p.

Fletcher R.L. 1987. Seaweeds of the British Isles. Vol. 3. Fucophyceae (Phaeophyceae) Part I. Natural History Museum, London. 359 pp.

Freshwater, D.W., Fredericq, S., Butler, B.S., Hommersand, M.H. \& Chase, M.W. 1994 A gene phylogeny of the red algae (Rhodophyta) based on plastid rbcL. Proceedings of the National Academy of Sciences of the United States of America, 91: 7281 - 7285.

Fritsch, F.E. 1943. Studies in the comparative morphology of the algae. III. Evolutionary tendencies and affinities among Phaeophyceae. Annals of Botany7:63-87.

Fritsch, F.E. 1945. The Structure and Reproduction of Algae, Vol. II. Cambridge University Press, Cambridge.

Gallardo, T. 1992. Nomenclatural notes on some Mediterranean algae, I: Phaeophyceae.Taxon 41: 324-326.

Geraldino, P. J. L., Yang, E.C. \& Boo, S.M. 2006. Morphology and molecular phylogeny of Hypnea flexicaulis (Gigartinales, Rhodophyta) from Korea. Algae 21:417-423.

Gerloff, J.1959. Bachelotia (Bornet)KuckuckexHameloder Bachelotia (Bornet). Nova Hedwigia 1: 37-39.

Gestinari, L.M.S., Nassar, C.A.G. \& Arantes, P.V.S. 1998. Algas marinhas bentônicas da Reserva Biológica Estadual da Praia do Sul, Ilha Grande, Angra dos Reis, Rio de Janeiro, Brasil.Acta Botânica Brasílica 12: 67-76.

Greville, R.K. 1830. Algae britannicae, or descriptions of the marine and other inarticulated plants of the British islands, belonging to the order Algae; with plates illustrative of the genera. Edinburgh \& London: McLachlan \& Stewart; Baldwin \& Cradock, [i*-iii*], [i]-Ixxxviii, [1]-218, pls 1-19.

Guimarães, S.M.P.B., Crispino, L.M.B. \& Nunes, J.M. de C. 2016. Flora Ficológica do Estado de São Paulo - vol. 14 - Phaeophyceae. RiMa Editora. 118p.

Guiry, M.D. \& Guiry, G.M. 2017. AlgaeBase. World-wide electronic publication, National University of Ireland, Galway. http://www.algaebase.org; searched on 05 January 2017. 
Hall, T.A. 1999. BioEdit: a user-friendly biological sequence alignment editor and analysis program for Windows 95/98/NT. Nucl. Acids Symp. Ser. 41: 95-8.

Hamel, G. 1939. Phéophycées de France. Fasc. V. pp. i-xlvii + 337-432, figs 56-60, 10 plates. Paris.

Harvey, W.H. 1841. A manual of the British algae: containing generic and specific descriptions of the known British species of seaweeds and of Confervae both marine and fresh-water. pp. [i-v]-Ivii, [1]-229. London: John Van Voorst.

Harvey, W.H. 1859. Algae. Part III. Flora Tasmaniae. In: The botany of the Antarctic voyage of H.M. discovery ships Erebus and Terror, in the years 1839-1843, under the command of Captain Sir James Clark Ross...Part III. Flora Tasmaniae. Monocotyledones and Acotyledones. (Hooker, J.D. Eds) Vol. II, pp. 282-343. London: Lovell Reeve.

Hoek, C. van den, Mann, D.G. \& Jahans, H.M. 1995. Algae: an introduction to Phycology.Cambridge University Press, Cambridge, 627 p.

Horta, P.A., Amâncio, E., Coimbra, C.S. \& Oliveira, E.C. 2001. Considerações sobre a distribuição e origem da flora de macroalgas marinhas brasileiras. Hoehnea $28: 243-265$.

Huelsenbeck, J.P. \& Ronquist, F. 2001. MRBAYES: Bayesian inference of phylogenetic trees. Bioinformatics 17:754-755

Jesus, P.B., Nauer, F., Lyra, G.M., Cassano, V., Oliveira, M.C., Nunes, J.M.C. \& Schnadelbach, A.S. 2016. Species-delimitation and phylogenetic analyses of some cosmopolitan species of Hypnea (Rhodophyta) reveal synonyms and misapplied names to $H$. cervicornis, including a new species from Brazil. Journal of Phycology 52: 774-792.

Joly, A.B. 1957. Contribuição ao conhecimento da flora ficológica marinha da baía de Santos e arredores. Boletim da Faculdade de Filosofia, Ciências e Letras, Universidade de São Paulo, série Botânica 14: 1 - 196.

Joly, A.B. 1965. Flora marinha do litoral norte do Estado de São Paulo e regiões circunvizinhas. Boletim da Faculdade de Filosofia, Ciências e Letras, Universidade de São Paulo, série Botânica 21: 1-393.

Joly, A.B., Pinheiro, F. \& Ferreira, M.M. 1967. Additions to the marine flora of Brazil, IX. Arquivos da Estação de Biologia Marinha da Universidade Federal do Ceará 7: 87-90.

Kawai, H., Hanyuda, T., Draisma, S.G.A., and Müller, D.G. 2007. Molecular phylogeny of iscosporangium mesarthrocarpum (Phaeophyceae) with a reinstatement of the order iscosporangiales. Journal of Phycology 43: 186-194.

Kawai, H. and Sasaki, H. 2004. Morphology, life history, and molecular phylogeny of Stschapovia flagellaris (Tilopteridales, Phaeophyceae) and the erection of the Stschapoviaceae fam. nov. Journal of Phycology40: 1156-1169. 
Kim, H.-S. 2010. Ectocarpaceae, Acinetopsoraceae, Chordariaceae. In: Algal flora of Korea. Volume 2, Number 1. Heterokontophyta: Phaeophyceae: Ectocarpales. Marine brown algae I. (Kim, H.-S. \& Boo, S.-M. Eds), pp. [3]-137. Incheon: National Institute of Biological Resources.

Kim H-S., Lee I.K., 1992. Morphotaxonomic Studies on the Korean Ectocarpaceae (Phaeophyta). II. Genus Hincksia J.E. Gray. The Korean Journal of Phycology. 7: 243-256.

Kim, H. \& Lee, I.K. 1994. Morphotaxonomic studies on the Korean Ectocarpaceae (Phaeophya). III. Genus Feldmannia Hamel, specially referred to morphogenesis and phylogenetic relationship among related genera. Korean Journal of Phycology 9: 153-168.

Knoepffler-Pèguy, M. 1970. Quelques Feldmannia Hamel, 1939 (PhaeophyceaeEctocarpales) des côtes d'Europe. Vie Milieu Ser. A, 21: 137-188.

Knoepffler-Pèguy, M. 1972. Étude espérimentale du polymorphisme chez quelques Ectocarpales (Feldmannia et Acinetospora). I. Méthodes d1étude expérimentale. Vie et Milieu(ser. A) 23 : 171-189.

Knoepffler-Pèguy, M. 1974. Le genre Acinetospora Bornet, 1891 (Phaeophyceae, Ectocarpales). Vie et Milieu(ser. A) $23:$ 43-72.

Knoepffler-Pèguy, M. 1977. Polymorphisme et environnemnt chez les Feldmannia (Ectocarpacées). Revue algol., N.S. 12 : 111-128.

Kornmann, P. 1953. Der Formenkreis von Acinetospora Bornet 1891 (Carm.) nov. comb. Helgol. Wiss. Meeresunters 4: 205-224.

Kützing, F.T. 1845. Phycologia germanica, d. i. Deutschlands Algen in bündigen Beschreibungen. Nebst einer Anleitung zum Untersuchen und Bestimmen dieser Gewächse für Anfänger. pp. i-x, 1-340. Nordhausen: W. Köhne.

Kylin, H. 1933. Über die Entwicklungsgeschiste der Phaeophyceen. Lunds Universitets Årsskrift, Ny Földj, Avd. 2, Band 29 (Nr 7).

Lane, C.E., Mayes, C., Druehl, L.D., and Saunders, G.W. 2006. A multi-gene molecular investigation of the kelp (Laminariales, Phaeophyceae) supports substantial taxonomic re-organization. Journal of Phycology 42: 493-512 (corrigendum on p. 962).

Lane, C.E., Lindstrom, S.C. \& Saunders, G.W. 2007. A molecular assessment of northeast Pacific Alaria species (Laminariales, Phaeophyceae) with reference to the utility of DNA barcoding. Mol. Phylogenet. Evol. 44: 634-648.

Lyngbye, H.C. 1819. Tentamen hydrophytologiae danicae continens omnia hydrophyta cryptogama Daniae, Holsatiae, Faeroae, Islandiae, Groenlandiae hucusque cognita, systematice disposita, descripta et iconibus illustrata, adjectis simul speciebus norvegicis. pp. [i]-xxxii, [1]-248, 70 pls. Hafniae [Copenhagen]: typis Schultzianis, in commissis Librariae Gyldendaliae. 
Martens, G. 1871. Algae brasiliensis circa Rio de Janeiro a cl. A. Glaziou, horti publici directore, botanico indefesso, annis 1869 et 1870 collectae. Vidensk. Meddr dansk naturh. Foren., Kjöbenhavn 1871(8-10): 144-148.

Martius, C.F.P. von, Eschwetiller, F.G. \& Esenbeck, C. 1833. Flora brasiliensis seu enumeratio plantarum in Brasilia...1, 1: IV + 390 pp. (Algae 1-50). 8 vol. Stuttgart et Tübingen.

McDevit, D.C. \& Saunders, G. W. 2009. On the utility of DNA barcoding for species differentiation among brown macroalgae (Phaeophyceae) including a novel extraction protocol. Phycological Research57: 131-141.

Milne, I., Lindner, D., Bayer, M., Husmier, D., McGuire, G., Marshall, D.F. \& Wright, F. 2009. TOPALi v2: a rich graphical interface for evolutionary analyses of multiple alignments on HPC clusters and multi-core desktops. Bioinformatics 25:126-127.

Müller, D.G. \& Parodi, E. 1994. Asteronema rhodochortonoides nov. comb. (Ectocarpales, Phaeophyceae) - a newly recognized taxon with stellate chloroplast arrangement. Phycologia 33: 471-474.

Müller, D.G., Parodi, E.R. \& Peters, A.F. 1999 '1998'. Asterocladon lobatum gen. et sp. nov., a new brown alga with stellate chloroplast arrangement, and its systematic position judged from nuclear rDNA sequences. Phycologia 37: 425432.

Mystikou, A., Aseni, A.O., De Clerck, O., Müller, D.G., Peters, A.F., Tsiamis, K., Fletcher, K.I., Westermeier, R., Brickle, P., van West, P. \& Küpper, F.C. 2016. New records and observations of macroalgae and associated pathogens from the Falkland Islands, Patagonia and Tierra del Fuego. Botanica Marina 59: 105121.

Nassar, C.A.G.R.R.S. \& Yoneshigue-Valentin, Y. 2001. Floristic survey of the benthic marine algae of Três Ilhas archipelago (Espírito Santo-Brazil): preliminary study. Leandra 16: 1-10.

Nauer, F., Cassano, V. \& Oliveira, M. C. 2015. Description of Hypneapseudomusciformis sp. nov., a new species based on molecularand morphological analyses, in the context of the H.musciformis complex (Gigartinales, Rhodophyta). Journal of Applied Phycology27:2405-17.

Nauer, F., Guimarães, N. R., Cassano, V., Yokoya, N. S. \& Oliveira, M. C. 2014. Hypnea species (Gigartinales, Rhodophyta) fromthe southeastern coast of Brazil based on molecular studiescomplemented with morphological analyses, includingdescriptions of Hypnea edeniana sp. nov. and $H$. flava sp. nov.European Journal of Phycology 49:550-75.

Noda, M. 1970. Some marine algae collected on the coast of Iwagasaki, Prov. Echigo facing the Japan Sea. Science Reports of Niigata University, Series D (Biology) 7: 27-35. 
Nunes, J.M.C. 1999. Phaeophyta da região metropolitana de Salvador, Bahia. Dissertação de mestrado. Universidade de São Paulo, São Paulo, 271p.

Nunes, J.M.C. \& Paula, E.J. 2004. Estudos taxonômicos de Ectocarpaceae e Ralfsiaceae (Phaeophyta) da região metropolitana de Salvador, BA, Brasil. Acta Biologica Leopoldensia 26: 37-50.

Nylander, J.A.A. 2004. Bayesian phylogenetics and the evolution of gall wasps. Comprehensive Summaries of Uppsala Dissertations from the Faculty of Science and Technology, 34p.

Oliveira-Filho, E. 1977. Algas marinhas bentônicas do Brasil. Tese de livre docência, Universidade de São Paulo, São Paulo, São Paulo, 407 p.

Oliveira Filho, E.C. de \& Ugadim, Y. 1974. Novas referências de algas marinhas bentônicas para a flora brasileira. Boletim de Botânica da Universidade de São Paulo 2: 71-91.

Ouriques, L.C. 1997. Feofíceas do litoral do estado de Santa Catarina. Dissertação de mestrado. Universidade Estadual Paulista, Rio Claro, 254p.

Ouriques, L.C. \& Bouzon, Z.L. (2000). Stellatechloroplastorganizationin Asteronema breviarticulatum comb. nov. (Ectocarpales, Phaeophyta). Phycologia 39: 267271.

Ouriques, L.C. \& Cordeiro-Marino, M. 2004. Levantamento florístico das ordens Ectocarpales, Chordariales, Scytosiphonales e Sphacelariales (Phaeophyta) do litoral do estado de Santa Catarina, Brasil. Hoehena 31: 293-312.

Patterson, D.J. 1989. Stramenopiles: chromophytes from a protistan perspective. In The Chromophyte Algae, Problemsand Perspectives (eds. J.C. Green, B.S.C. Leadbeater, and W.L. Diver). The Systematics Association special volume 38. Published for the Systematics Association by Clarendon Press, Oxford, pp. 357-379.

Pedersen, P.M. 1983. Notes on marine benthic alga from Madeira in nature and in culture. Bocagiana 70: 1-8.

Pedersen, P.M. \& A. Kristiansen. 2001. On the enigmatic brown alga Acinetospora crinita (Ectocarpales, Fucophyceae). Cryptogam. Algol. 22: 209-218.

Pereira, A.P.V. 2007. Caracterização fisionômica da comunidade marinha bentônica de substrato consolidado do infralitoral no costão oeste da Enseada das Palmas, Parque Estadual da Ilha Anchieta, Ubatuba-SP, Brasil. Tese de Doutorado. Universidade de São Paulo, São Paulo.

Peters AF, Clayton MN.1998. Molecular and morphological investigations of three brown algal genera with stellate plastids: evidence for Scytothamnales ord. Nov. (Phaeophyceae). Phycologia 37: 106-113. 
Peters, A. F., Ramírez, M.E. 2001.Molecular phylogeny of small brown algae, with special reference to the systematic position of Caepidium antarcticum (Adenocystaceae, Ectocarpales). Cryptogamie Algologie 22: 187-200.

Peters, A.F., Marie, D., Scornet, D., Kloareg, B. \& Cock, J.M. 2004. Proposal of Ectocarpus siliculosus (Ectocarpales, Phaeophyceae) as a model organism for brown algal genetics and genomics. Journal of Phycology 40: 1079-1088.

Peters A.F., Van Wijk S., Cho G.Y., Scornet D., Hanyuda T., Kawai H., Schroeder D.C., Cock J.M. \& Boo S.M. 2010. Reinstatement of Ectocarpus crouaniorum Thuret in Le Jolis as a third common species of Ectocarpus (Ectocarpales, Phaeophyceae) in Western Europe, and its phenology at Roscoff, Brittany. Phycological Research 58: 157-170.

Peters, A.F., L. Couceiro, K. Tsiamis, F.C. Kupper \& M. Valero. 2015. Barcoding of cryptic stages of marine brown algae isolated from incubated substratum reveals high diversity in Acinetosporaceae (Ectocarpales, Phaeophyceae). Cryptogam. Algol. 36: 3-29.

Phillips, N., Burrowes, R., Rousseau, F., de Reviers, B., Saunders, G.W., 2008. Resolving evolutionary relationships among the brown algae using chloroplast and nuclear genes. Journal of Phycology 44: 394-405.

Posada, D. \& Crandall, K.A. 1998 MODELTEST: testing the model of DNA substitution. Bioinformatics, 14: $817-818$.

Presting. G. G. 2006. Identification of conserved regions in the plastid genome: implications for DNA barcoding and biological function. Canadian Journal of Botany 84: 1434-1443.

Racault M.-F.L.P., Fletcher R.L., Reviers B. de, Cho G.Y., Boo S.M., Parente M.I. \& Rousseau F. 2009. Molecular phylogeny of the genus Petrospongium Nägeli ex Kützing (Phaeophyceae) with evidence for Petrospongiaceae fam. nov. Cryptogamie, Algologie 30: 111-123.

Ravanko, O. 1970. Morphological, developmental and taxonomic studies in the Ectocarpus complex (Phaeophyceae). Nova Hedwigia 20: 179-252.

Reis-Santos, R.P. 1990. Flora algal da lagoa de Araruama. Museu Nacional, Universidade Federal do Rio de Janeiro, Rio de Janeiro, Brasil. 325p.

Reviers, B. 2006. Biologia e filogenia das algas. Artmed, Porto Alegre. 280p.

Reviers, B. de and Rousseau, F. 1999. Towards a new classification of the brown algae. Progress in Phycological Research (eds. F.E. Round and D.J. Chapman), 13: 107-201.

Reviers, B. de \& Rousseau, F. 1999. Towards a new classification of the brown algae. In: Progress in Phycological Research, Volume 13(Round, F.E. \& Chapman, D.J., editors), 107-201. Biopress Ltd., Bristol. 
Reviers, B., Rousseau, F., Draisma, S.G.A. 2007. Classification of brown algae from past to present and current challenges. In: Brodie, J., Lewis, J. (Eds.), Unravelling the Algae - The Past, Present and Future of Algal Molecular Systematics. Systematics Association (Publ.), London, pp. 267-284.

Rousseau, F. \& Reviers, B. de 1999. Circumscription of the order Ectocarpales (Phaeophyceae): bibliographical synthesis and molecular evidence. Cryptogamie, Algologie 20: 5-18.

Rousseau F., Reviers B. de, Leclerc M.-C., Asensi A. \& Delépine R. 2000. Adenocystaceae fam. nov. (Phaeophyceae) based on morphological and molecularevidence. European Journal of Phycology 35: 35-43.

Rousseau, F., Burrowes, R., Peters, A.F., Kuhlenkamp, R., and Reviers, B. de. 2001. A comprehensive phylogeny of the Phaeophyceae based on nrDNA sequences resolves the earliest divergences. Compte Rendus de l'Académie des Sciences 324: 305-319.

Ronquist, F. \& Huelsenbeck, J.P. 2003 MrBayes 3: Bayesian phylogenetic inference under mixed models. Bioinformatics, 19: 1572 - 1574.

Ruiz, D. \& Ziemmeck, F. 2011. Checklist - Lista de Especies de Galápagos de la Fundación Charles Darwin. Charles Darwin Foundation / Fundación Charles Darwin, Puerto Ayora, Galapagos:

http://www.darwinfoundation.org/datazone/checklists/algae/chlorophyta/.

Russell, G. 1966. The genus Ectocarpus in Britain. I. The attached forms. Journal of the Marine Biological Association of the United Kingdom 46: 267-94.

Russell, G. 1967. The genus Ectocarpus in Britain. II. The free-living forms. Journal of the Marine Biological Association of the United Kingdom47: 233-50.

Russell, G. \& Fletcher, R.L. 1975. A numerical taxonomic study of the British Phaeophyta. Journal of the Marine Biological Association of the United Kingdom 55: 763-783.

Russell, G. \& Garbary, D. 1978. Generic circumscription in the family Ectocarpaceae (Phaeophyceae). Journal of the Marine Biological Association of the United Kingdom58: 517-526.

Sambrook, J., Fritsch, E.F. \& Maniatis, T. 1989.Molecular Cloning: A Laboratory Manual, 2nd ed., 3 vol. Cold Spring Harbour Laboratories press, New York.

Saunders, G.W. \& Hommersand, M.H. 2004 Assessing red algal supraordinal diversity and taxonomy in the context of contemporary systematic data. American Journal of Botany, 91 (10): 1494 - 1507.

Saunders, G.W. 2005. Applying DNA barcoding to red macroalgae: a preliminary appraisal holds promise for future applications. Philosophical Transactions of the Royal Society B, 360: 1879 - 1888. 
Saunders, G.W. \& Kucera, H. 2010. An evaluation of rbcL, tufA, UPA, LSU and ITS as DNA barcode markers for the marine green macroalgae. Cryptogamie, Algologie 31: 487-528.

Saunders G.W. \& Mcdevit D.C. 2012. Methods for DNA barcoding photosynthetic protists emphasizing the macroalgae and diatoms. Methods in Molecular Biology 858: 207 -222.

Schmidt, O.C. 1924. Meeresalgen der Sammlung v. Luetzelburg aus Brasilien. Hedwigia 65: 85-100.

Schneider, C.W. \& Searles, R.B. 1991. Seaweeds of the southeastern United States. Cape Hatteras to Cape Canaveral. pp. xiv + 553. Durham \& London: Duke University Press.

Stache-Crain, B., Müller, D.G. \& Goff, L.J. 1997. Molecular systematics of Ectocarpus and Kuckuckia (Ectocarpales, Phaeophyceae) inferred from phylogenetic analysis of nuclear- and plastid-encoded DNA sequences. Journal of Phycology 33: 152-168.

Setchell W.A. and Gardner N.L. 1925. The Marine algae of the Pacific coast of North America: Part III. Melanophyceae. University of California publications in Botany 8: 383-898.

Silberfeld, T, Leigh JW, Verbruggen H, Cruaud C, de Reviers B, Rousseau F. 2010. A multi-locus time-calibrated phylogeny of the brown algae (Heterokonta, Ochrophyta, Phaeophyceae): Investigating the evolutionary nature of the "brown algal crown radiation".Mol Phylogenet Evol. 2010 Aug;56(2):659-74.

Silberfeld, T., Racault, M.-F.L.P., Fletcher, R.L., Couloux, A., Rousseau, F. \& De Reviers, B. 2011. Systematics and evolutionary history of pyrenoid-bearing taxa in brown algae (Phaeophyceae). European Journal of Phycology 46: 361-377.

Silberfeld, T.,Rousseau, F. \& De Reviers, B. 2014. An Updated Classification of Brown Algae (Ochrophyta,Phaeophyceae). Cryptogamie, Algologie, 2014, 35 (2): 117-156.

Silva, P.C., Meñez, E.G. \& Moe, R.L. 1987. Catalog of the benthic marine algae of the Philippines. Smithsonian Contributions to Marine Sciences 27: 1-179.

Silva, P.C., Basson, P.W. \& Moe, R.L. 1996. Catalogue of the benthic marine algae of the Indian Ocean. University of California Publications in Botany 79: 1-1259.

Swofford, D.L. 2000 PAUP*. Phylogenetic Analysis Using Parsimony (*and Other Methods). Version 4. Sinauer Associates, Sunderland, Massachusetts.

Széchy, M.T.M. de \& Cordeiro-Marino, M. 1991. Feofíceas do litoral norte do estado do Rio de Janeiro, Brasil. Hoehnea 18: 205-241.

Széchy, M.T.M. \& Paula, E.J. 2000. Macroalgas associadas a bancos de Sargassum C. Agardh (Phaeophyta, Fucales) do litoral dos Estados do Rio de Janeiro e São Paulo, Brasil. Hoehnea, 27: 235-257. 
Szèchy, M.T.M., de Paula, J.C. 2015. Phaeophyceae in Lista de Espécies da Flora do Brasil. Jardim Botânico do Rio de Janeiro. Disponivel em: <http://floradobrasil.jbrj.gov.br/jabot/floradobrasil/FB104597>.

Tan, I.H. and Druehl, L.D. 1994. A molecular analysis of Analipus and Ralfsia (Phaeophyceae) suggests the order Ectocarpales is polyphyletic. Journal of Phycology, 30: 721-729.

Tan, I.H. and Druehl, L.D. 1996. A ribosomal DNA phylogeny supports the close evolutionary relationships among the Sporochnales, Desmarestiales, and Laminariales (Phaeophyceae). Journal of Phycology,32: 112-118.

Taylor, W.R. 1930. A synopsis of the marine algae of Brazil. Revue Algologique 5: 135.

Taylor, W.R. 1960 Marine algae of the eastern tropical and subtropical coasts of the Americas: IX $+1-870$ (incl. 80 pls.), Ann Arbor.

Ugadim, Y. 1973. Algas marinhas bentônicas do litoral sul do estado de São Paulo e do litoral do estado do Paraná, II- Divisão Phaeophyta. Portugaliae Acta Biologica 12: 69-131.

Ursi, S. \& Plastino E.M. 2001. Crescimento in vitro de linhagens de coloração vermelha e verde clara de Gracilaria birdiae (Gracilariales, Rhodophyta) em dois meios de cultura: análise de diferentes estádios reprodutivos. Rev Bras Bot. Vol. 24: 587-594

Womersley, H.B.S. 1987. The marine benthic flora of Southern Australia. Part II. Southern Australia Government Printing Division, Adelaide.

Wynne, M.J. 1982. Phaeophyceae. In Synopsis and Classification of Living Organisms, Vol. I (ed. S.P. Parker), McGraw-Hill, New York, pp. 115-125.

Wynne M.J. 1998. A checklist of benthic marine algae of tropical and subtropical western Atlantic: first revision. Nova HedwigiaBeihefte 116: 1-155.

Wynne, M.J. 2005 A checklist of benthic marine algae of the tropical and subtropical western Atlantic: second revision. Nova Hedwigia 129: 1-152.

Wynne, MJ. 2011. A checklist of benthic marine algae of tropical and subtropical western Atlantic: third revision. Nova Hedwigia 140: 1-166.

Wynne, M.J. \& Loiseaux, S. 1976. Recent advances in life history studies of the Phaeophyta. Phycologia 15: 435-452.

Yaegashi, K., Yamagishi, Y., Uwai, S., Abe, T., Santiañez, W.J.E. \& Kogame, K. 2015. Two species of the genus Acinetospora (Ectocarpales, Phaeophyceae) from Japan: A. filamentosa comb. nov. and A. asiatica sp. nov. Botanica Marina 58: 331-343.

Yang, E. C., Kim, M. S., Geraldino, P. J. L., Sahoo, D., Shin, J.A. \& Boo, S.M. 2007. Mitochondrial cox1 and plastid rbcL genes of Gracilaria 
vermiculophylla(Gracilariaceae, Rhodophyta). Journal of Applied Phycology, doi 10.1007/s10811-007-9201-8

Yoon, H.S., Lee, J.Y., Boo, S.M., Bhattacharya, D., 2001. Phylogeny of Alariaceae, Laminariaceae and Lessoniaceae (Phaeophyceae) based on plastid-encoded RuBisCo spacer and nuclear-encoded ITS sequence comparisons. Mol. Phylogenet. Evol. 21, 231-243.

Yoneshigue, Y. 1985. Taxonomie et ecologie des algues marines dans la region de Cabo Frio (Rio de Janeiro, Bresil). These de Docteur d' Etat-Sciences, Faculte de Sciences de Luminy, Universite d' AixMarseille II, France. 499 p.

Yoneshigue, Y. \& Figueiredo, M.A. de O. 1983. Flore marine de la région de Cabo Frio (Brésil). 3- Ectocarpaceae (Phaeophyta) nouvelles pour la cote brésilienne. Vie Milieu 33 (3/4): 181-190.

Yoneshigue, Y. \& M.A.O. Figueiredo 1987. Flora marinha da região de Cabo Frio (Estadodo Rio de Janeiro, Brasil). Chlorophyceae raras para o litoral brasileiro. Nerítica 2(sup.):119-134. 